\title{
Método de Rorschach em adultos: evidências psicométricas da Escola Francesa
}

\author{
Fabiana Rego Freitas
}

Tese apresentada ao Programa de Pós-Graduação em Psicologia da Faculdade de Filosofia, Ciências e Letras de Ribeirão Preto da Universidade de São Paulo, como parte das exigências para a obtenção do título de Doutor em Ciências, Área: Psicologia.

RIBEIRÃO PRETO - SP 
FABIANA REGO FREITAS

\section{Método de Rorschach em adultos: evidências psicométricas da Escola Francesa}

Tese apresentada ao Programa de Pós-Graduação em Psicologia da Faculdade de Filosofia, Ciências e Letras de Ribeirão Preto da Universidade de São Paulo, como parte das exigências para a obtenção do título de Doutor em Ciências, Área: Psicologia.

Orientadora:

Profa. Dra. Sonia Regina Pasian

RIBEIRÃO PRETO - SP 
Autorizo a reprodução e divulgação parcial deste trabalho, por qualquer meio convencional ou eletrônico, para fins de estudo e pesquisa, desde que citada a fonte.

Catalogação na Publicação

Serviço de Biblioteca e Documentação

Faculdade de Filosofia, Ciências e Letras de Ribeirão Preto

Universidade de São Paulo

\section{Freitas, Fabiana Rego}

Métodos de Rorschach em adultos: Evidências Psicométricas da Escola Francesa. Ribeirão Preto, 2016.

$395 \mathrm{f}$.

Tese (Doutorado) apresentada à Faculdade de Filosofia, Ciências e Letras de Ribeirão Preto/USP. Departamento de Psicologia. Programa de Pós-Graduação em Psicologia. Área de concentração: Psicologia.

Orientadora: Pasian, Sonia Regina.

1. Rorschach; 2. Validade; 3. Normas; 4. Adultos; 5. Avaliação Psicológica; 6. Métodos Projetivos; 6. Personalidade. 


\section{FOLHA DE APROVAÇÃO}

Nome: Fabiana Rego Freitas

Título: Método de Rorschach em adultos: evidências psicométricas da Escola Francesa

Tese apresentada ao Programa de Pós-Graduação em Psicologia da Faculdade de Filosofia, Ciências e Letras de Ribeirão Preto da Universidade de São Paulo, como parte das exigências para a obtenção do título de Doutor em Ciências, Área: Psicologia.

\section{Aprovado em:}

\section{Banca Examinadora}

Prof. Dr.

Instituição: Assinatura:

Prof. Dr.

Instituição: Assinatura:

Prof. Dr.

Instituição: Assinatura:

Prof. Dr.

Instituição:

Assinatura:

Prof. Dr.

Instituição: Assinatura: 


\section{Minha profunda gratidão...}

Ao Rafael, meu companheiro e parceiro de vida, que esteve sempre ao meu lado, oferecendo toda forma de suporte: afetivo, emocional, motivacional, computacional, para a realização do doutorado. Seu amor e apoio, em todos os momentos, foram decisivos em minha trajetória acadêmica, permitindo meu desenvolvimento como profissional e ser humano. Que venham novas aventuras para alegrar nossas vidas, em breve a maior delas. Muito obrigada, meu amor.

Aos meus pais, João e Zuleica, que sempre incentivaram e valorizaram a minha formação acadêmica e também ofereceram todo o suporte necessário para meu desenvolvimento, em um caminho com muito afeto, carinho e acolhimento por parte de vocês que facilitaram muito a dedicação e conclusão de mais esta etapa. Às minhas irmãs, Flávia e Fernanda, pela amizade, amor e toda a força que sempre me ofereceram; a minha vida é mais colorida porque vocês estão ao meu lado. Aos meus sobrinhos amados, João Pedro e Sarah, pela alegria e encanto que emanam, me renovando e alimentando minha alma.

À minha orientadora, professora Dra. Sonia Regina Pasian, por todo apoio, dedicação em ensinar, incentivar meu desenvolvimento e sempre sugerir que eu pudesse ir além. Seus cuidados, afeto, respeito e atenção fizeram toda a diferença no desenvolvimento do trabalho. Você é um modelo de profissional correta e dedicada que sempre me servirá de exemplo.

Ao professor doutor Gregory Meyer por me receber na Universidade de Toledo, Ohio, com muita disposição em ensinar e auxiliar no aprimoramento do estudo e trabalho com o Método de Rorschach. Sempre me lembrarei da dedicação e atenção dedicadas ao meu trabalho e da forma gentil como trata a todos.

Aos adultos voluntários dos estudos desenvolvidos. Aos adultos do estudo 1, sou grata por aceitarem colaborar com o desenvolvimento do trabalho por uma segunda vez. E aos adultos voluntários do estudo 2, por colaborarem com o desenvolvimento da pesquisa. Esta tese só se tornou possível pela participação de cada um de vocês.

Às amigas e colegas do Centro de Pesquisa em Psicodiagnóstico (CPP), Erika Okino, Carmem Coury, Suzani Duarte, Veridiana Ferrari, Joana Barroso, Katiusha Abreu, Roberta Cury-Jacquemim, Maria Luiza Jardim-Maran e Rafael Barrenha pela amizade construída e valiosa colaboração nas atividades relacionadas ao trabalho. E à 
todos os colegas do CPP pela constante troca de aprendizagem, torcida e apoio ao longo dos últimos quatro anos.

À professora Dra. Anna Elisa de Villemor-Amaral e à professora Dra. Sonia Regina Loureiro pelas tão valiosas contribuições sugeridas na ocasião do Exame de Qualificação, com vistas ao aprimoramento do trabalho e ao meu desenvolvimento.

À Daisaku Ikeda, presidente da Soka Gakkai Internacional (SGI), que por meio da filosofia budista de Nitiren Daishonin, transmite orientações e direcionamentos pautados em uma vida ética e voltadas ao humanismo, grande fonte de inspiração.

Ao Giovanni Raspantinni pelo trabalho de assessoria gráfica e digital, contribuindo com muita disposição e cuidado, para a conclusão e solidificação de um dos importantes objetivos do estudo.

À FAPESP pela concessão da bolsa de estudos, que possibilitou a efetivação do doutorado, a minha dedicação total ao trabalho e o aprimoramento profissional com a participação em diversos e importantes eventos e congressos científicos da área, entre outras importantes contribuições.

À CAPES/PDSE pela concessão da bolsa de estudos do doutorado sanduíche, o que permitiu o contato com um dos maiores pesquisadores da área e também o contato com uma nova cultura, contribuindo para meu crescimento nos planos acadêmico e individual.

Ao Centro Editor de Testes e Pesquisas em Psicologia (Cetepp) pela concessão de materiais originais do Rorschach permitindo a realização da pesquisa.

Ao Programa de Pós-Graduação em Psicologia pelas oportunidades de aprendizado, com o oferecimento de diversas disciplinas e contatos com excelentes pesquisadores do território nacional e também internacional e todo o respaldo oferecido nos últimos quatro anos.

Agradeço por fim aos meus queridos amigos: Alessandra, Renato, Andrea, Amália, Lidia, Patrícia, Livia, Anamaria, Renata Nakachima, Renata Odorissio, Paola, Ana Paula, Elizabeth, Laura, Rebeca, Inky e Giselle. Obrigada pela amizade e por todos os momentos compartilhados. 


\section{RESUMO}

Freitas, F. R. (2016). Método de Rorschach em Adultos: Evidências Psicométricas da Escola Francesa. Tese de doutorado, Faculdade de Filosofia, Ciências e Letras de Ribeirão Preto, Universidade de São Paulo, Ribeirão Preto.

O Método de Rorschach é internacionalmente utilizado e reconhecido como instrumento de avaliação psicológica em processos de investigação da personalidade. Para embasar seu adequado uso no contexto do Brasil, contínuos estudos sobre suas evidências psicométricas fazem-se necessários, sobretudo sobre seus indicadores de validade, precisão e referenciais normativos. Nesse contexto, este trabalho objetivou: a) verificar indicadores de precisão e validade do Rorschach (Escola Francesa ou de Paris), por meio da reavaliação de adultos não pacientes do estudo normativo de Pasian (1998), para checagem da estabilidade temporal (estrutural e funcional) das características de personalidade examinadas pelo método (ESTUDO 1); b) revisar e atualizar padrões normativos e atlas da Escola Francesa do Rorschach em adultos, avaliando-se eventuais especificidades de produção associadas ao sexo, à idade e à escolaridade (ESTUDO 2). No primeiro estudo foram reavaliados 88 adultos do estudo de Pasian (1998), com idade entre 34 a 69 anos, de ambos os sexos e de diferentes níveis de escolaridade (baixa, média e alta). No segundo estudo compôs-se nova amostra com 102 adultos, entre 18 e 65 anos, com sinais de desenvolvimento típico, distribuídos equitativamente em relação ao sexo e com diferentes graus de escolaridade (baixa, média e alta). Para elaboração dos dados normativos foram incluídos 66 adultos do Estudo 1, totalizando 168 casos nessa nova amostra ( 86 mulheres e 82 homens). Os participantes residiam no interior do Estado de São Paulo e foram avaliados, individualmente, por: a) instrumento de rastreamento de saúde mental (SRQ-20) - no estudo 1, utilizado para caracterização da amostra e no estudo 2 como critério de seleção dos participantes; b) instrumento de avaliação intelectual (Teste de Inteligência Não Verbal - INV, forma C - apenas no Estudo 2) para controle cognitivo da amostra; c) critério de classificação econômica Brasil (ABEP) e d) Método de Rorschach (Escola de Paris). Cada instrumento de avaliação psicológica foi aplicado, codificado e sistematizado conforme seus respectivos manuais técnicos. Especificamente o Método de Rorschach foi avaliado pelas diretrizes da Escola Francesa, sendo cada protocolo (de cada um dos dois estudos) examinado independentemente por dois avaliadores, chegando-se a uma classificação final dos casos. Calculou-se o índice de concordância entre examinadores pelo coeficiente Kappa para as quatro categorias de classificação das respostas do Rorschach (localização, determinante/qualidade formal, conteúdo e banalidades). Os resultados foram sistematizados inicialmente em termos descritivos (média, desvio-padrão, mediana, valor mínimo e máximo), realizando-se análises inferenciais específicas para as amostras de cada estudo em função de seus objetivos centrais. No Estudo 1, os achados relativos aos índices de correlação entre as duas avaliações dos 88 voluntários variaram entre 0,72 a $-0,005$, evidenciando estabilidade em um conjunto das características de personalidade dos adultos examinados após 15 anos, configurando evidências empíricas de precisão e de validade de método projetivo. Houve variáveis do Rorschach que não apresentaram resultados estáveis entre 
os dois momentos avaliativos (fórmulas vivenciais), sugerindo se tratarem de indicadores técnicos relativos ao funcionamento da personalidade, mais do que componentes estruturais. As análises do Estudo 2 apontaram reduzida influência dos fatores relacionados ao sexo, à escolaridade e à idade sobre as variáveis do Rorschach, não indicando a necessidade de normas específicas para grupos em termos desses fatores. Por fim, foi elaborado novo atlas de referência do Método de Rorschach (Escola de Paris) no contexto brasileiro, seguindo-se as diretrizes técnico-científicas nacionais e internacionais da área. Os dados fortalecem a relevância dos estudos de natureza psicométrica para embasar adequadas análises interpretativas desse instrumento de avaliação psicológica (FAPESP e CAPES/PDSE).

Palavras-Chave: Rorschach; Precisão; Validade; Normas; Adultos; Avaliação Psicológica; Métodos Projetivos; Personalidade. 


\begin{abstract}
Freitas, F.R. (2016). Rorschach Method in Adults: Psychometric Evidence of the French School. Dissertation (PhD's Degree), Faculty of Philosophy, Science and Letters of Ribeirão Preto, University of São Paulo, Ribeirão Preto.
\end{abstract}

The Rorschach Method is internationally used and known as a psychological assessment instrument in personality research. To support its proper use in the Brazilian context, studies about its psychometric evidence are required, particularly the ones that provide indicators of reliability, validity and normative references. This study aimed: a) to verify indicators of reliability and validity of the Rorschach (French School or School of Paris), through the revaluation of non-patient adults from Pasian's normative study (1998), to check the temporal stability (structural and functional) of personality traits examined by the Rorschach Inkblot Method (STUDY 1); b) to review and update the norms - the formal quality tables and the location tables of Rorschach (French School) in adults, evaluating any specific production associated with sex, age and education (STUDY 2). Study 1 reassessed 88 adults from Pasian's study (1998), ages ranging between 34-69 years, of both sexes and of different educational levels (low, medium and high). Study 2 assessed a new sample of 102 adults, between 18 and 65 years, with typical development indicators, equally distributed regarding sex and with different educational levels (low, medium and high). For the elaboration of the norms, 66 adults from Study 1 were added to the new sample resulting in a sample of 168 cases. Participants are from cities in the State of São Paulo and were evaluated individually using: a) the Mental Health Screening Questionnaire (SRQ-20), in Study 1 to characterize the mental health of adults and in Study 2 as selection criterion of participants; b) Non Verbal Intelligence Test (INV, form $\mathrm{C}$ - just in Study 2) for the cognitive control sample; c) Economic classification criteria Brazil (ABEP) and d) Rorschach Method (School of Paris). Each psychological assessment tool was applied, coded and systematized according to their respective manuals. Specifically the Rorschach Inkblot Method was evaluated by the guidelines of the School of Paris, each protocol (of each study) was examined by two independent judges, coming up to a final classification of the cases. The inter-rater reliability was calculated and a Kappa coefficient was obtained for the four categories of classification of Rorschach responses (location, determining/formal quality, content and banality). The results were examined by descriptive (mean, standard deviation, median, minimum and maximum) and inferencial statistical analyses for both samples, according to their main objectives. In Study 1, the correlation ratios between the test-retest of 88 volunteers ranged from 0.72 to -0.005 , indicating stability in a set of personality traits of adults evaluated after 15 years, and empirically evidencencing the reliability and validity of this projective method. Some Rorschach variables did not show stable results between the test-retest (Rorschach Personality Styles), suggesting that they can be indicators of personality functioning rather than structural components of personality. In Study 2, regarding the effects of sex, education and age, the analyses showed statistically significant differences in a small number of variables for this projective method. 
Rorschach French School norms were elaborated for adults aged 18-65 years of both sexes, with different levels of education. Formal quality tables and location tables of this specific method were reviewed and updated according to new data. These procedures were performed in the Brazilian context in accordance with national and international scientific guidelines for the area. Our findings strengthen the relevance of psychometric studies to support appropriate interpretative analysis of the Rorschach School of Paris (FAPESP e CAPES/PDSE).

Key-words: Rorschach; Reliability; Validity; Norms; Adults; Psychological Assessment; Projective Methods; Personality. 


\section{LISTA DE TABELAS}

Tabela 01- Contatos telefônicos com participantes de Pasian (1998), entre a faixa etária de 30 a 59 anos, efetivados para o Estudo 01

$\underline{\text { Tabela } 02}$ - Visitas domiciliares aos participantes de Pasian (1998) efetivadas para o Estudo 01

$\underline{\text { Tabela } 03}$ - Contatos eletrônicos (email e facebook) realizados com os participantes de Pasian (1998) para Estudo 01 68

Tabela 04 - Distribuição dos contatos realizados com os participantes de Pasian (1998) e que aceitaram colaborar com Estudo 01

Tabela 05 - Participantes de Pasian (1998) contatados e que recusaram participar do Estudo 01

Tabela 06 - Caracterização dos participantes do Estudo 1 em função do nível socioeconômico, sexo e escolaridade

Tabela 07 - Distribuição dos indivíduos do Estudo $1(\mathrm{n}=88)$ em função do resultado no Critério de Classificação Econômica Brasil (ABEP, 2012) . .72

Tabela 08 - Percurso amostral realizado para composição da amostra de adultos do Estudo 2, em função do nível socioeconômico .

Tabela 09 - Caracterização dos participantes $(\mathrm{n}=102)$ do Estudo 2, em função do nível socioeconômico, sexo e escolaridade.

Tabela 10 - Caracterização da amostra $(\mathrm{n}=102)$ do Estudo 2, em função da faixa etária, sexo e origem socioeconômica.

Tabela 11 - Distribuição dos indivíduos $(\mathrm{n}=102)$ do Estudo 2 em função do nível socioeconômico, sexo e resultados no Critério de Classificação Econômica Brasil (ABEP, 2012)

Tabela 12 - Composição da amostra do estudo normativo ( $\mathrm{n}=168)$, distribuída pelos diferentes níveis de escolaridade, sexo e faixa etária 101

Tabela 13 - Estatística descritiva da produtividade e ritmo de produção no Rorschach dos adultos reavaliados do Estudo $1(\mathrm{n}=88)$....

Tabela 14 - Estatística descritiva (em porcentagem) dos modos de apreensão no Rorschach dos adultos reavaliados do Estudo $1(\mathrm{n}=88)$ 114 Tabela 15 - Estatística descritiva (em porcentagem) dos determinantes, conteúdos e banalidades no Rorschach dos adultos reavaliados do Estudo $1(\mathrm{n}=88)$. 
Tabela 16 - Resultados descritivos e comparação estatística nos índices de produtividade e ritmo do Rorschach dos adultos reavaliados no Estudo $01(n=88)$ em função do sexo.

Tabela 17 - Resultados descritivos (em porcentagem) e comparação estatística em 50 variáveis do Rorschach relacionadas aos modos de apreensão, determinantes, conteúdos e banalidades dos adultos reavaliados do Estudo $01(n=88)$ em função do sexo. ......119 Tabela 18 - Resultados descritivos (em porcentagem) e comparação estatística nos índices de produtividade e ritmo do Rorschach dos adultos reavaliados do Estudo 01 ( $\mathrm{n}=$ 88) $(\mathrm{n}=88)$ em função dos níveis de escolaridade.

Tabela 19 - Resultados descritivos (em porcentagem) e comparação estatística em variáveis do Rorschach relacionadas aos modos de apreensão, determinantes, conteúdos e banalidades dos adultos reavaliados do Estudo $01(n=88)(n=88)$ em função da escolaridade. .

Tabela 20 - Resultados descritivos e comparação estatística nos índices de produtividade e ritmo do Rorschach dos adultos reavaliados do Estudo $01(n=88)(n=88)$ em função das faixas etárias

Tabela 21 - Resultados descritivos (em porcentagem) e comparação estatística em variáveis do Rorschach relacionadas aos modos de apreensão, determinantes, conteúdos e banalidades dos adultos reavaliados do Estudo $01(n=88)$ em função das faixas etárias

Tabela 22 - Resultados descritivos e comparação estatística das variáveis relacionadas à produtividade no Rorschach obtidos na primeira avaliação (Pasian, 1998) e na reavaliação dos adultos do Estudo $01(\mathrm{n}=88)$. .

Tabela 23 - Resultados descritivos (em porcentagem) e comparação estatística das variáveis relacionadas aos modos de apreensão no Rorschach obtidos na primeira avaliação (Pasian, 1998) e na reavaliação dos adultos do Estudo $01 \quad(n=88)$. .

. .137

Tabela 24 - Resultados descritivos (em porcentagem) e comparação estatística das variáveis relacionadas aos determinantes (forma, cor, sombreado e movimento) no Rorschach obtidos na primeira avaliação (Pasian, 1998) e na reavaliação dos adultos do Estudo $1(\mathrm{n}=88)$. 138

Tabela 25 - Resultados descritivos (em porcentagem) e comparação estatística das variáveis relacionadas aos conteúdos ( $\mathrm{A}, \mathrm{H}$, Anat, Obj e Bot) e banalidades no Rorschach 
obtidos na primeira avaliação (Pasian, 1998) e na reavaliação dos adultos do Estudo 01 $(\mathrm{n}=88)$. 140

Tabela 26 - Distribuição dos adultos ( $\mathrm{n}=88)$ em função do Tipo de Ressonância Íntima na avaliação de Pasian (1998) e na reavaliação (Estudo 01)

Tabela 27 - Distribuição dos adultos $(\mathrm{n}=88)$ em função da Fórmula das Tendências Latentes (TL) na avaliação de Pasian (1998) e na reavaliação (Estudo 01) 143

Tabela 28 - Distribuição dos adultos $(n=88)$ e estatística descritiva (em porcentagem) da Terceira Fórmula Afetiva do Rorschach na reavaliação (Estudo 01) 145

Tabela 29 - Resultados descritivos e comparação estatística da distribuição dos indivíduos em função das normas do Rorschach (Pasian, 1998) nos dois momentos avaliativos.

Tabela 30 - Resultados descritivos e comparação estatística das diferenças médias entre avaliação e reavaliação nas variáveis do Rorschach em função do sexo (Estudo 01).

Tabela 31 - Resultados descritivos e comparação estatístic das diferenças médias entre avaliação e reavaliação nas variáveis do Rorschach em função da escolaridade (Estudo $01)$.

Tabela 32 - Resultados descritivos e comparação estatísticadas diferenças médias entre avaliação e reavaliação nas variáveis do Rorschach em função das faixas etárias (Estudo $01)$.

Tabela 33 - Distribuição dos adultos do Estudo $1(\mathrm{n}=88)$ na pontuação do $S R Q-20$, divididos em função do sexo e do nível socioeconômico. 158

Tabela 34 - Estatística descritiva da produtividade e do ritmo no Rorschach da amostra do Estudo 2 ( $\mathrm{n}=168)$.

Tabela 35 - Resultados descritivos (frequência simples e porcentagem), para cada cartão, das variáveis associadas à produtividade no Rorschach) da amostra do Estudo 2 .......160 Tabela 36 - Distribuição (em frequência simples e porcentagem) do total de respostas $(\mathrm{R}=3.144)$ nas diferentes categorias de classificação do Método de Rorschach). 162

Tabela 37 - Distribuição (em frequência simples e porcentagem) dos adultos (n=168) em função do Tipo de Vivência Afetiva (TRI) e da Fórmula das Tendências Latentes (TL)

Tabela 38 - Distribuição dos adultos $(\mathrm{n}=168)$ e estatística descritiva (em porcentagem) na Terceira Fórmula Afetiva do Rorschach (amostra Estudo 02) .

Tabela 39 - Distribuição das respostas (somatória e dados médios) em variáveis do Rorschach associadas ao controle afetivo (amostra Estudo 02). 168 
Tabela 40 - Resultados descritivos e comparação estatística nos índices de produtividade e ritmo do Rorschach dos adultos avaliados no Estudo $02(n=168)$ em função do sexo. .

Tabela 41 - Resultados descritivos (em porcentagem) e comparação estatística em variáveis do Rorschach relacionadas aos modos de apreensão, determinantes, conteúdos e banalidades dos adultos e avaliados $(n=168)$ (amostra Estudo 02) em função do sexo.

Tabela 42- Resultados descritivos e comparação estatística nos índices de produtividade e ritmo do Rorschach dos adultos avaliados $(n=168)$ (amostra Estudo 02) em função dos níveis de escolaridade. 175

Tabela 43- Resultados descritivos (em porcentagem) e comparação estatística em variáveis do Rorschach relacionadas aos modos de apreensão, determinantes, conteúdos e banalidades dos adultos avaliados $(\mathrm{n}=168)$ (amostra Estudo 02) em função dos níveis de escolaridade. 176

Tabela 44- Resultados da análise post hoc de Bonferroni das variáveis com diferenças estatisticamente significativas no Rorschach, em função da escolaridade 181

Tabela 45- Resultados descritivos e comparação estatística nos índices de produtividade e ritmo do Rorschach dos adultos avaliados $(n=168)$ (amostra Estudo 02) em função das faixas etárias . 184

Tabela 46- Resultados descritivos (em porcentagem) e comparação estatística em variáveis do Rorschach relacionadas aos modos de apreensão, determinantes, conteúdos e banalidades dos adultos presentemente avaliados $(n=168)$ (amostra Estudo 02) em função da idade..

Tabela 47- Resultados médios (em porcentagem) da amostra do Estudo 2 ( $\mathrm{n}=168$ ) e sua comparação estatística com o estudo normativo de Pasian $(\mathrm{n}=405)$..

Tabela 48 - Resultados descritivos e inferenciais das variáveis do Rorschach em adultos $(\mathrm{n}=168)$. 194

Tabela 49 - Lista das respostas banais ao Rorschach, identificadas a partir do conjunto de respostas emitidas $(R=3.144)$ pela amostra total $(n=168)$ 197 


\section{LISTA DE APÊNDICES E ANEXOS}

APÊNDICE A - Carta-convite para participação na pesquisa (Estudo 01)............266 APÊNDICE B - Tabela 50 - Frequência relativa e absoluta das idades dos adultos

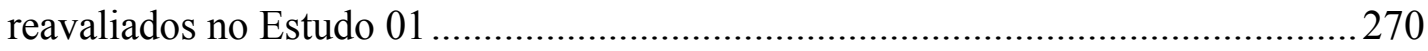

APÊNDICE C - Self Report Questionaire 20 (SRQ-20): .....................................2 274

APÊNDICE D - Termo de Consentimento Livre e Esclarecido (Estudo 01)......... 278

APÊNDICE E - Carta-convite para participação na pesquisa (Estudo 02) ............. 282

APÊNDICE F - Termo de Consentimento Livre e Esclarecido (Estudo 02) .......... 286

APENNDICE G - Atlas referente às localizações e à qualidade formal das respostas produzidas pela amostra normativa do estudo. 290

ANEXO 01 - Critério de Classificação Econômica Brasil da Associação Brasileira de Empresas de Pesquisa (ABEP, 2012) 391 ANEXO 02 - Aprovação da Pesquisa pelo Comitê de Ética em Pesquisa da Faculdade de Filosofia, Ciências e Letras de Ribeirão Preto da Universidade de São Paulo ...395 


\section{SUMÁRIO}

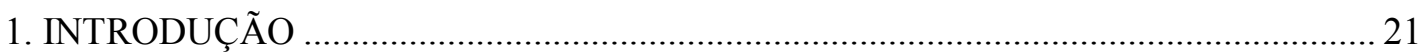

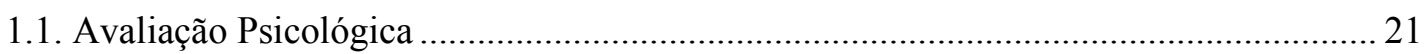

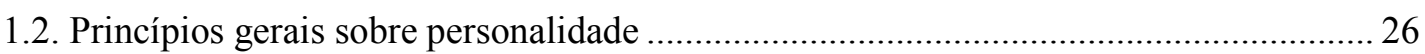

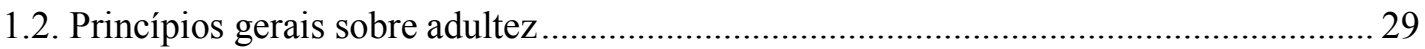

1.4. Método de Rorschach: princípios e histórico no Brasil.................................................... 34

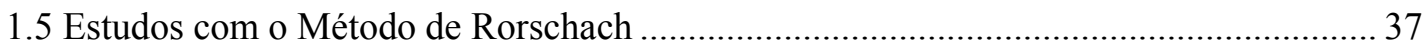

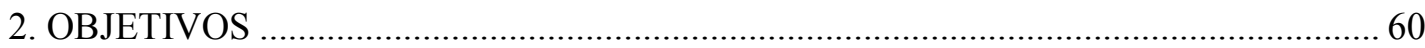

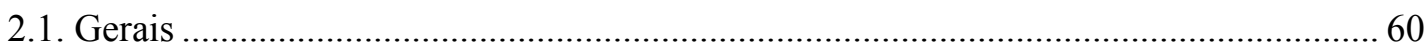

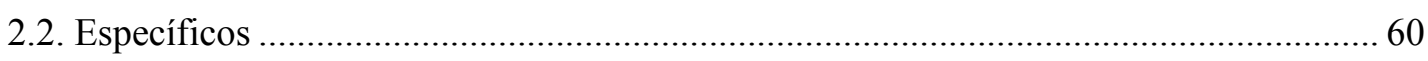

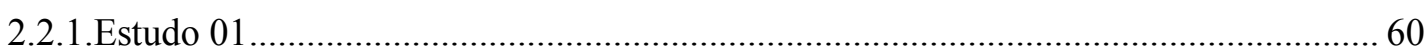

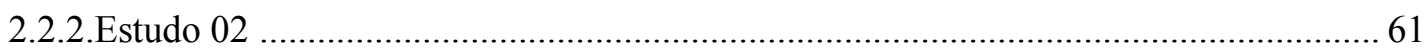

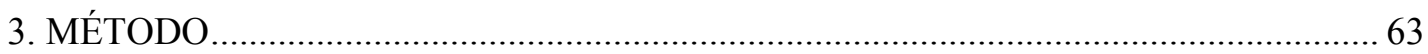

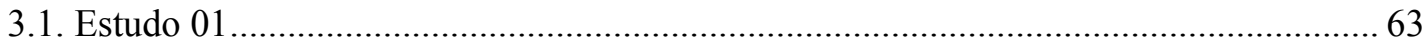

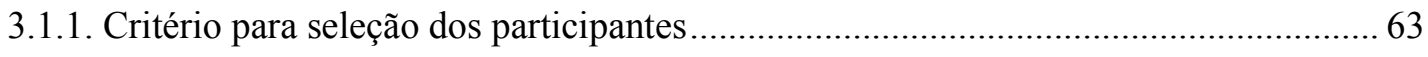

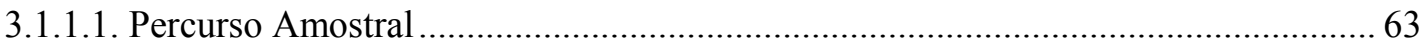

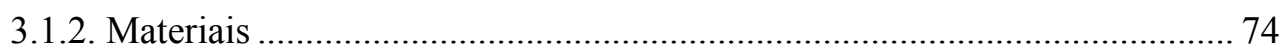

3.1.2.1. Carta de Convite a Participação na Pesquisa ..................................................... 74

3.1.2.2. Critério de Classificação Econômica, ABEP (2012) ........................................ 74

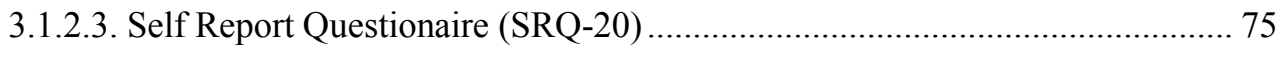

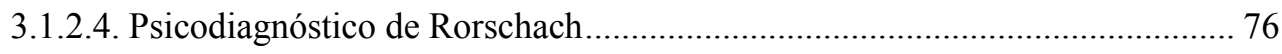

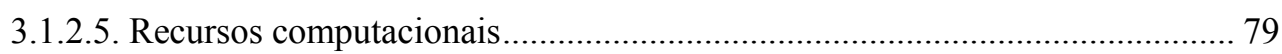

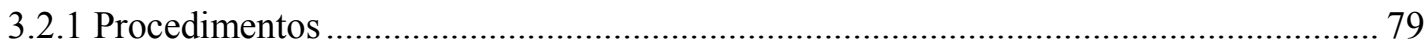

3.2.1.1. Considerações Éticas .................................................................................... 80

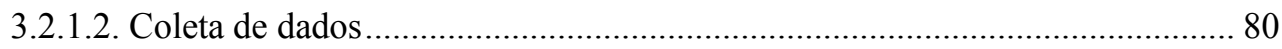

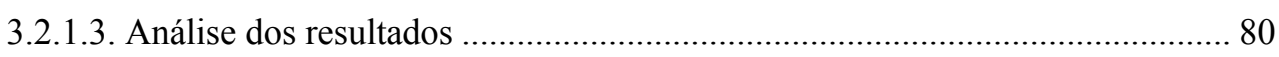

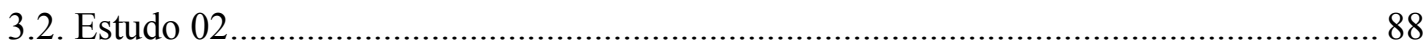

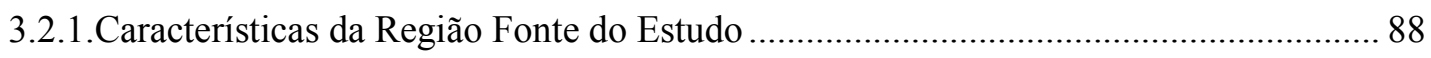

3.2.2. Critério de Seleção de Participantes............................................................................... 90

3.2.3. Seleção dos Participantes .......................................................................................... 91

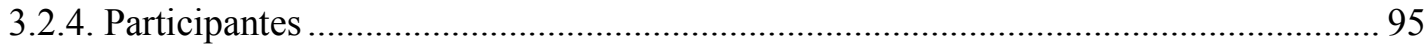

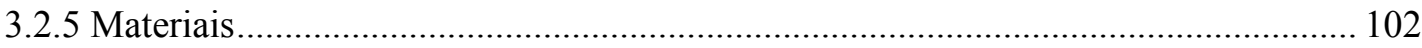

3.2.5.1. Carta de Convite a Participação na Pesquisa ................................................... 102

3.2.5.2.Critério de Classificação Econômica, ABEP (2012) ....................................... 103

3.2.5.3. Self Report Questionaire (SRQ-20) ........................................................... 103

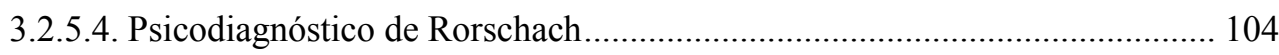


3.2.5.5. Teste de Inteligência Não Verbal - INV (Forma C)........................................ 104

3.2.5.6. Recursos computacionais............................................................................. 104

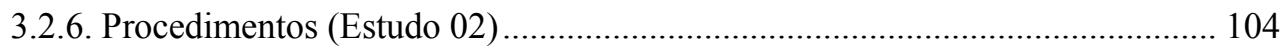

3.2.6.1 Análise de precisão do Rorschach...................................................................... 105

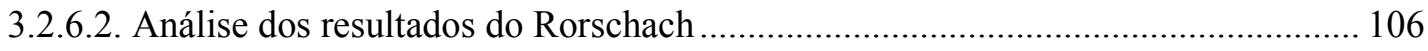

3.2.6.3. Elaboração do atlas do Rorschach.......................................................................... 107

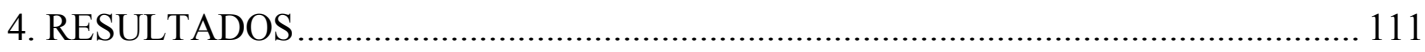

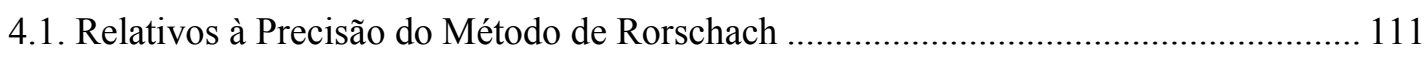

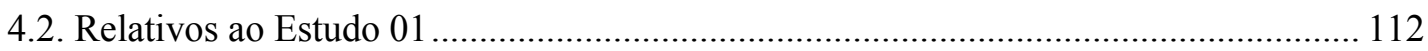

4.2.1 Perfil geral dos adultos no Rorschach........................................................... 112

4.2.2. Análise da influência do sexo no Rorschach .................................................. 117

4.2.3. Análise da influência da escolaridade no Rorschach ....................................... 123

4.2.4. Análise do efeito da idade no Rorschach........................................................... 129

4.2.5. Análise comparativa das duas avaliações pelo Rorschach................................. 135

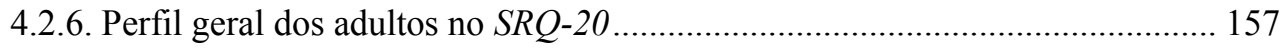

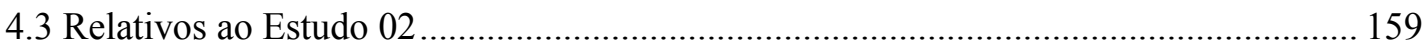

4.3.1. Perfil geral dos adultos no Estudo 02 ........................................................... 159

4.3.2. Análise da influência do sexo no Rorschach ................................................... 169

4.3.3 Análise da influência da escolaridade no Rorschach ........................................ 175

4.3.4. Análise da influência da idade no Rorschach. ............................................. 183

4.3.5. Análise comparativa do Rorschach em relação às normas para adultos .......... 190

4.3.6. Síntese geral do Rorschach (dados normativos atuais) ....................................... 193

4.3.7. Atlas do Rorschach .......................................................................................... 196

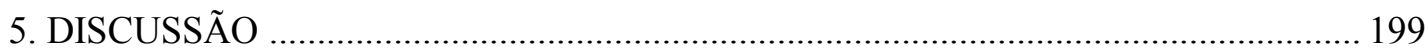

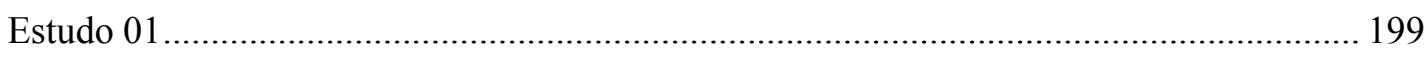

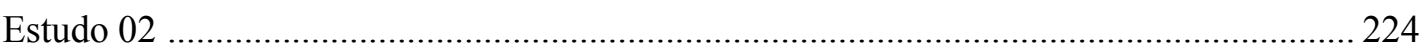

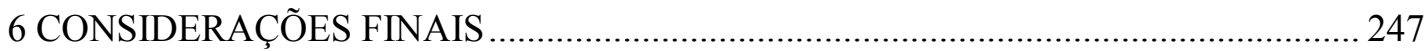

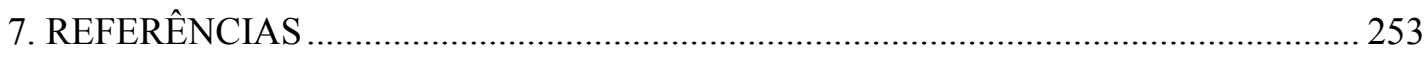

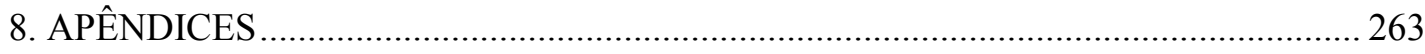

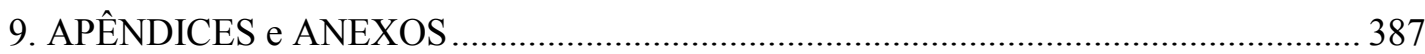




\section{INTRODUCẼ̃O}

Este trabalho de doutorado insere-se no campo da Avaliação Psicológica, domínio da área da Psicologia, abordando temas a respeito da personalidade, do método de Rorschach (Escola Francesa ou de Paris ${ }^{1}$ ) e suas evidências psicométricas, a partir da análise de casos não-clínicos de adultos. Desta forma, cada um destes elementos será apresentado nesta introdução, com o objetivo de contemplar e vincular as áreas de interesse citadas aos propósitos deste estudo.

\subsection{A avaliação psicológica}

A Avaliação Psicológica enquanto área do conhecimento a partir do desenvolvimento dos testes psicológicos no século XX compõe um campo específico da Psicologia (Urbina, 2007). Embora com vasto alcance e aplicabilidade no Brasil, os processos de avaliação psicológica baseados no uso de testes psicológicos são considerados práticas exclusivas do profissional psicólogo (CFP, 2015 http://site.cfp.org.br/)

A avaliação psicológica é um processo amplo que, segundo Primi (2010), constitui-se na "busca sistemática de conhecimento a respeito do funcionamento psicológico das pessoas, de tal forma a poder orientar ações e decisões futuras. Esse conhecimento é sempre gerado em situações que envolvem questões e problemas específicos" (p. 26). Neste processo podem ser utilizadas diversas estratégias e ferramentas, entre elas os instrumentos denominados testes psicológicos. Urbina (2007) define teste psicológico como "procedimento sistemático para a obtenção de amostras

\footnotetext{
${ }^{1}$ A Escola Francesa de Rorschach passou a ser também reconhecida pela denominação "Escola de Paris" (L'école de Paris: histoire et développements contemporains. J-Y Chagnon, 2014). Desta forma, acompanhando a perspectiva atual, o presente estudo passou a incorporar também essa nova denominação.
} 
de comportamento relevantes para o funcionamento cognitivo ou afetivo e para a avaliação destas amostras de acordo com certos padrões" (p. 11-12).

Para que os testes psicológicos possam ser considerados adequados para uso profissional, necessitam preencher determinados critérios técnico-científicos, em especial adequados índices psicométricos (bons indicadores de validade, de precisão e adequados referenciais normativos). Cada um destes critérios possui sua complexidade técnica específica e orientações científicas a serem devidamente contempladas. Desta forma, por exemplo, a padronização de um instrumento de avaliação psicológica implica em uniformidade na apresentação da atividade, na avaliação e na interpretação de seus resultados. E ainda, na avaliação dos dados, é fundamental que seu uso respeite os padrões provenientes de adequadas amostras normativas derivadas do desenvolvimento do instrumento (Urbina, 2007).

Apesar destas exigências científicas, a prática profissional do psicólogo, sobretudo no Brasil, tem sido permeada por usos de materiais pouco fundamentados por pesquisas ou atuações profissionais pouco adequadas, muitas vezes por deficiência na formação profissional na área de avaliação psicológica. Estas dificuldades foram apontadas por vários pesquisadores, tanto no tocante aos instrumentos em si (por exemplo, Noronha \& Alchieri, 2005), quanto aos limites da formação durante a graduação em Psicologia na área de avaliação psicológica (Alves, 2009; Noronha, 2009; Hutz, 2009). Muitos dos instrumentos utilizados não apresentavam os requisitos necessários para sua utilização, o que afetou negativamente a qualidade dos serviços prestados à população, comprometendo, ao longo dos anos, a própria imagem da avaliação psicológica, muitas vezes sustentada por preconceitos que não acompanham os avanços científicos da área, como argumentou Primi (2010). 
No cenário internacional, em 2000, profissionais da área de avaliação psicológica elaboraram diretrizes para o uso e revisão dos testes psicológicos, ação coordenada pela International Test Commission (ITC), que disponibiliza documentos de orientação técnica para os que utilizam instrumentos de avaliação psicológica. O Comitê também possibilita o intercâmbio de informações entre seus membros e fornece orientações para elaboração, distribuição e uso de instrumentos de avaliação psicológica. O objetivo é garantir o uso ético destes materiais, o respeito aos seus princípios científicos e também nortear os procedimentos necessários para a adaptação dos instrumentos em contextos e países diferentes do local onde foram criados (ITC, 2016 https://www.intestcom.org/files/guideline_test_use.pdf).

Nesta direção, o Conselho Federal de Psicologia (CFP), por meio da Resolução CFP n ${ }^{0}$ 002/2003, criou a Comissão Consultiva em Avaliação Psicológica, bem como o Sistema de Avaliação dos Testes Psicológicos (SATEPSI). A comissão é formada por especialistas em avaliação psicológica e tem por objetivo analisar e emitir pareceres sobre os instrumentos de avaliação psicológica encaminhados para análise técnica ao Conselho, baseando-se nos parâmetros definidos na referida resolução. Já o SATEPSI fíca responsável por divulgar as informações atualizadas sobre as etapas avaliativas de cada instrumento psicológico, bem como a relação dos materiais aprovados e informações correlacionadas a estes processos (Anache \& Correa, 2010). Desde a criação do SATEPSI, já em 2001, o CFP buscou implementar estratégias para garantir qualificações técnicas nos instrumentos psicológicos, passando a exigir que os testes psicológicos tivessem manuais com informações precisas de classificação e de interpretação dos escores, com normas expressas de forma detalhada, com procedimentos de aplicação e análise de resultados, além de suas evidências de validade e de precisão no contexto brasileiro (CFP, 2013). Esta preocupação também tem seus reflexos na decisão do CFP 
chegar a eleger 2011 como o ano temático da "Avaliação Psicológica” (Verona, 2011), enfatizando a necessidade de investimentos relevantes na qualificação técnica e científica da área, para aprimorar a qualidade do trabalho profissional do psicólogo brasileiro.

Ao retomar a questão conceitual do próprio teste psicológico, pode-se afirmar que muitas tentativas existiram para coordenar a diversidade de procedimentos existentes. Apesar desta variabilidade de critérios possíveis para classificação dos testes psicológicos, nas considerações de Urbina (2007) estes podem diferir em relação a sua natureza, que poderia ser objetiva, pertencente ao campo dos instrumentos psicométricos, ou subjetiva, representados pelas técnicas projetivas. Ainda de acordo com esta pesquisadora, os testes também podem ser diferenciados de acordo com a função psicológica que está sendo avaliada, como: funcionamento cognitivo, nível de conhecimento, habilidades, capacidades ou personalidade (Urbina, 2007).

No entanto, também coexistem questionamentos relativos sobre a adequação técnica desta denominação relativa a testes objetivos e projetivos de avaliação psicológica, propondo-se sua substituição, respectivamente, por instrumentos de autorrelato e instrumentos autoexpressivos, seguindo as considerações de Ritzler (2006). Independentemente de sua nomeação, o elemento relevante constitui-se no tipo de estrutura e de alcance informativo de cada classe de instrumentos de avaliação psicológica, sendo que, no atual momento, destaque será dado aos instrumentos de natureza projetiva.

Os métodos projetivos de avaliação psicológica diferenciam-se de instrumentos mais estruturados por possibilitarem o acesso a aspectos inconscientes do indivíduo, revelando informações importantes de sua personalidade e sua forma particular de perceber o mundo. Em tais métodos, os materiais são considerados ambíguos e as 
instruções permitem que o sujeito realize a tarefa de acordo com sua própria disposição e motivação interna (Anzieu, 1986).

Villemor-Amaral (2006) ressalta que os métodos projetivos advêm de um enfoque clínico em que se observa a interação entre indivíduo e observador; este procurará recolher o maior número de informações sobre diferentes aspectos do universo psíquico do sujeito. Além disso, estão fundamentados na teoria psicanalítica e tem como princípio básico o conceito de projeção no sentido ampliado de um fenômeno que denota o ato de expressar, por meio de produções e do desempenho em determinadas tarefas pouco definidas, algo da individualidade e do mundo interno de cada um (VillemorAmaral, 2006, p. 164). Além disso, Anzieu (1986) comenta sobre a liberdade presente na aplicação dos testes projetivos, pois em suas palavras, "não há-segundo o que é dito ao indivíduo - boas e más respostas predeterminadas” (p. 23).

Apesar dessas possibilidades, de maneira geral, muitas críticas de natureza metodológica existem em relação aos instrumentos projetivos de avaliação psicológica, sobretudo a respeito de suas evidências psicométricas (Bandeira, Lieberknecht, Trentini \& Winck, 2006). Fensterseifer e Werlang (2008) comentam três dessas principais críticas: a primeira refere-se à suposta ausência de cientificidade dos testes projetivos, tanto por parte de quem os constroem como por parte de quem os utilizam; a segunda questiona o valor intrínseco dos testes projetivos, supondo que o examinador influenciaria as respostas dos sujeitos e, por último, a fragilidade na tentativa de se validar tais instrumentos. As autoras rebatem tais críticas apresentando os "pontos fortes dessas técnicas" que seriam: a) a valorização do comportamento e do indivíduo como um todo, ao refletir seu funcionamento e a estrutura singular de seu mundo interno; b) menor suscetibilidade a fraude ou simulação (em relação aos inventários de autorrelato), já que 
o objetivo do método projetivo não é tão explícito e isto dificulta a possibilidade de que o sujeito controle racionalmente suas respostas.

Villemor-Amaral e Pasqualini-Casado (2006) também respondem às críticas direcionadas aos métodos projetivos, sobretudo no tocante a validade e fidedignidade deste tipo de instrumento de avaliação psicológica. As autoras argumentam que a cientificidade dos métodos projetivos não deveria se basear somente em seu rigor psicométrico, mas também em sua própria utilidade e validade clínica. Para as autoras, diferentemente dos instrumentos objetivos de avaliação psicológica, que examinam de forma direta as pessoas, as medidas projetivas avaliam necessidades implícitas que o indivíduo não acessa diretamente. Essa é uma de suas grandes riquezas, na medida em que esta forma de funcionar (pautada em necessidades implícitas) pode limitar o controle racional e a influência da desejabilidade social nos posicionamentos frente às atividades do instrumento.

Dentre os vários métodos projetivos de avaliação psicológica, disponíveis para uso no Brasil, segundo análise do CFP (CFP, 2013), este trabalho destacará um importante instrumento de avaliação da personalidade, o Método de Rorschach. Para chegar aos propósitos desse trabalho, no entanto, os próximos tópicos desta introdução abordarão, primeiramente, o construto personalidade e, em seguida, alguns aspectos relevantes sobre a fase adulta do desenvolvimento e sobre o Método de Rorschach, de modo a contextualizar esta investigação.

\subsection{Princípios gerais sobre Personalidade}

O construto personalidade é objeto de inúmeros estudos na área da Avaliação Psicológica (Silva \& Nakano, 2011). Essas autoras discutem que há uma multiplicidade de definições desse construto e que a avaliação da personalidade é realizada a partir da 
teoria escolhida pelo pesquisador. Portanto, faz-se necessário elencar alternativas teóricas a respeito, bem como apontar o caminho a ser explorado no presente trabalho sobre esse tema.

Feist, Feist \& Roberts (2015) comentam que a Psicologia conta com diversos autores que discutem a construção da personalidade a partir de diferentes abordagens. $\mathrm{O}$ presente estudo não se propõe a esgotar as possibilidades de interpretação teórica sobre o assunto, abordando-o de forma bastante breve, apenas para citar algumas das abordagens conhecidas e que servem de aporte teórico para os estudos sobre personalidade.

A Psicologia do Desenvolvimento preocupa-se em conhecer os estágios sequenciais ao longo do ciclo vital e as mudanças de comportamento que ocorrem ao longo do tempo, considerando os processos orgânicos individuais e a influência ambiental sobre o mesmo (Feist, Feist \& Roberts, 2015). Apresenta, portanto, um campo para se compreender a personalidade, enquanto construção ao longo do desenvolvimento.

Outro destaque teórico a respeito da personalidade deve ser dado à proposta da Psicanálise. De acordo com Feist, Feist \& Robberts (2015). Freud criou estratégias para compreensão do ser humano, chegando a um modelo estrutural para conceber a personalidade, postulando três componentes: Id, Ego e Superego. Para Freud o desenvolvimento da personalidade é subsidiário ao desenvolvimento das pulsões sexuais, sendo derivado da passagem pelas fases do desenvolvimento psicossexual.

Nesta direção, Zimmerman (1999) pondera que para a Psicanálise há muitos e diversos fatores que interagem e influenciam na formação da personalidade. Assim, a evolução da psicossexualidade não ocorre de maneira linear e sujeita à programação da natureza genética. Ao contrário, é construída ao longo do tempo: por meio do efeito dos fatores constitucionais inatos da criança e os que são adquiridos pela influência do ambiente externo, principalmente sob a influência dos pais. 
Outro autor da Psicanálise, Erik Erikson, ressalta o viés "dinâmico e histórico de Freud" a respeito da personalidade, porém afirma a importância do ambiente social e seu impacto no desenvolvimento da personalidade (Feist, Feist \& Robberts, 2015). Para Erikson, o enfoque passa a ser o ego, desviando-se da sexualidade e objetivando a compreensão das relações sociais. Além disso, sugere que a cada etapa do desenvolvimento, o ego passa por uma crise e que a cada crise, a personalidade se reestrutura e se reformula de acordo com as experiências vividas (Rabelo \& Passos, 2007).

Estes autores comentam que, segundo Erickson, as etapas da vida adulta seriam marcadas por três fases, a do jovem adulto, em que a crise vivida é "intimidade versus isolamento". A intimidade demanda que a questão da identidade pessoal esteja estabelecida de modo a facilitar o relacionamento com o outro, enquanto as dificuldades do relacionamento íntimo podem contribuir para o isolamento. Em um segundo momento, o conflito foi denominado como "generatividade versus estagnação", nesta fase haveria o desejo de produção e interesse em desenvolver as potencialidades como ser ativo no mundo. Enquanto as preocupações mais voltadas para si mesmo, tenderiam a levar os indivíduos à estagnação. Por fim, a crise se estabeleceria em torno da questão "integridade versus desespero". A integridade seria o resultado de um balanço positivo e a satisfação com a vida vivida, enquanto o desespero revelaria uma vida pouco produtiva e de poucas realizações (Rabelo \& Passos, 2007).

Além dessas e de outras abordagens psicodinâmicas há modelos que descrevem a estrutura da personalidade baseando-se na teoria dos traços. Silva e Nakano (2011) afirmam que, do ponto de vista psicométrico, o modelo dos Cinco Grandes Fatores da Personalidade constituem teoria explicativa e preditiva da personalidade humana com grande acúmulo de evidências empíricas, em diferentes contextos mundiais. Esse modelo 
teve origem em estudos sobre personalidade a partir das teorias fatoriais e de traços de personalidade. Sisto e Oliveira (2007 apud Silva e Nakano, 2011) sugerem que os traços de personalidade estão relacionados a características psicológicas que, por sua vez, representam tendências "relativamente estáveis na forma de pensar, sentir e atuar com as pessoas, caracterizando, contudo, possibilidades de mudanças, como produto das interações das pessoas com seu meio social” (p. 52).

Diante dessa breve contextualização do construto personalidade, nota-se a existência de diversas e complexas teorias a respeito. Cada qual procurou sistematizar procedimentos e estratégias técnicas para acessá-la, derivando grande multiplicidade de instrumentos psicológicos disponíveis. Não cabe aqui mapear a diversidade técnicoteórica existente sobre o construto, mas apenas sinalizar esse contexto que vigora no Brasil e internacionalmente, exigindo grande investimento investigativo para adequado conhecimento do tema. Diante disso, o presente trabalho propõe-se a investigar a personalidade na fase adulta, a partir do instrumento projetivo conhecido como Método de Rorschach, pautando-se num referencial psicodinâmico de personalidade, elementos explorados nos tópicos a seguir.

\subsection{Princípios gerais sobre Adultez}

Caracterizar a entrada na vida adulta pode ser uma tarefa complexa. Seria a idade biológica que definiria a adultez? Ou fatores como a independência econômica, a constituição da família ou o processo de sair da casa dos pais? Existem etapas ao longo da vida, como a infância e a adolescência, que parecem circunscritas (ao menos biologicamente) e, muitas vezes, permitem sua delimitação concreta, embora também com grandes variações socioculturais. A entrada para a vida adulta, no entanto, parece 
seguir um caminho menos linear, especialmente nas últimas décadas, considerando as mudanças econômicas, sociais e culturais da sociedade (Camarano \& Mello, 2006).

Além disso, durante muito tempo, entendeu-se a fase adulta como uma etapa estanque. Camarano, Mello e Kanso (2006) criticam esse caráter de rigidez e estabilidade conferido a esse momento da vida. Para as autoras, o mundo está em permanente transformação, tornando as fases da vida mais instáveis e, por serem mudanças complexas e heterogêneas, exigem reflexões e avanços teóricos para se compreender esse período da vida e do ciclo vital em geral.

É certo que a transformação demográfica da sociedade, a partir do envelhecimento da população, promove reflexões sobre mudanças de comportamento humano, sendo interessante avaliar com atenção e cuidado a etapa da adultez. Santos e Antunes (2007) destacam que se trata da fase mais longa da existência humana. Por cobrir um período relativamente extenso da vida dos indivíduos certamente tem sua complexidade e abarca uma série de características que merecem explanação.

Sobre a cognição, Bee (1997) sugere que o pensamento formal prevalece no início da vida adulta, mas que com o passar do tempo ocorrem mudanças na estrutura do pensamento em função das exigências que acompanham esse período. As mudanças no pensamento estariam, primeiramente, relacionadas a uma visão pragmática de solução de problemas e desafios que surgem em função do desempenho de novos papéis sociais e do exercício profissional. Com o passar do tempo, esse pensamento cederia espaço a uma visão mais aberta e imaginativa, portanto, mais flexível. Esta compreensão contraria a clássica visão proposta por Rappaport (1981), argumentando que o pensamento formal predomina no raciocínio utilizado pelo adulto, com ampliação de conhecimentos, porém sem a aquisição de novos modos de funcionamento mental. 
Além do funcionamento cognitivo, o afeto é considerado elemento estruturante na formação da identidade dos sujeitos também na vida adulta. A capacidade de se conectar com o outro e estabelecer relações duradouras, por exemplo, converge com o que Erikson argumenta a respeito do desafio dessa fase de vida: construir identidade versus isolamento (Rabello \& Passos, 2007). Como citado anteriormente, na proposta de Erikson, se o jovem adulto consegue fundar um verdadeiro comprometimento pessoal com os outros, tenderá a não se sentir isolado e poderá estabelecer relações de maior conexão e intimidade com as pessoas. Esse movimento tende a influenciar a maneira como os indivíduos se adaptam e reagem às mudanças inerentes a essa fase da vida.

Sobre fases mais avançadas da idade adulta, Rebelo (2007) descreve um modelo contextual para conceituar os processos típicos do envelhecer desta etapa. $\mathrm{O}$ autor sugere a integração de quatro elementos que fazem parte desse processo: 1) a maturidade, em que existem estruturas de pensamento pós-formal, maior complexidade emocional e maior competência no relacionamento interpessoal, 2) efeito geracional, relacionado ao momento histórico do nascimento dos indivíduos que caracterizam a maneira como o sujeito vive o presente, 3) contexto social, determinante da maneira de se viver e se desenvolver; 4) mudanças específicas da idade adulta avançada, relativas a doenças crônicas, déficits e perdas.

Do ponto de vista da Psicanálise, é fundamental compreender o papel do inconsciente em todas as etapas do desenvolvimento humano. Freud, propulsor da teoria, enfoca os aspectos que ocorrem no desenvolvimento infantil para a compreensão da vida mental adulta. Bergeret (2006) afirma que para o pai da Psicanálise "toda a psicologia do adulto origina-se das dificuldades experimentadas no nível do desenvolvimento da sexualidade infantil" (p. 29). 
Ainda com objetivo final de compreender o ser humano e seu desenvolvimento, Melanie Klein observou crianças de pouca idade em sessões de análise, enfatizando as primitivas relações do bebê com a mãe, e acrescentou contribuições importantes à teoria psicanalítica (Zimerman, 1999). No capítulo "Nosso mundo adulto e suas raízes na infância", Klein (1959) afirma que é essencial compreender as pessoas em seu ambiente social e para isso é importante explorar como ocorre o desenvolvimento do indivíduo desde a infância até a maturidade. Para a autora, quando compreendemos a vida social, compreendemos também a personalidade dos indivíduos. Nas palavras de Klein (1959): As descobertas de Freud têm nos ajudado, no decorrer do tempo, a entender a complexidade das emoções da criança e têm revelado que as crianças passam por sérios conflitos. Isso levou a uma melhor compreensão da mente infantil e de suas conexões com os processos mentais do adulto (p. 281). Ela faz um resgate do funcionamento mental a partir do bebê, identificando as fantasias mais primitivas, a vivência em relação aos objetos bons e maus, os impulsos destrutivos, as ansiedades persecutórias que despertam emoções que ainda vão atuar posteriormente na vida. Reafirma ainda que, mesmo em circunstâncias externas favoráveis ao bebê, os impulsos destrutivos, que variam de indivíduo para indivíduo, são parte integrante da vida mental. Ela argumenta que é necessário considerar o desenvolvimento da criança e as atitudes dos adultos como resultantes da interação entre influências internas e externas.

Além disso, relembra que a grande descoberta de Freud e Abraham refere-se às noções de que os processos projetivos e de introjeção são da maior importância nas graves desordens mentais e também na vida mental normal. Seria por meio da introjeção que a imagem transformada do mundo influenciaria o que ocorre na mente do bebê, ajudandoo a construir seu mundo interno. Os processos de introjeção e projeção continuariam ao longo da vida, transformando-se na maturidade, mas sem perder a importância na relação 
do indivíduo com o mundo que o cerca. Ainda no adulto, o julgamento da realidade não seria livre da influência de seu mundo interno, bem como, as fantasias inconscientes comporiam outro aspecto que acompanharia as atividades humanas ao longo da vida, não podendo ser desconsideradas. Klein também argumenta que, no desenvolvimento normal, com a crescente integração do ego, os processos de cisão diminuem e ocorre maior capacitação para entender a realidade externa e harmonizar os impulsos primitivos conflitantes, promovendo síntese dos aspectos bons e maus do objeto (Klein, 1959). Para esclarecer esse processo, vale destacar a seguinte passagem da referida autora:

Se olharmos para nosso mundo adulto do ponto de vista de suas raizes na infância, obtemos um insight sobre o modo pelo qual nossa mente, nossos hábitos e nossas concepções foram construídos desde as fantasias e emoções infantis mais arcaicas até as mais complexas e sofisticadas manifestações adultas. Há mais uma conclusão a ser tirada: aquilo que já existiu no inconsciente nunca perde completamente sua influência sobre a personalidade (Klein, 1959, p. 295).

Zimerman (1999) afirma que, enquanto M. Klein valoriza o mundo interno do bebê e explora sua relação com a vida mental posterior, Winnicott o valoriza, mas considera o papel do ambiente exterior, representado pela mãe real (ou quem executa a função materna), fundamental na compreensão do desenvolvimento emocional da criança e, consequentemente, do adulto. Mas para Zimerman (1999) é Bion quem confere um valor equitativo a ambos esses aspectos na formação do psiquismo humano. Entre diversas contribuições teóricas, destaca-se aqui a compreensão de Bion sobre a possibilidade da coexistência de diferentes estados psíquicos na mente, atuando de forma multidimensional, o que possibilita um funcionamento dinâmico entre as partes da personalidade (Wolff, Carvalho \& Costa, 2015). 
As breves considerações aqui expostas sobre a fase adulta do desenvolvimento foram elaboradas como estímulos a reflexão sobre as características esperadas para os indivíduos dessa faixa etária, uma vez que os adultos são a população alvo deste trabalho. Assume-se, portanto, uma perspectiva psicodinâmica para exploração da personalidade no presente estudo, examinada a partir de metodologia projetiva de avaliação psicológica, mais especificamente pelo Método de Rorschach, objeto a ser trabalhado no próximo tópico.

\subsection{Método de Rorschach: princípios e histórico no Brasil}

O Método de Rorschach foi desenvolvido pelo psiquiatra suíço Hermann Rorschach e publicado em 1921. Adrados (1985) afirma que o Rorschach é uma técnica de investigação da personalidade universalmente aceita e se baseia na percepção e na comunicação verbal simples. É um instrumento eficiente e sensível para a compreensão da dinâmica do psiquismo humano e ocupa posição de destaque entre os métodos de investigação científica de características (estruturais e funcionais) da personalidade, não apenas no Brasil, mas também, em outros países. De acordo com Azoulay et al. (2007) trata-se de um dos métodos mais utilizados para a avaliação da personalidade.

Shapiro (2012) fornece uma importante opinião que ressalta o valor deste método de avaliação da personalidade. Vale citar o seguinte trecho desse pesquisador:

Além de seu valor diagnóstico, testes psicológicos, especialmente o teste de Rorschach, têm um valor teórico importante para a compreensão da psicopatologia. Eles apresentam um quadro de uma pessoa viva, em contraste com uma imagem de forças e agências dentro da pessoa. Este baseia-se em duas vantagens dos testes sobre as entrevistas psiquiátricas e psicanalíticas habituais: 
os testes são atemporais e eles apresentam informações principalmente de um tipo formal (p. 558) .

Para Castro (2008) a riqueza do Rorschach advém das possibilidades técnicocientíficas para sua interpretação, o que permite que se faça uma análise da personalidade do indivíduo em termos estruturais e dinâmicos. O autor ressalta a possibilidade de se realizar um trabalho de natureza quantitativa (descritiva), a partir dos itens de codificação, que permitem análise de caracterização da personalidade, mas também, com base nas verbalizações ao Rorschach, pode-se elaborar análise qualitativa sobre o funcionamento do indivíduo e sobre sua relação consigo e com o mundo.

No Brasil, a partir da recuperação histórica realizada por Castro (2008), a primeira discussão científica sobre o Rorschach no país ocorreu em 1929, em Minas Gerais, com a participação da psicóloga russa Helena Antipoff. Ou seja, na mesma década de sua criação na Suíça, o Psicodiagnóstico de Rorschach já era introduzido no Brasil. Os primeiros registros de aplicação datados do método, segundo o referido pesquisador, são de 1932 e a primeira publicação científica brasileira aconteceu em 1935 (Castro, 2008). Com essas informações, o referido pesquisador demonstra que os profissionais da área de avaliação psicológica do Brasil, desde então, procuraram acompanhar o desenvolvimento e estudos sobre o Método de Rorschach no mundo todo.

Provavelmente deste grande investimento nesse método de avaliação psicológica houve a fundação de três associações científicas brasileiras vinculadas ao Rorschach, a saber: Sociedade Rorschach de São Paulo, fundada em 1952; Sociedade Brasileira de

\footnotetext{
2 "Apart from their diagnostic value, psychological tests, especially the Rorschach test, have an important theoretical value for understanding psychopathology. They present a picture of a living person, in contrast to a picture of forces and agencies within the person. This rests on 2 advantages of tests over the usual psychiatric and psychoanalytic interviews: tests are ahistorical and they present information primarily of a formal kind" (p. 558).
} 
Rorschach, fundada em 1993 (atual “Associação Brasileira de Rorschach e Métodos Projetivos - ASBRo) e Associação Goiânia de Rorschach, fundada em 1997. Entre suas atividades constam discussões e atualizações científicas a respeito deste instrumento de avaliação da personalidade. Em outras palavras, este método projetivo agrega diversidade de profissionais e de atuações práticas em diversos contextos de aplicação, corroborando o seu destaque internacional também no Brasil.

A pesquisa e a prática com o Método do Rorschach são realizadas por meio de distintos enfoques metodológicos, que, por sua vez, refletem seus diferentes sistemas de classificação e de interpretação das variáveis. Pasian (2002) aponta que, apesar da existência desses diferentes sistemas interpretativos, há uma "mesma estrutura básica para a aplicação da técnica, procurando manter a proposição original do autor desse método” (p. 6). Na lista do SATEPSI, os sistemas do Rorschach que estão aprovados para utilização no Brasil são: "Rorschach - Sistema da Escola Francesa"; "Rorschach Sistema Klopfer", "Rorschach - Sistema Compreensivo" e "Rorschach Clínico" (CFP, 2015).

Em levantamento realizado por Noronha, Primi e Alchieri (2004) constatou-se que, no país, entre os profissionais da Psicologia, o Método de Rorschach está entre os 10 instrumentos mais utilizados nos processos de avaliação psicológica. Além disso, este método projetivo é objeto de estudo de inúmeras pesquisas nacionais e internacionais em diferentes perspectivas e com variados objetivos.

A fim de oferecer um panorama atual sobre trabalhos relativos ao Método de Rorschach, foi realizado levantamento da produção científica indexada sobre o tema. Os achados desse trabalho estão a seguir sistematizados, de modo a enfatizar trabalhos de pesquisa realizados com o Método de Rorschach nos últimos anos. 


\subsection{Estudos com o Método de Rorschach}

Em janeiro de 2016 realizou-se busca sistemática sobre a produção científica a respeito do Método de Rorschach, utilizando as bases de dados PsycInfo com o termo "Rorschach". Delimitou-se a pesquisa nos documentos do tipo "Journal Article", entre os anos de 2010 a 2015, encontrando-se 446 estudos. Apenas esse dado revela a multiplicidade de aplicações e investigações científicas que utilizam este método, ressaltando sua importância e utilidade em termos mundiais. Após incluir no campo de busca a palavra "Abstract" restaram 304 estudos. Essa decisão foi tomada uma vez que alguns artigos não puderam ser acessados na íntegra e não estava citado no "Abstract" o teste de Rorschach e nem como o mesmo havia sido utilizado.

Os estudos localizados nesse levantamento da literatura científica foram desenvolvidos em diferentes contextos socioculturais, com indivíduos de várias faixas etárias e com diversas perspectivas metodológicas. Houve predomínio de estudos de abordagem clínica (139), seguidos por estudos de caso (59), revisão bibliográfica, relato de experiência ou pesquisa documental (58), trabalhos voltados às qualidades psicométricas do instrumento (39), estudos de caráter experimental (oito) e relacionados à prática no campo forense (um).

No contexto brasileiro, a partir da base de dados Scielo Brasil, a mesma pesquisa de literatura citada acima resultou na identificação de 24 artigos. Nesse conjunto de investigações realizadas nos últimos cinco anos, quatro delas (uma com enfoque clínico e três com enfoque psicométrico) foram as mesmas já localizadas na pesquisa bibliográfica anterior (baseada na PsycInfo), restando a análise de 20 artigos. Assim, foi possível notar que 12 (dos 20 novos artigos localizados na base da dados da Scielo) foram desenvolvidos com enfoque clínico, enquanto sete artigos evidenciaram aspectos psicométricos do instrumento e outro estudo foi uma revisão de literatura. Apesar de seu 
frequente uso, nota-se que a maior parte das publicações encontradas em ambas as bases de dados, concentra-se na divulgação de estudos de natureza clínica sobre o Método do Rorschach e, em menor quantidade, focalizam a verificação psicométrica do instrumento.

Estes achados reforçam as afirmações apresentadas por Pasian (2011), ao argumentar que "[...] mesmo com a instituição do SATEPSI e dos esforços das Associações Científicas Nacionais de Avaliação Psicológica (sobretudo o Instituto Brasileiro de Psicologia - IBAP e Associação Brasileira do Rorschach e Métodos Projetivos - ASBRo), ainda há grande desconhecimento destas necessidades de evidências empíricas que embasem os métodos e os processos de avaliação psicológica no Brasil”, (p. 31).

Desta forma, faz-se necessário retomar a reflexão a respeito das necessidades de evidências de validade, precisão e normas atualizadas para os métodos projetivos, incluindo o Rorschach. Em consonância com as diretrizes internacionais e o cumprimento proposto pelo SATEPSI, estudos que demonstrem as evidências psicométricas (normatização, validade e precisão) do Rorschach são, e devem continuar sendo, foco de pesquisas.

Em relação à normatização, Urbina (2007) afirma que interpretar resultados de um teste segundo suas normas significa usar padrões de respostas baseados no desempenho de grupos específicos de pessoas, fornecendo possibilidades de compreensão dos dados. O desenvolvimento de referenciais normativos constitui-se, portanto, em processo útil quando se quer comparar indivíduos, ou uns com os outros, ou com grupos adotados como padrão de respostas, de modo a poder avaliar eventuais diferenças entre eles nas características medidas pelo instrumento. Urbina (2007) conclui que as "normas referem-se ao desempenho no teste ou ao comportamento típico de um ou mais grupos de referência” (p. 84). 
Especificamente dentre as investigações científicas voltadas à elaboração dos padrões normativos do Método de Rorschach procurou-se identificar trabalhos disponíveis no livro de resumos de dois recentes e importantes Congressos Internacionais da área. Assim, pensou-se acessar eventuais trabalhos em desenvolvimento e divulgados no IX Congressso Iberoamericano de Avaliação Psicológica, que ocorreu em parceria com o VI Congresso Brasileiro de Avaliação Psicológica, no ano de 2013, em Maceió (Alagoas) e também o XXI International Congress of Rorschach and Projective Methods, promovido pela International Society of Rorschach (ISR), ocorrido em Julho de 2014 em Istambul (Turquia).

No congresso Iberoamericano, em relação aos estudos normativos do Rorschach, foram localizados os seguintes trabalhos listados a seguir: 1) padrões normativos elaborados em três diferentes sistemas avaliativos do Rorschach voltados a crianças e adolescentes (Hisatugo, 2013); 2) dados normativos do Rorschach-SC em crianças (Resende, Martins, Martins \& Nogueira, 2013); 3) comparação de variáveis relacionadas ao funcionamento lógico e afetivo do Rorschach da Escola Francesa entre adolescentes participantes de três estudos normativos realizados nos contextos brasileiro, francês e turco (Jardim-Maran, Pasian \& Cury-Jacquemim, 2013); 4) comparação de resultados de estudos normativos de crianças das cidades de São Paulo e Goiânia (Nascimento \& Resende, 2013); 5) especificidades de produção no Rorschach (sistema francês) associadas ao desenvolvimento (Fernandes, Raspantini \& Pasian, 2013); 6) comparação de dados normativos do Rorschach (SC) de crianças da região de Cuiabá e Goiânia (Resende e Ribeiro, 2013).

No congresso da $I S R$, realizado em 2014, as investigações relatadas a respeito de referenciais normativos do Rorschach foram: 1) normas do Rorschach - Sistema Compreensivo - para população adulta, entre 20-65 anos, da Polônia (Czeredercka \& 
Wroclawska, 2014); 2) normas do Rorschach da Escola de Paris para a população idosa, 65 a 84 anos, da Turquia (Ikiz, Düsgör, Atak, Mete \& Kalem, 2014); 3) dados normativos da Escola de Paris do Rorschach para adultos, 25-65 anos, do Leste da França (Laurent, Rivat, Alnot, Claudon, Huckel \& De Tychey, 2014); 4) comparação de adolescentes e jovens adultos franceses, entre 13 a 24 anos, de diferentes categorias socioeconômicas provenientes de dados normativos franceses, seguindo a Escola de Paris (Azoulay \& Emmanuelli, 2014); 5) normas para adolescentes turcos, de 13 a 19 anos, também seguindo a Escola de Paris (Ikiz, Zabci, Düsgör, Atak \& Sever, 2014).

Depreende-se, desses destaques realizados sobre os trabalhos em desenvolvimento no Brasil e no mundo, que a pesquisa de natureza normativa do Rorschach continua atual e necessária. Essa tendência se fortalece ainda mais diante das grandes mudanças socioculturais existentes na realidade, associadas ao movimento de globalização, o que pode produzir efeitos sobre os referenciais analíticos a serem utilizados em processos de avaliação da personalidade por meio do Rorschach e que, portanto, merecem a devida investigação científica.

Além dos trabalhos já citados, outras pesquisas voltadas à elaboração das normas do Rorschach, segundo as diretrizes da Escola Francesa, foco do presente trabalho, merecem aqui a devida explanação. Os estudos a serem apresentados, em ordem cronológica de sua divulgação, possuem circulação internacional e nacional.

Na França, Azoulay et al. (2007) elaboraram padrões normativos do Rorschach para adolescentes e jovens-adultos. Os autores investigaram 278 indivíduos, de ambos os sexos, não pacientes, na faixa etária de 13 a 25 anos de idade. Os participantes foram distribuídos em três grupos etários: 13 a 15 anos $(n=98), 16$ a 18 anos $(n=87)$ e 19 a 24 anos $(\mathrm{n}=93)$ e em três níveis socioeconômicos (favorecidos, intermediários e desfavorecidos). Os resultados deste trabalho não revelaram diferenças estatisticamente 
significativas nas variáveis do Rorschach em função do sexo, idade e nível socioeconômico. Identificaram, empiricamente, sinais de semelhança de seus dados com as normas francesas anteriormente disponíveis na França, com apenas duas exceções.

Na Turquia, Ikiz et al. (2010) avaliaram 423 sujeitos entre 13 e 19 anos, de ambos os sexos e de diferentes níveis socioeconômicos, com o objetivo de elaborar referenciais normativos do Método de Rorschach para a população adolescente turca. Os dados deste estudo foram comparados com as normas francesas mais recentes (Azoulay et al., 2007), não identificando diferenças estatisticamente significativas entre esses referenciais normativos na maioria das variáveis do Rorschach examinadas, mostrando similaridade no padrão de respostas de adolescentes turcos e franceses frente a este método projetivo de avaliação psicológica.

Em 2012, Tychey, Huckel, Rivat \& Claudon realizaram, em parceria com os estudos de Azoulay et. al (2007), esforços para atualização das normas do Rorschach investigando 310 adultos de 25 a 65 anos, com média etária de 45,5 anos. Os indivíduos foram caracterizados e subdivididos em três grupos de idade, compondo as seguintes faixas etárias: 25-39 anos $(\mathrm{n}=114), 40-54 \operatorname{anos}(\mathrm{n}=121)$ e 55 a 65 anos $(\mathrm{n}=75)$, sendo 140 homens e 170 mulheres, adultos solteiros $(n=108)$, casados $(n=172)$, divorciados ( $n=24)$ e viúvos (seis), subdivididos em três categorias socioeconômicas: favorecidos (n $=128)$, intermediários $(\mathrm{n}=62)$ e desfavorecidos $(\mathrm{n}=120)$. Os autores concluíram que muitos dos índices do psicograma foram muito estáveis num intervalo de 90 anos quando comparados às normas apresentadas por Rorschach em 1921, quando da apresentação do instrumento ao público. Exemplo da estabilidade dos dados do Rorschach foi encontrado na porcentagem de respostas de conteúdo animal e humano, além dos indicadores de produtividade e na porcentagem de respostas determinadas pelos aspectos formais dos estímulos. 
Ikiz, Zabci, Düsgör, Atak, \& Kalem (2013) realizaram estudo normativo com a população adulta turca, avaliando 724 adultos não pacientes, entre 20 e 64 anos, com o Método Rorschach do sistema francês. O grupo foi subdividido em função do sexo, da idade (20-34 anos, com 135 mulheres e 118 homens; 35-49 anos, incluindo 89 mulheres e 111 homens; 50-64 anos, com 45 mulheres e 48 homens) e em relação ao nível socioeconômico (desfavorecidos, intermediários e favorecidos). Os resultados mostraram que o número médio de respostas $(19,6)$ não se alterou significativamente entre os subgrupos de diferentes faixas etárias, mas foram diferenciados em relação ao sexo e ao nível socioeconômico. Seus dados apontaram que os adultos mais favorecidos produziram maior número de respostas do que os menos favorecidos, assim como as mulheres produziram maior número de respostas que os homens. Entre outras observações, os autores destacam a ausência de diferenças estatisticamente significativas entre as normas dos adolescentes e dos adultos turcos, apesar de existirem tendências a especificidades de produção associadas a faixa etária. Assim, comparando adolescentes e adultos turcos, notou-se diminuição no número de respostas Dd nos adultos, enquanto a proporção de $\mathrm{A} \%$ aumentou. A lista de respostas banais apresentou o dobro de respostas nos adultos quando comparada com os adolescentes, o que sugere o uso ao recurso do coletivismo e do conformismo nos indivíduos mais velhos. Concluem ainda que, de maneira geral, os dados dos adultos turcos não diferiram expressivamente dos adultos franceses (Tychey et al., 2012), e que, futuramente, novas análises mais rigorosas poderão especificar e discutir determinadas especificidades culturais.

Ao circunscrever a pesquisa sobre referenciais normativos do Rorschach no contexto nacional, na perspectiva da Escola de Paris, pode-se apontar que a última década tem apresentado alguns esforços nesta direção. Os trabalhos identificados serão brevemente descritos a seguir. 
Lelé (2006, 2008b) avaliou 100 indivíduos adultos, de ambos os sexos, com idade entre 18 e 36 anos, de diferentes níveis de escolaridade, residentes no Estado de Minas Gerais (MG). Seus resultados mostraram diferenças estatisticamente significativas em relação a trabalhos desenvolvidos em outras regiões do país, o que foi interpretado pelo autor como a sinalização da presença de influências culturais nos índices avaliados pelo Rorschach, indicando a necessidade de realização de trabalhos de investigação específicos nesta área.

Souza e Duarte Junior (2008) realizaram um estudo com 506 adultos da cidade de Belém, de 18 a 50 anos, com o objetivo de verificar as respostas banais ao Rorschach produzidas neste contexto sociocultural. Os dados, quando comparados a estudos realizados em outras regiões do país, revelaram diferenças estatisticamente significativas entre eles. Essa constatação indicou, novamente, a necessidade de se estabelecer normas regionais do Rorschach para a população brasileira, talvez em função da dimensão territorial e diversidade cultural do Brasil.

Fernandes, Pasian e Alves (2011) examinaram os possíveis efeitos da origem escolar sobre variáveis do Rorschach relativas à produtividade (número de respostas e tempo de reação médio) de crianças escolares brasileiras. Dos 180 estudantes, de seis a oito anos de idade, 90 provinham de escola pública e 90 de escola particular, equitativamente distribuídos em relação a idade e sexo, todos com sinais de desenvolvimento típico. Os dados passaram por análises descritivas e inferenciais (simples e múltipla ajustada) e revelaram algumas diferenças estatisticamente significativas nos índices de produtividade ao Rorschach em função da origem escolar. Crianças provenientes de escolas particulares apresentaram, em termos médios, maior número de respostas no Rorschach, ao passo que as provindas de escolas públicas utilizaram mais tempo em suas produções. Essas evidências sugerem a necessidade de 
cuidados técnicos nos processos interpretativos do Rorschach em função das experiências acadêmicas e socioculturais de crianças de seis a oito anos.

Com o objetivo de fundamentar cientificamente o uso da Escola de Paris do Rorschach no Brasil, Pasian (2011) descreve e apresenta diretrizes principais dos trabalhos de investigação desenvolvidos no Centro de Pesquisas em Psicodiagnóstico do Departamento de Psicologia da Faculdade de Filosofia Ciências e Letras da Universidade de São Paulo (USP). Nesse contexto é que surgiu e se desenvolveu o estudo de Fernandes (2010), voltado à avaliação, por meio do Método de Rorschach, de 180 crianças com desenvolvimento típico, de seis a oito anos de idade, de ambos os sexos, provenientes de instituições de ensino público e particular da região de Ribeirão Preto (SP), mais especificamente da cidade de Porto Ferreira, visto que as normas para esta população estavam desatualizadas. Seus dados foram comparados com o estudo normativo realizado por Jacquemin (1976) com 480 crianças, de ambos os sexos, com idade entre três e dez anos e 11 meses, estudantes de escolas públicas e particulares de Ribeirão Preto (SP). Os resultados apontaram que, comparando com as dados encontrados por Jacquemim em 1976, em relação ao $\mathrm{R}$ (número total de respostas), ao RA (número de respostas adicionais), ao Rec (número de recusas), ao Den (número de respostas negadas durante investigação), ao TLm (tempo de latência médio) e ao TRm (tempo de reação médio) houve diferenças estatisticamente significativas na maioria dessas variáveis, indicando a necessidade da elaboração de um novo atlas, com a atualização das normas para essa faixa etária da população.

Nessa mesma direção, Raspantini (2010) avaliou uma amostra de 180 crianças, com idades entre nove e 11 anos, de ambos os sexos, provenientes de escolas públicas e particulares da cidade de Pirassununga, interior do Estado de São Paulo. Os resultados também foram comparados com o estudo normativo de Jacquemin (1976), sendo possível 
observar diferenças estatísticas significativas em variáveis relevantes do Rorschach a partir da análise das respostas produzidas por estes dois grupos normativos de crianças.

Estas evidências empíricas reforçaram a necessidade de revisão dos parâmetros normativos do Rorschach (Escola de Paris) para crianças no Brasil, atualizando o trabalho desenvolvido por Jacquemin (1976), levando à elaboração de novo atlas de referência para classificação das respostas produzidas por indivíduos da faixa etária estudada em Raspantini (2010) e Fernandes (2010). Também foi possível demonstrar, por dados destes citados estudos, que o sexo, a idade e a origem escolar das crianças pareceram não afetar o padrão de respostas na maioria das variáveis do Rorschach, permitindo a elaboração de padrões normativos gerais para as crianças de ambos os sexos e de escolas públicas e particulares do ensino fundamental.

Ainda no mesmo Centro de Pesquisas em Psicodiagnóstico, foram desenvolvidos estudos com objetivo de examinar a validade e elaborar normas do Rorschach para adolescentes (Cury-Jacquemim, 2012; Jardim-Maran, 2011). O estudo de Jardim-Maran (2011) teve como objetivo desenvolver padrões normativos do Rorschach para adolescentes de 15 a 17 anos de idade, avaliando-se também eventuais especificidades de produção associadas ao sexo, à idade e à origem escolar (instituições públicas e particulares). Participaram do estudo 180 estudantes, de Ribeirão Preto (SP), com sinais de desenvolvimento típico, distribuídos equitativamente em relação às variáveis acima citadas. No que se refere à análise das possíveis influências de tais variáveis nos resultados do Rorschach da amostra avaliada, foram observadas diferenças estatisticamente significativas em reduzido número de variáveis desta técnica projetiva, sugerindo a possibilidade de composição de um atlas único para adolescentes de 15 a 17 anos de idade, de ambos os sexos e provenientes de escolas públicas e particulares do interior do Estado de São Paulo. 
Seguindo esta linha de investigação, Cury-Jacquemim (2012) avaliou uma amostra de 180 estudantes de escolas públicas e particulares, de ambos os sexos, focalizando a faixa etária de 12 a 14 anos, provenientes do interior do Estado de São Paulo, atualizando os referenciais normativos deste instrumento projetivo, na perspectiva da Escola de Paris do Rorschach. Neste estudo verificou-se também a possibilidade de compor um único atlas para os adolescentes da faixa etária estudada.

Em relação à população adulta, as normas disponíveis até o momento para o Psicodiagnóstico de Rorschach, seguindo a Escola de Paris, foram elaboradas por Pasian (1998). Neste trabalho, desenvolvido na cidade de Ribeirão Preto (SP), 405 indivíduos não pacientes, entre 20 e 59 anos, compuseram a amostra estratificada e representativa da população, distribuídas igualmente em relação a: faixa etária, nível socioeconômico, graus de escolaridade e sexo. Os resultados demonstraram diferenças estaticamente significativas em variáveis relevantes do Rorschach em função da escolaridade e do nível econômico dos adultos, destacando que estas características demográficas devem ser levadas em consideração no momento de análise e de interpretação dos indicadores deste método projetivo de avaliação psicológica. A partir deste estudo foi possível elaborar um novo atlas de avaliação do Rorschach, na perspectiva da Escola de Paris (Pasian, 2000), bem como embasar cientificamente a utilização deste método projetivo nos processos de avaliação de personalidade no contexto do Brasil, atendendo às diretrizes do CFP (CFP, 2003). Contudo, há que lembrar que este trabalho focalizou a faixa adulta da população, tendo dele derivado as demais iniciativas de estudos desenvolvidos no referido Centro de Pesquisas em Psicodiagnóstico (Cury-Jacquemim, 2012; Fernandes, 2010; JardimMaran, 2011; Raspantini, 2010).

Gavião (2002) usou o sistema francês do Método de Rorschach para avaliar 180 voluntários entre 60 a 102 anos do Estado de São Paulo, distribuídos igualmente quanto 
ao sexo e em proporção diferenciada em relação às faixas etárias, ao nível socioeconômico e à escolaridade. Os resultados apontaram indicadores com algumas semelhanças e outros com diferenças quando comparados aos dados de Pasian (1998). Os idosos apresentaram maior índice de apreensão global e pequena redução de respostas detalhe (D) e pequeno detalhes (Dd), enquanto o índice de F\% foi maior entre os idosos. Os conteúdos tiveram frequência semelhante com os adultos, bem como alguns índices relacionados a expressão da afetividade, como a proporção de respostas globais $(\mathrm{G})$ maior que as de movimento humano $(\mathrm{K})$, além do total de pequenas cinestesias $(\mathrm{k})$ maior que as grandes cinestesias $(\mathrm{K})$. Em relação às fórmulas vivenciais, o tipo extratensivo foi predominante no Tipo de Ressonância Íntima (50,0\%) e o tipo introversivo predominou (73,9\%) na fórmula das Tendências Latentes. A autora apresentou detalhadamente os dados, buscando compreender os fenômenos subjetivos nos idosos, baseando-se na interpretação psicanalítica, oferecendo rica interpretação sobre os resultados alcançados.

É preciso considerar que os dados empíricos das evidências psicométricas de um instrumento de avaliação psicológica precisam ser revisados periodicamente, sendo que, para os estudos referentes à padronização, o intervalo de segurança aceitável, conforme o Art. 14 da Resolução CFP n. ${ }^{\circ}$ 002/2003 (CFP, 2013), é de 15 anos. Já os dados referentes a validade e precisão não poderiam ultrapassar 20 anos desde seu desenvolvimento, de modo a embasar suficientemente e com o devido rigor as práticas profissionais com estes materiais de avaliação psicológica.

Considerações importantes a respeito de dados normativos são realizadas por Azoulay (2014) no artigo intitulado: "Nina Rausch de Traubenberg, le long d'une transmission...La question des normes au Rorschach". Essa pesquisadora resgata o início dos estudos normativos realizados por Herman Rorschach em 1921, relembrando que a amostra do autor inclui casos não clínicos ("normaux cultivés et non cultivés") e clínicos 
("malade", "surtout des schizophrènes") para as análises e comparações. A autora compreende que os "normais" para H. Rorschach seriam, atualmente, correspondentes aos indivíduos que, no momento da pesquisa, não estariam se consultando com psiquiatra ou com grupo especializado em atendimento a indivíduos com problemas mentais. Sobre o conceito de "normalidade", ela reflete e compartilha a posição levantada por Georges Canguillem em 1966. Já naquela época ele afirmava que a Medicina habituou-se a subordinar a média à norma (enquanto resultado frequente) e questiona se a vida normal seria aquela que está em conformidade com os padrões, além de se perguntar se deveríamos tomar quaisquer desvios da norma como indicadores de anormalidade. Para ele, normal é o organismo vivo e saudável, mas que pode entrar em desequilíbrio pela vivência de doenças e experiências dolorosas, e que pode se restabelecer, sendo esse dinâmico equilíbrio entendido como normal para a vida humana. Segundo Azoulay (2014) esse entendimento a respeito da norma está próximo da definição freudiana sobre o funcionamento mental, sendo adotado pela Psicologia Projetiva da Escola de Paris. Além disso, reafirma as palavras de Nina Rausch de Traubenberg a respeito do psicograma do Rorschach, compondo conjunto reduzido e estático de dados frente a riqueza de vivências relatadas num protocolo desse método projetivo, o que não pode, em nenhuma circunstância, ser suficiente para avaliar a personalidade do indivíduo. Para Rausch de Traubenberg, comparar os dados quantitativos com os referenciais normativos do Rorschach é apenas um dos passos na interpretação qualitativa do protocolo (Azoulay, 2014).

Além da preocupação com as atualizações dos padrões normativos do Método de Rorschach, é importante focalizar os estudos que são voltados a verificar a precisão do instrumento. Urbina (2007) afirma que para poder confiar nos escores obtidos em um instrumento, esses resultados deveriam ser consistentes caso fossem repetidos com os 
mesmos indivíduos ou grupos. Dessa forma, a precisão do instrumento pode ser obtida pela estabilidade das respostas em aplicações sucessivas, independente do "fator aprendizagem" e da concordância de juízes independentes que avaliam um mesmo protocolo.

Apesar dessa possibilidade, há grande dificuldade para se replicar achados no campo da avaliação da personalidade, como aponta Alves (2006) ao argumentar sobre as críticas existentes nesse campo, "sendo a principal delas referente à dificuldade de se ‘conhecer' a personalidade de um individuo” (p. 173). Esta autora discute que, nos testes projetivos, como no Rorschach, a sensibilidade para discriminar os sujeitos avaliados poderia refletir mudanças que ocorrem na personalidade em função da idade, de doenças e outras circunstâncias específicas, de forma coerente com a teoria. Assim, a esperada estabilidade de resultados entre aplicações sucessivas do método de Rorschach poderia inexistir ou emergir com fracos indícios, nem por isso fragilizando suas informações sobre as características de personalidade dos indivíduos avaliados.

Ao explorar esse tema, Silva Neto e Custódio (2008) definem a estabilidade temporal como "o grau em que os resultados de um teste repetem-se em momentos diferentes" (p. 54) alcançando-se, desta forma, indicadores sobre a precisão de um instrumento de avaliação psicológica. A estabilidade temporal pode ser estimada quando um teste é aplicado e, após um determinado tempo, reaplicado a um mesmo grupo de sujeitos, calculando-se a correlação entre resultados dos dois momentos avaliativos. Os autores comentam que testes de personalidade deveriam, em termos teóricos, apresentar resultados estáveis, mesmo em longo prazo, o que confirmaria que o instrumento avalia traços de personalidade que tendem a apresentar características mais permanentes.

Este tipo de investigação e de enfoque metodológico de pesquisa já foi desenvolvido com o Método de Rorschach (Escola de Paris), como atesta, por exemplo, 
o estudo de Romaro e Loureiro (1994). Estas pesquisadoras objetivaram identificar e comparar a forma de expressão de mecanismos defensivos primitivos em pacientes Borderline, recorrendo a metodologia de estudo de caso, envolvendo teste e reteste após um período de aproximadamente cinco anos, com pelo menos três métodos projetivos, entre eles o Rorschach. Participaram do estudo cinco pacientes psiquiátricos adultos, diagnosticados como Borderline, que foram atendidos por quase cinco anos, pelo Setor de Psicodiagnóstico do Serviço de Psiquiatria do Hospital das Clínicas da Faculdade de Medicina de Ribeirão Preto - Universidade de São Paulo (HC/FMRP-USP). Os resultados indicaram estável estruturação de personalidade, sinalizada por verbalizações semelhantes referentes a mecanismos de defesa, durante a aplicação e reaplicação do Rorschach, atestando a estabilidade estrutural dos achados com este método projetivo de avaliação psicológica, tendo por base a vertente da Escola de Paris.

Entre os anos de 1993 e 1994, Pereira (2001), interessada em conhecer as características de personalidade de psicólogos, investigou 30 indivíduos formados há 10 anos ou mais no curso de Psicologia, na cidade de São Paulo, dividindo-os em dois grupos de 15 pessoas. No primeiro grupo (Grupo A), constavam voluntários previamente examinados em estudo anterior realizado por Camargo (1979). A amostra do estudo de 1979 tinha como requisito de inclusão: indivíduos brasileiros, entre 18 e 24 anos de idade, cursando Psicologia (como o curso de primeira opção), sendo critério de exclusão: possuir outra formação acadêmica, estar em processo de psicoterapia ou tratamento psicológico, apresentar transtornos psiquiátricos ou neurológicos. Pereira (2001) subdividiu o grupo A em A1 e A2, alocando no grupo A1 quem exercia a Psicologia como profissão no momento de sua pesquisa e, no grupo A2, quem não exercia a profissão de psicólogo. No outro grupo da pesquisa de Pereira (2001), (Grupo B), havia 15 participantes que há mais de 10 anos exerciam a profissão de psicólogo, sendo este o principal exercício 
profissional. Os instrumentos utilizados na pesquisa foram: entrevista padronizada para caracterização da amostra e o Método de Rorschach (sistema Aníbal Silveira). Aqui será dado maior enfoque na comparação dos resultados dos mesmos indivíduos avaliados e reavaliados, tendo em vista a discussão sobre estabilidade teste-reteste. Os dados revelaram que na reavaliação, os indivíduos do grupo A apresentaram mais respostas ao Rorschach (A1 passou de média 24,83 para 38,5, enquanto A2 caminhou de 32,29 para 39,22 respostas) e o tempo médio para produção de respostas diminuiu. O índice de respostas globais $(\mathrm{G})$, que era variável para o grupo A1 na avaliação, passou a ser significativamente menor ou ausente na reavaliação, mas para o grupo A2 o uso reduzido de $\mathrm{G}$ permaneceu. Na esfera cognitiva, indicada por $\mathrm{M}<\mathrm{m}+\mathrm{m}$, os grupos já evidenciavam imaturidade emocional em 1979 e, na segunda avaliação, predominaram as concepções mais infantis. O índice Lambda foi variável para os grupos, mas não revelou diferença estatisticamente significativa, exceto no grupo A2 (diante de decisões a tomar, houve rebaixamento na utilização de recursos pessoais). A proporção $\mathrm{FC}$ : $\mathrm{CF}+\mathrm{C}$, que em 1979 eram mais diretas e até impulsivas, sinalizaram maior adequação social na reavaliação dos dois grupos. Na análise do "equilíbrio das forças subjetivas", o grupo A2 não apresentou tendência a diferença estatisticamente significativa em 1979, enquanto o grupo A1 apresentou predomínio do tipo extratensivo. Na reavaliação, o grupo A1 manteve a mesma tendência à extroversão, enquanto em A2 houve predomínio da introversão. As respostas de conteúdo humano ou parte do ser humano (que estavam acima da média para a maioria dos psicogramas em 1979) permaneceram acima da média na reavaliação de A2. No geral, observou-se que, para o grupo A1, houve diferenças estatisticamente significativas em praticamente todos os índices (com exceção do índice de afetividade Af e de $\% F+$ nas pranchas coloridas). No grupo A2 quase o mesmo ocorreu, apenas um índice apresentou não apresentou diferença estatisticamente 
significativa entre os dois momentos avaliativos ( $\% F+$ das pranchas monocromáticas). A pesquisadora concluiu que houve diferenças importantes em quase todos os dados dos protocolos com o passar do tempo, sinalizando dado "diferente da expectativa de que, em geral e, principalmente nas respostas movimento, não ocorreriam mudanças, a menos que houvesse real mudança na personalidade do indivíduo, como através de psicoterapia bem sucedida ou após acontecimentos traumáticos" (Pereira, 2001, p. 118).

Com base na perspectiva teórico-metodológica do Sistema Compreensivo do Rorschach outras investigações demonstraram a estabilidade temporal deste método projetivo, como os trabalhos descritos por Exner (2003). No contexto brasileiro, especificamente, Silva Neto e Custódio (2008) realizaram uma pesquisa com 39 adultos não pacientes (30 mulheres e nove homens) da cidade de São Paulo (SP). Foi delineado um estudo de teste-reteste, sendo que o intervalo entre as testagens variou de 91 a 157 dias e a fidedignidade intercodificadores foi calculada utilizando-se o software Rorschach Research Utilities (RRU), versão 1.0.2. Os resultados foram positivos no sentido de reafirmar evidências de precisão do Rorschach, com indicadores classificados como níveis moderados de estabilidade temporal $(r=0,59)$. Os pesquisadores foram bastante cautelosos a interpretar estes dados do Brasil, contrapondo-os a outros resultados internacionais, relatando que as evidências de seu trabalho foram menos intensas do que as de outros trabalhos. Consideram que seus resultados poderiam ter sido influenciados pelo reduzido tamanho de sua amostra, bem como pelo fato dela ter sido composta predominantemente por mulheres. Além disso, argumentam que a evidência de estabilidade temporal pode ter sofrido interferência de variáveis intervenientes no índice de fidedignidade intercodificadores (que foi menor do que em estudos internacionais) e no próprio resultado geral de precisão teste-reteste, sugerindo novas investigações nesse campo no contexto nacional. 
No contexto internacional, o estudo de Roberts e DelVecchio (2000) utilizou a metanálise como procedimento metodológico para compreensão de aspectos da personalidade. Neste trabalho, os autores buscaram verificar se a consistência do traço de personalidade se maximiza e estabiliza em um período específico do curso da vida. Os autores examinaram estimativas sobre a consistência de traços de personalidade analisando 152 estudos longitudinais a respeito de características de personalidade relacionados a estados (menos estáveis) e traços (mais estáveis). Para compreender a relação entre idade e consistência do traço, eles categorizaram estimativas de teste-reteste em faixas etárias gerais associadas com transições do desenvolvimento. A expectativa dos autores era de que a consistência do traço iria aumentar com cada categoria de idade até atingir um pico, provavelmente por volta dos 20 anos. Para a busca bibliográfica, foram incluídos estudos que cumprissem quatro critérios: 1) o estudo deveria incluir variáveis disposicionais (traços, temperamento e caráter), enquanto os que usaram medidas de atitudes, valores, autoestima, afeto, humor, inteligência, funcionamento cognitivo e escalas de validade não foram incluídos; 2) para enfatizar a consistência longitudinal dos traços foram incluídos estudos com intervalos de teste-reteste maiores do que um ano; 3) no mínimo, era necessário que cada estudo contivesse informações sobre o intervalo de teste e reteste, tamanho e idade da amostra; 4) a amostra estudada deveria ser não clínica. Os métodos utilizados pelos estudos selecionados para a metanálise foram categorizados em três categorias: autorrelato, observações e métodos projetivos, sendo utilizadas as faixas etárias: do nascimento aos 2,9 anos; de 3 a 5,9 anos; 6 a 11,9 anos; 12 e 17,9 anos; 18 a 21,9 anos. As classificações por pontos decimais foram utilizadas para as categorias de idade até 21,9 anos, pois alguns estudos reportavam a idade em meses ao invés de anos inteiros. A partir da idade de 22 anos, os estudos foram classificados em décadas de vida dos indivíduos, sendo que a idade de 73 anos foi usada 
como teto para a última faixa etária. A taxonomia do Modelo Big Five para traços de personalidade foi usada para organizar os coeficientes de teste-reteste, incluindo as categorias de extroversão, amabilidade, consciência, neuroticismo e abertura para a experiência. Os coeficientes de correlação dos estudos analisados foram derivados de medidas de autorrelato (em 50\% dos trabalhos), $41 \%$ a partir de observações e 9\% derivados de testes projetivos. As análises mostraram que, no geral, a consistência dos traços de personalidade aumentou de forma linear até as idades de 50-59 anos, quando atingiu seu pico. Nos períodos da infância, houve menor estabilidade na consistência do traço, enquanto entre os 18 e 21,9 anos e na primeira década do jovem-adulto (idade de 22 a 29 anos) voltou a aumentar consideravelmente e, entre os 51 aos 57 anos, se estabilizou. A consistência dos traços de personalidade voltou a aumentar na meia-idade (40-49 anos) e na segunda metade da meia-idade (50-59 anos). Essa estimativa atingiu um patamar, sendo bastante semelhante entre as faixas etárias 50-59 anos e 60-73 anos. Observou-se que a consistência dos traços de personalidade aumentou em três momentos especiais no curso da vida: da infância e primeira infância para o período pré-escolar; a partir dos 18-21 anos para os primeiros estágios da vida do jovem adulto; e de meia-idade para depois da meia-idade. Ao usar da análise de regressão, incluindo a idade e o tempo como preditores de consistência do traço, pode-se estimar a média da consistência do traço por tempo. Assim, em um período de um ano a correlação entre teste-reteste seria 0,55; em cinco anos, seria 0,52; em 10 anos, atingiria 0,49; em 20 anos, seria 0,41 e, em 40 anos, alcançaria um valor de 0,25 . Apesar da distribuição desigual dos estudos em termos de delineamento metodológico, as estimativas iniciais de estabilidade dos traços de personalidade foram semelhantes em magnitude. Foi possível notar que, para os estudos pautados em medidas de autorrelato, os indicadores de estabilidade dos traços de personalidade foram mais consistentes ( $r$ médio=0,52), seguidos por métodos de 
observação $(r$ médio $=0,48)$ e métodos projetivos $(r$ médio=0,43). Estes dados contribuem com a literatura da área, demonstrando que há estabilidade de traços de personalidade no curso da vida, porém também sinalizando possibilidades de mudança no decorrer da vida adulta, tendo em vista as estimativas pouco elevadas de consistência desses traços.

Também no contexto internacional, Sultan, Andronikof, Réveillère e Lemmel (2006) verificaram a estabilidade do Rorschach, a partir estudo empírico com o Sistema Compreensivo. Foram avaliados 75 adultos franceses não pacientes (média de idade 39,2 anos; 28 homens e 47 mulheres) e reavaliados em um intervalo de três meses. Os examinadores do estudo (treinados e com experiência na aplicação do instrumento) não testaram os mesmos participantes na condição de teste e reteste. O nível geral de estabilidade em um conjunto selecionado de variáveis ficou abaixo das expectativas $(r$ médio $=0,53)$. Os índices cognitivos ou variáveis auto-relacionais alcançaram valores de correlações teste-reteste maiores $(r>0,70)$ do que variáveis emocionais e de enfrentamento (valores de $r$ entre 0,47 a 0,61 ). Os autores indicam que a influência dos examinadores sobre a produtividade e o engajamento na tarefa foram identificados como importantes aspectos a serem investigados em pesquisas futuras, uma vez que maior engajamento na tarefa mostrou-se associado a maior estabilidade temporal para uma série de variáveis, enquanto menor engajamento na tarefa mostrou maior associação com a estabilidade na variável $F$, por exemplo. Também identificaram que alguns examinadores associaram-se com menor número de respostas, menor engajamento na tarefa, menores valores de $E A$ e estabilidade temporal mais baixa, ainda que, ao excluir os protocolos desses examinadores menos estáveis, os níveis médios de estabilidade dos dados do Rorschach não tenham sofrido alteração. Esse estudo foi bastante importante por destacar diferentes tipos de variáveis envolvidos nos processos de avaliação de personalidade, com foco no exame de sua estabilidade temporal. 
Nesse mesmo ano, Grønnerød (2006) reviu dados de estudo de metanálise que havia publicado em 2003 sobre estabilidade temporal do Método de Rorschach (Sistema Compreensivo), para a correção de problemas metodológicos. Na publicação de 2003, descreveu a análise de artigos publicados entre os anos de 1921 a 2002, incluindo aqueles que discutiam sobre seguimento em psicoterapia por apresentarem dados de grupos controle. Os resultados revelaram elevada estabilidade temporal $(0,68$ a 0,73$)$ para todos os estudos analisados, com período médio de reteste de três anos. Em 2006, o autor reanalisou os artigos utilizando um modelo de regressão hierárquica, estimando o coeficiente de precisão por meio do Coeficiente de Correlação Intraclasse (CCI) para dados contínuos e índice Kappa para dados dicotômicos. A reanálise confirmou a bons níveis de estabilidade entre as medidas (entre 0,69 a 0,74 ). Ele ainda afirmou que os resultados sugerem que apenas a psicoterapia ativa leva a mudanças de personalidade pronunciáveis em curto espaço de tempo, o que vai além das inevitáveis mudanças observadas durante longos períodos de tempo.

Nesta direção, estudos que utilizam o método de teste-reteste do Rorschach (e de qualquer instrumento de avaliação psicológica), verificando a estabilidade temporal dos resultados, certamente são relevantes, úteis e necessários para embasar os procedimentos avaliativos, informando sobre índices de precisão dos mesmos. Contudo, como classicamente debatido na literatura sobre métodos projetivos de avaliação psicológica (Anderson \& Anderson, 1967), não alcançam, necessariamente, informações relativas à estabilidade dos conteúdos avaliados, o que permitiria evidenciar também a validade do instrumento, no nosso caso, do construto personalidade examinado pelo Método de Rorschach. A respeito das evidências de validade, Primi, Muniz e Nunes (2009) consideram que um instrumento sem esses indicadores, não fornece interpretações seguras a respeito das características psicológicas dos indivíduos que respondem aos 
testes. Portanto, sem esses indicadores, não há como garantir o que o instrumento avalia e se o faz adequadamente.

Villemor-Amaral (2009) reafirma a importância das evidências de validade, porém, ressalta que é fundamental relacionar tais evidências aos contextos em que serão úteis. A autora aponta que, em alguns casos, as próprias atividades implicadas no instrumento de avaliação psicológica podem limitar os dados a respeito do comportamento que se pretende prever com seus achados. Assim, deve-se relativizar a exigência psicométrica clássica em favor das evidências de natureza clínica e consequencial dos dados, como também argumentou Tavares (2003).

Frente ao conjunto de considerações prévias, pode-se questionar: será que os processos vivenciados pelos indivíduos ao longo do tempo interferem na permanência ou na mudança de componentes de sua personalidade? Seria possível examinar a estabilidade temporal do Método de Rorschach (Sistema Francês) na avaliação da personalidade, confirmando suas evidências de informação sobre estruturação da personalidade? A reaplicação do Rorschach após longo intervalo de tempo, em indivíduos adultos não pacientes, pode vir a evidenciar indicadores de precisão e validade do método para compreensão de estilos de personalidade?

Diante do panorama apresentado, o foco da presente investigação científica foi a investigação da estabilidade temporal de variáveis do Método de Rorschach teoricamente representativas da estruturação da personalidade, pela perspectiva da Escola de Paris. Pretendeu-se reavaliar, por meio desse método projetivo, indivíduos adultos com indicadores de desenvolvimento típico, previamente examinados há 15 anos, bem como examinar novo grupo de indivíduos de modo a obter dados suficientes para atualização de seus parâmetros normativos. Almejou-se, portanto, examinar e aprimorar evidências psicométricas sobre o Método de Rorschach, oferecendo subsídios para seu 
aprimoramento técnico e para sua utilização na prática profissional do psicólogo brasileiro. A revisão e atualização das evidências psicométricas do Rorschach em adultos não pacientes, de acordo com a Escola de Paris, poderá fornecer dados que contemplem as diretrizes nacionais do CFP para uso deste método projetivo de avaliação psicológica. Essas possibilidades investigativas tornam-se necessárias na realidade nacional, sobretudo com as novas tecnologias e procedimentos estatísticos de maior refinamento, permitindo a busca de desenvolvimento de análises metodológicas mais elaboradas de dados com indivíduos adultos.

As hipóteses delineadas para o trabalho envolvem a noção de que a personalidade no adulto seria constituída por elementos estruturais, estáveis ao longo da vida, porém agregando também componentes dinâmicos, suscetíveis a variações, aspectos esses passíveis de investigação por meio do Método de Rorschach (Sistema Francês ou Escola de Paris). Esperar-se-ia, desse modo, identificar evidências empíricas relativas aos elementos estruturais e funcionais da personalidade, a partir da reaplicação do Rorschach após intervalo de 15 anos.

Outra linha investigativa central no presente trabalho diz respeito a necessidade de atualização de referenciais normativos para o Método de Rorschach em adultos, conforme preconizado pelas diretrizes vigentes do Conselho Federal de Psicologia no Brasil.

O desenvolvimento deste trabalho justifica-se pela possibilidade de aprimoramento técnico-científico do Método de Rorschach e da área de avaliação da personalidade no Brasil, atendendo a demandas contemporâneas nacionais e internacionais sobre instrumentos de avaliação psicológica. 


\section{OBJETIVOS}

\subsection{Gerais}

Este trabalho teve como propósito a realização de dois estudos. O primeiro objetivou verificar indicadores de precisão do Método de Rorschach (Escola de Paris), por meio da reavaliação (após período de 15 anos) de adultos não pacientes do estudo normativo de Pasian (1998), examinando indicadores da estabilidade temporal (estrutural e funcional) das características de personalidade examinadas por este método projetivo. O segundo estudo objetivou examinar a necessidade da atualização dos padrões normativos de adultos para este instrumento, além de elaborar novos referenciais normativos do Rorschach para indivíduos dessa faixa etária. Visou, assim, contribuir para o aprimoramento técnico-científico dos processos de avaliação psicológica por meio deste método projetivo de avaliação psicológica, no contexto do Brasil.

\subsection{Específicos}

\subsubsection{Estudo 1}

2.2.1.1. Caracterizar e descrever o perfil geral de resultados dos adultos reavaliados após 15 anos por meio do Método de Rorschach (Escola de Paris).

2.2.1.2. Analisar a possível influência do sexo, da escolaridade e da idade sobre os resultados dos adultos na reavaliação com o Rorschach.

2.2.1.3. Caracterizar, descrever e comparar a distribuição dos indivíduos nas fórmulas afetivas do Rorschach na avaliação e reavaliação, em termos de estilos de personalidade. 2.2.1.4. Comparar e correlacionar resultados do Rorschach de adultos não pacientes estudados por Pasian (1998) com dados obtidos em sua reavaliação atual (decorrido 
intervalo de 15 anos da primeira avaliação), ou seja, verificar evidências de precisão deste método projetivo.

2.2.1.5. Identificar a estabilidade temporal de resultados nas principais variáveis da Escola de Paris do Rorschach, de modo a reconhecer representantes de componentes estruturais (mais estáveis) e componentes funcionais da personalidade (menos estáveis, ligados a contextos situacionais dos indivíduos).

2.2.1.6. Verificar indicadores de convergência nos resultados no Rorschach de dois momentos avaliativos de adultos não pacientes, examinando a existência de esperados indicadores de estabilidade das características de personalidade nessa faixa etária, o que poderá constituir também evidência de validade desse método no Brasil.

\subsubsection{Estudo 2}

2.2.2.1. Caracterizar o padrão de respostas ao Rorschach (Escola de Paris) de nova amostra de adultos não pacientes, atualizando referenciais normativos deste método projetivo. Pretendeu-se examinar a distribuição de frequência das diversas categorias de classificação das respostas (localizações, determinantes, conteúdos e banalidades), verificando-se especificidades de produção possivelmente associadas ao sexo, à escolaridade e idade na amostra dos adultos.

2.2.2.2. Atualizar e revisar o atlas do Rorschach (Escola de Paris) para população adulta, listando as áreas interpretadas e a qualidade formal de suas respectivas respostas a esse método de avaliação da personalidade.

\section{MÉTODO}




\subsection{ESTUDO 1 - AVALIAÇÃO DA ESTABILIDADE DE VARIÁVEIS DO RORSCHACH}

Trata-se de estudo longitudinal, descritivo-comparativo, implicando em delineamento de reavaliação psicológica (após longo intervalo de tempo) de casos estudados em pesquisa anterior (Pasian, 1998) e análise comparativa dos possíveis efeitos do desenvolvimento, ao longo do tempo, sobre variáveis relacionadas à estrutura e ao funcionamento da personalidade nesses indivíduos.

\subsubsection{CRITÉRIO PARA SELEÇÃO DOS PARTICIPANTES}

Os participantes do Estudo 1 foram todos recrutados dentre os indivíduos avaliados por Pasian (1998). Conforme descrito nesse trabalho anterior, foram considerados os seguintes critérios para seleção dos participantes: indivíduos adultos entre 20 a 59 anos, de níveis de escolaridade diversos (baixo, médio e alto) e pertencentes aos grupos de baixo e alto nível socioeconômico, que não apresentavam antecedentes críticos de ordem psiquiátrica, grave transtorno psicológico ou déficit intelectual. Frente aos objetivos delineados para o atual Estudo 1, foi efetivado o percurso amostral a seguir descrito.

\subsubsection{Percurso Amostral:}

Planejou-se que a amostra do Estudo 1 seria composta por indivíduos que teriam hoje entre 34 e 59 anos, representando 289 prováveis casos dos 405 coletados por Pasian (1998). No contato direto com esses possíveis participantes, estabelecido por ligação telefônica da pesquisadora, houve dificuldade em localizar muitos dos indivíduos. Havia 147 números de telefone registrados à época da primeira coleta (54 do grupo de baixo 
nível socioeconômico e 93 do grupo de alto nível socioeconômico), porém 75 não estavam mais funcionando ( 29 do grupo de baixo nível socioeconômico e 43 do grupo alto nível socioeconômico), o que, em si, dificultou o acesso aos próprios participantes.

A partir dessa realidade, a pesquisadora procurou na lista telefônica novos registros telefônicos, recorrendo ao nome e/ou sobrenome do participante e, quando este não era localizado, ao endereço que estava registrado na base de dados original. Por meio desse rastreamento encontrou 76 possíveis novos números de telefones (35 do grupo de baixo nível socioeconômico e 41 do grupo de alto nível socioeconômico). Os contatos realizados encontram-se sinteticamente descritos a seguir.

a) Para o grupo de baixo nível socioeconômico: foi possível contatar 21 participantes, sendo que 10 deles aceitaram participar do atual estudo, enquanto 11 não aceitaram colaborar. Dois participantes não moravam mais na cidade, conforme informação de familiares; três participantes faleceram e um havia sofrido um Acidente Vascular Cerebral (AVC); 23 registros telefônicos não pertenciam ao participante o qual tentávamos entrar em contato; em 10 registros telefônicos não foi obtido contato com o participante (em diferentes tentativas de contato).

b) Para o grupo de alto nível socioeconômico: foi possível contatar 17 participantes, sendo que 12 aceitaram colaborar com o atual estudo e cinco recusaram-se; 14 participantes não moravam mais na cidade ou no país, conforme relato de seus familiares; três faleceram; 34 números telefônicos não pertenciam ao indivíduo que tentávamos entrar em contato; em 23 registros telefônicos não foi obtido contato com o participante (em diferentes tentativas).

A síntese dos contatos efetivados por meio de recursos telefônicos pode ser visualizada na Tabela 1. 


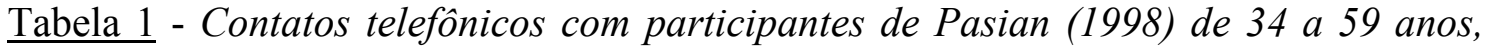
efetivados para o Estudo 1.

\begin{tabular}{|c|c|c|c|c|c|c|c|}
\hline \multicolumn{2}{|l|}{ Grupo } & \multicolumn{3}{|c|}{ Baixo NSE } & \multicolumn{3}{|c|}{ Alto NSE } \\
\hline Sexo & M & $\mathrm{F}$ & Subtotal & M & $\mathrm{F}$ & Subtotal & TOTAL \\
\hline Contato efetivado & 9 & 12 & 21 & 5 & 12 & 17 & 38 \\
\hline Aceite atual estudo & 3 & 7 & 10 & 3 & 9 & 12 & 22 \\
\hline Não aceite atual estudo & 6 & 5 & 11 & 2 & 3 & 5 & 16 \\
\hline
\end{tabular}

Diante da dificuldade para localizar os participantes por meio de contato telefônico, avaliou-se a estratégia de tentar encontrá-los diretamente em visitas aos endereços residenciais registrados à época da primeira avaliação. Nessas visitas aos endereços, a pesquisadora entregava uma carta-convite para participação na pesquisa (APÊNDICE A). Quando não havia ninguém na residência, a carta era deixada para posterior recuperação em novas visitas da pesquisadora. Nas residências em que não havia ninguém no momento da visita, a pesquisadora retornou aos endereços por até três vezes para tentar localizar moradores. Caso não conseguisse contato nessas três visitas, registrava-se a impossibilidade de obtenção de dados naquele endereço.

Nesse momento também se considerou oportuno convidar para a pesquisa os indivíduos atualmente com idade até 69 anos (alargando a faixa etária teto para análise), de forma a ampliar a rede de possíveis contatos advindos da base original de Pasian (1998). Isso porque o presente estudo se propõe a examinar aspectos do funcionamento psíquico individual ao longo do desenvolvimento e apresenta uma perspectiva longitudinal a respeito da adaptação socioafetiva de indivíduos adultos. Ao incluir os indivíduos entre 60 e 69 anos para compor o Estudo 1, ampliou-se a quantidade de 
potenciais colaboradores para o atual estudo, visto que o total de casos possíveis da base de Pasian (1998) passou a um total de 369 indivíduos.

No total foram realizadas visitas a 295 endereços residenciais, sendo localizados 71 participantes (31 do grupo de baixo e 40 do alto nível socioeconômico). Deste total de contatos, 50 indivíduos aceitaram participar do estudo (21 do grupo de baixo nível socioeconômico e 29 do alto) e 21 não aceitaram (10 do grupo de baixo nível socioeconômico e 11 do alto). E ainda, em 166 residências ( 80 do grupo de baixo nível socioeconômico e 86 do alto), os participantes já não residiam mais no endereço registrado.

A seguir estão descritos os principais informes advindos das visitas domiciliares aos endereços dos colaboradores originais de Pasian (1998). Essa parte do percurso amostral auxilia a compreensão do processo de identificação dos participantes do estudo. a) No bairro de baixo nível socioeconômico: uma família informou que um participante não residia na cidade; um faleceu; três residências estavam vazias; seis transformaram-se em comércio local (oficinas, sorveteria, salão de beleza, lojas); em nove residências não foram encontrados participantes em, pelo menos, duas tentativas de visitas realizadas (além disso, nessas residências a pesquisadora não conseguiu descobrir se os indivíduosalvo ainda residiam naquele endereço); sete cartas foram deixadas nas residências em que foi possível descobrir (por meio de contato com vizinhos) que pertenciam aos mesmos participantes, porém não havia ninguém na casa no momento da visita e nem em outras duas visitas realizadas.

b) No grupo de alto nível socioeconômico: duas famílias informaram que os participantes não residiam na cidade; um faleceu; onze residências transformaram-se em comércio local (clínicas de saúde, salões de beleza, pet shop, escritórios de advocacia, lojas); oito residências estavam vazias (para alugar ou à venda); uma residência estava demolida, 
restando apenas o terreno vazio; em sete residências a pesquisadora não conseguiu descobrir se os participantes ainda moravam no local.

Desta forma, os contatos efetivados com os participantes de Pasian (1998), por meio de visitas residenciais, estão sintetizados na Tabela 2 .

$\underline{\text { Tabela } 2}$ - Visitas domiciliares aos participantes de Pasian (1998) efetivadas para o Estudo 1.

\begin{tabular}{lccccccc}
\hline \multicolumn{1}{c}{ Grupo } & \multicolumn{3}{c}{ Baixo NSE } & \multicolumn{3}{c}{ Alto NSE } \\
& M & F & Subtotal & M & F & Subtotal & TOTAL \\
\hline Contatos Efetivados & 6 & 25 & 31 & 18 & 22 & 40 & 71 \\
Aceite & 2 & 19 & 21 & 13 & 16 & 29 & 50 \\
Não aceite & 4 & 6 & 10 & 5 & 6 & 11 & 21 \\
& *NSE = nivel socioeconomico; $M=$ sexo masculino; $F=$ sexo feminino.
\end{tabular}

Após as visitas aos endereços, a pesquisadora ainda conseguiu contato telefônico com outros cinco indivíduos com mais de 60 anos, a saber: uma mulher do bairro de baixo nível socioeconômico (que não aceitou colaborar com o estudo) e quatro indivíduos do bairro de alto nível socioeconômico (uma mulher e três homens). Desse último subgrupo apenas um homem não teve interesse em participar do estudo.

Outra estratégia utilizada, em paralelo, para tentar localizar os possíveis participantes do estudo, foi a pesquisa dos possíveis voluntários em sites de busca da internet (colocando o nome completo do indivíduo). Disso resultaram possíveis endereços eletrônicos (email) e contato por meio de rede social (facebook), aos quais foram enviadas mensagens que continham o mesmo conteúdo da carta-convite (APÊNDICE A). Desta forma, foram localizados 28 indivíduos. Contudo apenas sete retornaram o contato e aceitaram o convite para participação no trabalho, conforme mostra a Tabela 3. 
$\underline{\text { Tabela } 3}$ - Contatos eletrônicos (email e facebook) realizados com os participantes de Pasian (1998) para o Estudo 1.

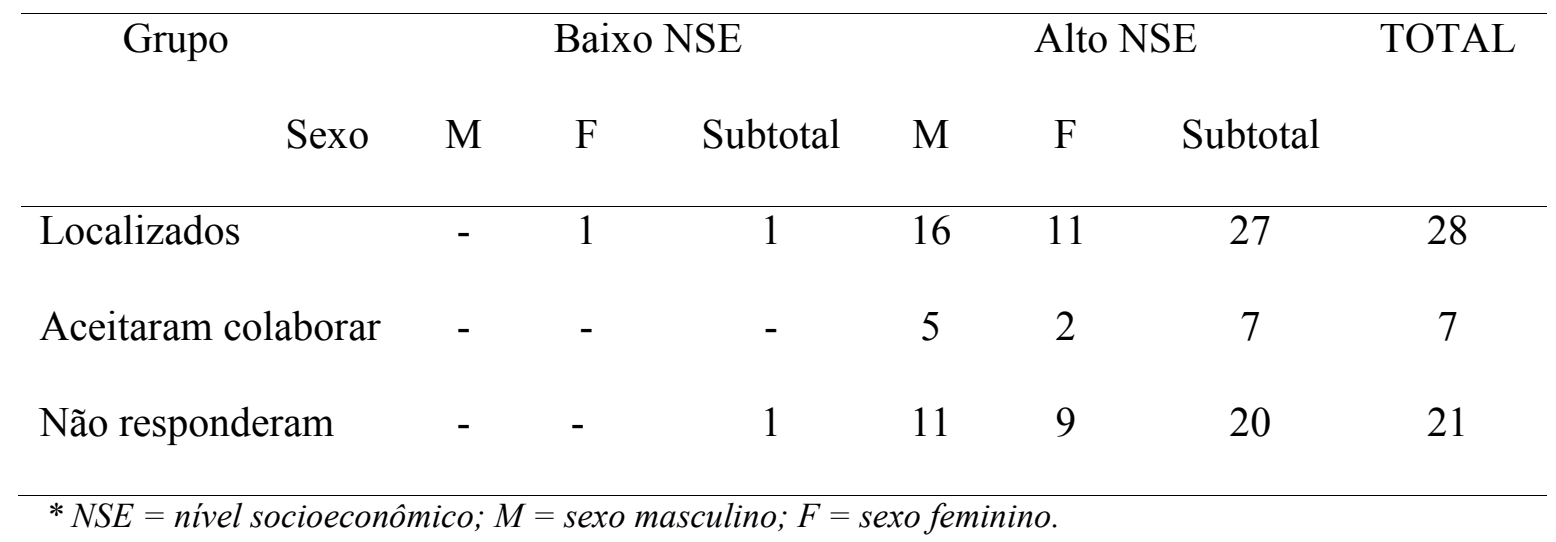

Finalmente, também foi possível contar com a colaboração de indivíduos que foram localizados via rede de contatos da orientadora (sete participantes). Desta forma, todas as formas de contatos efetivados com os possíveis participantes do Estudo 1 foram sintetizadas na Tabela 4.

$\underline{\text { Tabela } 4}$ - Distribuição dos contatos realizados com os participantes de Pasian (1998)e que aceitaram colaborar com o Estudo 1.

\begin{tabular}{|c|c|c|c|c|c|c|c|}
\hline \multirow[t]{2}{*}{ Grupo } & \multicolumn{3}{|c|}{ Baixo NSE } & \multicolumn{3}{|c|}{ Alto NSE } & \multirow[b]{2}{*}{ TOTAL } \\
\hline & M & $\mathrm{F}$ & Subtotal & M & $\mathrm{F}$ & Subtotal & \\
\hline Telefonemas & 3 & 7 & 10 & 6 & 8 & 14 & 24 \\
\hline Visitas a residências & 2 & 19 & 21 & 13 & 16 & 29 & 50 \\
\hline Email & - & - & - & 4 & - & 4 & 4 \\
\hline
\end{tabular}




$\begin{array}{lccccccc}\text { Facebook } & - & - & - & 1 & 2 & 3 & 3 \\ \text { Contatos orientadora } & 3 & 1 & 4 & 3 & - & 3 & 7 \\ \text { TOTAL } & 8 & 27 & 35 & 27 & 26 & 53 & 88 \\ \text { *NSE = nivel socioeconômico; } M=\text { sexo masculino; } F=\text { sexo feminino. }\end{array}$

Do conjunto dos contatados para o presente trabalho, 38 indivíduos, de ambos os sexos, não se dispuseram a colaborar com o estudo. A faixa etária desses adultos variou de 36 a 67 anos e pertenciam a ambos os grupos socioeconômicos, conforme dados da Tabela 5 .

Tabela 5 - Participantes de Pasian (1998) presentemente contatados e que recusaram participar do Estudo 1.

Sexo Feminino Masculino Geral

Nível socioeconômico

\begin{tabular}{cccc}
\hline Baixo & 12 & 10 & 22 \\
Alto & 7 & 9 & 16 \\
Total & 22 & 14 & 38 \\
\hline
\end{tabular}

A justificativa para a não adesão ao estudo foi "falta de tempo" para 35 participantes. Um afirmou "discordância quanto ao trabalho" e dois afirmaram “desinteresse" em participar do estudo.

Desta forma, considerando o número de indivíduos que aceitaram colaborar com o estudo (88), os que não aceitaram (38) e aqueles que não residem mais na cidade (19), a pesquisadora contatou, direta ou indiretamente, 145 indivíduos. Além disso, identificou que um participante se encontrava adoecido e nove haviam falecido, totalizando uma rede de 155 contatos. Esses indivíduos representam contato com $42 \%$ dos 369 casos possíveis 
para reavaliação nesse presente trabalho (Estudo 1), o que foi considerado índice bastante satisfatório para esse tipo de estudo (sobretudo após 15 anos da pesquisa original de Pasian, 1998).

\subsubsection{Participantes}

Diante dos elementos previamente apresentados, compuseram o Estudo 1 os participantes de Pasian (1998) que foram localizados e aceitaram colaborar com a proposta do trabalho, compondo uma amostra de conveniência. Totalizam 88 indivíduos, com idade entre 34 a 69 anos (média de idade: 53,6 anos, $d p=9,6$ ), sendo 53 mulheres e 35 homens, de baixo e alto nível socioeconômico e diferentes níveis de escolaridade, conforme caracterização descrita na Tabela 6. No Apêndice B, encontra-se a tabela com a frequência das idades dos participantes deste estudo.

Tabela 6 - Caracterização dos participantes do Estudo 1 em função do nível socioeconômico, sexo e escolaridade.

\begin{tabular}{|c|c|c|c|c|c|c|c|}
\hline \multirow{2}{*}{$\begin{array}{c}\text { Variável } \\
\text { Escolaridade ** }\end{array}$} & \multicolumn{3}{|c|}{ Baixo NSE* } & \multicolumn{3}{|c|}{ Alto NSE* } & \multirow[t]{2}{*}{ TOTAL } \\
\hline & $\mathrm{M}$ & $\mathrm{F}$ & Subtotal & $\mathrm{M}$ & $\mathrm{F}$ & Subtotal & \\
\hline Baixa & - & 4 & 4 & - & - & - & 4 \\
\hline Média & 3 & 14 & 17 & - & - & - & 17 \\
\hline Alta & 5 & 9 & 14 & 27 & 26 & 53 & 67 \\
\hline TOTAL & 8 & 27 & 35 & 27 & 26 & 53 & 88 \\
\hline
\end{tabular}


No grupo de baixo nível socioeconômico há um predomínio de mulheres $(77 \%)$ em relação aos homens (23\%). Já no grupo de alto nível sócio econômico esta composição foi equilibrada ( $49 \%$ de mulheres e $51 \%$ de homens).

Em relação aos anos de estudo, no grupo de baixo nível socioeconômico, 15 adultos não completaram o ensino fundamental (14 mulheres e um homem) e seis completaram (quatro mulheres e dois homens); nove possuem o ensino médio completo (seis mulheres e três homens); quatro possuem o ensino superior completo (duas mulheres e dois homens) e uma mulher estava realizando a graduação no momento da pesquisa. $\mathrm{O}$ menor nível de escolaridade para o grupo de alto nível socioeconômico foi o ensino médio completo, identificado em oito casos (cinco homens e três mulheres). Os demais indivíduos desse subgrupo possuem ensino superior completo e, destes, 15 possuem pósgraduação (oito mulheres e sete homens).

No intervalo entre a primeira avaliação (Pasian, 1998) e a reavaliação (atual estudo) três mulheres do grupo de baixo nível socioeconômico comentaram sobre a mudança em seus níveis de escolaridade. Foram os seguintes: uma mulher (idade atual: 55 anos) estava cursando a graduação no momento de realização desta pesquisa; uma mulher (idade atual: 54 anos) que em 1998 possuía apenas o ensino fundamental completo e na atualidade havia concluído o ensino médio completo; uma mulher (idade atual: 42 anos) havia realizado duas especializações.

A classificação econômica dos participantes também foi realizada a partir do levantamento de características dos domicílios, tendo sido realizada a correspondência entre faixas de pontuação do critério e estratos de classificação econômica (ABEP, 2012). A partir destes dados, a amostra aqui subdividida em baixo e alto nível socioeconômico pode ser caracterizada conforme informações da Tabela 7. 
Tabela 7 - Distribuição dos indivíduos do Estudo $1(n=88)$ em função do resultado no Critério de Classificação Econômica Brasil (ABEP, 2012).

\begin{tabular}{|c|c|c|c|c|c|c|c|c|}
\hline Classificação & & ixo & $\mathrm{SE}^{*}$ & & lito & $\mathrm{SE}^{*}$ & & TAL \\
\hline ABEP & M & $\mathrm{F}$ & Subtotal & $\mathrm{M}$ & $\mathrm{F}$ & Subtotal & $\mathrm{f}$ & $\%$ \\
\hline $\mathrm{A}(\mathrm{A} 1 \mathrm{e} \mathrm{A} 2)$ & 2 & - & 2 & 19 & 18 & 37 & 39 & 44,3 \\
\hline B (B1 e B2) & 7 & 12 & 19 & 8 & 8 & 16 & 35 & 39,8 \\
\hline $\mathrm{C}(\mathrm{C} 1$ e $\mathrm{C} 2)$ & - & 14 & 14 & - & - & - & 14 & 15,9 \\
\hline TOTAL & 9 & 26 & 35 & 27 & 26 & 53 & 88 & 100,0 \\
\hline
\end{tabular}

Segundo o Critério da ABEP (2012), no subgrupo de baixo nível socioeconômico 54\% (19 indivíduos) pertencem à classe econômica B (sendo quatro da subclasse B1 e 15 da subclasse $\mathrm{B} 2$ ); 40\% (14 adultos) pertencem à classe econômica $\mathrm{C}$ (sendo 10 da $\mathrm{C} 1 \mathrm{e}$ quatro da $\mathrm{C} 2$ ) e $6 \%$ (dois voluntários) pertencem à classe $\mathrm{A}(\mathrm{A} 2)$. Para os indivíduos recrutados na região de alto nível socioeconômico, 30\% (16 indivíduos) pertencem à classe econômica B (B1) e 70\% (37 adultos) pertencem à classe econômica A (27 da A2 e 10 da A1).

Desse modo, embora os indivíduos tenham sido acessados por conveniência dentre os casos avaliados por Pasian (1998), foi possível compor amostra atual que consegue representar, em termos gerais, os dois extratos socioeconômicos pretendidos (baixo e alto NSE). Nota-se que mesmo dentro de uma região de reduzidos recursos socioculturais (região supostamente de baixo NSE) foram encontrados, pelo instrumento Critério de Classificação Econômica Brasil (ABEP, 2012), alguns indivíduos considerados como de bom poder aquisitivo. No geral, contudo, os dados advindos desse instrumento de classificação econômica apenas reafirmaram a distribuição inicialmente 
delineada dos voluntários, subdivididos em termos socioeconômicos a partir de sua região de moradia no município em estudo (Ribeirão Preto, SP).

Na perspectiva de tentar visualizar dados confirmadores do NSE dos participantes, foram tomados em consideração achados do estudo de Roza (2011). Essa pesquisadora fez um levantamento de áreas da cidade de Ribeirão Preto (SP) para estimar a incidência de tuberculose na cidade entre os anos de 2006 a 2009, realizando um recorte que mostra a distribuição do Índice Paulista de Vulnerabilidade Social (IPVS) da cidade. O IPVS consiste em uma "tipologia derivada da combinação entre duas dimensões (socioeconômica e demográfica), que classifica as áreas geográficas intramunicipais em seis grupos de vulnerabilidade social. A dimensão socioeconômica é composta pela renda apropriada pelas famílias e o poder de geração da mesma por seus membros, enquanto a demográfica relaciona-se ao ciclo de vida familiar" (p. 43). Seus dados indicam que o bairro de baixo nível sócio econômico onde foi realizado parte do Estudo 1, é uma área com IPVS de níveis 1 (nenhuma vulnerabilidade), 3 (vulnerabilidade baixa) e 4 (vulnerabilidade média), comportando indivíduos com escolaridade de nível fundamental e médio. Essas informações mais recentes sobre a região de moradia dos participantes do Estudo 1 reafirmam a distribuição socioeconômica e os níveis de escolaridade presentemente encontrados nesse subgrupo, mesmo após 15 anos do trabalho efetivado por Pasian (1998).

\subsubsection{MATERIAIS}

3.1.2.1. Carta convite de participação na pesquisa: A carta convite de participação do Estudo 1 (APÊNDICE A) foi entregue aos possíveis participantes de modo a apresentar a proposta do trabalho, contendo informações a respeito do objetivo do estudo e sobre o 
procedimento de coleta de dados. Nela havia espaço disponível para atestar ou não a concordância em participar com a pesquisa, cuja coleta de dados seria posteriormente agendada com os disponíveis.

3.1.2.2. Critério de Classificação Econômica Brasil: Com o intuito de caracterizar o nível econômico dos participantes utilizou-se o "Critério de Classificação Econômica Brasil" da Associação Brasileira de Empresas de Pesquisa (ABEP, 2012), aqui adaptado para a pesquisa (ANEXO 1). Trata-se de instrumento de segmentação econômica a partir do levantamento de características dos domicílios (presença e quantidade de alguns itens considerados de conforto doméstico, além do grau de escolaridade do chefe de família). São atribuídos pontos em função dos itens disponíveis na residência e realizada a soma total dos mesmos. Desta forma faz-se uma correspondência entre faixas de pontuação do critério e estratos de classificação econômica, a saber: A1, A2, B1, B2, C1, C2, D, E, sendo A o nível mais elevado e E o mais rebaixado. (www.abep.org). Esses diferentes estratos correspondem a classificações econômicas que representam a renda total familiar mensal, sendo que quanto maior a renda, mais alta a classe social e quanto menor a renda, menor a classe social.

\subsubsection{Self Report Questionaire 20 (SRQ-20) (APÊNDICE C): desenvolvido pela} Organização Mundial de Saúde com objetivo de avaliar elementos relativos à saúde mental (OMS, 2001), para ser utilizado em serviços de atenção primária em saúde. Esse instrumento foi objeto específico de estudo de validação e de padronização no Brasil por Santos, Araújo e Oliveira (2009), ficando composto por vinte itens, dado que foram excluídos quatro itens referentes aos distúrbios psicóticos existentes no instrumento original. A nota de corte ficou determinada como igual ou superior a sete ou oito pontos 
no SRQ. Apresentou adequados índices de validade e de consistência interna também na realidade nacional (Santos, Araújo \& Oliveira, 2009).

Compõe-se como instrumento capaz de identificar sintomas que podem estar relacionados à ausência ou presença de transtorno mental, sem oferecer um diagnóstico específico (Santos, Araújo, Pinho \& Silva, 2010). As questões são respondidas no formato "sim" ou "não", atribuindo-se pontos para as respostas assinalas positivamente. A soma dos pontos (respostas "sim") dá a nota no instrumento, sendo que, pelo referido estudo brasileiro, são casos prováveis de transtornos mentais os indivíduos que tiverem nota igual ou superior a sete ou oito pontos.

De acordo com Gonçalves, Stein e Kapczinski (2008), no Brasil, na década de 1980, ao se comparar o SRQ-20 com a entrevista psiquiátrica CIS (Clinical Interview Schedule), os índices alcançados foram $83 \%$ de sensibilidade e $80 \%$ de especificidade do instrumento para detecção de casos de transtornos mentais do tipo neurótico, com ponto de corte 7/8 para mulheres e 5/6 para homens. Os autores também afirmaram que o ponto de corte varia de $5 / 6$ a 10/11, em função do contexto cultural em que é utilizado. Ao realizar nova verificação desse instrumento no contexto brasileiro, os referidos pesquisadores não encontraram diferenças no ponto de corte para homens e mulheres. Asseguraram ainda que o ponto de corte mais adequado para o SRQ-20 seria 7/8 para ambos os sexos, sendo que os novos índices de sensibilidade e especificidade foram de $86,33 \%$ e de $89,31 \%$, respectivamente.

A literatura científica evidencia, assim, o SRQ como prática e útil ferramenta em processos de investigação no campo da saúde, podendo ser utilizado em formato de entrevista. No presente trabalho foi aplicado nessa perspectiva (em formato de entrevista), possibilitando a realização do rapport com os participantes do Estudo 1. Foi possível, 
desse modo, obter dados para caracterizar seu padrão atual de saúde mental, a serem posteriormente contrapostos aos demais dados da avaliação psicológica efetivada.

3.1.2.4. Psicodiagnóstico de Rorschach: O Psicodiagnóstico de Rorschach foi desenvolvido pelo psiquiatra suíço Hermann Rorschach (1884-1922) e é um instrumento projetivo de avaliação da personalidade. O material de aplicação e avaliação é composto por conjunto padronizado de 10 pranchas (com manchas de tinta), folhas de registro de dados, folhas padronizadas para localização das respostas, folhas para codificação das respostas e cronômetro para registro do ritmo do trabalho de associação e de interpretação do indivíduo. A aplicação é individual e cada cartão é apresentado um a um, seguindo-se a sequência numérica dos cartões (de I a X).

Neste trabalho, o processo de aplicação, de codificação e de análise das respostas seguiu os padrões da Escola de Paris/ Francesa do Rorschach, nomeadamente Rausch de Traubenberg (1998) e Anzieu (1986). O referencial teórico-metodológico deste método projetivo foi também objeto de explanação e de atualização nos trabalhos de Azoulay et al. (2007) e Ikiz et al. (2010), que foram utilizados como referenciais técnicos para o desenvolvimento dessa pesquisa. As categorias das respostas são subdivididas em Localização, Determinantes, Conteúdo e Banalidades, conforme descrito a seguir, a partir da síntese proposta por Jardim-Maran (2011).

Para a variável localização das respostas, a Escola Francesa do Rorschach prevê cinco seguintes possibilidades de avaliação: área global= G; grande detalhe $=\mathrm{D}$; pequeno detalhe $=\mathrm{Dd}$; detalhe branco $=\mathrm{Dbl}$; detalhe oligofrênico/inibitório= Do.

A classe dos determinantes apresenta diferentes possibilidades de categorização das respostas, a saber: 
a) Forma: resposta determinada unicamente pela forma (contorno) da mancha. A qualidade formal da resposta pode ser classificada dos seguintes modos:

$\mathrm{F}+$ : forma associada à precisão perceptual. Corresponde à resposta que obteve frequência igual ou superior a 2\% do total de indivíduos avaliados. Caso não atinja esta frequência, também é classificada desta maneira quando, na avaliação independente de juízes, obteve classificação de resposta com "boa forma, forma precisa".

F-: forma considerada "mal vista" ou imprecisa: resposta que, determinada pela forma, apresenta imprecisão formal. Corresponde à resposta que, determinada forma, obteve frequência inferior a $2 \%$ do total de sujeitos avaliados. Pode corresponder também àquela resposta que na avaliação independente de examinadores obteve classificação de "má forma", indicando, em termos perceptuais, uma interpretação distorcida da área indicada. F+-: forma imprecisa (conteúdo pouco delimitado formalmente) que circunscrevesse em uma área imprecisa/ambígua do cartão.

b) Movimento: resposta determinada pela cinestesia e pode ser classificada em: movimento humano $=\mathrm{K}$; movimento de parte humana $=\mathrm{kp}$; movimento animal (inteiro)= kan; movimento de objeto= kob.

c) $\underline{\text { Cor }(\mathbf{C})}$ : resposta determinada de forma prioritária pela cor(es) do cartão, classificada como: $\mathrm{FC}=$ cor com boa qualidade formal; $\mathrm{CF}=$ cor com má qualidade formal; $\mathrm{C}=$ cor pura.

d) Cor branca ou preta $\left(\mathbf{C}^{\prime}\right)$ : caso o determinante da resposta inclua as cores branca ou preta, o símbolo C é trocado por C', podendo a classificação das respostas apresentarem as mesmas combinações citadas acima para o código C.

d) Sombreado/Estompage (E): resposta determinada prioritariamente pelo manchado e pelo sombreado do cartão, tendo a possibilidade de ser classificada como: $\mathrm{FE}=$ sombreado 
com boa qualidade forma; $\mathrm{EF}=$ sombreado com má qualidade formal; $\mathrm{E}=$ sombreado puro.

Inclui-se também a possibilidade de classificação com o código $\underline{\text { Clob }}$ (claro/escuro, na língua francesa) e suas combinações, que variam em relação à qualidade formal da resposta (FClob, ClobF e Clob). O código Clob é atribuído para a resposta determinada por uma área escura da prancha e está associada, unicamente, a conteúdo disfórico, que é caracterizado por uma reação impregnada de aspectos afetivos negativos.

Em relação aos conteúdos presentes nas associações, Rausch de Traubenberg (1998) e Anzieu (1986) oferecem 22 possibilidades de categorização: relacionados ao

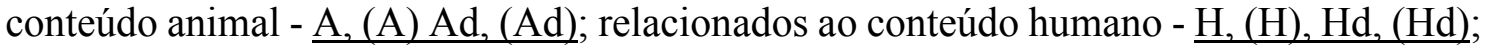
conteúdo anatômico - $\underline{\text { Anat; }}$ conteúdo sexual - $\underline{\mathrm{Sex}}$; conteúdo sangue - $\underline{\mathrm{Sg}}$; conteúdo botânico - Bot; conteúdo geográfico - $\underline{\text { Geo; }}$ conteúdo alusivo à natureza - Nat; conteúdo

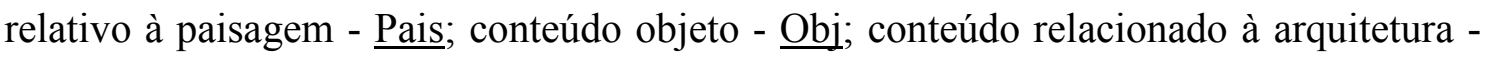

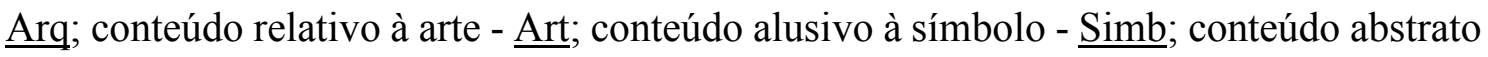
- $\underline{\text { Abs; }}$ conteúdo elemento - Elem (ar, terra, fogo ou água) e conteúdo fragmento - Frag.

As respostas banais ( $\underline{\text { Ban }})$ são baseadas em critérios estatísticos, existindo variabilidade em sua operacionalização em função da referência teórica do pesquisador. No presente estudo seguiu-se a proposta de Jacquemin (1976) e de Pasian (1998), onde a resposta foi considerada banal quando atingiu frequência igual ou superior a uma ocorrência a cada seis protocolos.

Em relação ao funcionamento afetivo, a Escola de Paris oferece três fórmulas para avaliar os modos peculiares de vivência emocional (em relação ao mundo e a si mesmo) e a expressão de conflitos e angústia, classificando o indivíduo a partir de quatro tipos de vivência: introversivo, extratensivo, ambigual e coartado/coartativo (Rausch de Traunbenberg, 1998). A primeira fórmula afetiva denomina-se Tipo de Ressonância 


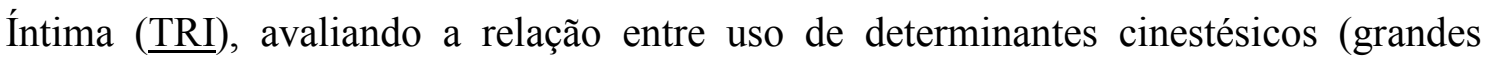
cinestesias $=\mathrm{K})$ e as cores ponderadas $(\Sigma \mathrm{Cp})$. A segunda fórmula afetiva, também conhecida como Tendências Latentes (TL), expressa a proporção entre soma das pequenas cinestesias $\left(\sum \mathrm{kan}+\mathrm{kp}+\mathrm{kob}\right)$ e as respostas determinadas pelo sombreado ponderado ( $\Sigma \mathrm{Ep})$. A terceira fórmula afetiva, comumente denominada como Reatividade Cromática $(\underline{\mathrm{RC}})$, expressa a proporção entre o número total de respostas dadas nos três últimos cartões (cromáticos) e o total de respostas.

3.1.2.5. Recursos Computacionais: Para fins de registro, digitalização e análise de dados foram utilizados recursos computacionais como Microsoft Word 2010, Microsoft Excel 2010, Statistical Package for the Social Sciences (SPSS) para Windows (versão 17.0).

\subsubsection{PROCEDIMENTOS}

\subsubsection{Considerações Éticas}

Este estudo foi submetido à avaliação pelo Comitê de Ética em Pesquisa da Faculdade de Filosofia, Ciências e Letras de Ribeirão Preto da Universidade de São Paulo, conforme orientações técnicas vigentes à época de seu início (Resolução 196/96 do Conselho Nacional de Saúde; conselho.saude.gov/br/docs/ Resoluções/Reso196.doc; Resolução 16/00 do Conselho Federal de Psicologia). Após sua aprovação (ANEXO 2), iniciou-se o processo de coleta de dados em si, de modo a adequadamente cuidar dos direitos dos possíveis participantes

Foi elaborado um Termo de Consentimento Livre e Esclarecido (APÊNDICE D) que apresentou os objetivos da pesquisa, convidando os adultos a dela participarem, 
expondo seus direitos e atividades, bem como nome e telefone de contato da pesquisadora responsável e da orientadora. O documento foi assinado (por aqueles que aceitaram participar da pesquisa) em duas vias, uma para o participante e outra para a pesquisadora.

Os participantes do Estudo 1 vincularam-se voluntariamente à pesquisa, sendo esclarecidos sobre a inviabilidade de devolutivas individuais dos resultados. Nos casos onde se detectou indicadores de dificuldades em termos de saúde mental (sete ou oito pontos no Self Report Questionaire-20), os indivíduos receberam orientações específicas a respeito, bem como, caso aceite, encaminhamento para serviços de referência na área em sua região de moradia. Isso foi necessário em apenas um caso, em que a participante foi encaminhada à um serviço de saúde mental da cidade.

\subsubsection{Coleta de dados}

Após a apresentação da carta convite ao participante, a pesquisadora combinava um horário para a realização da coleta de dados. Essa, por sua vez, foi realizada na residência do voluntário, em local reservado e sem interrupções. Realizava-se um breve diálogo com o voluntário, reapresentando os objetivos da pesquisa e iniciava-se o processo de aplicação dos instrumentos, conforme a ordem: Critério de Classificação Econômica Brasil, SRQ-20 e Psicodiagnóstico de Rorschach, seguindo as orientações da Escola Francesa (Rausch de Traubenberg, 1998). Ao apresentar o SRQ-20, a pesquisadora explicava que se tratava de um instrumento de 20 perguntas sobre a saúde física e emocional (do participante), com respostas do tipo "sim" e "não".

Em seguida, foi proposto o Método de Rorschach, baseando-se nas instruções de Pasian (1998):

"Vou lhe apresentar alguns cartões onde existem manchas de tintas e quero que você me diga o que essas manchas podem ser, o que podem parecer. Elas podem se 
parecer com muitas coisas, então, aqui não existe resposta certa nem errada, é a sua opinião que importa, e você pode dizer tudo o que achar que parece. Enquanto você estiver respondendo, vou anotar suas respostas aqui, da forma como você me falar. Eu também vou anotar o tempo, mas é apenas para registro, você tem o tempo que precisar. Quando você achar que não se parece com mais nada você me devolve o cartão, e eu lhe darei outro. Tem alguma dúvida? Podemos começar?” (p. 227).

Após a apresentação dos 10 cartões, iniciava-se a fase de investigação (inquérito) das respostas fornecidas e suas respectivas localizações. A seguir, investigavam-se os determinantes de cada resposta, etapa em que o participante era solicitado a explicar o que havia no cartão que fizesse parecer a(s) resposta(s) fornecida(s). Para a conclusão dessa aplicação, a pesquisadora solicitava que o participante escolhesse qual o cartão que havia gostado mais e qual havia gostado menos, justificando suas escolhas.

Ao final, a pesquisadora perguntava ao participante sobre suas impressões a respeito das atividades realizadas, procurando acolher os comentários realizados e esclarecer eventuais dúvidas existentes. Para encerrar, agradecia a disponibilidade dos participantes em colaborarem com o trabalho e explicava que os materiais ficariam guardados com a pesquisadora responsável.

De forma geral, os participantes mostraram-se motivados a realizarem as atividades propostas e a contribuírem com o trabalho proposto. Na primeira abordagem realizada pela pesquisadora (de sua apresentação e da apresentação dos objetivos da pesquisa), a grande maioria comentava não se lembrar de terem participado do estudo de Pasian (1998). No momento da aplicação do Rorschach alguns referiam recordar-se da atividade. Outros, por outro lado, perguntavam se a própria pesquisadora era quem tinha realizado a pesquisa na época da primeira avaliação, demonstrando que a lembrança da participação na pesquisa, realizada há 15 anos, era bastante tênue, quando presente. 


\subsubsection{Análise de dados}

O processo de análise dos resultados ocorreu em diferentes etapas. Além de resgatar a base de cadastro de casos de Pasian (1998) para contatos com possíveis participantes do Estudo 1, foram recuperados, na tecnologia computacional existente na atualidade, um sistema para registro e análise dos dados relativos às variáveis do Método de Rorschach (Escola Francesa) coletados naquele momento. O trabalho foi desenvolvido a partir dos modelos de bases de dados do Rorschach desenvolvidos no Centro de Pesquisas em Psicodiagnóstico - FFCLRP - USP para os estudos de Raspantini (2010), Fernandes (2010), Jardim-Maran (2011) e Cury-Jacquemin (2012), porém adaptado para a faixa etária de adultos. Elaborou-se uma planilha de dados em Microsoft Excel 2010 e foram realizados testes variados com essas planilhas (com casos fictícios e avaliados em estudo-piloto, até sua completa certificação), de modo a permitir os registros adequados dos casos. Essa etapa foi necessária para subsidiar a pretendida análise comparativa de resultados entre as duas épocas das avaliações.

Os dados do Estudo 1 foram organizados em dois momentos específicos. Inicialmente foi realizado o processo de classificação da produção no Psicodiagnóstico do Rorschach seguindo o referencial técnico-científico proposto pela Escola Parisiense, nomeadamente Anzieu (1986) e Rausch de Traubenberg (1998). O estudo de Pasian (1998) com adultos de Ribeirão Preto (SP) foi tomado como atlas básico de referência para a classificação das respostas presentemente obtidas neste trabalho.

Cada protocolo do Rorschach foi classificado pela pesquisadora e também por outro avaliador (juiz), em atividades independentes. A classificação final das respostas foi elaborada pela pesquisadora, para cada caso, composta a partir do consenso entre os julgamentos realizados. Casos em que isto não ocorreu, um terceiro avaliador codificou 
as respostas em questão, aplicando a classificação mais apropriada, diante das considerações dos juízes que o precederam.

A classificação final das respostas dos 88 adultos presentemente avaliados foi transposta para planilhas específicas do programa estatístico computacional Statistical Package for the Social Sciences (SPSS) para Windows, versão 17.0. Os resultados das 56 principais variáveis da Escola Francesa do Rorschach estão subdivididos em Localizações, Determinantes, Conteúdos e Banalidade.

Os dados relativos às avaliações independentes das respostas também foram usados para análise da precisão da Escola Francesa do Rorschach. Os juízes que colaboraram nesse trabalho são psicólogos que possuem experiência prévia com esse método projetivo de avaliação psicológica, quatro são mestres na área de avaliação psicológica e uma é doutora na área, todos com conhecimento e habilidade em classificar a analisar dados do Rorschach. Ainda assim, receberam orientação específica adicional para a realização das codificações do material coletado. No total, seis psicólogos compuseram a equipe de examinadores, sendo um deles a própria pesquisadora (Juiz 1) e, os demais, colaboradores da pesquisa. Os casos do Estudo 1 foram distribuídos para classificação das respostas ao Rorschach conforme o seguinte esquema:

- Juiz 1 (pesquisadora) $=88$ casos

- Juiz $2=10$ casos

- Juízes 3, 4 e 5 = 15 casos cada

- Juiz $6=18$ casos

A precisão (entre avaliadores independentes) foi verificada pelo cálculo do índice Kappa, sendo atribuído zero para a ausência e um para presença da variável analisada. Cohen (1960) desenvolveu o índice Kappa como indicador da concordância dos julgamentos de juízes para dados nominais, sendo esta uma análise mais acurada do que 
o cálculo da porcentagem de concordância entre examinadores. Isto porque, apesar da porcentagem de acordo ser, possivelmente, o método mais simples para se aceder à fidedignidade das variáveis categoriais, não considera que a proporção desse acordo pode ocorrer ao acaso (Fonseca, Silva \& Silva, 2007). No presente trabalho, tomou-se para análise um conjunto de 22 protocolos do Rorschach, selecionados aleatoriamente da amostra do Estudo 1 (25\% dos casos), examinando-se o coeficiente Kappa para o total das respostas identificadas nessa subamostra (379 respostas).

Para o cálculo de Kappa, a distribuição dos dados na planilha estatística considerou quatro variáveis para analisar os modos de apreensão (G, D, Dd, Dbl). A categoria Detalhe Oligrofênico (Do) não obteve frequência necessária ( $0 \%$ ) para suportar análise estatística. Os valores individuais do Kappa para cada variável de localização foram então somados e divididos por quatro, obtendo-se um valor médio de Kappa para Localizações. Em relação aos determinantes, o cálculo considerou as categorias Forma, Cor, Sombreado e Movimento. A título de exemplificação, quando uma resposta foi classificada por dois juízes como sendo puramente formal, considerava-se concordância, mas se um juiz classificasse como puramente formal e o outro considerasse outro determinante, considerava-se discordância, e assim sucessivamente para as demais categorias de determinantes. O valor final de Kappa para a categoria dos determinantes foi a média desses índices individuais. Os conteúdos considerados para a análise de concordância entre examinadores foram: animal e humano (os dois mais frequentes nos protocolos), anatomia, objeto, botânico e "outros" (quando nenhum dos conteúdos citados anteriormente foi classificado pelos avaliadores). Foram escolhidos os conteúdos anatomia, objeto e botânico por apresentarem frequência igual ou maior que $2 \%$ nos dois momentos avaliativos, suficientes para suportar análises estatísticas. Também foi realizada a soma de cada valor individual de Kappa e sua divisão pelo número de 
conteúdos examinados, para obtenção do valor médio de Kappa para essa categoria de classificação das respostas ao Rorschach. A variável banalidade apresenta o valor real do índice Kappa obtido nessa categoria avaliativa.

Após o cálculo dos indicadores de precisão do Rorschach, os resultados nesse método projetivo (já digitados em planilhas) foram examinados, primeiramente, em termos de estatísticas descritivas, calculando-se média, desvio-padrão, mediana, valor mínimo e máximo, considerando-se o conjunto dos adultos avaliados $(\mathrm{n}=88)$. A seguir foram realizadas análises inferenciais desses dados (adotando-se como nível de significância o valor de $p \leq 0,05)$, com as perspectivas apresentadas a seguir.

Em relação aos achados da reavaliação estão apresentados:

1) o perfil geral dos adultos por meio da análise descritiva nas variáveis relacionadas aos índices de produtividade, determinantes, conteúdos e banalidades.

2) a análise do possível efeito do sexo, da escolaridade e da idade sobre os resultados atuais no Método de Rorschach na amostra de 88 casos de adultos não pacientes.

3) a análise descritiva dos indivíduos em função dos tipos de personalidade, obtidos pelas fórmulas vivenciais (TRI, TL e RC) do Rorschach.

As análises dos indivíduos avaliados em 1998 e na reavaliação, apresentadas são: 4) a análise comparativa em função dos tipos de personalidade, obtidos pelas fórmulas vivenciais (TRI e TL) do Rorschach.

5) a comparação e correlação de resultados médios dos 88 casos avaliados por Pasian (1998) e reavaliados nesse Estudo 1. Foram consideradas as seguintes variáveis do Rorschach: índices de produtividade [número de Respostas (R), número de Respostas Adicionais (RA), número de Recusas (Rec) e Denegação (Den)]; determinantes: [forma $(\mathrm{F}+, \mathrm{F}+\%$ e $\mathrm{F}+\operatorname{ext} \%$, ) cor (FC, $\mathrm{CF}, \mathrm{C})$; sombreado/estompage (FE, EF, E) que incluindo determinantes claro-escuro (FClob, ClobF e Clob); movimentos (K, kan, kob, kp)]; 
conteúdos: [A e H (mais frequentes) e Anat, Bot, Geo (que apareceram com frequência mínima de 2\% nas duas avaliações)]; banalidades (Ban).

Para tanto, em função do número de participantes, recorreu-se ao Teste $t$ de Student e ao método de correlação de Pearson, ambos para amostras pareadas. Procurouse aqui testar a estabilidade dos resultados de adultos saudáveis ao longo do tempo, de modo a se obter evidências empíricas sobre indicadores de características de personalidade (funcionamento dinâmico e estruturação), a partir das variáveis da Escola Francesa do Rorschach.

6) Com a intenção de verificar se a mudança ou estabilidade dos aspectos da personalidade podem ter variado em função do sexo, da escolaridade e da idade (faixas etárias) foram checadas as variáveis do Rorschach citadas anteriormente. Foi criada uma nova variável para cada categoria de classificação do Rorschach, calculada a partir da diferença entre as duas aplicações do método projetivo (variável "diferença" = Momento 1 - Momento 2). Os resultados médios encontrados foram, então, comparados (Teste $t$ de Student para amostras pareadas) em função do sexo, da escolaridade e da idade, testando seu possível efeito sobre os dados.

7) Comparação dos resultados atuais no Rorschach (reavaliação dos indivíduos) em relação aos padrões normativos específicos para os diferentes níveis de escolaridade (baixo, médio e alto) elaborados por Pasian (1998), apresentados em percentis, nas seguintes variáveis: índices de produtividade (R, RA, Rec e Den), os Modos de Apreensão (G, D, Dd e Dbl), os índices de Funcionamento Lógico (F\%, F +\% e F + ext\%), Conteúdos ( $\mathrm{A} \%$ e $\mathrm{H} \%$ ) e Banalidades. Objetivou-se verificar como os indivíduos se comportaram na reavaliação frente aos parâmetros normativos disponíveis para adultos. Desse modo, cada adulto foi classificado em relação às suas normas específicas nas variáveis do Rorschach citadas acima, em uma das seguintes categorias: abaixo da média (resultados iguais ou 
inferiores ao percentil 40 do grupo normativo), na média (entre percentil 40 e 60 do grupo normativo), acima da média (resultados iguais ou superiores ao percentil 60 do grupo

normativo). Isso foi realizado para os resultados atuais, considerando-se as normas elaboradas em 1998 (primeiro momento avaliativo). Tais achados relativos a suas posições ocupadas nos dois momentos avaliativos foram comparados (Teste de Postos sinalizados de Wilcoxon para amostras relacionadas).

Por fim, também foi elaborada a análise descritiva dos resultados relativos ao SRQ-20 com os 88 participantes do Estudo 1.

\subsection{ESTUDO 2 - ATUALIZAÇÃO DAS NORMAS DO RORSCHACH EM ADULTOS}

Trata-se de estudo transversal, descritivo e interpretativo de resultados do Método de Rorschach em amostra de adultos não pacientes, atualizando referenciais normativos e atlas deste instrumento de avaliação psicológica de natureza projetiva.

\subsubsection{Características da região fonte do Estudo}

A coleta de dados do Estudo 2 foi desenvolvida com moradores de uma cidade do interior do Estado de São Paulo, a saber: a cidade de São Carlos (SP), situada no centro geográfico do Estado de São Paulo, a $230 \mathrm{~km}$ da capital paulista. O município conta com dois distritos (Santa Eudóxia e Água Vermelha), e sua área territorial é de $1.141 \mathrm{Km}^{2}$. Foi realizada busca ativa de dados dessa região do Estado de São Paulo, de modo a realizar sua breve caracterização e futura base comparativa com moradores de condições similares, de modo a tornar os achados passíveis de transposição para outros contextos. Desse modo, foram consultados os endereços eletrônicos: da Fundação Sistema Estadual 
de Análise de Dados (SEADE), do Instituto Brasileiro de Geografia e Estatística (IBGE) e da Prefeitura Municipal São Carlos (SP), chegando as informações a seguir sintetizadas.

A principal rodovia de acesso ao município é a Washington Luis, que liga São Carlos a São Paulo, Campinas, Araraquara e São José do Rio Preto, entre outras cidades. Outras três rodovias permitem acesso a várias regiões do estado e do país, como Ribeirão Preto, Bauru, Marília e Londrina.

Em relação às características sociodemográficas, o Censo de 2010, realizado pelo Instituto Brasileiro de Geografia e Estatística (IBGE), estimou que a população de São Carlos, para 2013, seria de 221.950 pessoas. O grau de urbanização é de 95,99\% e crescimento populacional anual de 1,02. O Índice de Desenvolvimento Humano Municipal (IDHM) é de 0,805, superior ao do Estado de São Paulo que é de 0,783. A coleta de lixo está acessível a 99,90\% da população, o nível de atendimento de abastecimento de água atinge a taxa de $99,66 \%$, enquanto $99,43 \%$ dos moradores têm acesso à rede de esgoto. A renda per capita do município é de R\$ 923,62. (http://www.imp.seade.gov.br/frontend/\#/perfil).

Em relação à população economicamente ativa do ano de 2010, a plataforma de consulta ao Índice de Desenvolvimento Humano Municipal IDHM (2013) indica que 60,86\% possuem Ensino Médio completo (http://www.pnud.org.br/IDH/Atlas2013).

São Carlos recebeu grande impulso para seu desenvolvimento tecnológico e educacional a partir da segunda metade do século XX, com a implantação, em 1953, da Escola de Engenharia de São Carlos, vinculada à Universidade de São Paulo (USP), e, na década de 1970, com a criação da Universidade Federal de São Carlos (UFSCar), sendo ambas as instituições reconhecidas pela excelência em ensino, pesquisa e extensão universitária. 
Além das Instituições de Ensino Superior Público, a Empresa Brasileira de Pesquisa Agropecuária (Embrapa) possui dois centros de atividades instalados na cidade: o Centro de Pesquisa de Pecuária do Sudeste e o Centro Nacional de Pesquisa e Desenvolvimento de Instrumentação Agropecuária, ambos responsáveis por produzirem tecnologia de ponta nas áreas de melhoramento genético bovino e de desenvolvimento de equipamentos agropecuários.

Outra fundação de destaque instalada na cidade é a Fundação ParqTec, organização não governamental sem fins lucrativos, que tem o objetivo gerenciar e promover o desenvolvimento do Polo Tecnológico de São Carlos, a partir da transferência de tecnologia das Universidades e centros de pesquisas para as empresas. A dinâmica acadêmica, tecnológica e industrial permitiu que a cidade recebesse o título de "Capital da Tecnologia".

Esta contextualização do município de São Carlos (SP) tem como objetivo apresentar informações relevantes para auxiliar eventual utilização dos padrões normativos do Rorschach aqui encontrados, seguindo o referencial da Escola Francesa, para outros contextos e regiões do país, na medida em que apresentem semelhanças ao padrão sociocultural anteriormente descrito.

\subsubsection{Critérios de seleção da amostra do Estudo 2}

De acordo com os objetivos propostos para a presente pesquisa, procurou-se realizar adequada seleção e composição da amostra. Decidiu-se buscar voluntários adultos na região de moradia da pesquisadora (São Carlos), que procurou replicar o trabalho original de Pasian (1998), embora em menor proporção.

Como no Estudo 1, foram considerados os seguintes critérios para seleção dos participantes: indivíduos adultos (entre 18 a 65 anos), não pacientes, de ambos os sexos, 
de níveis de escolaridade diversos (baixo, médio e alto) e pertencentes aos grupos de baixo e alto nível socioeconômico, que não apresentavam antecedentes críticos de ordem psiquiátrica, grave transtorno psicológico ou déficit intelectual. Para avaliar o nível cognitivo recorreu-se a instrumento específico (Teste de Inteligência Não Verbal - INV, forma C), aceitando-se na amostra aqueles com resultado igual ou superior ao percentil 25. Para triagem em termos de saúde mental foi utilizado o instrumento SRQ-20, deixando-se no estudo aqueles indivíduos que não atingissem a nota de corte (sete/oito pontos) para transtornos psíquicos.

Assim, a amostra de adultos do Estudo 2 contou com indivíduos não pacientes, entre 18 e 65 anos. Cabe destacar que os estudos normativos da Escola Francesa do Rorschach desenvolvidos pelo Centro de Pesquisa em Psicodiagnóstico (CPP) da Faculdade de Filosofia, Ciências e Letras de Ribeirão Preto (USP), onde também se desenvolveu o presente trabalho, estão agrupados nas seguintes faixas etárias: 6 a 8 anos (Fernandes, 2010); 9 a 11 anos (Raspantini 2010); 12 a 14 anos (Cury-Jacquemim, 2012) e 15 a 17 anos (Jardim-Maran, 2011). Desta forma, considerou-se oportuno incluir neste estudo de atualização das normas dos adultos, indivíduos a partir dos 18 anos. Além disso, ampliou-se a faixa etária (em relação a Pasian, 1998) para inclusão de adultos até 65 anos, considerando que a expectativa de vida vem aumentando nos últimos anos, estimando-se que até 2025 o Brasil contará com cerca de 32 milhões indivíduos com mais de 60 anos (Alonso da Costa \& Ciosak, 2010).

Objetivando-se preservar a representatividade em relação à escolaridade da população, já que esta variável tem se mostrado relevante na caracterização das produções no Psicodiagnóstico do Rorschach, partiu-se da premissa que indivíduos menos escolarizados pertenceriam a bairros de baixo nível socioeconômico e os mais escolarizados pertenceriam a bairros de alto nível socioeconômico, conforme discutido 
por Pasian (1998). A partir da delimitação física dessas áreas é que os indivíduos foram contatados, conforme estratégia a seguir apresentada.

\subsubsection{Seleção dos participantes}

Para acessar uma parcela da população que viesse a compor a amostra, considerou-se necessário localizar as regiões da cidade que fossem representativas de áreas de baixo e alto nível socioeconômico e que, possivelmente, pudessem abranger indivíduos adultos com diferentes graus de escolarização. Nesta direção, a pesquisadora entrou em contato com quatro diferentes órgãos oficiais da prefeitura do município de São Carlos (SP), a saber: Secretaria de Planejamento e Gestão, Secretaria de Habitação e Desenvolvimento Urbano, Secretaria de Cidadania e Assistência Social e Secretaria da Saúde, na tentativa de acessar dados oficiais que pudessem orientar o processo de seleção dos locais de realização da pesquisa na cidade, como, por exemplo, índice de desenvolvimento humano ou outro indicador da realidade social dos bairros.

A partir da secretaria de Cidadania e Assistência Social foram obtidos dados referentes aos bairros economicamente menos favorecidos, em que grande parte da população é beneficiada pelo programa bolsa família, concedido pelo Governo Federal. A secretaria de Habitação e Desenvolvimento Urbano orientou que as informações sobre a cidade fossem retiradas da página da internet (oficial) do Instituto Brasileiro de Geografia e Estatística (IBGE). Contudo, no IBGE, o município de São Carlos não apresenta uma divisão por bairros e sim por áreas/distritos que englobam diferentes regiões da cidade, o que impossibilitou o acesso a informações específicas necessárias para a localização de possíveis participantes em função do nível socioeconômico. As demais secretarias municipais consultadas pela pesquisadora não dispunham de suficientes e organizadas informações sobre os bairros da cidade, em função da recente 
mudança na gestão da prefeitura (ocorrida um mês anterior ao início deste estudo) e, desta forma, não tinham condições de fornecer dados atualizados que norteassem o trabalho a ser aqui efetivado.

Diante da dificuldade em obter acesso a dados oficiais específicos dos setores do município selecionado, a escolha do bairro de nível socioeconômico baixo ocorreu após a pesquisadora ter visitado dois diferentes Centros de Referência de Assistência Social (CRAS). Os CRAS são locais em que são desenvolvidas ações de proteção social básica com o objetivo de prevenir situações de risco em que estão sujeitas a "população em situação de vulnerabilidade social decorrente de pobreza, privação elou fragilização de vínculos afetivos/relacionais e de pertencimento social (discriminações etárias, étnicas, de gênero ou por deficiências, entre outras)" (www.saocarlos.sp.gov.br/).

O primeiro CRAS visitado abrange uma região de grande extensão da cidade (três grandes bairros: Cidades Aracy, Antenor Garcia e Jardim Social Presidente Collor). Neste CRAS, a assistente social afirmou que as visitas às residências da região são sempre realizadas por duplas de funcionárias e sugeriu que a pesquisadora não visitasse as residências desacompanhada, visando a sua proteção pessoal, já que poderia se expor a situações de risco. Essa observação foi considerada como inviabilizadora da coleta dos dados nesses locais, não sendo uma região selecionada para a pesquisa (por segurança da pesquisadora).

No segundo CRAS visitado, também localizado em região periférica da cidade, a assistente social afirmou que realizava as visitas domiciliares desacompanhada e, indicou que, apesar de ser área com altos índices de violência e com tráfico de drogas, havia pouco risco de exposição da pesquisadora na busca por possíveis colaboradores para o estudo. A assistente social sugeriu que a pesquisadora fosse à Unidade da Saúde da Família (USF) do bairro para se apresentar aos agentes comunitários, que são profissionais ainda mais 
próximos dos membros da comunidade. Esses, por sua vez, reafirmaram que, de forma geral, a população era receptiva aos contatos e apenas indicaram que a pesquisadora evitasse visitas domiciliares em horários noturnos. Diante dessas informações, por viabilidade prática, esse bairro indicado pelos profissionais do CRAS foi selecionado para compor a região de onde seriam feitos os contatos e a seleção dos possíveis voluntários ao Estudo 2, representando o baixo nível socioeconômico da cidade.

O bairro de alto nível socioeconômico foi selecionado por ser publicamente reconhecido pelos moradores da cidade como uma região economicamente privilegiada do município. Além disso, dados disponíveis no site da Prefeitura Municipal de São Carlos por meio da "Planta Genérica de Valores" dos terrenos da cidade (instrumento oficial em que estão estabelecidos os valores unitários de metro quadrado de terreno e de construção do município) indicavam que os terrenos desse bairro possuíam o terceiro maior valor da cidade, entre aqueles que não são os bairros de condomínios residenciais fechados (www.saocarlos.sp.gov.br/).

Selecionadas as duas regiões da cidade de São Carlos (SP) postulando-se que representariam, respectivamente, o bairro de alto nível socioeconômico (região Norte) e o bairro de baixo nível socioeconômico (região Oeste), demarcou-se o acesso a indivíduos de diferentes condições socioculturais, chegando-se a amostra a ser apresentada. O mapa de cada região foi numerado a partir de seus quarteirões e foi sorteada, aleatoriamente, quadras que poderiam ser visitadas para a seleção dos participantes. Procurou-se estabelecer contato direto com os moradores das residências e, quando não eram encontrados naquele momento, deixava-se uma carta convite à participação na pesquisa (APENNDICE E).

Buscou-se efetivar os contatos com todas as residências do quarteirão sorteado para, então, seguir a próxima quadra até completar os adultos da amostra de cada região, 
procurando-se respeitar a proporção semelhante, por faixa etária, de distribuição dos indivíduos avaliados. Contudo, o procedimento de entrega das cartas de apresentação da pesquisa nem sempre se tornou uma estratégia viável, já que: a) em algumas residências

a pesquisadora não encontrou moradores; b) algumas vezes os moradores não encontravam a carta no momento que a pesquisadora tentava recolhê-las; c) algumas cartas foram recolhidas em branco e outras apenas com a sinalização de não haver interesse em participar do estudo, sem justificativa e/ou dados pessoais do(s) adulto(s) que compunham a residência. Desta forma, no presente trabalho considerou-se sensato descrever o conjunto desses passos técnicos, bem como descrever os contatos da pesquisadora e seu resultado: favorável (aceite do estudo) ou não (recusa).

No bairro de baixo nível socioeconômico foram visitados sete quarteirões e as visitas em que foi possível efetivar contatos com moradores ocorreu com 98 adultos. No bairro de alto nível socioeconômico, foram visitadas casas de nove quarteirões e foi possível efetivar o contato com 89 adultos. Quando havia voluntários disponíveis para participar do estudo na residência contatada e estes preenchiam os critérios de inclusão na amostra (idade), realizava-se a avaliação psicológica naquele momento ou combinavase uma data que fosse mais apropriada para o colaborador.

\subsubsection{Participantes}

Diante dos objetivos e planejamento inicial da amostra do Estudo 2, iniciou-se a coleta de dados a partir da visita à região de baixo nível socioeconômico, respeitando-se os devidos critérios de seleção dos participantes. Foram efetivados 98 contatos com moradores do bairro selecionado, resultando em 60 concordâncias de adultos com o estudo e 38 recusas em participar, alegando falta de tempo ou desinteresse na proposta. Os 60 voluntários foram avaliados pela pesquisadora, conforme padrão técnico descrito 
nos procedimentos, mas houve necessidade de exclusão de alguns desses casos $(n=10), a$ saber: nove casos (sete mulheres e dois homens) por alcançarem ou ultrapassarem a nota de corte (7/8 pontos) no SRQ, sendo que dois deles (uma mulher e um homem) também não atingiram o percentil 25 no INV- forma C. Por fim, um participante (homem) foi excluído da amostra por não ter conseguido realizar a tarefa proposta no INV - forma C. Desse modo, na região de baixo nível socioeconômico, a amostra foi concluída com a participação de 24 mulheres e 26 homens, entre 18 e 65 anos, de diversos níveis de escolaridade.

Para os adultos da região de alto nível socioeconômico, foram efetivados (no total) 89 contatos com moradores, resultando em 45 aceitações e 24 recusas ao estudo, justificadas unicamente por falta de tempo. Dos 45 casos avaliados, dois participantes (um do sexo feminino e um do sexo masculino) foram excluídos da amostra em função da pontuação superior à nota de corte no SRQ. Nessa região a pesquisadora conseguiu, majoritariamente, a participação de mulheres (28) e apenas cinco homens aceitaram colaborar. Desta forma, a carta convite à pesquisa foi reelaborada para essa região da cidade, solicitando, preferencialmente, a colaboração de voluntários do sexo masculino. Com esta estratégia e visitas persistentes da pesquisadora ao local selecionado por conveniência, foi possível contatar outros 20 possíveis voluntários masculinos ao estudo, sendo que 11 homens aceitaram colaborar e nove recusaram o trabalho.

Após a visita às residências dos quarteirões sorteados nessa região de alto nível socioeconômico, ainda faltavam, pelo menos, nove adultos do sexo masculino que pudessem compor a amostra de forma que ela ficasse equitativa em relação à distribuição por sexo. Em função disso e do tempo disponível para finalizar a coleta de dados, foram contatados nove indivíduos do sexo masculino para participar da pesquisa via rede de contatos da pesquisadora (indicações sugeridas por alguns voluntários, por colegas de 
trabalho e por sua rede social de contatos) e oito destes indivíduos aceitaram participar do trabalho. Desta forma, para o grupo de alto nível socioeconômico, a coleta de dados foi concluída com a participação de 28 mulheres e 24 homens, todos entre 18 e 65 anos.

Com intuito de descrever de modo sintético o conjunto de contatos realizados pela pesquisadora nesse processo de busca dos participantes do Estudo 2, elaborou-se a Tabela 8. Os dados resumem o percurso amostral desse estudo em termos de indivíduos contatados, avaliados, excluídos e as recusas em participar da pesquisa.

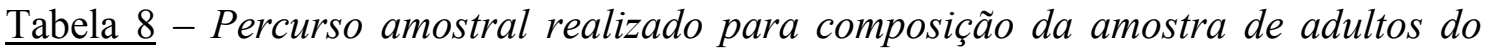
Estudo 2, em função do nível socioeconômico.

\begin{tabular}{|c|c|c|c|c|c|c|c|c|c|}
\hline \multirow{2}{*}{$\begin{array}{c}\text { Grupo } \\
\text { Indivíduos }\end{array}$} & \multicolumn{3}{|c|}{ Baixo NSE* } & \multicolumn{3}{|c|}{ Alto NSE* } & \multicolumn{2}{|c|}{ Subtotal } & \multirow[t]{2}{*}{ TOTAL } \\
\hline & M & $\mathrm{F}$ & Subtotal & M & $\mathrm{F}$ & Subtotal & M & $\mathrm{F}$ & \\
\hline Avaliados & 29 & 31 & 60 & 25 & 29 & 54 & 54 & 60 & 114 \\
\hline Excluídos & 3 & 7 & 10 & 1 & 1 & 2 & 4 & 8 & 12 \\
\hline Recusas ** & - & - & 38 & - & - & 25 & - & - & 63 \\
\hline
\end{tabular}

A partir dos contatos com os residentes da cidade de São Carlos (SP), moradores das regiões selecionadas, a amostra do Estudo 2 ficou composta por 102 novos casos de indivíduos adultos, entre 18 e 65 anos, 51 mulheres e 51 homens, de diferentes grupos socioeconômicos e níveis de escolaridade. As características da amostra constituída podem ser visualizadas na Tabela 9.

$\underline{\text { Tabela } 9}$ - Caracterização dos participantes $(n=102)$ do Estudo 2, em função do nível socioeconômico, sexo e escolaridade. 


\begin{tabular}{|c|c|c|c|c|c|c|c|}
\hline Escolaridade $* *$ & $\mathrm{M}$ & $\mathrm{F}$ & Subtotal & $\mathrm{M}$ & $\mathrm{F}$ & Subtotal & \\
\hline Baixa & 9 & 10 & 19 & - & - & - & 19 \\
\hline Média & 17 & 14 & 31 & 2 & 4 & 6 & 37 \\
\hline Alta & - & - & - & 22 & 24 & 46 & 46 \\
\hline TOTAL & 26 & 24 & 50 & 24 & 28 & 52 & 102 \\
\hline
\end{tabular}

Segundo a Lei Nacional de Diretrizes e Bases da Educação Nacional de 1996, atualizada em 2015, a educação escolar compõe-se de Educação Básica, Ensino Fundamental, Ensino Médio e Educação Superior. Para este estudo optou-se por considerar "baixa escolaridade" os indivíduos com até o ensino fundamental; "média escolaridade" aqueles com até o ensino médio e, por fim, "alta escolaridade" os que tinham curso superior (completo ou incompleto) uma vez que a classificação proposta pelo IBGE considera diferentes níveis em função dos anos de estudo: 1) sem instrução, 2) um a três anos, 3) quatro a sete anos, 4) oito a 10 anos, 5) 11 a 14 anos, 6) 15 anos ou mais.

Em relação à escolaridade dos participantes, foram encontrados 19 (38\%) indivíduos do bairro de baixo nível socioeconômico com baixo grau de escolaridade e 31 $(62 \%)$ adultos apresentaram média escolaridade. Por outro lado, dos adultos do bairro de alto nível socioeconômico, seis apresentaram média escolaridade (12\%) enquanto 46 (88\%) apresentaram alta escolaridade, conforme apresentado na Tabela 9. É importante considerar que nenhum adulto do bairro de baixo nível socioeconômico possuía ensino superior; o nível de escolaridade mais elevado encontrado nessa região foi ensino médio completo. Já no bairro de alto nível socioeconômico, apenas três indivíduos tinham ensino médio completo; os demais apresentavam nível superior completo ou em curso, alguns, 
inclusive, pós-graduados. Além disso, os postos de trabalho ocupados pelos moradores da região de baixo nível social eram, em sua maioria, relacionados a serviços gerais como pedreiros, carpinteiros, mecânicos, diaristas, atendentes, alguns aposentados, outros em situação de desemprego, entre outros. Já na região de alto nível socioeconômico, foram encontrados professores, profissionais autônomos (advogados, engenheiros, fisioterapeutas) e outros. O conjunto dessas características dos participantes do Estudo 2 reafirma a pluralidade e diversidade de indivíduos avaliados ao longo desse estudo.

Foi possível ainda caracterizar os participantes do Estudo 2 em função da distribuição nas várias faixas etárias, além do sexo e origem socioeconômica. Esses dados podem ser visualizados na Tabela 10 .

Tabela 10 - Caracterização da amostra $(n=102)$ do Estudo 2, em função da faixa etária, sexo e origem socioeconômica.

\begin{tabular}{ccccccccc}
\hline Grupo & \multicolumn{3}{c}{ Baixo NSE* } & \multicolumn{3}{c}{ Alto NSE* } & \multicolumn{2}{c}{ TOTAL } \\
Faixa etária & M & F & Subtotal & M & F & Subtotal & F & $\%$ \\
\hline $18-29$ anos & 8 & 4 & 12 & 5 & 7 & 12 & 24 & 24 \\
30-39 anos & 5 & 4 & 09 & 6 & 4 & 10 & 19 & 19 \\
$40-49$ anos & 8 & 5 & 13 & 4 & 4 & 8 & 21 & 21 \\
$50-59$ anos & 6 & 7 & 13 & 8 & 11 & 19 & 32 & 32 \\
$60-65$ anos & 2 & 1 & 3 & 1 & 2 & 3 & 6 & 6 \\
TOTAL & 29 & 21 & 50 & 24 & 28 & 52 & 102 & 100 \\
\hline *NSE = nivel socioeconômico; $M=$ sexo masculino; $F=$ sexo feminino.
\end{tabular}


Apesar do predomínio de indivíduos com mais de 50 anos, em termos totais, foi possível garantir adequada representação de cada faixa etária entre os casos que compõe a amostra do estudo. A média de idade dos participantes ficou em 45,4 anos $(d p=12,4)$.

Foi possível também considerar os resultados obtidos a partir do Critério de Classificação Econômica Brasil (ABEP, 2012) para caracterizar os participantes. Assim, a amostra, subdividida a partir das regiões de baixo e alto nível socioeconômico, pode ser caracterizada em termos da classificação econômica, conforme proposta advinda desse instrumento. Esses dados estão apresentados na Tabela 11.

Tabela 11 - Distribuição dos indivíduos (n=102) do Estudo 2 em função do nível socioeconômico, sexo e resultados no Critério de Classificação Econômica Brasil (ABEP, 2012).

\begin{tabular}{|c|c|c|c|c|c|c|c|c|}
\hline \multirow{2}{*}{$\begin{array}{c}\text { Classificação } \\
\text { ABEP }\end{array}$} & \multicolumn{3}{|c|}{ Baixo NSE* } & \multicolumn{3}{|c|}{ Alto NSE* } & \multicolumn{2}{|c|}{ TOTAL } \\
\hline & $\mathrm{M}$ & $\mathrm{F}$ & Subtotal & $\mathrm{M}$ & $\mathrm{F}$ & Subtotal & $\mathrm{f}$ & $\%$ \\
\hline $\mathrm{A}(\mathrm{A} 1 \mathrm{e} \mathrm{A} 2)$ & - & - & - & 15 & 20 & 35 & 35 & 34,3 \\
\hline B (B1 e B2) & 9 & 17 & 26 & 11 & 6 & 17 & 43 & 42,2 \\
\hline $\mathrm{C}(\mathrm{C} 1$ e $\mathrm{C} 2)$ & 8 & 16 & 24 & - & - & - & 24 & 23,5 \\
\hline TOTAL & 17 & 33 & 50 & 26 & 26 & 52 & 102 & 100,0 \\
\hline
\end{tabular}

Segundo o Critério da ABEP (2012), a maioria (26 casos $=52 \%$ ) dos indivíduos residentes no bairro de baixo nível socioeconômico pertencia à classe econômica $\mathrm{B}$ (quatro se encontram na subclasse $\mathrm{B} 1 ; 22$ na $\mathrm{B} 2$ ) e 48\% na classe $\mathrm{C}(14$ na $\mathrm{C} 1 ; 10$ na $\mathrm{C} 2$ ). Dos indivíduos moradores do bairro de alto nível socioeconômico, 33\% pertenciam à classe econômica B (B1) e 67\% foram classificados no nível econômico A (sete da subclasse A1; 28 da A2). Ou seja, pode-se notar que a região de moradia, selecionada por 
conveniência, funcionou como adequado critério para identificação dos participantes em termos econômicos, como confirmado pelos dados do Critério de Classificação Econômica Brasil.

A princípio, o Estudo 2 englobou a avaliação de 102 novos voluntários adultos, individualmente examinados pela pesquisadora. Porém, por se tratar de estudo de revisão de normas do Rorschach para essa população, considerou-se apropriado incorporar nele os casos do Estudo 1 que se adequassem aos critérios pré-estabelecidos para este objetivo, ou seja, adultos entre 18 e 65 anos, não pacientes, de ambos os sexos, com níveis de escolaridade diversos e pertencentes aos grupos de baixo e alto nível socioeconômico, que não apresentassem antecedentes críticos de ordem psiquiátrica, grave transtorno psicológico ou déficit intelectual. Desta forma, dos 88 possíveis casos examinados no Estudo 1, foi possível considerar dados de 66 adultos para compor também o Estudo 2. Não foram considerados nesse processo 12 indivíduos do Estudo 1 (seis mulheres e cinco homens) com mais de 65 anos e 10 indivíduos (dois homens e nove mulheres) que, no Estudo 1, atingiram 7/8 pontos ou mais no SRQ-20.

A composição final da amostra do Estudo 2 pode, assim, ser visualizada na Tabela 12. Os participantes estão caracterizados em função do sexo, idade e escolaridade.

Tabela 12- Composição da amostra atual do estudo normativo ( $n=168)$ distribuida pelos diferentes níveis de escolaridade, sexo e faixa etária.

\section{Escolaridade*}

Sexo**

\begin{tabular}{|c|c|c|c|c|c|c|c|c|}
\hline \multirow{2}{*}{$\begin{array}{c}\text { Faixas } \\
\text { Etárias }\end{array}$} & \multicolumn{2}{|c|}{ Baixa } & \multicolumn{2}{|c|}{ Média } & \multicolumn{2}{|c|}{ Alta } & \multicolumn{2}{|c|}{ TOTAL } \\
\hline & F $\quad M$ & Subtotal & M & Subtotal & F $\quad \mathrm{M}$ & Subtotal & $\mathrm{F} \quad \mathrm{M}$ & Subtotal \\
\hline $18-29$ & 1 & 2 & 8 & 12 & 4 & 10 & 13 & 24 \\
\hline
\end{tabular}




\begin{tabular}{rccc|ccc|ccc|ccc}
\hline $30-39$ & - & 1 & 1 & 6 & 6 & 12 & 9 & 7 & 16 & 15 & 14 & $\mathbf{2 9}$ \\
$40-49$ & 4 & 4 & 8 & 7 & 7 & 14 & 7 & 10 & 17 & 18 & 21 & $\mathbf{3 9}$ \\
$50-65$ & 13 & 7 & 20 & 5 & 9 & 14 & 22 & 20 & 42 & 40 & 36 & $\mathbf{7 6}$ \\
TOTAL & 18 & 13 & 31 & 25 & 25 & 52 & 42 & 43 & 85 & 86 & 82 & $\mathbf{1 6 8}$ \\
\hline
\end{tabular}

* Niveis de Escolaridade: Baixo (Ensino Fundamental completo ou incompleto); Médio (Ensino Médio completo ou incompleto); Alto (Ensino Superior completo e incompleto, e pós-graduação).

**Sexo: $M=$ Masculino; $F=$ Feminino.

É importante ressaltar que esses 66 indivíduos, incluídos no estudo para composição da amostra normativa, advém de região (Ribeirão Preto) com características similares aos casos avaliados no Estudo 2, de São Carlos (SP). A cidade de Ribeirão Preto situa-se a 93,4 km de São Carlos e a 318,6 km da capital São Paulo. Os dados obtidos por acesso ao site da Fundação Sistema Estadual de Análise de dados (Seade, 2015), indica que o município apresenta índice populacional de 647.862, grau de urbanização de 99,72\%. O índice de Desenvolvimento Humano Municipal (IDHM) é de 0,800, a renda per capita (do município) é de RS 1.052,76, a coleta de lixo alcança índice de 99,8\%, o abastecimento de água é de $99 \%$ e a população de 18 a 24 anos com ensino médio completo de 60,40\% (http://www.imp.seade.gov.br/frontend/\#/perfil). Além disso, os dados apresentados a respeito da caracterização dos indivíduos em relação à escolaridade e relacionados ao critério de classificação econômica (ABEP, 2012), indicado pelo instrumento aqui utilizado nos Estudos 1 e 2, reforça as características das semelhanças sociodemográficas entre os adultos de ambos os estudos que compõe a amostra do estudo normativo.

\subsubsection{Materiais}


Em função dos objetivos delineados para o Estudo 2, os materiais utilizados foram praticamente os mesmos do Estudo 1, apenas com ajustes técnicos necessários para essa parte da pesquisa nas cartas convite e termos elaborados, como a seguir explanado.

3.2.5.1. Carta convite de participação na pesquisa: A carta convite de participação do Estudo 2 (APÊNDICE E) foi entregue aos possíveis participantes de modo a apresentar a proposta do trabalho, contendo informações a respeito do objetivo do estudo e sobre o procedimento de coleta de dados. Nela havia espaço disponível para atestar ou não a concordância em participar do estudo, cuja coleta de dados foi agendada com os disponíveis da residência, conforme critérios de seleção de participantes.

3.2.5.2. Critério de Classificação Econômica Brasil: Com o intuito de caracterizar a classificação econômica dos indivíduos utilizou-se o "Critério de Classificação Econômica Brasil” da Associação Brasileira de Empresas de Pesquisa (ABEP, 2012) (ANEXO 1), conforme descrição presente no Estudo 1.

3.2.5.3. Self Report Questionaire 20 (SRQ-20) (APÊNDICE C): foi utilizado em formato de entrevista, possibilitando a realização do rapport com os participantes. Suas características técnicas e padrões analíticos constam na descrição do Estudo 1 desse trabalho. Cabe destacar que, neste estudo, também foram excluídos da amostra os voluntários que atingiram oito pontos ou mais no SRQ-20, considerando a necessidade de se compor uma amostra de adultos não pacientes.

3.2.5.4. Psicodiagnóstico de Rorschach: Neste trabalho, o processo de aplicação, de codificação e de análise das respostas seguiu os padrões da Escola Francesa do 
Rorschach, nomeadamente Rausch de Traubenberg (1998). Este referencial teóricometodológico deste método projetivo foi também objeto de explanação e de atualização nos trabalhos de Azoulay et al. (2007) e Ikiz et al. (2010), que foram aqui também utilizados como referenciais técnicos para o desenvolvimento da pesquisa, como já descrito no Estudo 1.

3.2.5.5. Teste de Inteligência Não Verbal (INV) - Forma C: criado no Brasil em 1971, por Pierre Weil e Eva Nick (Weil \& Nick, 1971), para fins de pesquisa e também de diagnóstico, destina-se à avaliação do desenvolvimento intelectual. Em sua Forma $\mathrm{C}$ o teste conta com 60 itens e mais quatro exemplos iniciais, presentes em um caderno de aplicação, além de um crivo de correção das respostas. Em cada uma das cinco páginas do caderno de aplicação existem 12 itens, devendo ser apurado o total de acertos. Sua aplicação, na Forma C, abrange todas as idades a partir do sexto ano de vida, sendo de aplicação e avaliação rápida.

O Teste INV foi objeto do estudo de Lopes (2009), que buscou atualizar os parâmetros psicométricos deste teste, embora investigando uma amostra de crianças da região de Belo Horizonte (MG). Conseguiu demonstrar adequados índices de validade e de precisão do instrumento no contexto brasileiro atual, reforçando as possibilidades de uso da técnica para avaliação intelectual em termos globais.

O INV - Forma C foi aplicado após a coleta das informações de classificação econômica, com intuito de conhecer o potencial cognitivo dos participantes. Foram incluídos no Estudo 2 os adultos que atingiram desempenho igual ou superior ao percentil 25, a partir dos padrões analíticos desenvolvidos por Weil e Nick (1971). 
3.2.5.6. Recursos Computacionais: Para fins de registro, digitalização e análise de dados foram utilizados recursos computacionais como Microsoft Word 2010, Microsoft Excel 2010, Statistical Package for the Social Sciences (SPSS) para Windows (versão 22.0).

\subsubsection{Procedimentos}

Os procedimentos do Estudo 2 foram os mesmos do Estudo 1, excetuando-se, como já explicado, o processo de seleção de participantes. Assim, os cuidados éticos e o processo de coleta de dados do Estudo 2 seguiram as mesmas diretrizes do Estudo 1, acrescida da inclusão do Teste de Inteligência Não Verbal (INV - Forma C), e o instrumento SRQ-20 (usado como critério de inclusão/exclusão dos voluntários ao estudo). O Termo de consentimento Livre e Esclarecido deste segundo estudo, também aprovado pelo Comitê de Ética e Pesquisa com seres humanos, encontra-se no Apêndice F.

\subsubsection{Análise de precisão do Rorschach}

Em relação ao Psicodiagnóstico de Rorschach, cada protocolo foi classificado pela pesquisadora e por outro juiz, em atividades independentes, seguindo-se o referencial técnico-científico proposto pela Escola Francesa. O estudo de Pasian (1998), com adultos de Ribeirão Preto (SP), foi tomado como atlas básico de referência para a classificação das respostas. Cada avaliador independente examinou um total de 17 protocolos do Rorschach (foram os mesmos cinco colaboradores do Estudo 1), além das classificações realizadas pela pesquisadora no conjunto de casos $(n=102)$.

Neste segundo estudo, a precisão dos avaliadores independentes também foi verificada por cálculo do índice Kappa. Nessa análise foram considerados os 102 casos da amostra (total de 1.930 respostas), seguindo-se os mesmos procedimentos para a 
análise da precisão do Estudo 1. Desta vez, as variáveis localização, determinantes, conteúdos e banalidades foram acrescidas pelo índice "qualidade formal" das respostas, o que possibilitou levar em consideração a concordância ou discordância em relação a esse elemento relevante da produção individual (qualidade formal adequada ou qualidade formal distorcida). O valor Kappa para a qualidade formal das respostas foi calculado pela média dos índices encontrados para as respostas bem vistas e para as respostas mal vistas.

\subsubsection{Análise dos resultados do Rorschach}

A sistematização dos resultados do Rorschach no Estudo 2 foi realizada, inicialmente, em termos descritivos (média, desvio-padrão, mediana, valor mínimo e máximo), considerando-se o conjunto dos adultos avaliados (n=168). A descrição desses achados foi desenvolvida tendo em vista agrupamentos das variáveis do Rorschach representativas das seguintes funções psíquicas: (a) produtividade e ritmo; (b) funcionamento lógico; (c) afetividade (Tipo de Ressonância Íntima - TRI; Tendências Latentes - TL), controle de impulsos e adaptação social. Para a caracterização dos padrões gerais de produção no Rorschach dos adultos avaliados foram observadas a frequência simples e a porcentagem dos resultados nas principais variáveis de classificação das respostas ao Rorschach na amostra investigada. Foram levantados os índices de produtividade em cada cartão, e frequência e porcentagem nas categorias de classificação de respostas do Rorschach.

Também foram contrapostos os atuais resultados aos referenciais normativos do Método de Rorschach em adultos elaborados por Pasian (1998), por meio de análises comparativas das médias nas principais variáveis desse método projetivo de avaliação psicológica. Desse modo buscou-se responder a questão relativa a estabilidade ou não das normas disponíveis (na Escola Francesa) para essa faixa etária. 
Os estilos vivenciais dos adultos do Estudo 2 foram identificados e apresentados, em termos de frequência simples e porcentagem dos casos. Para examinar esses tipos de vivência dos adultos, suas fórmulas afetivas no Rorschach (primeira, segunda e terceira fórmulas) foram examinadas. Por fim, foram realizadas análises inferenciais dos dados (adotando-se como nível de significância o valor de $p \leq 0,05$ ), examinando-se possível influência do sexo, da idade (faixas-etárias) e da escolaridade sobre os resultados no Método de Rorschach na amostra de 168 casos de adultos não pacientes.

\subsubsection{Elaboração do atlas do Rorschach}

Referente à atualização e revisão do atlas do Rorschach (sistema francês) para população adulta, foram listadas as áreas interpretadas e a qualidade formal de suas respectivas respostas, organizado-as em um banco de dados em planilhas do Microsoft Office Excel 2010, com o conjunto das respostas (3.144 interpretações aos cartões) produzidas pelos 168 participantes (66 casos do Estudo 1 e 102 casos do Estudo 2). Cada conteúdo interpretado foi relacionado a sua área específica de localização no cartão onde foi produzido (APÊNDICE G). De tal modo, foram sistematizadas as áreas interpretadas, a frequência com que cada área foi evocada e sua respectiva resposta para cada cartão do Rorschach, permitindo revisão do atlas de classificação das respostas ao Rorschach, comparativamente ao material produzido por Pasian (1998).

Em função do grande número de recortes feitos pelos participantes em suas respostas aos cartões, tomou-se a decisão técnica de aglutinar as localizações que se assemelhassem, de maneira a obter integrado conjunto de dados. Desta forma, respostas em recortes interpretados com baixa frequência, mas com características semelhantes entre si (área interpretada e seu conteúdo) foram transpostas para áreas evocadas com maior frequência. Essas decisões técnicas foram tomadas a partir do consenso entre a 
pesquisadora e sua orientadora, examinando de maneira criteriosa e precisa a pertinência e relevância das transposições realizadas.

Buscou-se, em seguida, definir as áreas que passariam a ser consideradas D (grande detalhe) e Dd (pequeno detalhe), seguindo os critérios técnicos adotados Pasian (1998), devidamente justificados no referido estudo. As áreas "grande detalhe” (D) foram aquelas interpretadas com frequência maior ou igual a 4\% do total de respostas dada em cada cartão. Por sua vez, os recortes com frequência inferior a 4\% das respostas dadas ao cartão foram considerados "pequeno detalhe" (Dd).

A seguir foi realizada análise da qualidade formal das respostas, relacionadas ao nível de precisão das interpretações $($ bem vistas $=$ código + , mal vistas $=$ código - ou imprecisas $=$ código +- ). Para a decisão sobre a qualidade formal das respostas seguiu-se os mesmos procedimentos adotados por Pasian (1998), Azoulay et al. (2007) e Ikiz et al. (2010), que consideram aspectos estatísticos e qualitativos. Do ponto de vista estatístico, uma resposta de boa (positiva) qualidade formal é aquela que atinge, numa área específica do cartão, frequência maior ou igual a $2 \%$ dos indivíduos. No caso da atual amostra normativa, a resposta foi considerada como possuidora de qualidade formal positiva quando atingiu, numa área específica do cartão, pelo menos quatro ocorrências ( $2 \%$ de 168 participantes $=3,36$ ). Quando este índice não foi alcançado, foi considerada a análise qualitativa da resposta, realizada por análise independente de examinadores, que classificaram o nível de adequação formal daquele conteúdo na área interpretada (bem vista $=$ código,+ mal vista $=$ código - ou imprecisa $=$ código +-$)$. Quando não houve correspondência entre a resposta e à área interpretada, ela foi avaliada como sendo de má qualidade formal (mal vista) e, quando houve correspondência, boa qualidade formal (bem vista). Recorreu-se às decisões tomadas pelos juízes do estudo, tendo sido considerada a qualidade formal de consenso entre examinadores. Nos casos em que houve 
divergência na classificação da qualidade formal, foi considerada a análise de um terceiro juiz, chegando-se a uma classificação final, em termos formais, para cada resposta.

Para a elaboração do atlas do Rorschach foi ainda necessário identificar as respostas do Rorschach de adultos que atingiram a frequência para serem consideradas como banalidades (Ban). Considerou-se como resposta banal aquele conteúdo que atingiu frequência, numa área específica do cartão, maior ou igual a $16,7 \%$ do total dos adultos avaliados. Em outras palavras, tomou-se o critério para resposta Ban utilizado por Pasian (1998), seguindo diretrizes clássicas da Escola Francesa de Rorschach (Rausch de Traubenberg, 1998), correspondendo a cada resposta ocorrida numa proporção 1/6 da amostra em estudo. Nesse trabalho, portanto, foram consideradas como respostas Ban aquelas que ocorreram no mínimo 28 vezes $(\mathrm{n}=168 ; 1 / 6$ de $168=28)$ numa mesma área específica do cartão.

Por fim, foi necessário recorrer a assessoria digital e gráfica (por profissional qualificado na área) para reproduzir, de forma digital, as áreas interpretadas em cada cartão do Rorschach pelos participantes do estudo, de maneira a representar e ilustrar o conjunto das produções alcançadas com o total dos adultos avaliados. Esse processo foi acompanhando diretamente pela pesquisadora, de maneira que os recortes fossem registrados de forma mais precisa e fidedigna, a fim de preservar as produções originais.

Após esses procedimentos, foi possível elaborar uma listagem didática das áreas interpretadas pelos adultos em cada um dos 10 cartões do Rorschach, com as respectivas respostas, suas frequências de ocorrência na amostra e respectiva qualidade formal. Desse modo, realizou-se a atualização do mapeamento completo dos recortes ao Rorschach realizados pelos participantes de 18 a 65 anos, registrando os conteúdos interpretados e sua precisão formal, constituindo atlas atualizado para esse método projetivo de avaliação psicológica, na realidade do Brasil. 


\section{RESULTADOS}

Frente aos objetivos delineados para o presente trabalho, composto por dois estudos, considerou-se adequado apresentar e sistematizar seus resultados a partir de tópicos específicos. Essa estratégia tem por finalidade oferecer clareza aos achados, para sua posterior discussão no momento oportuno. Desse modo, iniciar-se-á pelos aspectos comuns aos dois estudos (indicadores de precisão do Rorschach), seguidos pelos resultados específicos de cada um dos estudos realizados.

\subsection{RELATIVOS À PRECISÃO DO MÉTODO DE RORSCHACH}

Diante dos procedimentos utilizados, os valores médios de acordo entre examinadores (independente e às cegas) obtidos pela análise do coeficiente Kappa no Estudo 1, para as quatro principais categorias de classificação das respostas ao Método de Rorschach (Escola Francesa) foram: (a) Localização =0,88; (b) Determinantes =0,78; (c) Conteúdos $=0,88$; (d) Banalidades $=0,88$. No Estudo 2, esses valores atingiram índices ainda mais altos, possivelmente por ter englobado maior número de respostas na análise, lembrando que aqui uma nova categoria foi incluída, relativa à qualidade formal das respostas. Os valores médios de Kappa foram: (a) Localização $=0,92$; (b) Determinantes $=0,85 ;$ (c) Qualidade formal $=0,72 ;$ (d) Conteúdos $=0,88 ;(\mathrm{e})$ Banalidades $=0,90$.

Fleiss e Cohen (1973) e Cicchetti (1994) oferecem diretrizes de interpretação para o coeficiente Kappa. Segundo esses pesquisadores, valores de Kappa maiores que 0,74 representam nível excelente de concordância, valores abaixo de 0,40 representam concordância pobre, os valores situados entre 0,40 e 0,59 representam concordância 
regular e aqueles situados entre 0,60 e 0,74 são considerados como boa concordância. Desta forma, pode-se considerar que os valores de Kappa alcançados nos dois estudos do presente trabalho representam excelente concordância entre examinadores independentes. Esses dados atestam, portanto, evidências empíricas de bons índices de precisão para a Escola Francesa do Rorschach, fortalecendo seus achados com adultos no Brasil.

\subsection{RELATIVOS ao ESTUDO 1}

\subsubsection{Perfil geral dos adultos no Rorschach}

Inicialmente será apresentado o perfil geral dos resultados nas principais variáveis da Escola Francesa do Método de Rorschach, elaborado a partir do grupo de 88 participantes examinados no Estudo 1. Em seguida, será apresentada a análise comparativa dos atuais achados em relação a sua primeira avaliação psicológica realizada por Pasian (1998), cujo banco de dados foi selecionado para esse estudo em específico (comparação dos dois momentos avaliativos dos mesmos indivíduos, após longo intervalo de tempo).Como já citado, foram comparadas as seguintes variáveis do Método de Rorschach (Escola Francesa): índices de produtividade (número de respostas, respostas adicionais, recusas e denegações), determinantes (forma, cor, movimento e sombreado), conteúdos (animais e humanos, além de outros mais frequentes no grupo) e banalidades (respostas ban).

Procurou-se seguir uma análise sequencial desses resultados a partir das funções psíquicas que representam, conforme proposta da Escola Francesa do Rorschach (Rausch de Traubenberg, 1998): (a) produtividade e ritmo; (b) funcionamento lógico; (c) afetividade, controle de impulsos e adaptação social. A Tabela 13 apresenta os resultados 
relativos a produtividade e ritmo de trabalho no Rorschach dos 88 adultos reavaliados que compõem a amostra do Estudo 1.

$\underline{\text { Tabela } 13}$ - Estatística descritiva da produtividade e ritmo no Rorschach da amostra do Estudo $1(n=88)$.

\begin{tabular}{|c|c|c|c|c|c|}
\hline Variável* & Média & Desvio Padrão & Mínimo & Mediana & Máximo \\
\hline $\mathrm{R}$ & 18,2 & 11,6 & 6 & 14,5 & 88 \\
\hline RA & 1,2 & 1,8 & 0 & 0 & 11 \\
\hline Rec & 0,3 & 0,7 & 0 & 0 & 4 \\
\hline Den & 0,1 & 0,4 & 0 & 0 & 2 \\
\hline TLm & 19,6 & 11,1 & 7 & 16,7 & 73 \\
\hline $\mathrm{TRm}$ & 36,6 & 16,3 & 11 & 31,5 & 90 \\
\hline
\end{tabular}

A análise dos dados relativos à produtividade do Rorschach demonstra que os adultos avaliados apresentaram adequado número médio de respostas $(\mathrm{R}=18,2)$. Ao considerar o tempo médio de latência (TLm $=19,6$ segundos $)$ e o tempo médio de resposta $(\mathrm{TRm}=36,6$ segundos $)$, depreende-se bons indicadores relativos à capacidade associativo-interpretativa da realidade, sobretudo ao se notar que respostas adicionais, recusas e denegações ocorreram em baixa frequência.

A Tabela 14 apresenta os resultados relativos aos modos de apreensão no Rorschach dos 88 adultos reavaliados que compõem a amostra do Estudo 1. 
$\underline{\text { Tabela } 14}$ - Estatística descritiva (em porcentagem) dos modos de apreensão no Rorschach da amostra do Estudo $1(n=88)$.

\begin{tabular}{|c|c|c|c|c|c|}
\hline Variável* & Média & Desvio Padrão & Mínimo & Mediana & Máximo \\
\hline $\mathrm{G}$ & 51,7 & 24,5 & 6 & 53,7 & 100 \\
\hline $\mathrm{D}$ & 31,1 & 16,2 & 0 & 33,3 & 71 \\
\hline $\mathrm{Dd}$ & 16,5 & 15,4 & 0 & 14,3 & 74 \\
\hline Dbl & 0,72 & 2 & 0 & 0 & 11 \\
\hline Do & 0 & - & 0 & 0 & 0 \\
\hline
\end{tabular}

$\mathrm{Na}$ reavaliação, os adultos apresentaram número médio de respostas globais predominante em relação às demais $(\mathrm{G}=51,7)$, seguido pelos modos de apreensão grande Detalhe $(31,1)$. Também apresentaram respostas do tipo pequeno detalhe $(\mathrm{Dd}=16,5)$, poucas respostas detalhe branco $(\mathrm{Dbl}=0,72)$ e ausência de respostas do tipo detalhe oligrofênico $(\mathrm{Do}=0)$. Grande parte dos adultos apresentou uma captação dos aspectos mais gerais da realidade, com preservação de aspectos práticos e também atenção às minúcias, dados que já estavam presentes na avaliação de Pasian (1998).

Em relação às demais variáveis da Escola Francesa do Rorschach, a Tabela 15 apresenta a estatística descritiva relativa aos determinantes, conteúdos e banalidades dos 88 adultos reavaliados no presente trabalho.

$\underline{\text { Tabela } 15}$ - Estatística descritiva (em porcentagem) dos determinantes, conteúdos e banalidades no Rorschach da amostra do Estudo $1(n=88)$. 


\begin{tabular}{|c|c|c|c|c|c|}
\hline Variável* & Média & Desvio Padrão & Mínimo & Mediana & Máximo \\
\hline $\mathrm{F}+$ & 18,6 & 11,3 & 0 & 17,2 & 50 \\
\hline $\mathrm{F}+-$ & 0,49 & 1,73 & 0 & 0 & 9,1 \\
\hline F- & 11,7 & 11,2 & 0 & 9,1 & 50 \\
\hline $\mathrm{F} \%$ & 32,1 & 17,6 & 0 & 29,4 & 79 \\
\hline $\mathrm{F}+\%$ & 61,8 & 28,4 & 0 & 60 & 100 \\
\hline $\mathrm{F}+\mathrm{ext} \%$ & 71,6 & 14,5 & 37 & 72,2 & 100 \\
\hline $\mathrm{FC}$ & 11,2 & 8,1 & 0 & 10,1 & 38 \\
\hline $\mathrm{CF}$ & 8,6 & 7,6 & 0 & 8,2 & 26 \\
\hline $\mathrm{C}$ & 0,9 & 2,4 & 0 & 0 & 10 \\
\hline FE & 9,8 & 7,3 & 0 & 9,3 & 33 \\
\hline $\mathrm{EF}$ & 4,9 & 5,8 & 0 & 4,25 & 25 \\
\hline $\mathrm{E}$ & 0 & - & - & - & - \\
\hline FClob & 0,3 & 1,55 & 0 & 0 & 11,1 \\
\hline ClobF & 0.16 & 1,07 & 0 & 0 & 8,3 \\
\hline Clob & 0 & - & - & - & - \\
\hline K & 10,1 & 7,2 & 0 & 9,84 & 25 \\
\hline kan & 21,3 & 13,7 & 0 & 18,7 & 67 \\
\hline kob & 0,7 & 2,1 & 0 & 0 & 10 \\
\hline $\mathrm{kp}$ & 0,8 & 2,2 & 0 & 0 & 10 \\
\hline A & 40,6 & 16,5 & 15 & 38,5 & 100 \\
\hline (A) & 4 & 5,7 & 0 & 0 & 30,8 \\
\hline $\mathrm{Ad}$ & 3,2 & 4,4 & 0 & 0 & 19,4 \\
\hline (Ad) & 2,7 & 4,2 & 0 & 0 & 20 \\
\hline$\sum \mathrm{A}$ & 50,6 & 15,3 & 15 & 52,1 & 100 \\
\hline
\end{tabular}




\begin{tabular}{|c|c|c|c|c|c|}
\hline Variável* & Média & Desvio Padrão & Mínimo & Mediana & Máximo \\
\hline $\mathrm{H}$ & 12 & 7,89 & 0 & 10 & 33,3 \\
\hline$(\mathrm{H})$ & 3,8 & 4,96 & 0 & 0 & 20 \\
\hline $\mathrm{Hd}$ & 4 & 5,26 & 0 & 0 & 20,7 \\
\hline$(\mathrm{Hd})$ & 0,40 & 1,52 & 0 & 0 & 9,1 \\
\hline$\sum \mathrm{H}$ & 20,3 & 11,8 & 0 & 18,2 & 55 \\
\hline Anat & 8,4 & 10,6 & 0 & 5,56 & 50 \\
\hline $\mathrm{Sg}$ & 0,03 & 0,34 & 0 & 0 & 3,2 \\
\hline Sex & 2,5 & 6,3 & 0 & 0 & 36,8 \\
\hline Obj & 8 & 7,5 & 0 & 7,27 & 30 \\
\hline Art & 1,07 & 2,91 & 0 & 0 & 13,3 \\
\hline Arq & 0,6 & 1,92 & 0 & 0 & 10 \\
\hline Simb & 1,17 & 3,03 & 0 & 0 & 15,4 \\
\hline Abst & 0,62 & 2 & 0 & 0 & 9,1 \\
\hline Bot & 4 & 6,9 & 0 & 0 & 38 \\
\hline Geo & 1,31 & 2,8 & 0 & 0 & 10,5 \\
\hline Nat & 0,11 & 0,9 & 0 & 0 & 8,3 \\
\hline Pais & 0,35 & 2 & 0 & 0 & 16,7 \\
\hline Elem & 0,07 & 0,60 & 0 & 0 & 5,6 \\
\hline Frag & 1,24 & 3,12 & 0 & 0 & 15,4 \\
\hline Ban & 31,7 & 14,9 & 7 & 31 & 83 \\
\hline
\end{tabular}

Em relação os determinantes, os adultos reavaliados captaram os estímulos de diversas maneiras, sendo que a somatória dos determinantes cinestésicos foi de $33 \%$ $(\mathrm{K}+\mathrm{kan}+\mathrm{kob}+\mathrm{kp})$, seguido pelos determinantes relacionados exclusivamente à forma $(\mathrm{F} \%$ $=32,1)$. Os relacionados à cor também apareceram em frequência considerável $=20,7 \%$ $(\mathrm{FC}+\mathrm{CF}+\mathrm{C})$, bem como, determinantes estompage $(\mathrm{FE}+\mathrm{EF})=14,7 \%$. Desta forma, 
percebe-se utilização de diferentes recursos internos dos adultos na reavaliação, preservando um modo já característico presente na amostra normativa de Pasian (1998)

Dentre os conteúdos, houve presença majoritária de A\% $(50,6)$, seguido pelos conteúdos humanos H\% (20,3). Outros conteúdos também estiveram presentes, sendo interessante destacar os mais frequentes: conteúdos de caráter Anatômico $(8,4 \%)$, Objeto (8\%), Botânico (4\%) e Sexual (2,5\%). A frequência de respostas banais foi de $31,7 \%$. Mais uma vez, observa-se semelhança com o padrão normativo alcançado nos dados de Pasian de 1998.

Em sequência à apresentação do perfil geral dos resultados dos 88 indivíduos reavaliados neste estudo, será realizada a análise inferencial do possível efeito das variáveis demográficas (sexo, escolaridade e idade) sobre os resultados do Estudo 1. Esse exame tem por objetivo clarear, a partir dessa segunda avaliação psicológica realizada com esse grupo de indivíduos, o quanto esses dados demográficos podem ser relevantes em processos de avaliação psicológica, conforme exposto a seguir.

\subsubsection{Análise da influência do sexo no Rorschach}

Com base no princípio de que o Método de Rorschach examina características de personalidade, pensou-se na possibilidade de se verificar eventuais especificidades de produção diante desse método projetivo em função do sexo do respondente. Os resultados no Rorschach dos 88 indivíduos avaliados no presente momento foram tomados com a perspectiva de comparação dos dados de 53 mulheres e 35 homens nas principais variáveis técnicas da Escola Francesa.

Inicialmente são apresentados os resultados descritivos (média, desvio padrão e mediana) relativos à produtividade e ritmo no Método de Rorschach, comparando-se 
esses dados médios em função do sexo (grupo masculino $\mathrm{X}$ grupo feminino). Para a comparação estatística recorreu-se ao Teste $t$ de Student para amostras independentes $(p \leq 0,05)$. Esses dados compõem a Tabela 16 .

$\underline{\text { Tabela } 16}$ - Resultados descritivos e comparação estatística nos índices de produtividade e ritmo do Rorschach dos adultos presentemente avaliados $(n=88)$ em função do sexo.

\begin{tabular}{|c|c|c|c|c|c|c|}
\hline \multirow{2}{*}{$\begin{array}{l}\text { Variáveis } \\
\text { Rorschach }\end{array}$} & \multirow[b]{2}{*}{ Sexo } & \multicolumn{3}{|c|}{ Dados descritivos } & \multicolumn{2}{|c|}{ Comparação estatística } \\
\hline & & Média & $\mathrm{DP}$ & Mediana & $\mathrm{t}$ & $p$-value \\
\hline \multirow[t]{2}{*}{$\mathrm{R}$} & Feminino & 18,2 & 12,9 & 14,0 & 0,37 & 0,97 \\
\hline & Masculino & 18,1 & 9,6 & 15,0 & & \\
\hline \multirow[t]{2}{*}{ RA } & Feminino & 1,2 & 1,5 & 1,0 & 0,60 & 0,54 \\
\hline & Masculino & 1,0 & 2,3 & 0 & & \\
\hline \multirow[t]{2}{*}{ Rec } & Feminino & 0,4 & 0,9 & 0 & 1,45 & 0,14 \\
\hline & Masculino & 0,2 & 0,5 & 0 & & \\
\hline \multirow[t]{2}{*}{ Den } & Feminino & 0,1 & 0,4 & 0 & 0,60 & 0,55 \\
\hline & Masculino & 0,1 & 0,3 & 0 & & \\
\hline \multirow{2}{*}{ TLm } & Feminino & 19,6 & 12,0 & 16,3 & 0,12 & 0,89 \\
\hline & Masculino & 19,3 & 9,6 & 17,6 & & \\
\hline \multirow{2}{*}{$\mathrm{TRm}$} & Feminino & 37,0 & 17,4 & 30,3 & 0,34 & 0,73 \\
\hline & Masculino & 35,1 & 14,4 & 32,9 & & \\
\hline
\end{tabular}

$R=$ número total de respostas; $R A=$ número de respostas adicionais; $R e c=$ número de recusas; Den $=$ número de respostas negadas durante o inquérito;TLm = tempo de latência médio (em segundos); TRm = tempo de reação médio (em segundos).

Em relação aos índices de produtividade e ritmo não foram observadas diferenças estatisticamente significativas entre mulheres e homens na avaliação psicológica presentemente realizada com o conjunto dos 88 adultos. Isso aponta para similaridade no potencial de responder a uma tarefa de interpretação de manchas fortuitas e no padrão lógico-associativo desses indivíduos, independentemente de seu sexo.

O exame mais detalhado de possíveis padrões específicos de resposta ao Método de Rorschach pode ser visualizado na Tabela 17. Ela traz resultados descritivos e 
analíticos, em função do sexo dos adultos, no tocante às variáveis relacionadas aos modos de apreensão, aos determinantes e aos conteúdos produzidos diante desse método projetivo de avaliação psicológica. Todos os dados estão apresentados em porcentagem (em função do total de respostas em cada caso).

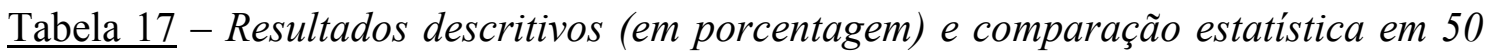
variáveis do Rorschach relacionadas aos modos de apreensão, determinantes, conteúdos e banalidades dos adultos presentemente avaliados $(n=88)$ em função do sexo.

\begin{tabular}{|c|c|c|c|c|c|c|}
\hline \multirow[t]{2}{*}{$\begin{array}{l}\text { Variáveis } \\
\text { Rorschach }\end{array}$} & \multirow[t]{2}{*}{ Sexo } & \multicolumn{3}{|c|}{ Dados descritivos } & \multicolumn{2}{|c|}{$\begin{array}{l}\text { Comparação } \\
\text { Estatística }\end{array}$} \\
\hline & & Média & DP & Mediana & $t$ & $p$-value \\
\hline \multirow[t]{2}{*}{$\mathrm{G}$} & Feminino & 47,7 & 24,2 & 50,0 & 1,70 & 0,92 \\
\hline & Masculino & 56,9 & 25,3 & 63,6 & & \\
\hline \multirow[t]{2}{*}{$\mathrm{D}$} & Feminino & 34,3 & 15,3 & 33,3 & $-1,89$ & 0,62 \\
\hline & Masculino & 27,8 & 16,5 & 22,5 & & \\
\hline \multirow[t]{2}{*}{$\mathrm{Dd}$} & Feminino & 17,0 & 16,1 & 15,3 & $-0,79$ & 0,42 \\
\hline & Masculino & 14,4 & 13,7 & 13,3 & & \\
\hline \multirow[t]{2}{*}{ Dbl } & Feminino & 0,8 & 2,3 & 0 & 0,89 & 0,92 \\
\hline & Masculino & 0,8 & 1,8 & 0 & & \\
\hline \multirow[t]{2}{*}{ Do } & Feminino & - & - & - & - & - \\
\hline & Masculino & & & & & \\
\hline \multirow[t]{2}{*}{$\mathbf{F}+$} & Feminino & 16,9 & 10,9 & 17,0 & 2,08 & $\mathbf{0 , 0 4}$ \\
\hline & Masculino & 22,0 & 11,5 & 23,0 & & \\
\hline \multirow[t]{2}{*}{$\mathrm{F}+-$} & Feminino & 0,5 & 1,7 & 0 & $-0,79$ & 0,42 \\
\hline & Masculino & 0,6 & 2,1 & 0 & & \\
\hline \multirow[t]{2}{*}{ F- } & Feminino & 11,1 & 10,9 & 9,0 & 0,66 & 0,51 \\
\hline & Masculino & 12,7 & 11,7 & 10,0 & & \\
\hline \multirow[t]{2}{*}{$\mathrm{F} \%$} & Feminino & 27,9 & 16,7 & 24,1 & 1,96 & 0,53 \\
\hline & Masculino & 35,2 & 17,0 & 33,3 & & \\
\hline \multirow{2}{*}{$\begin{array}{l}\text { Variáveis } \\
\text { Rorschach }\end{array}$} & Sexo & Dados & Comparação & Variáveis & & Dados \\
\hline & & descritivos & Estatística & Rorschach & & descritivos \\
\hline \multirow[t]{2}{*}{$\mathrm{F}+\%$} & Feminino & 59,5 & 30,8 & 60,0 & 1,08 & 0,28 \\
\hline & Masculino & 66,5 & 27,4 & 66,6 & & \\
\hline \multirow[t]{2}{*}{$\mathrm{F}+\mathrm{ext} \%$} & Feminino & 71,0 & 15,4 & 72,7 & 0,40 & 0,69 \\
\hline & Masculino & 72,3 & 14,3 & 70,0 & & \\
\hline
\end{tabular}




\begin{tabular}{|c|c|c|c|c|c|c|}
\hline $\mathrm{K}$ & $\begin{array}{l}\text { Feminino } \\
\text { Masculino }\end{array}$ & $\begin{array}{l}9,2 \\
9,6\end{array}$ & $\begin{array}{l}6,4 \\
8,7\end{array}$ & $\begin{array}{l}9,0 \\
8,0\end{array}$ & 0,30 & 0,76 \\
\hline kan & $\begin{array}{l}\text { Feminino } \\
\text { Masculino }\end{array}$ & $\begin{array}{l}22,7 \\
19,4\end{array}$ & $\begin{array}{l}14,0 \\
13,3\end{array}$ & $\begin{array}{l}19,0 \\
18,0\end{array}$ & $-1,11$ & 0,26 \\
\hline kob & $\begin{array}{l}\text { Feminino } \\
\text { Masculino }\end{array}$ & $\begin{array}{l}0,8 \\
0,7\end{array}$ & $\begin{array}{l}2,5 \\
2,2\end{array}$ & $\begin{array}{l}0 \\
0\end{array}$ & $-0,11$ & 0,90 \\
\hline $\mathrm{Kp}$ & $\begin{array}{l}\text { Feminino } \\
\text { Masculino }\end{array}$ & $\begin{array}{l}1,1 \\
0,4\end{array}$ & $\begin{array}{l}2,6 \\
1,4\end{array}$ & $\begin{array}{l}0 \\
0\end{array}$ & $-1,47$ & 0,14 \\
\hline$\sum \mathrm{k}$ & $\begin{array}{l}\text { Feminino } \\
\text { Masculino }\end{array}$ & $\begin{array}{l}33,6 \\
32,4\end{array}$ & $\begin{array}{l}31,0 \\
30,0\end{array}$ & $\begin{array}{l}14,9 \\
17,5\end{array}$ & 0,35 & 0,73 \\
\hline $\mathrm{FC}$ & $\begin{array}{l}\text { Feminino } \\
\text { Masculino }\end{array}$ & $\begin{array}{l}11,1 \\
10,4\end{array}$ & $\begin{array}{l}8,9 \\
7,7\end{array}$ & $\begin{array}{l}10,0 \\
9,0\end{array}$ & $-0,38$ & 0,70 \\
\hline $\mathrm{CF}$ & $\begin{array}{l}\text { Feminino } \\
\text { Masculino }\end{array}$ & $\begin{array}{l}9,4 \\
7,5\end{array}$ & $\begin{array}{l}7,6 \\
7,7\end{array}$ & $\begin{array}{l}8,0 \\
6,0\end{array}$ & $-1,17$ & 0,24 \\
\hline $\mathrm{C}$ & $\begin{array}{l}\text { Feminino } \\
\text { Masculino }\end{array}$ & $\begin{array}{l}0,8 \\
1,0\end{array}$ & $\begin{array}{l}2,4 \\
2,6\end{array}$ & $\begin{array}{l}0 \\
0\end{array}$ & 0,38 & 0,70 \\
\hline $\mathrm{FE}$ & $\begin{array}{l}\text { Feminino } \\
\text { Masculino }\end{array}$ & $\begin{array}{l}10,2 \\
9,4\end{array}$ & $\begin{array}{l}7,6 \\
6,8\end{array}$ & $\begin{array}{c}9,0 \\
10,0\end{array}$ & $-0,51$ & 0,60 \\
\hline $\mathrm{EF}$ & $\begin{array}{l}\text { Feminino } \\
\text { Masculino }\end{array}$ & $\begin{array}{l}5,8 \\
3,6\end{array}$ & $\begin{array}{l}6,5 \\
4,0\end{array}$ & $\begin{array}{l}5,0 \\
0,0\end{array}$ & $-1,76$ & 0,82 \\
\hline $\mathrm{E}$ & $\begin{array}{l}\text { Feminino } \\
\text { Masculino }\end{array}$ & $\begin{array}{l}0 \\
0\end{array}$ & $\begin{array}{l}0 \\
0\end{array}$ & $\begin{array}{l}0 \\
0\end{array}$ & - & - \\
\hline FClob & $\begin{array}{l}\text { Feminino } \\
\text { Masculino }\end{array}$ & $\begin{array}{c}0,5 \\
0\end{array}$ & $\begin{array}{c}1,9 \\
0\end{array}$ & $\begin{array}{l}0 \\
0\end{array}$ & $-1,47$ & 0,14 \\
\hline ClobF & $\begin{array}{l}\text { Feminino } \\
\text { Masculino }\end{array}$ & $\begin{array}{l}0 \\
0\end{array}$ & $\begin{array}{l}0 \\
0\end{array}$ & $\begin{array}{l}0 \\
0\end{array}$ & 1,75 & 0,83 \\
\hline Clob & $\begin{array}{l}\text { Feminino } \\
\text { Masculino }\end{array}$ & $\begin{array}{l}0 \\
0\end{array}$ & $\begin{array}{l}0 \\
0\end{array}$ & $\begin{array}{l}0 \\
0\end{array}$ & - & - \\
\hline A & $\begin{array}{l}\text { Feminino } \\
\text { Masculino }\end{array}$ & $\begin{array}{l}42,3 \\
37,8\end{array}$ & $\begin{array}{l}16,0 \\
16,9\end{array}$ & $\begin{array}{l}41,0 \\
33,0\end{array}$ & $-1,26$ & 0,21 \\
\hline $\begin{array}{l}\text { Variáveis } \\
\text { Rorschach }\end{array}$ & Sexo & $\begin{array}{c}\text { Dados } \\
\text { descritivos }\end{array}$ & $\begin{array}{c}\text { Comparação } \\
\text { Estatística }\end{array}$ & $\begin{array}{c}\text { Variáveis } \\
\text { Rorschach }\end{array}$ & & $\begin{array}{c}\text { Dados } \\
\text { descritivos }\end{array}$ \\
\hline (A) & $\begin{array}{l}\text { Feminino } \\
\text { Masculino }\end{array}$ & $\begin{array}{l}3,8 \\
4,2\end{array}$ & $\begin{array}{l}6,1 \\
5,4\end{array}$ & $\begin{array}{l}0 \\
0\end{array}$ & 0,33 & 0,73 \\
\hline $\mathrm{Ad}$ & Feminino & 3,8 & 2,5 & 0 & 1,72 & 0,88 \\
\hline
\end{tabular}




\begin{tabular}{|c|c|c|c|c|c|c|}
\hline & Masculino & 4,2 & 5,1 & 3,0 & & \\
\hline \multirow[t]{2}{*}{ (Ad) } & Feminino & 2,5 & 3,3 & 0 & \multirow[t]{2}{*}{2,91} & \multirow[t]{2}{*}{0,005} \\
\hline & Masculino & 4,2 & 5,0 & 3,0 & & \\
\hline \multirow[t]{2}{*}{$\sum \mathrm{A}$} & Feminino & 50,4 & 50,0 & 14,9 & \multirow[t]{2}{*}{,- 078} & \multirow[t]{2}{*}{0,938} \\
\hline & Masculino & 50,7 & 53,3 & 16,2 & & \\
\hline \multirow[t]{2}{*}{$\mathrm{H}$} & Feminino & 10,9 & 8,2 & 9,0 & \multirow[t]{2}{*}{0,71} & \multirow[t]{2}{*}{0,47} \\
\hline & Masculino & 12,6 & 8,4 & 12,0 & & \\
\hline \multirow[t]{2}{*}{$(\mathrm{H})$} & Feminino & 3,6 & 5,2 & 0 & \multirow[t]{2}{*}{$-0,50$} & \multirow[t]{2}{*}{0,61} \\
\hline & Masculino & 4,1 & 4,7 & 4,0 & & \\
\hline \multirow[t]{2}{*}{$\mathrm{Hd}$} & Feminino & 3,7 & 5,6 & 0 & \multirow[t]{2}{*}{0,42} & \multirow[t]{2}{*}{0,67} \\
\hline & Masculino & 4,3 & 4,8 & 3,0 & & \\
\hline \multirow{2}{*}{$(\mathrm{Hd})$} & Feminino & 0,5 & 1,7 & 0 & \multirow[t]{2}{*}{$-0,50$} & \multirow[t]{2}{*}{0,61} \\
\hline & Masculino & 0,3 & 1,2 & 0 & & \\
\hline \multirow{2}{*}{$\sum \mathrm{H}$} & Feminino & 19,2 & 16,7 & 11,1 & & \multirow[t]{2}{*}{0,426} \\
\hline & Masculino & 21,3 & 21,4 & 12,2 & 0,799 & \\
\hline \multirow[t]{2}{*}{ Anat } & Feminino & 8,1 & 10,9 & 5,0 & \multirow[t]{2}{*}{0,43} & \multirow[t]{2}{*}{0,96} \\
\hline & Masculino & 8,2 & 9,8 & 5,5 & & \\
\hline \multirow[t]{2}{*}{$\mathrm{Sg}$} & Feminino & 0,6 & 0,4 & 0 & \multirow[t]{2}{*}{$-0,81$} & \multirow[t]{2}{*}{0,42} \\
\hline & Masculino & 0 & 0 & 0 & & \\
\hline \multirow[t]{2}{*}{ Sex } & Feminino & 2,9 & 7,6 & 0 & \multirow[t]{2}{*}{$-0,66$} & \multirow[t]{2}{*}{0,51} \\
\hline & Masculino & 2,0 & 3,6 & 0 & & \\
\hline \multirow[t]{2}{*}{ Obj } & Feminino & 8,3 & 7,5 & 7,4 & \multirow[t]{2}{*}{$-0,71$} & 0,47 \\
\hline & Masculino & 7,2 & 6,7 & 7,1 & & \\
\hline Art & Feminino & 1,1 & 3,0 & 0 & 0,17 & 0,98 \\
\hline & Masculino & 1,2 & 3,3 & 0 & & \\
\hline Arq & Feminino & 0,6 & 2,9 & 0 & 0,81 & 0,93 \\
\hline & Masculino & 0,6 & 1,8 & 0 & & \\
\hline Simb & Feminino & 1,4 & 3,4 & 0 & $-1,54$ & 0,12 \\
\hline & Masculino & 0,5 & 1,2 & 0 & & \\
\hline
\end{tabular}

\begin{tabular}{ccccccc}
\hline $\begin{array}{c}\text { Variáveis } \\
\text { Rorschach }\end{array}$ & Sexo & $\begin{array}{c}\text { Dados } \\
\text { descritivos }\end{array}$ & $\begin{array}{c}\text { Comparação } \\
\text { Estatística }\end{array}$ & $\begin{array}{c}\text { Variáveis } \\
\text { Rorschach }\end{array}$ & $\begin{array}{c}\text { Dados } \\
\text { descritivos }\end{array}$ \\
\hline Bot & Feminino & 4,2 & 7,4 & 0 & $-0,14$ & 0,88 \\
& Masculino & 4,0 & 6,5 & 0 & & \\
Geo & $\begin{array}{c}\text { Feminino } \\
\text { Masculino }\end{array}$ & 1,2 & 2,5 & 0 & 0,49 & 0,62 \\
& 1,5 & 3,2 & 0 & &
\end{tabular}




\begin{tabular}{ccccccc} 
Nat & Feminino & 0,03 & 0,3 & 0 & 1,02 & 0,30 \\
& Masculino & 0,2 & 1,4 & 0 & & \\
\multirow{2}{*}{ Pais } & Feminino & 0,2 & 1,2 & 0 & 0,80 & 0,422 \\
& Masculino & 0,6 & 2,8 & 0 & & \\
\multirow{2}{*}{ Elem } & Feminino & 0,1 & 0,8 & 0 & $-0,96$ & 0,34 \\
& Masculino & 0 & 0 & 0 & & \\
\multirow{2}{*}{ Frag } & Feminino & 1,5 & 3,6 & 0 & $-0,76$ & 0,44 \\
& Masculino & 0,9 & 2,3 & 0 & & \\
\multirow{2}{*}{ Ban } & Feminino & 33,0 & 15,1 & 33,3 & $-1,10$ & 0,27 \\
& Masculino & 29,4 & 14,7 & 30,0 & & \\
\hline
\end{tabular}

$\mathrm{Na}$ presente avaliação, observa-se que para apenas duas variáveis houve diferenças estatisticamente significativas entre os grupos feminino e masculino, a saber: em relação ao determinante $\mathrm{F}+$ e ao conteúdo $(\mathrm{Ad})$, sendo que os homens apresentaram maior frequência de respostas nessas variáveis. Contudo, estas diferenças devem ser cuidadosamente ponderadas frente ao conjunto dos dados. Em relação a maior frequência de $\mathrm{F}+$, poder-se-ia inferir sinal de maior precisão perceptiva para os homens em relação às mulheres. Contudo, na proporção de $\mathrm{F}+\%$ essa diferença não se manteve, enfraquecendo o próprio achado anterior. Em relação ao conteúdo Ad, a diferença estatisticamente significativa identificada entre grupo masculino e feminino também deve ser relativizada, visto sua baixa frequência no conjunto total das respostas, sobretudo porque, na somatória de respostas de conteúdos animais não houve diferenças estatisticamente significativas entres os grupos.

Ao se considerar o conjunto das 56 variáveis da Escola Francesa do Rorschach aqui analisadas, pode-se verificar que o padrão de respostas dos adultos foi bastante semelhante, diferindo apenas em algumas particularidades em função do sexo. Esses achados sugerem reduzida influência dessa variável demográfica nos processos de avaliação de características de personalidade em adultos. 


\subsubsection{Análise da influência da escolaridade no Rorschach}

Para verificar possível interferência do grau de escolaridade nas variáveis examinadas pela Escola Francesa do Rorschach utilizou-se a mesma estratégia técnica anteriormente proposta para comparação dos resultados médios dos adultos. Foram estatisticamente comparados os dados em 56 variáveis do Rorschach dos adultos, agora subdivididos em dois grupos, a saber: grupo 1 com os indivíduos de baixo (zero a dois anos de estudo) e médio (três a oito anos de estudo) nível de escolaridade $(n=21)$; grupo 2, composto pelos adultos com alto nível de escolaridade (nove ou mais anos de estudo) $(\mathrm{n}=67)$. Optou-se por unir os dados dos adultos de baixo e médio nível de escolaridade tendo em vista o pequeno número de adultos com até dois anos de estudo ( $\mathrm{n}=4)$.

Os dados estão sistematizados inicialmente em função da produtividade e ritmo no Rorschach. A Tabela 18 apresenta esses achados.

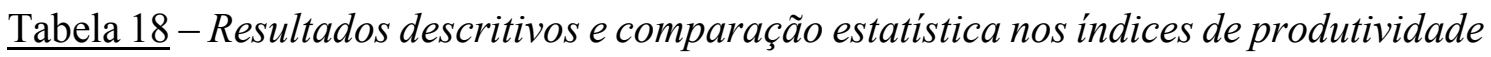
e ritmo do Rorschach dos adultos presentemente avaliados $(n=88)$ em função dos níveis de escolaridade.

\begin{tabular}{ccccccc}
\hline $\begin{array}{c}\text { Variáveis } \\
\text { Rorschach }\end{array}$ & Escolaridade & \multicolumn{3}{c}{ Dados descritivos } & \multicolumn{2}{c}{ Comparação Estatística } \\
& & Média & DP & Mediana & $t$ & $p$-value \\
\hline $\mathrm{R}$ & Baixa/Média & 15,2 & 7,3 & 13,0 & $-1,351$ & 0,18 \\
& Alta & 19,1 & 12,5 & 15,0 & & \\
& & & & & & 0,60 \\
RA & Baixa/Média & 1,3 & 1,3 & 1,0 & 0,525 & \\
& Alta & 1,1 & 1,9 & 0 & & \\
& & & & & & \\
\hline
\end{tabular}

\begin{tabular}{ccccccc}
\hline $\begin{array}{c}\text { Variáveis } \\
\text { Rorschach }\end{array}$ & Escolaridade & \multicolumn{2}{c}{ Dados descritivos } & \multicolumn{3}{c}{ Comparação Estatística } \\
& & Média & DP & Mediana & $t$ & $p$-value \\
\hline Rec & Baixa/Média & 0,6 & 1,2 & 0 & 2,005 & $\mathbf{0 , 0 4 8}$ \\
& Alta & 0,2 & 0,5 & 0 & &
\end{tabular}




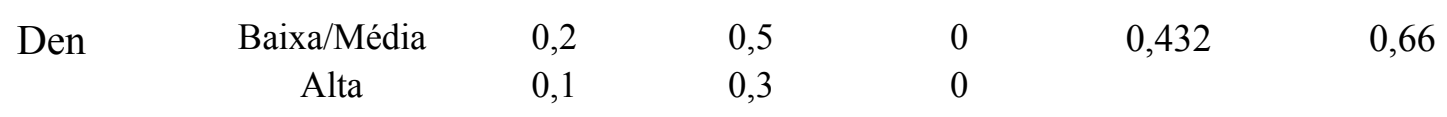

$\begin{array}{llllll}\text { TLm Baixa/Média } & 25,4 & 15,6 & 25,4 & 2,894 & \mathbf{0 , 0 0 5}\end{array}$

Alta $\quad 17,7 \quad 8,5 \quad 15,3$

$\begin{array}{ccccccc}\text { TRm } \quad \text { Baixa/Média } & 45,2 & 21,5 & 41,6 & 2,938 & \mathbf{0 , 0 0 4}\end{array}$

$\mathrm{R}=$ número total de respostas; $\mathrm{RA}=$ número de respostas adicionais; Rec $=$ número de recusas; Den $=$ número de respostas negadas durante o inquérito;TLm = tempo de latência médio (em segundos); TRm = tempo de reação médio (em segundos).

Em relação aos anos de estudo, encontrou-se significativo maior número de recusas entre os adultos com baixa/média escolaridade quando comparados com o grupo de alta escolaridade. Cabe destacar, no entanto, que esse índice de recusas aos cartões do Rorschach foi bastante pequeno no grupo como um todo, podendo representar uma diferença estatisticamente significativa, porém espúria, com reduzido significado clínico. Além disso, foram encontradas diferenças estatisticamente significativas entre tempo de latência médio e tempo de reação médio, sendo que o grupo de baixa/média escolaridade apresentou maior tempo médio de latência e maior tempo médio de reação que o grupo de alta escolaridade. Esses achados sugerem que o grupo de alta escolaridade apresentou maior agilidade em seus processos associativos. Apesar de não terem sido encontradas diferenças significativamente estatísticas em relação ao número de respostas, a média de interpretações dos indivíduos de alta escolaridade (18,9 respostas) é maior do que dos adultos de baixa e média escolaridade (15,2 respostas). Pode-se supor, portanto, que há fatores de facilitação no processo lógico-associativo derivados do treino acadêmico, embora aqui não diferenciadores de recursos produtivos nesses indivíduos adultos com diversificadas experiências de vida.

A seguir são sistematizados os achados relativos às variáveis vinculadas a modos de apreensão, determinantes, conteúdos e banalidades do Rorschach, em função do nível 
de escolaridade dos 88 adultos presentemente avaliados. Esses dados compõem a Tabela 19, sendo apresentadas as porcentagens de cada variável técnica examinada.

$\underline{\text { Tabela } 19}$ - Resultados descritivos (em porcentagem) e comparação estatística em variáveis do Rorschach relacionadas aos modos de apreensão, determinantes, conteúdos e banalidades dos adultos presentemente avaliados $(n=88)$ em função da escolaridade.

\begin{tabular}{|c|c|c|c|c|c|c|}
\hline \multirow[t]{2}{*}{$\begin{array}{l}\text { Variáveis } \\
\text { Rorschach }\end{array}$} & \multirow[t]{2}{*}{ Escolaridade } & \multicolumn{3}{|c|}{ Dados descritivos } & \multicolumn{2}{|c|}{$\begin{array}{c}\text { Comparação } \\
\text { Estatística }\end{array}$} \\
\hline & & Média & DP & Mediana & $t$ & $p$-value \\
\hline \multirow[t]{2}{*}{$\mathrm{G}$} & Baixa/média & 43,7 & 22,6 & 41,1 & $-1,628$ & 0,10 \\
\hline & Alta & 53,8 & 25,3 & 57,1 & & \\
\hline \multirow[t]{2}{*}{$\mathrm{D}$} & Baixa/média & 36,0 & 11,8 & 35,2 & 1,400 & 0,16 \\
\hline & Alta & 30,4 & 17,1 & 28,5 & & \\
\hline \multirow[t]{2}{*}{ Dd } & Baixa/média & 19,0 & 17,0 & 18,1 & 1,032 & 0,30 \\
\hline & Alta & 15,1 & 14,6 & 14,2 & & \\
\hline \multirow[t]{2}{*}{ Dbl } & Baixa/média & 1,2 & 3,1 & 0 & 1,016 & 0,31 \\
\hline & Alta & 0,7 & 1,7 & 0 & & \\
\hline \multirow{2}{*}{$\mathrm{F}+$} & Baixa/média & 19,0 & 11,3 & 17,0 & 0,048 & 0,96 \\
\hline & Alta & 19,0 & 11,4 & 18,0 & & \\
\hline \multirow[t]{2}{*}{$\mathrm{F}+-$} & Baixa/média & 0 & 0 & 0 & $-1,552$ & 0,12 \\
\hline & Alta & 0,7 & 2,1 & 0 & & \\
\hline \multirow[t]{2}{*}{ F- } & Baixa/média & 17,1 & 12,7 & 17,0 & 2,636 & 0,010 \\
\hline & Alta & 10,0 & 10,2 & 8,0 & & \\
\hline \multirow[t]{2}{*}{$\mathrm{F} \%$} & Baixa/média & 36,4 & 18,6 & 36,3 & 1,739 & 0,08 \\
\hline & Alta & 29,0 & 16,4 & 27,2 & & \\
\hline \multirow[t]{2}{*}{$\mathbf{F}+\%$} & Baixa/média & 50,9 & 30,4 & 57,1 & $-2,054$ & 0,043 \\
\hline & Alta & 65,9 & 28,6 & 66,6 & & \\
\hline
\end{tabular}

\begin{tabular}{ccccccc}
\hline $\begin{array}{c}\text { Variáveis } \\
\text { do } \\
\text { Rorschach }\end{array}$ & Escolaridade & \multicolumn{2}{c}{ Dados descritivos } & \multicolumn{2}{c}{ Comparação Estatística } \\
& & Média & DP & Mediana & $t$ & $p$-value \\
\hline F+ext\% & Baixa/média & 72,0 & 14,1 & 71,4 & $-0,529$ & 0,59 \\
& Alta & 70,0 & 17,2 & 73,3 & & \\
K & Baixa/média & 6,6 & 6,1 & 6,0 & $-2,630$ & $\mathbf{0 , 0 1 0}$ \\
& Alta & 11,2 & 7,2 & 10,0 & & \\
kan & Baixa/média & 28,1 & 18,4 & 23,0 & 2,727 & $\mathbf{0 , 0 0 8}$
\end{tabular}


$\begin{array}{llll}\text { Alta } & 19,1 & 11,1 & 17,0\end{array}$

\begin{tabular}{|c|c|c|c|c|c|c|}
\hline kob & $\begin{array}{c}\text { Baixa/média } \\
\text { Alta }\end{array}$ & $\begin{array}{l}0,1 \\
1,1\end{array}$ & $\begin{array}{l}0,7 \\
2,9\end{array}$ & $\begin{array}{l}0 \\
0\end{array}$ & $-1,500$ & 0,13 \\
\hline $\mathrm{kp}$ & $\begin{array}{c}\text { Baixa/média } \\
\text { Alta }\end{array}$ & $\begin{array}{l}1,0 \\
0,8\end{array}$ & $\begin{array}{l}2,7 \\
2,0\end{array}$ & $\begin{array}{l}0 \\
0\end{array}$ & 0,464 & 0,64 \\
\hline$\sum \mathrm{k}$ & $\begin{array}{c}\text { Baixa/média } \\
\text { Alta }\end{array}$ & $\begin{array}{l}36,0 \\
32,2\end{array}$ & $\begin{array}{l}21,5 \\
13,8\end{array}$ & $\begin{array}{l}30,0 \\
31,0\end{array}$ & 0,914 & 0,36 \\
\hline FC & $\begin{array}{c}\text { Baixa/média } \\
\text { Alta }\end{array}$ & $\begin{array}{c}8,0 \\
12,2\end{array}$ & $\begin{array}{l}8,3 \\
7,9\end{array}$ & $\begin{array}{c}7,0 \\
11,0\end{array}$ & $-2,093$ & $\mathbf{0 , 0 3 9}$ \\
\hline $\mathrm{CF}$ & $\begin{array}{c}\text { Baixa/média } \\
\text { Alta }\end{array}$ & $\begin{array}{l}6,6 \\
9,1\end{array}$ & $\begin{array}{l}6,9 \\
7,9\end{array}$ & $\begin{array}{l}8,0 \\
8,0\end{array}$ & $-1,314$ & 0,19 \\
\hline $\mathrm{C}$ & $\begin{array}{c}\text { Baixa/média } \\
\text { Alta }\end{array}$ & $\begin{array}{l}0,4 \\
1,0\end{array}$ & $\begin{array}{l}2,0 \\
2,6\end{array}$ & $\begin{array}{l}0 \\
0\end{array}$ & $-0,950$ & 0,34 \\
\hline $\mathrm{FE}$ & $\begin{array}{c}\text { Baixa/média } \\
\text { Alta }\end{array}$ & $\begin{array}{c}8,1 \\
10,4\end{array}$ & $\begin{array}{l}7,9 \\
7,7\end{array}$ & $\begin{array}{c}8,0 \\
10,0\end{array}$ & -1.266 & 0,20 \\
\hline $\mathrm{EF}$ & $\begin{array}{c}\text { Baixa/média } \\
\text { Alta }\end{array}$ & $\begin{array}{l}4,5 \\
5,1\end{array}$ & $\begin{array}{l}6,0 \\
5,8\end{array}$ & $\begin{array}{c}0 \\
5,0\end{array}$ & - & - \\
\hline $\mathrm{E}$ & $\begin{array}{c}\text { Baixa/média } \\
\text { Alta }\end{array}$ & $\begin{array}{l}0 \\
0\end{array}$ & $\begin{array}{l}0 \\
0\end{array}$ & $\begin{array}{l}0 \\
0\end{array}$ & - & - \\
\hline FClob & $\begin{array}{c}\text { Baixa/média } \\
\text { Alta }\end{array}$ & $\begin{array}{c}0 \\
0,4\end{array}$ & $\begin{array}{c}0 \\
1,8\end{array}$ & $\begin{array}{l}0 \\
0\end{array}$ & $-1,008$ & 0,31 \\
\hline ClobF & $\begin{array}{c}\text { Baixa/média } \\
\text { Alta }\end{array}$ & $\begin{array}{c}0 \\
0,2\end{array}$ & $\begin{array}{c}0 \\
1,2\end{array}$ & $\begin{array}{l}0 \\
0\end{array}$ & $-0,786$ & 0,43 \\
\hline Clob & $\begin{array}{l}\text { Baixa/média } \\
\text { Alta }\end{array}$ & $\begin{array}{l}0 \\
0\end{array}$ & $\begin{array}{l}0 \\
0\end{array}$ & $\begin{array}{l}0 \\
0\end{array}$ & - & - \\
\hline $\mathbf{A}$ & $\begin{array}{c}\text { Baixa/média } \\
\text { Alta }\end{array}$ & $\begin{array}{l}55,5 \\
35,9\end{array}$ & $\begin{array}{l}18,2 \\
13,0\end{array}$ & $\begin{array}{l}53,0 \\
35,0\end{array}$ & 5,392 & $\leq \mathbf{0 , 0 0 1}$ \\
\hline (A) & $\begin{array}{c}\text { Baixa/média } \\
\text { Alta }\end{array}$ & $\begin{array}{l}1,7 \\
4,7\end{array}$ & $\begin{array}{l}3,0 \\
6,3\end{array}$ & $\begin{array}{c}0 \\
3,0\end{array}$ & $-2,105$ & 0,038 \\
\hline
\end{tabular}

\begin{tabular}{ccccccc}
\hline $\begin{array}{c}\text { Variáveis } \\
\text { Rorschach }\end{array}$ & Escolaridade & \multicolumn{3}{c}{ Dados descritivos } & \multicolumn{3}{c}{ Comparação Estatística } \\
& & Média & DP & Mediana & $t$ & $p$-value \\
\hline Ad & Baixa/média & 2,4 & 4,3 & 0 & $-0,937$ & 0,351 \\
& Alta & 3,4 & 4,5 & 0 & & \\
& & & & & & \\
$($ Ad) & Baixa/média & 2,0 & 3,7 & 0 & $-0,829$ & 0,40 \\
& Alta & 2,9 & 4,5 & 0 & & \\
$\sum \mathbf{A} \%$ & Baixa/média & 61,6 & 16,3 & 63,0 & 4,112 & $\leq \mathbf{0 , 0 0 1}$ \\
& Alta & 47,0 & 13,4 & 48,0 & &
\end{tabular}




\begin{tabular}{|c|c|c|c|c|c|c|}
\hline $\mathbf{H}$ & $\begin{array}{c}\text { Baixa/média } \\
\text { Alta }\end{array}$ & $\begin{array}{c}8,8 \\
12,9\end{array}$ & $\begin{array}{l}7,7 \\
7,7\end{array}$ & $\begin{array}{l}9,0 \\
11,0\end{array}$ & $-2,119$ & $\mathbf{0 , 0 3 7}$ \\
\hline \multirow[t]{2}{*}{ (H) } & Baixa/média & 0,7 & 1,9 & 0 & $-3,465$ & 0,001 \\
\hline & Alta & 4,7 & 5,2 & 5,0 & & \\
\hline \multirow[t]{2}{*}{$\mathrm{Hd}$} & Baixa/média & 3,9 & 6,4 & 0 & $-0,049$ & 0,96 \\
\hline & Alta & 3,9 & 4,9 & 0 & & \\
\hline \multirow[t]{2}{*}{$(\mathrm{Hd})$} & Baixa/média & 0,6 & 2,0 & 0 & 0,634 & 0,52 \\
\hline & Alta & 0,3 & 1,3 & 0 & & \\
\hline \multirow{2}{*}{$\sum \mathbf{H \%}$} & Baixa/média & 14,0 & 9,8 & 11,4 & $-2,882$ & 0,005 \\
\hline & Alta & 22,0 & 11,4 & 19,2 & & \\
\hline \multirow[t]{2}{*}{ Anat } & Baixa/média & 6,8 & 11,2 & 0 & $-0,963$ & 0,33 \\
\hline & Alta & 9,62 & 11,8 & 6 & & \\
\hline \multirow[t]{2}{*}{$\mathrm{Sg}$} & Baixa/média & 0 & 0 & 0 & $-0,558$ & 0,57 \\
\hline & Alta & 0,01 & 0,1 & 0 & & \\
\hline \multirow[t]{2}{*}{ Sex } & Baixa/média & 4,8 & 10,2 & 0 & 1,648 & 0,10 \\
\hline & Alta & 2,1 & 4,6 & 0 & & \\
\hline \multirow[t]{2}{*}{ Obj } & Baixa/média & 4,4 & 6,9 & 0 & $-2,508$ & 0,014 \\
\hline & Alta & 10,5 & 10,5 & 8,0 & & \\
\hline \multirow[t]{2}{*}{ Art } & Baixa/média & 0,8 & 2,9 & 0 & $-0,706$ & 0,48 \\
\hline & Alta & 1,4 & 3,5 & 0 & & \\
\hline \multirow[t]{2}{*}{ Arq } & Baixa/média & 0,5 & 2,2 & 0 & $-0,741$ & 0,46 \\
\hline & Alta & 0,9 & 2,4 & 0 & & \\
\hline \multirow{2}{*}{ Simb } & Baixa/média & 0,3 & 1,3 & 0 & $-1,974$ & 0,052 \\
\hline & Alta & 1,9 & 3,8 & 0 & & \\
\hline \multirow[t]{2}{*}{ Abs } & Baixa/média & 0,4 & 2,0 & 0 & $-0,476$ & 0,63 \\
\hline & Alta & 0,7 & 2,1 & 0 & & \\
\hline \multirow[t]{2}{*}{ Bot } & Baixa/média & 5,1 & 9,2 & 0 & $-0,153$ & 0,87 \\
\hline & Alta & 5,4 & 10,6 & 0 & & \\
\hline \multirow[t]{2}{*}{ Geo } & Baixa/média & 0,5 & 1,5 & 0 & $-1,703$ & 0,09 \\
\hline & Alta & 2,0 & 4,1 & 0 & & \\
\hline \multirow{2}{*}{$\begin{array}{l}\text { Variáveis } \\
\text { Rorschach }\end{array}$} & Escolaridade & \multicolumn{2}{|c|}{ Dados descritivos } & \multicolumn{3}{|c|}{ Comparação Estatística } \\
\hline & & Média & DP & Mediana & $t$ & $p$-value \\
\hline \multirow[t]{2}{*}{ Nat } & Baixa/média & 0 & 0 & 0 & $-0,790$ & 0,43 \\
\hline & Alta & 0,3 & 1,6 & 0 & & \\
\hline \multirow[t]{2}{*}{ Pais } & Baixa/média & 0 & 0 & 0 & $-0,984$ & 0,32 \\
\hline & Alta & 0,9 & 4,0 & 0 & & \\
\hline \multirow[t]{2}{*}{ Elem } & Baixa/média & 0 & 0 & 0 & $-0,692$ & 0,49 \\
\hline & Alta & 0,1 & 0,9 & 0 & & \\
\hline
\end{tabular}




\begin{tabular}{ccccccc} 
Frag & Baixa/média & 1,0 & 3,0 & 0 & $-0,575$ & 0,56 \\
& Alta & 1,4 & 3,0 & 0 & & \\
& Baixa/média & 35,5 & 19,4 & 36,3 & 1,380 & 0,17 \\
\hline
\end{tabular}

Os dados permitem observar diferenças estatisticamente significativas em 12 das 49 variáveis do Rorschach examinadas acima e tendência em um das variáveis (Simb). Esses padrões diferenciados de responder ao Rorschach dos indivíduos dos dois níveis de escolaridade foram identificados nos determinantes e nos conteúdos das respostas, não se revelando nos modos de apreensão dos estímulos. Pode-se inferir, portanto, que os anos de estudo não pareceram interferir, de modo significativo, nas maneiras como adultos apreendem a realidade. Predominam as captações globais dos estímulos, seguidas pela interpretação dos grandes detalhes e depois os pequenos detalhes, sugerindo padrão adaptativo geral dos indivíduos no contexto sociocultural contemporâneo, na realidade ocidental.

As diferenças estatisticamente significativas entre os grupos apareceram nas seguintes variáveis do Rorschach: a) na classe dos determinantes: má qualidade formal (F-), índice de boa qualidade formal (F+\%), movimento humano $(\mathrm{K})$, movimento animal (kan) e cor (FC); b) nos conteúdos: animal [A e (A)], somatório de animais ( $\Sigma \mathrm{A} \%)$, humanos [H e (H)],somatório de humanos ( $\Sigma \mathrm{H} \%)$ e em objeto (Obj).

A respeito dos determinantes das respostas, ressalta-se que os adultos com maior escolaridade apresentaram porcentagem média superior em: F+\%, FC (uso da cor associada a forma precisa) e K. Por sua vez, os indivíduos de menor escolaridade apresentaram índices estatisticamente superiores em relação ao determinante associado à má qualidade formal (F-) e ao determinante movimento animal (kan). Esses dados indicam que os adultos de alta escolaridade sinalizaram maior precisão lógica em suas análises formais dos estímulos, conseguindo integrar o afeto (resposta cor) e criatividade 
(respostas de grande cinestesia). Já os adultos de baixa/média escolaridade revelaram sinais de maior imprecisão em suas análises lógicas da realidade (F-), acompanhadas de espontaneidade e indicadores de imaturidade emocional (respostas kan), quando comparados com indivíduos de mais de nove anos de estudo.

No tocante aos conteúdos identificados nas respostas ao Rorschach, os adultos se diferenciaram de modo estatisticamente significativo nas seguintes variáveis: A, (A), $\sum \mathrm{A} \%, \mathrm{H},(\mathrm{H}), \sum \mathrm{H} \%$, Obj e tendência em relação ao conteúdo Símbolo. Os adultos com menor escolaridade apresentaram maior proporção nas respostas de conteúdo animal (tanto em A quanto na $\sum \mathrm{A} \%$ ), enquanto o grupo com mais anos de estudo apresentou porcentagem média superior nos demais conteúdos $\left[\mathrm{H},(\mathrm{H}), \sum \mathrm{H} \%\right.$ e Obj]. Esses achados podem ser compreendidos como evidências de relevante efeito da escolaridade sobre os processos de organização psíquica em adultos, na medida em que o menor número de anos de estudo favoreceu conteúdos sinalizadores de imaturidade e estereotipia na interpretação da realidade. Já os adultos com maior treino acadêmico sinalizaram maior expressão de conteúdos humanos, indicando maior identificação e interesse pelo contato humano (sinal de preservação da identidade), além de indicador de intelectualização (respostas objeto). De maneira geral, pode-se considerar que a escolaridade interferiu na forma de produção e de interpretação dos estímulos propostos pelo Método de Rorschach, devendo ser considerada em processos interpretativos desse método de avaliação da personalidade.

\subsubsection{Análise do efeito da idade no Rorschach}

Em relação às idades dos participantes avaliados, buscou-se verificar seu possível efeito sobre as variáveis examinadas pela Escola Francesa do Rorschach. Nesta análise optou-se por agrupar os indivíduos em três faixas etárias diferentes. Como havia apenas 10 indivíduos com idade entre 34 e 39 anos, optou-se por agrupá-los com os indivíduos 
da faixa etária entre 40 a 49 anos. Este agrupamento permitiu a composição de grupos quase numericamente homogêneos, a saber: grupo 1 com indivíduos entre 34 a 49 anos $(\mathrm{n}=31)$; grupo 2 com indivíduos entre 50 a 59 anos $(\mathrm{n}=28)$ e grupo 3 com indivíduos entre 60 a 69 anos $(n=29)$. Os dados foram comparados pelo método da Análise de Variância (ANOVA), verificando possíveis diferenças significativas entre grupos pelo teste post hoc de Bonferroni. Os resultados dessa análise estão apresentados na Tabela 20.

$\underline{\text { Tabela } 20}$ - Resultados descritivos e comparação estatística nos índices de produtividade e ritmo do Rorschach dos adultos presentemente avaliados $(n=88) \mathrm{em}$ função das faixas etárias.

\begin{tabular}{|c|c|c|c|c|c|c|}
\hline \multirow{2}{*}{$\begin{array}{c}\text { Variáveis } \\
\text { Rorschach* }\end{array}$} & \multirow[t]{2}{*}{ Faixas etária } & \multicolumn{3}{|c|}{ Dados descritivos } & \multicolumn{2}{|c|}{ Comparação Estatística } \\
\hline & & Média & DP & Mediana & $z$ & $p$-value \\
\hline \multirow{3}{*}{$\mathrm{R}$} & $34-49$ & 17,9 & 9,5 & 14 & \multirow{3}{*}{2,329} & \multirow{3}{*}{0,10} \\
\hline & $50-59$ & 21,6 & 17 & 17 & & \\
\hline & $60-69$ & 15,1 & 5,11 & 14 & & \\
\hline \multirow{3}{*}{ RA } & $34-49$ & 1,26 & 2,33 & 0 & \multirow{3}{*}{0,212} & \multirow{3}{*}{0,80} \\
\hline & $50-59$ & 1,21 & 1,81 & 1 & & \\
\hline & $60-69$ & 0,97 & 1,21 & 1 & & \\
\hline \multirow{3}{*}{ Rec } & $34-49$ & 0,29 & 0,64 & 0 & \multirow{3}{*}{0,218} & \multirow{3}{*}{0,80} \\
\hline & $50-59$ & 0,32 & 0,86 & 0 & & \\
\hline & $60-69$ & 0,41 & 0,73 & 0 & & \\
\hline \multirow{3}{*}{ Den } & $34-49$ & 0,06 & 0,25 & 0 & \multirow{3}{*}{0,780} & \multirow{3}{*}{0,46} \\
\hline & $50-59$ & 0,18 & 0,39 & 0 & & \\
\hline & $60-69$ & 0,10 & 0,40 & 0 & & \\
\hline \multirow{2}{*}{$\begin{array}{c}\text { Variáveis } \\
\text { Rorschach* }\end{array}$} & \multirow[t]{2}{*}{ Faixas etária } & \multicolumn{3}{|c|}{ Dados descritivos } & \multicolumn{2}{|c|}{ Comparação Estatística } \\
\hline & & Media & DP & Mediana & $z$ & $p$-value \\
\hline \multirow{3}{*}{ TLm } & $34-49$ & 18,4 & 11,2 & 14,7 & \multirow{3}{*}{0,229} & \multirow{3}{*}{0,79} \\
\hline & $50-59$ & 20,3 & 13 & 17,5 & & \\
\hline & $60-69$ & 20 & 9 & 17,8 & & \\
\hline \multirow{3}{*}{$\mathrm{TTm}$} & $34-49$ & 35,6 & 17,7 & 29,4 & \multirow{3}{*}{0,362} & \multirow{3}{*}{0,69} \\
\hline & $50-59$ & 35,5 & 17,3 & 31,4 & & \\
\hline & $60-69$ & 38,6 & 13,6 & 36 & & \\
\hline
\end{tabular}


$* R=$ número total de respostas; $R A=$ número de respostas adicionais; $R e c=$ número de recusas; Den $=$ número de respostas negadas durante o inquérito;TLm = tempo de latência médio (em segundos); TRm = tempo de reação médio (em segundos).

Em relação aos índices de produtividade, apesar do grupo de 50 a 59 anos apresentarem número médio de respostas maior que os demais, não foram localizadas diferenças estatísticas significativas entre os indivíduos de faixas etárias diferentes entre os índices. Isso indica que, independente das idades, os adultos reavaliados apresentaram comportamentos semelhantes diante dos cartões, com apropriado número médio de respostas, poucas respostas adicionais, recusas, denegações e tempo médio de latência e reação semelhantes entre si.

A Tabela 21, apresenta a mesma análise para as demais variáveis do Rorschach.

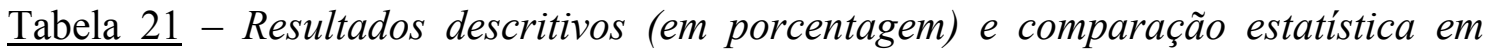
variáveis do Rorschach relacionadas aos modos de apreensão, determinantes, conteúdos e banalidades dos adultos presentemente avaliados $(n=88)$ em função das faixas etárias.

\begin{tabular}{|c|c|c|c|c|c|c|}
\hline \multirow{2}{*}{$\begin{array}{l}\text { Variáveis } \\
\text { Rorschach }\end{array}$} & \multirow[t]{2}{*}{ Faixa etária } & \multicolumn{3}{|c|}{ Dados descritivos } & \multicolumn{2}{|c|}{ Comparação Estatística } \\
\hline & & Média & DP & Mediana & $z$ & $p$-value \\
\hline \multirow{3}{*}{ G } & $34-49$ & 51 & 25,6 & 52,3 & \multirow{3}{*}{0,017} & \multirow{3}{*}{0,98} \\
\hline & $50-59$ & 51,3 & 27,9 & 52,2 & & \\
\hline & $60-69$ & 52,07 & 21,8 & 57,1 & & \\
\hline \multirow{3}{*}{ D } & $34-49$ & 31,1 & 17,3 & 30 & \multirow{3}{*}{0,809} & \multirow{3}{*}{0,44} \\
\hline & $50-59$ & 29,3 & 17,4 & 30 & & \\
\hline & $60-69$ & 34,7 & 13,1 & 35 & & \\
\hline \multirow{2}{*}{$\begin{array}{l}\text { Variáveis } \\
\text { Rorschach }\end{array}$} & Faixa etária & \multicolumn{3}{|c|}{ Dados descritivos } & \multicolumn{2}{|c|}{ Comparação Estatística } \\
\hline & & Média & DP & Mediana & $z$ & $p$-value \\
\hline \multirow{3}{*}{ Dd } & $34-49$ & 17,5 & 14,2 & 15,3 & \multirow{3}{*}{1,317} & \multirow{3}{*}{0,25} \\
\hline & $50-59$ & 18,3 & 18,7 & 16 & & \\
\hline & $60-69$ & 12,2 & 12 & 11,1 & & \\
\hline \multirow{3}{*}{ Dbl } & $34-49$ & 0,4 & 1,23 & 0 & \multirow{3}{*}{0,835} & \multirow{3}{*}{0,43} \\
\hline & $50-59$ & 1,02 & 2,22 & 0 & & \\
\hline & $60-69$ & 0,97 & 2,65 & 0 & & \\
\hline \multirow{3}{*}{ Do } & $34-49$ & 0 & \multirow{3}{*}{ - } & & \multirow{3}{*}{-} & \multirow{3}{*}{-} \\
\hline & $\begin{array}{l}50-59 \\
60-69\end{array}$ & 0 & & - & & \\
\hline & $60-69$ & 0 & & & & \\
\hline
\end{tabular}




\begin{tabular}{|c|c|c|c|c|c|c|}
\hline \multirow{3}{*}{$\mathrm{F}+$} & $34-49$ & 20 & 10 & 19 & \multirow{3}{*}{0,456} & \multirow{3}{*}{0,63} \\
\hline & $50-59$ & 17,1 & 11,7 & 16,7 & & \\
\hline & $60-69$ & 18,5 & 12,4 & 15,4 & & \\
\hline \multirow{3}{*}{$\mathbf{F}+-$} & $34-49$ & 1,17 & 2,6 & 0 & \multirow{3}{*}{4,124} & \multirow{4}{*}{$\mathbf{0 , 0 2 0}$} \\
\hline & $50-59$ & 0,25 & 1,12 & 0 & & \\
\hline & $60-69$ & 0 & 0 & 0 & & \\
\hline \multirow{3}{*}{ F- } & $34-49$ & 7,54 & 7,75 & 7,4 & \multirow{3}{*}{3,529} & \\
\hline & $50-59$ & 13,7 & 12 & 10,2 & & \multirow[t]{2}{*}{0,034} \\
\hline & $60-69$ & 14,2 & 12,6 & 11,2 & & \\
\hline \multirow{3}{*}{$\mathrm{F} \%$} & $34-49$ & 34,5 & 18,5 & 35,7 & \multirow{3}{*}{0,656} & \multirow{3}{*}{0,52} \\
\hline & $\begin{array}{r}50-59 \\
6-60\end{array}$ & 29,2 & 17,4 & 27,2 & & \\
\hline & 60-69 & 32,3 & 17 & 28,5 & & \\
\hline \multirow{3}{*}{$\mathrm{F}+\%$} & $34-49$ & 61,2 & 25 & 60 & \multirow{3}{*}{1,040} & \multirow{3}{*}{0,35} \\
\hline & $50-59$ & 56,7 & 32,4 & 58,5 & & \\
\hline & $60-69$ & 67,5 & 27,7 & 66,7 & & \\
\hline \multirow{3}{*}{$\mathrm{F}+\mathrm{ext} \%$} & $34-49$ & 70 & 14,3 & 70,3 & \multirow{3}{*}{1,215} & \multirow{3}{*}{0,30} \\
\hline & $50-59$ & 70 & 14,6 & 71,8 & & \\
\hline & 60-69 & 75 & 14,5 & 75 & & \\
\hline \multirow{3}{*}{$\mathrm{FC}$} & $34-49$ & 10,1 & 9,87 & 10 & \multirow{3}{*}{0,484} & \multirow{3}{*}{0,61} \\
\hline & $50-59$ & 11,4 & 7,54 & 8,45 & & \\
\hline & 60-69 & 12,2 & 6,86 & 11,1 & & \\
\hline \multirow{3}{*}{$\mathrm{CF}$} & $34-49$ & 6,87 & 7,75 & 5 & \multirow{3}{*}{1,249} & \multirow{3}{*}{0,20} \\
\hline & 50-59 & 9,45 & 8 & 8,3 & & \\
\hline & $60-69$ & 9,66 & 7,11 & 9 & & \\
\hline \multirow{3}{*}{$\mathrm{C}$} & $34-49$ & 1,16 & 3,0 & 0 & \multirow{3}{*}{0,308} & \multirow{3}{*}{0,73} \\
\hline & $50-59$ & 0,73 & 1,9 & 0 & & \\
\hline & 60-69 & 0,71 & 2,3 & 0 & & \\
\hline \multirow{3}{*}{ FE } & $34-49$ & 11,2 & 8 & 9,7 & \multirow{3}{*}{0,933} & \\
\hline & $50-59$ & 8,77 & 5,2 & 8,7 & & 0,39 \\
\hline & $60-69$ & 9,4 & 8,26 & 8,3 & & \\
\hline & $34-49$ & 4,4 & 4,63 & 3,7 & & \\
\hline $\mathrm{EF}$ & 50-59 & 5,85 & 6,45 & 6,25 & 0,529 & 0,59 \\
\hline & $60-69$ & 4,6 & 6,31 & 0 & & \\
\hline
\end{tabular}

\begin{tabular}{ccccccc}
\hline $\begin{array}{c}\text { Variáveis } \\
\text { Rorschach }\end{array}$ & Faixa etária & \multicolumn{3}{c}{ Dados descritivos } & \multicolumn{2}{c}{ Comparação Estatística } \\
& & Média & DP & Mediana & $z$ & $p$-value \\
\hline \multirow{2}{*}{ E } & $34-49$ & 0 & & & - & \\
& $50-59$ & 0 & - & - & & - \\
& $60-69$ & 0 & & & & \\
\multirow{2}{*}{ FClob } & $34-49$ & 0,15 & 0,86 & 0 & & \\
& $50-59$ & 0,06 & 0,36 & 0 & 1,267 & \\
& $60-69$ & 0,67 & 2,52 & 0 & & 0,12 \\
ClobF & & & & & & \\
& $34-49$ & 0 & 0 & 0 & 2,162 & \\
& $50-59$ & 0,50 & 1,89 & 0 & &
\end{tabular}




\begin{tabular}{|c|c|c|c|c|c|c|}
\hline Clob & $\begin{array}{l}34-39 \\
50-59 \\
60-69\end{array}$ & $\begin{array}{l}0 \\
0 \\
0\end{array}$ & - & - & - & - \\
\hline \multirow{3}{*}{$\mathrm{K}$} & $34-49$ & 7,54 & 5,34 & 8,33 & \multirow{3}{*}{3,714} & \multirow{3}{*}{$\mathbf{0 , 0 2 8}$} \\
\hline & $50-59$ & 10,4 & 8,57 & 10,3 & & \\
\hline & $60-69$ & 12,3 & 6,86 & 10,5 & & \\
\hline \multirow{3}{*}{ kan } & $34-49$ & 22,7 & 14,6 & 20 & \multirow{3}{*}{0,787} & \multirow{3}{*}{0,45} \\
\hline & $50-59$ & 22,5 & 21,4 & 15,2 & & \\
\hline & $60-69$ & 18,7 & 11,2 & 18,1 & & \\
\hline \multirow[t]{3}{*}{ kob } & $\begin{array}{r}34-49 \\
50-50\end{array}$ & 0,46 & 1,63 & 0 & \multirow{3}{*}{2,363} & \multirow{3}{*}{0,10} \\
\hline & $60-69$ & 1,43 & 2,94 & 0 & & \\
\hline & & 0,33 & 1,45 & 0 & & \\
\hline \multirow[t]{4}{*}{$\mathrm{kp}$} & $34-49$ & 1.51 & 2,86 & 0 & \multirow[t]{3}{*}{2,545} & \multirow[t]{3}{*}{0,08} \\
\hline & $50-59$ & 0,30 & 1,57 & 0 & & \\
\hline & $60-69$ & 0,57 & 1,77 & 0 & & \\
\hline & $34-49$ & 35,7 & 14,5 & 35,5 & \multirow[t]{3}{*}{2,348} & \multirow[t]{3}{*}{0,10} \\
\hline \multirow[t]{2}{*}{ A } & $50-59$ & 41,6 & 14,2 & 43,8 & & \\
\hline & & 44,7 & 19,6 & 38,5 & & \\
\hline \multirow{3}{*}{ (A) } & $34-49$ & 6,16 & 7,13 & 6 & \multirow{3}{*}{3,602} & \multirow{3}{*}{0,32} \\
\hline & $50-59$ & 3 & 5,09 & 0 & & \\
\hline & $60-69$ & 2,68 & 4,07 & 0 & & \\
\hline \multirow{3}{*}{$\mathrm{Ad}$} & & 3,06 & 4,56 & 0 & \multirow{3}{*}{0,877} & \multirow{3}{*}{0,42} \\
\hline & $\begin{array}{l}34-49 \\
50-59\end{array}$ & 4,06 & 4,5 & 2,85 & & \\
\hline & $60-69$ & 2,51 & 4,4 & 0 & & \\
\hline \multirow{3}{*}{ (Ad) } & & 3,12 & 4,91 & 0 & \multirow[t]{3}{*}{0,179} & \multirow[t]{3}{*}{0,83} \\
\hline & $\begin{array}{r}34-49 \\
50-50\end{array}$ & 2,7 & 4,3 & 0 & & \\
\hline & $60-69$ & 2,46 & 4,4 & 0 & & \\
\hline \multirow{3}{*}{$\sum \mathrm{A}$} & $34-49$ & 48,14 & 14,5 & 53,8 & \multirow{3}{*}{0,624} & \multirow{3}{*}{0,53} \\
\hline & $50-59$ & 51,36 & 12,6 & 51,3 & & \\
\hline & $60-69$ & 52,4 & 18,6 & 51,6 & & \\
\hline $\mathrm{H}$ & $34-49$ & 13,7 & 7,96 & 11,1 & 1,285 & 0,28 \\
\hline & 50-59 & 11,2 & 8,5 & 10,6 & & \\
\hline & $60-69$ & 10,6 & 7,1 & 8,3 & & \\
\hline
\end{tabular}

\begin{tabular}{crrrrrr}
\hline $\begin{array}{c}\text { Variáveis } \\
\text { Rorschach }\end{array}$ & Faixa etária & \multicolumn{3}{c}{ Dados descritivos } & \multicolumn{2}{c}{ Comparação Estatística } \\
& & Média & DP & Mediana & $z$ & $p$-value \\
\hline \multirow{2}{*}{$(\mathrm{H})$} & $34-49$ & 3,65 & 4,86 & 0 & & \\
& $50-59$ & 4,32 & 5,54 & 3,15 & 0,228 & 0,79 \\
& $60-69$ & 3,48 & 4,6 & 0 & & \\
& & & & & & \\
$\mathrm{Hd}$ & $34-49$ & 4,9 & 5,73 & 3,2 & 0,897 & 0,41 \\
& $50-59$ & 3,6 & 5,25 & 0 & & \\
& $60-69$ & 3,17 & 4,75 & 0 & & 0,80 \\
$(\mathrm{Hd})$ & & & & & 0,218 & \\
& $34-49$ & 0,52 & 1,82 & 0 & &
\end{tabular}




\begin{tabular}{|c|c|c|c|c|c|c|}
\hline$\sum \mathrm{H}$ & $\begin{array}{l}34-49 \\
50-59 \\
60-69\end{array}$ & $\begin{array}{l}22,8 \\
19,6 \\
17,6\end{array}$ & $\begin{array}{c}12,5 \\
12,5 \\
9\end{array}$ & $\begin{array}{l}19,2 \\
16,7 \\
17,6\end{array}$ & 1,62 & 0,20 \\
\hline Anat & $\begin{array}{l}30-39 \\
50-59 \\
60-69\end{array}$ & $\begin{array}{l}9,72 \\
8,78 \\
6,81\end{array}$ & $\begin{array}{l}10,5 \\
10,1 \\
11,4\end{array}$ & $\begin{array}{c}9 \\
5,65 \\
0\end{array}$ & 0,570 & 0,56 \\
\hline $\mathrm{Sg}$ & $\begin{array}{l}34-49 \\
50-59 \\
60-69\end{array}$ & $\begin{array}{c}0 \\
0 \\
0,11\end{array}$ & $\begin{array}{c}0 \\
0 \\
0,6\end{array}$ & $\begin{array}{l}0 \\
0 \\
0\end{array}$ & 1,018 & 0,36 \\
\hline Sex & $\begin{array}{l}34-49 \\
50-59 \\
60-69\end{array}$ & $\begin{array}{l}1,71 \\
1,51 \\
4,41\end{array}$ & $\begin{array}{l}4,57 \\
3,37 \\
9,26\end{array}$ & $\begin{array}{l}0 \\
0 \\
0\end{array}$ & 1,945 & 0,14 \\
\hline Obj & $\begin{array}{l}34-49 \\
50-59 \\
60-69\end{array}$ & $\begin{array}{c}6,73 \\
9,42 \\
8\end{array}$ & $\begin{array}{l}7,76 \\
6,35 \\
8,25\end{array}$ & $\begin{array}{c}5,8 \\
8,33 \\
5,88\end{array}$ & 0,940 & 0,39 \\
\hline Art & $\begin{array}{l}34-49 \\
50-59 \\
60-69\end{array}$ & $\begin{array}{c}0,9 \\
1,26 \\
1,05\end{array}$ & $\begin{array}{l}2,51 \\
2,95 \\
3,35\end{array}$ & $\begin{array}{l}0 \\
0 \\
0\end{array}$ & 0,104 & 0,90 \\
\hline Nat & $\begin{array}{l}34-49 \\
50-59 \\
60-69\end{array}$ & $\begin{array}{c}0 \\
0,16 \\
0\end{array}$ & $\begin{array}{c}0 \\
0,62 \\
0\end{array}$ & $\begin{array}{l}0 \\
0 \\
0\end{array}$ & 1,565 & 0,21 \\
\hline Pais & $\begin{array}{l}34-49 \\
50-59 \\
60-69\end{array}$ & $\begin{array}{l}0,10 \\
0,72 \\
0,26\end{array}$ & $\begin{array}{c}0,57 \\
3,2 \\
1,43\end{array}$ & $\begin{array}{l}0 \\
0 \\
0\end{array}$ & 0,752 & 0,47 \\
\hline Elem & $\begin{array}{l}34-49 \\
50-59 \\
60-69\end{array}$ & $\begin{array}{c}0 \\
0,23 \\
0\end{array}$ & $\begin{array}{c}0 \\
1,07 \\
0\end{array}$ & $\begin{array}{l}0 \\
0 \\
0\end{array}$ & 1,500 & 0,22 \\
\hline Frag & $\begin{array}{l}34-49 \\
50-59 \\
60-69\end{array}$ & $\begin{array}{l}1,5 \\
1,3 \\
0,9\end{array}$ & $\begin{array}{l}3,61 \\
2,96 \\
2,76\end{array}$ & $\begin{array}{l}0 \\
0 \\
0\end{array}$ & 0,289 & 0,75 \\
\hline Ban & $\begin{array}{l}34-49 \\
50-59 \\
60-69\end{array}$ & $\begin{array}{c}29,9 \\
30 \\
35,3\end{array}$ & $\begin{array}{l}15,2 \\
13,6 \\
15,7\end{array}$ & $\begin{array}{c}30 \\
31,6 \\
36,3\end{array}$ & 1,242 & 0,29 \\
\hline
\end{tabular}

Apenas em três variáveis, F+-, F- e $\mathrm{K}$, os indivíduos dos grupos de diferentes

faixas etárias tenderam a apresentar diferenças significativas. Contudo, a análise post hoc de Bonferroni revelou existir diferença apenas na variável F+- e K. Na variável F+-, o grupo de 34 a 49 anos apresentou média maior do que o grupo de maior faixa etária, de 60 a 69 anos. Importante destacar, que esta é uma variável de baixa frequência em todos os grupos, por isso, esta diferença deve ser relativizada, uma vez que nas variáveis F\% e 
$\mathrm{F}+\%$, esta diferença desaparece. Em relação à variável $\mathrm{K}$, houve diferença também entre os mesmos grupos de idade, sendo que os indivíduos mais novos apresentaram média menor do que os mais velhos, podendo indicar maior utilização dos recursos internos de dinamismo por parte dos indivíduos de mais idade.

Na sequência, serão apresentados diferentes tipos de análises comparativas entre os resultados da avaliação pelo Rorschach realizada em 1998 e os dados da reavaliação dos mesmos indivíduos.

\subsubsection{Análise comparativa das duas avaliacões pelo Rorschach}

O objetivo dessa seção voltou-se ao exame das possíveis similaridades ou diferenças no padrão de respostas ao Rorschach dos 88 adultos avaliados em dois momentos:primeira avaliação (Pasian, 1998 - momento 1) e na reavaliação (atual momento 2). Para tanto, as análises foram realizadas por grupos de variáveis desse método projetivo de avaliação psicológica.

Com relação à produtividade, a análise descritiva e comparativa dos índices alcançados pela amostra nos dois momentos avaliativos pode ser visualizada na Tabela 22. Foi calculado o índice de correlação entre os resultados, bem como realizada a comparação dos resultados médios (Teste $t$ de Student).

Tabela 22- Resultados descritivos e comparação estatística das variáveis relacionadas à produtividade no Rorschach obtidos na primeira avaliação (Pasian, 1998) e na reavaliação $(n=88)$.

\begin{tabular}{cccccc}
\hline $\begin{array}{c}\text { Variáveis } \\
\text { pareadas* }\end{array}$ & Média & $\begin{array}{c}\text { Desvio } \\
\text { Padrão }\end{array}$ & Correlação & $\begin{array}{c}\text { Estatística } \\
(t)\end{array}$ & $p$-value \\
\hline R_1 & 18,2 & 10,4 & & & \\
R_2 & 18,2 & 11,6 & 0,722 & 0,090 & 0,949
\end{tabular}




$\begin{array}{llllll}\text { RA_1 } & 1,6 & 2,0 & & & \\ \text { RA_2 } & 1,2 & 1,8 & 0,225 & 1,846 & 0,073\end{array}$

$\begin{array}{llllll}\text { Rec_1 } & 0,5 & 0,9 & & & \\ \text { Rec_2 } & 0,3 & 0,7 & 0,532 & 1,416 & 0,160\end{array}$

$\begin{array}{llllll}\text { Den_1 } & 0,4 & 0,7 & & \\ \text { Den_2 } & 0,1 & 0,4 & 0,238 & 4,071 & <0,001\end{array}$

* O número 1 refere-se à avaliação realizada por Pasian (1998 - momento 1) e o número 2 refere-se à reavaliação (atual - momento 2); $R=$ número total de respostas; $R A=$ número de respostas adicionais; $R e c=$ número de recusas; Den $=$ número de respostas negadas durante o inquérito.

Observa-se que não houve diferença estatisticamente significativa nos indicadores de produtividade diante do Rorschach nos dois momentos avaliativos, excetuando-se a variável denegação. Contudo, diante do número total bruto de respostas (1.604 na primeira avaliação e 1.599 na reavaliação), em ambos os casos houve inexpressivo número de denegações (36 na primeira e 10 na segunda avaliação), o que relativiza o significado clínico dessa diferença estatística.

Os índices de correlação relativos ao total de interpretações do Rorschach nas duas avaliações foi bastante elevado $(r=0,722)$, sinalizando estabilidade temporal no padrão geral de respostas dos adultos avaliados. O índice de correlação na variável Recusas também pode ser considerado satisfatório $(r=0,532)$

A seguir, são apresentadas a correlação e as comparações entre dados médios referentes aos modos de apreensão no Rorschach obtidos na primeira avaliação (1998 momento 1) e na reavaliação (atual - momento 2). Esses resultados compõem a Tabela 23. 
Tabela 23 - Resultados descritivos (em porcentagem) e comparação estatística das variáveis relacionadas aos modos de apreensão no Rorschach obtidos na primeira avaliação (Pasian, 1998) e na reavaliação $(n=88)$.

\begin{tabular}{|c|c|c|c|c|c|}
\hline $\begin{array}{l}\text { Variáveis } \\
\text { pareadas* }\end{array}$ & Média & $\begin{array}{l}\text { Desvio } \\
\text { Padrão }\end{array}$ & Correlação & $\begin{array}{c}\text { Estatística } \\
(t)\end{array}$ & $p$-value \\
\hline G_1 & 47,9 & 24,3 & 0,59 & $-1,631$ & 0,106 \\
\hline G_2 & 51,7 & 24,6 & & & \\
\hline D_1 & 33,6 & 15,7 & 0,35 & 1,297 & 0,198 \\
\hline D_2 & 31,1 & 16,2 & & & \\
\hline Dd_1 & 16,4 & 15,3 & 0,46 & $-0,051$ & 0,960 \\
\hline Dd_2 & 16,5 & 15,4 & & & \\
\hline Dbl_1 & 0,91 & 2,6 & $-0,17$ & 0,517 & 0,607 \\
\hline Dbl_2 & 0,72 & 2,0 & & & \\
\hline
\end{tabular}

Os achados revelam bom nível de correlação (índices satisfatórios, segundo Urbina, 2007) entre as respostas ocorridas nas áreas globais do cartão $(r=0,59)$ e nos pequenos detalhes interpretados pelos indivíduos $(r=0,46)$. Já nas áreas de grandes detalhes e detalhe branco ( $r=0,35$ e $-0,17$ respectivamente) foram alcançados menores índices de correlação. Não foram encontradas diferenças estatisticamente significativas nos modos de apreensão utilizados pelos indivíduos nos dois momentos avaliativos do Rorschach. Nota-se que, em ambas as aplicações, a área preferencialmente eleita pelos respondentes para interpretação do Rorschach corresponde ao total do cartão (resposta global), seguida pelas apreensões de grande detalhe e pelas respostas pequeno detalhe. Por fim, as respostas exclusivamente localizadas na área branca do cartão (localização Dbl) foram pouco frequentes nas duas avaliações realizadas. 
$\mathrm{Na}$ continuidade das análises, focalizou-se o exame dos determinantes das respostas dos adultos frente ao Método de Rorschach nos dois momentos avaliativos (em 1998 e na atualidade). Esses resultados estão apresentados na Tabela 24, seguindo o mesmo padrão de análise já realizado para as outras variáveis desse método projetivo.

Tabela 24 - Resultados descritivos (em porcentagem) e comparação estatística das variáveis relacionadas aos determinantes (forma, cor, sombreado e movimento) no Rorschach obtidos na primeira avaliação (Pasian, 1998) e na reavaliação (atual) $(n=$ 88).

\begin{tabular}{|c|c|c|c|c|c|}
\hline $\begin{array}{l}\text { Variáveis } \\
\text { pareadas* }\end{array}$ & Média & $\begin{array}{l}\text { Desvio } \\
\text { Padrão }\end{array}$ & Correlação & Estatística $(t)$ & $p$-value \\
\hline F\%_1 & 33,8 & 18,8 & 0,300 & 0,771 & 0,443 \\
\hline $\mathrm{F} \%$ 2 & 32,1 & 17,6 & & & \\
\hline $\mathrm{F}+\% \_1$ & 57,4 & 30,1 & 0,141 & $-1,076$ & 0,285 \\
\hline $\mathrm{F}+\% \_2$ & 61,8 & 28,4 & & & \\
\hline $\mathrm{F}+\mathrm{ext} \%$ & 68,1 & 15,7 & 0,332 & $-1,871$ & 0,650 \\
\hline $\mathrm{F}+\mathrm{ext} \%{ }_{2}$ & 71,6 & 14,5 & & & \\
\hline $\mathrm{FC} 1$ & 9,5 & 8,4 & 0,037 & $-1,352$ & 0,180 \\
\hline $\mathrm{FC}_{-} 2$ & 11,2 & 8,1 & & & \\
\hline CF_1 & 7,8 & 7,4 & 0,009 & $-0,648$ & 0,519 \\
\hline CF_2 & 8,6 & 7,6 & & & \\
\hline $\begin{array}{l}\text { Variáveis } \\
\text { pareadas* }\end{array}$ & Média & $\begin{array}{l}\text { Desvio } \\
\text { Padrão }\end{array}$ & Correlação & Estatística $(t)$ & $p$-value \\
\hline C_1 & 1,1 & 3,8 & 0,294 & 0,642 & 0,523 \\
\hline $\mathrm{C}_{-} 2$ & 0,9 & 2,4 & & & \\
\hline FE_1 & 10,6 & 9,1 & 0,222 & 0,456 & 0,650 \\
\hline FE_2 & 10,1 & 8,0 & & & \\
\hline $\mathrm{EF}_{-} 1$ & 6,0 & 6,1 & 0,300 & 1,263 & 0,210 \\
\hline EF_2 & 4,9 & 5,4 & & & \\
\hline E_1 & 0 & - & - & - & - \\
\hline
\end{tabular}


E_2 0

$\begin{array}{llllll}\text { K_1 } & 10,7 & 9,6 & 0,261 & 0,623 & 0,535 \\ \text { K_2 } & 10,1 & 7,2 & & & \end{array}$

$\begin{array}{llllll}\text { kan_1 } & 18,5 & 12,0 & 0,399 & -1,828 & 0,071\end{array}$

kan_2 $21,3 \quad 13,7$

$\begin{array}{llllll}\text { kob_1 } & 1,2 & 3,2 & 0,009 & 1,214 & 0,228\end{array}$

kob_2 $\quad 0,7 \quad 2,1$

$\begin{array}{llllll}\text { kp_1 } & 0,7 & 2,0 & -0,005 & -0,275 & 0,784\end{array}$

$\begin{array}{ccc}\mathrm{kp}_{2} 2 & 0,8 & 2,2 \\ * \text { O número } 1 \text { refere-se à avaliação realizada por Pasian (1998 - momento 1) e o número } 2 \text { refere-se à }\end{array}$ reavaliação (atual-momento 2).

Os determinantes, de forma geral, apresentaram os menores índices de correlação entre as avaliações realizadas, quando examinados de forma isolada. Os maiores índices de correlação identificados ocorreram na variável movimento animal $(r=0,399)$ e em $\mathrm{F}+\operatorname{ext} \%(r=0,332)$. Apesar de inexistirem diferenças estatisticamente significativas nos dados médios desses determinantes, pode-se comentar que os indivíduos utilizaram os componentes dos cartões (aspectos formais, cor, sombreado e movimento) de modo peculiar em cada uma das aplicações do Rorschach, tendo em vista a reduzida correlação identificada entre cada determinante das respostas. No entanto, essa análise isolada dos determinantes também precisa ser relativizada, uma vez que o relevante no protocolo do Rorschach é a distribuição do conjunto das variáveis examinadas e não apenas indicadores específicos dos modos de reagir a esse método de avaliação psicológica.

A partir dos mesmos procedimentos de comparação estatística, foram examinados os índices médios dos conteúdos predominantes no Método de Rorschach: animais e humanos, além dos conteúdos anatômicos (Anat), objetos (Obj) e conteúdos botânicos (Bot) por apresentarem, nos dois momentos avaliativos, frequência igual ou superior a 
2\% no conjunto das respostas encontradas. A mesma análise também foi realizada para os índices médios de respostas banais (Ban), conforme descrito na Tabela 25.

$\underline{\text { Tabela } 25}$ - Resultados descritivos (em porcentagem) e comparação estatística das variáveis relacionadas aos conteúdos (A, H, Anat, Obj e Bot) e banalidades no Rorschach obtidos na primeira avaliação (Pasian, 1998) e na reavaliação $(n=88)$.

\begin{tabular}{cccccc}
\hline $\begin{array}{c}\text { Variáveis } \\
\text { pareadas* }\end{array}$ & Médias & $\begin{array}{c}\text { Desvio } \\
\text { Padrão }\end{array}$ & Correlação & $\begin{array}{c}\text { Estatística } \\
(t)\end{array}$ & $p$-value \\
\hline A_1 & 49,2 & 15,2 & 0,331 & $-0,701$ & 0,485 \\
A_2 & 50,6 & 15,3 & & & \\
H_1 & 18,3 & 12,1 & 0,484 & $-1,554$ & 0,124 \\
H_2 & 20,3 & 11,8 & & & \\
Anat_1 & 8,2 & 10,7 & 0,345 & $-0,203$ & 0,840 \\
Anat_2 & 8,4 & 10,6 & & & \\
& & & & & \\
Obj_1 & 6,5 & 6,9 & 0,356 & $-1,713$ & 0,900 \\
Obj_2 & 8,0 & 7,5 & & & \\
Bot_1 & 4,6 & 6,6 & 0,199 & 0,650 & 0,517 \\
Bot_2 & 4,0 & 6,9 & & \\
Ban_1 & 29,8 & 16,1 & & & \\
Ban_2 & 31,7 & 14,9 & 0,614 & $-1,265$ & 0,209 \\
É possível notar, em relação aos conteúdos interpretados diante do Rorschach, que
\end{tabular}
os resultados demonstraram predominância dos conteúdos animal sobre os conteúdos humanos em ambas as avaliações. Não foram identificadas diferenças estatisticamente significativas nos conteúdos e nas banalidades produzidos pelos adultos nos dois momentos avaliativos. Além disso, os índices de correlação obtidos podem ser considerados satisfatórios (Urbina, 2007), sobretudo para conteúdos Humano e Animal $(r=0,48$ e 0,33 , respectivamente) e respostas banais $(r=0,61)$. Esses achados podem ser compreendidos como similaridades nos elementos interpretativos utilizados pelos adultos 
diante do Rorschach aplicado em 1998 e no momento atual desse trabalho, sugerindo estabilidade em seus interesses e vínculos objetais.

Em relação às variáveis teoricamente representativas dos estilos de vivência afetiva na Escola Francesa do Método de Rorschach têm-se os resultados sistematizados na Tabela 26. Essa tabela apresenta a distribuição dos adultos avaliados em função de seu estilo afetivo, conforme evidência da primeira fórmula afetiva: Tipo de Ressonância Intima (TRI), na avaliação de Pasian (1998) e na reavaliação (atual), respectivamente.

Tabela 26-Distribuição dos adultos (n=88) em função do Tipo de Ressonância Íntima na avaliação de Pasian (1998) e na reavaliação (atual).

\begin{tabular}{|c|c|c|c|c|c|c|c|}
\hline \multirow{2}{*}{\multicolumn{2}{|c|}{$\begin{array}{c}\text { Tipo de Ressonância } \\
\text { Íntima (TRI) }\end{array}$}} & \multicolumn{3}{|c|}{ 1ª Avaliação (1998) } & \multicolumn{3}{|c|}{ Reavaliação (atual) } \\
\hline & & \multicolumn{2}{|c|}{ Frequência simples } & \multirow[t]{2}{*}{ Porcentagem } & \multicolumn{2}{|c|}{ Frequência simples } & \multirow{3}{*}{$\begin{array}{c}\text { Porcentagem } \\
53,4\end{array}$} \\
\hline \multirow{2}{*}{$\begin{array}{l}\text { Extra- } \\
\text { tensivo }\end{array}$} & Puro & 10 & \} 40 & & 6 & \} 47 & \\
\hline & Dilatado & 30 & & 45,5 & 41 & & \\
\hline \multirow{2}{*}{$\begin{array}{l}\text { Intro- } \\
\text { versivo }\end{array}$} & Puro & 2 & \} 20 & & 2 & \} 19 & \\
\hline & Dilatado & 18 & & 22,7 & 17 & & 21,5 \\
\hline \multicolumn{2}{|c|}{ Coartativo } & 20 & 24 & & 15 & 20 & \\
\hline \multicolumn{2}{|c|}{ Coartado } & 4 & & 27,3 & 5 & & 22,7 \\
\hline \multicolumn{2}{|c|}{ Ambigual } & & 4 & 4,5 & & 2 & 2,3 \\
\hline \multicolumn{8}{|c|}{ vivência afetiva sinalizado pelo Rorschach nos 88 adultos avaliados em dois momentos } \\
\hline \multicolumn{8}{|c|}{ distintos de sua vida, após longo intervalo de tempo (15 anos). Há um claro predomínio } \\
\hline \multicolumn{8}{|c|}{ de indivíduos com TRI extratensivo nas duas avaliações. Contudo, na reavaliação dos } \\
\hline \multicolumn{8}{|c|}{ indivíduos no momento atual notou-se aumento do tipo extratensivo (em especial do } \\
\hline \multicolumn{8}{|c|}{ extratensivo dilatado) e diminuição dos casos de expressão coartativa/coartada do afeto. } \\
\hline
\end{tabular}


no ambiente no momento atual(após 15 anos da primeira avaliação) desses adultos, enquanto estilo de vivência afetiva.

No entanto, há que se ressaltar que esse tipo de comparação do TRI da amostra oferece genérico mapeamento da distribuição dos adultos em função do estilo afetivo. Para se analisar a estabilidade das vivências afetivas em cada indivíduo ao longo desses 15 anos de vida faz-se necessário outro tipo de sistematização dos resultados, examinando-se o acordo interno entre os dois momentos avaliativos para cada caso em termos de seu Tipo de Ressonância Íntima (TRI). A observação detalhada dos tipos possíveis de ressonância íntima (extratensivo, introversivo, coartativo/coartado e ambigual), em uma análise individual, revelou que dos 88 indivíduos avaliados, 41 (46,5\% dos casos) mantiveram o mesmo estilo de vivência afetiva no TRI nos dois momentos avaliativos. Esses achados empíricos sugerem que o modo habitual de vivenciar os afetos, em indivíduos adultos, tende a se manter estável ao longo do tempo, porém não se compõe como variável imutável no decorrer dos anos.

Ao examinar, com mais detalhe, esses casos onde o estilo de vivência afetiva permaneceu o mesmo nos dois momentos avaliativos (41 casos), notou-se predomínio de mulheres (23 mulheres e 18 homens), nas várias faixas etárias (três na faixa etária dos 30 anos, quatro na faixa etária dos 40 anos, oito na faixa etária dos 50 e oito na faixa dos 60 anos). Entre os homens o mesmo tipo de TRI ocorreu em diferentes idades: um na faixa etária dos 30 anos, sete na faixa dos 40 anos, sete na faixa dos 50 anos e três na faixa etária dos 60 anos. Notou-se também que o tipo extratensivo pareceu mais estável entre as duas avaliações, ocorrendo em 15 casos nesse subgrupo feminino (com 23 mulheres ao total) e 10 homens (entre 18 desse subgrupo masculino). Apesar dessa análise descritiva, é preciso relativizar possíveis inferências interpretativas, visto se tratar de 
exame exploratório dessas variáveis relativas ao estilo de personalidade ao longo do tempo, o que exigiria estudos específicos que ultrapassam os achados do momento.

Em relação aos dados relacionados à segunda fórmula afetiva, intitulada como Fórmula das Tendências Latentes - TL (Rausch de Traubenberg, 1998), representativa dos recursos individuais disponíveis e não obrigatoriamente utilizados (potenciais afetivos) tem-se a Tabela 27. Nesta Tabela consta a distribuição dos 88 adultos avaliados nos dois diferentes momentos, em relação a seu estilo de personalidade derivado dessa segunda fórmula afetiva do Rorschach.

Tabela 27 - Distribuição dos adultos $(n=88)$ em função da Fórmula das Tendências Latentes (TL) na avaliação de Pasian (1998) e na reavaliação (atual).

\begin{tabular}{|c|c|c|c|c|c|c|c|}
\hline \multirow{2}{*}{\multicolumn{2}{|c|}{$\begin{array}{c}\text { Segunda Fórmula } \\
\text { Afetiva (T.L.) }\end{array}$}} & \multicolumn{3}{|c|}{$1^{\text {a }}$ Avaliação (1998) } & \multicolumn{3}{|c|}{ Reavaliação (atual) } \\
\hline & & \multicolumn{2}{|c|}{$\begin{array}{l}\text { Frequência } \\
\text { simples }\end{array}$} & \multirow[t]{2}{*}{ Porcentagem } & \multicolumn{2}{|c|}{$\begin{array}{l}\text { Frequência } \\
\text { simples }\end{array}$} & \multirow[t]{2}{*}{ Porcentagem } \\
\hline \multirow{2}{*}{$\begin{array}{l}\text { Extra- } \\
\text { tensivo }\end{array}$} & Puro & 3 & \} 16 & & 1 & \} 11 & \\
\hline & Dilatado & 13 & & 18,1 & 10 & & 12,5 \\
\hline \multirow{2}{*}{$\begin{array}{l}\text { Intro- } \\
\text { versivo }\end{array}$} & Puro & 8 & 57 & \multirow[b]{2}{*}{64,6} & 4 & 66 & \multirow[b]{2}{*}{75,0} \\
\hline & Dilatado & 49 & & & 62 & & \\
\hline \multirow{2}{*}{\multicolumn{2}{|c|}{$\begin{array}{l}\text { Coartativo } \\
\text { Coartado }\end{array}$}} & 11 & \} 12 & \multirow[b]{2}{*}{13,6} & 9 & \} 10 & \multirow[b]{2}{*}{11,4} \\
\hline & & 1 & & & 1 & & \\
\hline \multicolumn{2}{|c|}{ Ambigual } & & 3 & 3,4 & 1 & & 1,1 \\
\hline \multicolumn{8}{|c|}{ Em ambas as avaliações identifica-se predomínio do tipo introversivo de vivência } \\
\hline \multicolumn{8}{|c|}{ afetiva na Fórmula de Tendências Latentes (TL) dos 88 adultos, sugerindo recursos de } \\
\hline \multicolumn{8}{|c|}{ reflexão e de dobramento sobre si, complementando seu estilo habitual extratensivo, } \\
\hline \multicolumn{8}{|c|}{ advindo do TRI. A inspeção visual comparativa dos dois momentos avaliativos aponta } \\
\hline \multicolumn{8}{|c|}{ similaridade entre os dados no tocante às tendências latentes, embora com elevação na } \\
\hline \multicolumn{8}{|c|}{ porcentagem de indivíduos introversivos, em detrimento dos extratensivos, na segunda } \\
\hline
\end{tabular}


indicadores de estabilidade na fórmula das tendências latentes, já que 48 indivíduos (55\%) dos 88 avaliados mantiveram-se constantes nessa variável de vivência afetiva.

Esses resultados podem ser compreendidos como evidências de estabilidade nos recursos internos (de reflexão e dobramento sobre si) disponíveis nos adultos para lidar com suas emoções. Porém, uma vez mais há que se comentar que existiram casos onde foi possível detectar mudanças nesses potenciais em função dos 15 anos de vida decorridos entre as duas avaliações aqui comparadas, mostrando-se passível de alteração ao longo do tempo.

O levantamento descritivo dos 48 indivíduos estáveis nessa segunda fórmula do Rorschach indicou que 29 são mulheres e 19 homens, com faixas etárias variadas, mas com estilo predominantemente introversivo (apenas quatro homens e uma mulher dos 48 indivíduos apresentaram outro estilo afetivo na segunda fórmula). Assim, pode-se comentar que o estilo introversivo sinalizou maior estabilidade entre os dois momentos avaliativos, mas foi também o estilo mais frequente na segunda fórmula afetiva do Rorschach em ambas as avaliações. Mais uma vez, esses achados precisam ser pensados com devida parcimônia, não permitindo inferências claras sobre a estabilidade dos estilos de personalidade ao longo da vida em adultos, o que exige estudos de outra natureza, diferente do presentemente efetivado.

Na continuidade da análise das vivências afetivas a partir da Escola Francesa do Método de Rorschach tem-se a possibilidade de exame da reatividade emocional dos indivíduos a partir da Terceira Fórmula Afetiva (Rausch de Traubenberg, 1998). Esses dados foram sistematizados apenas para a atual aplicação do Rorschach (Estudo 1), visto não ter sido possível, neste momento, recuperar essa informação da base de dados de Pasian (1998). Cabe lembrar que essa Terceira Fórmula Afetiva é classificada como indicativa dos seguintes estilos de reatividade emocional, a partir de seus resultados: valor 
superior a $40 \%=$ extratensivo; valor inferior a $30 \%=$ introversivo; valor entre 30 a $40 \%$ $=$ ambigual. Com base nessas diretrizes, os resultados dos 88 adultos avaliados no presente trabalho foram sistematizados como mostra a Tabela 28.

$\underline{\text { Tabela } 28}$ - Distribuição dos adultos $(n=88)$ e estatística descritiva (em porcentagem) na Terceira Fórmula Afetiva do Rorschach na atual avaliação.

\begin{tabular}{cccccc}
\hline Terceira Fórmula Afetiva & \multicolumn{2}{c}{ Casos } & \multicolumn{3}{c}{ Dados descritivos (\%) } \\
& $f$ & $\%$ & Média & DP & Mediana \\
\hline Extratensivo & 21 & 23,9 & & & 34 \\
Introversivo & 28 & 31,8 & 34 & 9 & \\
Ambigual & 39 & 44,3 & & & \\
\hline
\end{tabular}

É possível notar que os adultos sinalizaram, a partir da Terceira Fórmula Afetiva do Rorschach, predomínio de reatividade do tipo ambigual, ou seja, mostraram-se sensíveis aos elementos cromáticos dos cartões (representantes afetivos), porém não de modo prioritário, permanecendo também atentos a outros determinantes no momento de produzir suas respostas. Esse indicador sugere flexibilidade dos indivíduos no modo de reagir à realidade, atendendo ao solicitado pelo ambiente (no caso, os cartões do Rorschach) conforme as demandas apresentadas a cada momento. Houve também importante proporção de indivíduos que se mostraram introversivos e menor frequência de reatividade emocional do tipo extratensiva. Isso pode sugerir que os adultos, além de mostrarem flexibilidade às demandas ambientais, também preferem (em sua maioria) refletir e pensar antes de prontamente reagir aos estímulos, característica do estilo introversivo de vivência afetiva. 
A análise individual dos 88 estilos de vivência afetiva (extratensivo, introversivo e ambigual) expressos na Terceira Fórmula Afetiva (reatividade emocional situacional) comparativamente a seu Tipo de Ressonância Íntima (estilo habitual de vivenciar os afetos) apontou que 31,8\% dos casos alcançou a mesma classificação no Rorschach. Esse dado é considerado como revelador de consistência no estilo pessoal de vivências afetivas, configurando-se como sinal de estabilidade psíquica frente às emoções, característica teoricamente esperada em adultos, como nessa atual amostra avaliada.

Uma nova tentativa de análise dos resultados do conjunto de adultos em seus dois momentos avaliativos (há 15 anos e no presente trabalho) foi realizada tendo em vista a posição percentílica de cada indivíduo nas seguintes variáveis do Rorschach [índices de produtividade (R, RA, Rec e Den), os Modos de Apreensão (G, D, Dd e Dbl), os índices de Funcionamento Lógico (F\%, F +\% e F + ext\%), Conteúdos (A\% e H\%) e Banalidades], em função do referencial normativo elaborado por Pasian (1998), o qual levou em conta os diferentes níveis de escolaridade (baixa, média e alta). Desse modo, cada adulto foi classificado em relação às suas normas específicas nas variáveis do Rorschach, numa das seguintes categorias: abaixo da média (resultados iguais ou inferiores ao percentil 40 do grupo normativo), na média (entre percentil 40 e 60 do grupo normativo), acima da média (resultados iguais ou superiores ao percentil 60 do grupo normativo). Isso foi realizado para os resultados atuais, considerando-se as normas elaboradas em 1998 (primeiro momento avaliativo). Assim, os indivíduos poderiam ocupar posição atual igual a primeira avaliação, superior ou inferior. Esses achados relativos a suas posições ocupadas nos dois momentos avaliativos foram comparados (Teste de Postos sinalizados de Wilcoxon para amostras relacionadas). Esses resultados encontram-se sistematizados na Tabela 29. 
Tabela 29: Resultados descritivos e comparação estatística da distribuição dos indivíduos em função das normas do Rorschach (Pasian, 1998)nos dois momentos avaliativos.

\begin{tabular}{|c|c|c|c|c|c|c|}
\hline \multirow{2}{*}{$\begin{array}{l}\text { Variáveis } \\
\text { Rorschach } \\
\text { pareadas* }\end{array}$} & \multicolumn{2}{|c|}{ Dados descritivos } & \multicolumn{4}{|c|}{ Comparação estatística } \\
\hline & Média & $\begin{array}{l}\text { Desvio } \\
\text { Padrão }\end{array}$ & $\begin{array}{l}\text { Categorias } \\
\text { avaliativas }\end{array}$ & Casos ** & Estatística(z) & $p$-value \\
\hline & & & R_2> R_1 & 22 & $-0,940$ & 0,347 \\
\hline R_1 & 18,2 & 10,4 & $\mathrm{R} \_2<\mathrm{R} \_1$ & 27 & & \\
\hline R_2 & 18,2 & 11,6 & R_2=R_1 & 39 & & \\
\hline RA_1 & 1,6 & 2,0 & RA_2>RA_1 & 21 & $-2,348$ & 0,019 \\
\hline \multirow[t]{2}{*}{ RA_2 } & 1,2 & 1,8 & $\mathrm{RA}_{2} 2<\mathrm{RA}_{-}^{-} 1$ & 37 & & \\
\hline & & & RA_2=RA_1 & 30 & & \\
\hline Rec_1 & 0,5 & 0,9 & Rec_2> Rec_1 & 11 & & \\
\hline \multirow[t]{2}{*}{ Rec_2 } & 0,3 & 0,7 & Rec_2 $<$ Rec_1 & 16 & $-0,962$ & 0,336 \\
\hline & & & Rec_2=Rec_1 & 61 & & \\
\hline Den_1 & 0,4 & 0,7 & Den_2> Den_1 & 5 & & \\
\hline \multirow[t]{2}{*}{ Den_2 } & 0,1 & 0,4 & Den_2 $<$ Den_1 & 24 & $-3,536$ & $<0,001$ \\
\hline & & & Den_2=Den_1 & 59 & & \\
\hline G_1 & 47,9 & 24,3 & $\mathrm{G} \_2>\mathrm{G} \_1$ & 14 & & \\
\hline \multirow[t]{2}{*}{$\mathrm{G}_{-}^{-} 2$} & 51,7 & 24,5 & G_2 $<\mathrm{G}_{-} 1$ & 30 & 2703 & 0007 \\
\hline & & & $\mathrm{G} \_2=\mathrm{G}_{-} 1$ & 44 & $2, / 05$ & $0,00 /$ \\
\hline D_1 & 33,6 & 15,7 & D_2>D_1 & 17 & $-1,548$ & 0,122 \\
\hline \multirow[t]{2}{*}{ D_2 } & 31,1 & 16,2 & D_2 $<$ D_1 & 24 & & \\
\hline & & & D_2=D_1 & 47 & & \\
\hline \multirow{3}{*}{$\begin{array}{l}\text { Variáveis } \\
\text { Rorschach } \\
\text { pareadas* }\end{array}$} & \multicolumn{2}{|c|}{ Dados descritivos } & \multicolumn{4}{|c|}{ Comparação estatística } \\
\hline & & & Categorias avaliativas & Casos** & Estatística $(z$ & $p$-value \\
\hline & Média & Desvio Padrão & & & & \\
\hline Dd_1 & 16,4 & 15,3 & Dd_2>Dd_1 & 22 & & \\
\hline \multirow[t]{2}{*}{ Dd_2 } & 16,5 & 15,4 & Dd_2<Dd_1 & 23 & $-0,231$ & 0,817 \\
\hline & & & Dd_2= Dd_1 & 43 & & \\
\hline Dbl_1 & 0,91 & 2,6 & Dbl_2> Dbl_1 & 10 & & \\
\hline \multirow[t]{2}{*}{ Dbl_2 } & 0,72 & 2,0 & $\mathrm{Dbl} \_2<\mathrm{Dbl} \_1$ & 13 & $-0,939$ & 0,348 \\
\hline & & & Dbl_2= Dbl_1 & 65 & & \\
\hline F\%_1 & 33,8 & 18,8 & $\mathrm{~F} \% \_2>\mathrm{F} \% \_1$ & 21 & & \\
\hline \multirow[t]{2}{*}{$\mathrm{F} \%$ 2 } & 32,1 & 17,6 & $\mathrm{~F} \% \_2<\mathrm{F} \% \_1$ & 26 & $-1,848$ & 0,065 \\
\hline & & & $\mathrm{F} \% \_2=\mathrm{F} \% \_1$ & 41 & & \\
\hline
\end{tabular}




\begin{tabular}{|c|c|c|c|c|c|c|}
\hline $\mathrm{F}+\% \_1$ & 57,4 & 30,1 & $\mathrm{~F}+\% \_2>\mathrm{F}+\% \_1$ & 26 & \multirow{3}{*}{$-0,123$} & \multirow{3}{*}{0,902} \\
\hline \multirow[t]{2}{*}{$\mathrm{F}+\% \_2$} & 61,8 & 28,4 & $\mathrm{~F}+\% \_2<\mathrm{F}+\% \_1$ & 26 & & \\
\hline & & & $\mathrm{F}+\% \_2=\mathrm{F}+\% \_1$ & 36 & & \\
\hline $\mathrm{F}+\mathrm{ext} \%$ _1 & 68,1 & 15,7 & $\mathrm{~F}+\operatorname{ext} \% \_2>\mathrm{F}+\mathrm{ext} \% \_1$ & 30 & \multirow{3}{*}{1,585} & \multirow{3}{*}{0,113} \\
\hline \multirow[t]{2}{*}{$\mathrm{F}+\mathrm{ext} \%{ }_{-} 2$} & 71,6 & 14,5 & $\mathrm{~F}+\mathrm{ext} \% \_2<\mathrm{F}+\mathrm{ext} \% \_1$ & 16 & & \\
\hline & & & $\mathrm{F}+\mathrm{ext} \% \_2=\mathrm{F}+\mathrm{ext} \% \_1$ & 42 & & \\
\hline A_1 & 49,2 & 15,2 & A_2>A_1 & 29 & \multirow{3}{*}{0,846} & \multirow{3}{*}{0,398} \\
\hline \multirow[t]{2}{*}{ A_2 } & 50,6 & 15,3 & A_ $2<$ A_1 & 20 & & \\
\hline & & & A_2=A_1 & 39 & & \\
\hline H_1 & 18,3 & 12,1 & H_2> H_1 & 27 & \multirow{3}{*}{1,020} & \multirow{3}{*}{0,308} \\
\hline \multirow[t]{2}{*}{ H_2 } & \multirow[t]{2}{*}{20,3} & \multirow[t]{2}{*}{11,8} & H_2 $<$ H_1 & 16 & & \\
\hline & & & H_2 $=$ H_1 & 45 & & \\
\hline \multirow{3}{*}{$\begin{array}{l}\text { Ban_1 } \\
\text { Ban_2 }\end{array}$} & \multirow{3}{*}{$\begin{array}{l}29,8 \\
31,7\end{array}$} & \multirow{3}{*}{$\begin{array}{l}16,1 \\
14,9\end{array}$} & Ban_2> Ban_1 & 22 & \multirow{3}{*}{1,289} & \multirow{3}{*}{0,067} \\
\hline & & & Ban_2< Ban_1 & 12 & & \\
\hline & & & Ban_2= Ban_1 & 54 & & \\
\hline
\end{tabular}

Observou-se que em apenas três das 14 variáveis examinadas houve diferença estatisticamente significativa nos dois momentos avaliativos, sendo duas relacionadas aos índices de produtividade (RA e Den) e outra relacionada ao modo de apreensão (G). Em função do reduzido número de ocorrências de respostas adicionais (RA) e denegações (Den) no Rorschach, as análises estatísticas derivadas dessas variáveis sempre devem ser examinadas com muita cautela, pois sua significância estatística pouco se associa, no geral, a relevância clínica.

Nesse contexto, ao explorar os achados, pode-se notar que houve mais casos com RA acima da média normativa e também na média durante a primeira avaliação, enquanto nas denegações predominou similaridade entre os dois momentos avaliativos dos adultos, com resultados compatíveis aos referenciais normativos dessa faixa etária. No tocante à 
variável G\% do Rorschach, observa-se predomínio de casos acompanhando os dados normativos para adultos nos dois momentos avaliativos, seguindo-se o subgrupo de indivíduos que tiveram maior proporção de respostas globais na primeira avaliação. Assim, dessa análise comparativa pode-se inferir que a distribuição dos adultos em função dos referenciais normativos pouco se diferenciou ao longo do tempo, sugerindo estabilidade em seu padrão de respostas ao método de Rorschach.

Ainda com a intenção de verificar se a mudança ou estabilidade dos aspectos da personalidade podem ter variado em função do sexo, da escolaridade e da idade (faixas etárias) ao longo do tempo, foram comparadas as 27 variáveis do Rorschach, já analisadas anteriormente, mas agora considerando o resultado identificado pela diferença entre os valores obtidos nas duas avaliações (em 1998 e no presente trabalho). Assim foi criada a variável denominada "diferença", correspondente a: (resultado: Momento 1 - resultado Momento 2). Os dados médios obtidos por meio desse procedimento foram, então, comparados (Teste $t$ de Student para amostras pareadas), em função das referidas características demográficas dos adultos. A Tabela 30 apresenta a análise realizada em função do sexo (53 mulheres e 35 homens).

Tabela 30: Resultados descritivos e comparação estatística das diferenças médias entre avaliação e reavaliação nas variáveis do Rorschach em função do sexo.

\begin{tabular}{cccccc}
\hline $\begin{array}{c}\text { Variáveis } \\
\text { Rorschach }\end{array}$ & Sexo & $\begin{array}{c}\text { Diferença } \\
\text { Média }\end{array}$ & $\begin{array}{c}\text { Desvio } \\
\text { Padrão }\end{array}$ & $\begin{array}{c}\text { Estatística } \\
(t)\end{array}$ & $p$-value \\
\hline $\mathrm{R}$ & Feminino & 0,01 & 8,28 & $-0,052$ & 0,958 \\
& Masculino & 0,11 & 8,42 & & \\
RA & Feminino & 0,47 & 2,22 & 0,028 & 0,978 \\
& Masculino & 0,45 & 2,70 & & \\
Rec & Feminino & 0,15 & 0,86 & 0,360 & 0,720 \\
& Masculino & 0,08 & 0,78 & & \\
Den & Feminino & 0,20 & 0,63 & $-1,501$ & 0,137 \\
& Masculino & 0,42 & 0,73 & &
\end{tabular}




\begin{tabular}{|c|c|c|c|c|c|}
\hline G & $\begin{array}{l}\text { Feminino } \\
\text { Masculino }\end{array}$ & $\begin{array}{l}-2,23 \\
-6,22\end{array}$ & $\begin{array}{l}21,50 \\
22,60\end{array}$ & 0,833 & 0,407 \\
\hline D & $\begin{array}{l}\text { Feminino } \\
\text { Masculino }\end{array}$ & $\begin{array}{l}3,24 \\
1,42\end{array}$ & $\begin{array}{l}18,70 \\
17,70\end{array}$ & 0,455 & 0,651 \\
\hline $\mathrm{Dd}$ & $\begin{array}{l}\text { Feminino } \\
\text { Masculino }\end{array}$ & $\begin{array}{c}-1,75 \\
2,43\end{array}$ & $\begin{array}{l}16,80 \\
14,10\end{array}$ & $-1,210$ & 0,229 \\
\hline Dbl & $\begin{array}{l}\text { Feminino } \\
\text { Masculino }\end{array}$ & $\begin{array}{l}0,01 \\
0,44\end{array}$ & $\begin{array}{l}2,38 \\
4,53\end{array}$ & $-0,582$ & 0,562 \\
\hline $\mathrm{F} \%$ & $\begin{array}{l}\text { Feminino } \\
\text { Masculino }\end{array}$ & $\begin{array}{r}3,04 \\
-0,15\end{array}$ & $\begin{array}{l}23,50 \\
18,20\end{array}$ & 0,679 & 0,499 \\
\hline $\mathrm{F}+\%$ & $\begin{array}{l}\text { Feminino } \\
\text { Masculino }\end{array}$ & $\begin{array}{l}-2,54 \\
-7,24\end{array}$ & $\begin{array}{l}44,40 \\
27,50\end{array}$ & 0,559 & 0,578 \\
\hline $\mathrm{F}+\operatorname{ext} \%$ & $\begin{array}{l}\text { Feminino } \\
\text { Masculino }\end{array}$ & $\begin{array}{l}-2,72 \\
-4,67\end{array}$ & $\begin{array}{l}19,20 \\
14,70\end{array}$ & 0,506 & 0,614 \\
\hline K & $\begin{array}{l}\text { Feminino } \\
\text { Masculino }\end{array}$ & $\begin{array}{c}1,12 \\
0,002\end{array}$ & $\begin{array}{c}10,70 \\
9,75\end{array}$ & 0,482 & 0,631 \\
\hline kan & $\begin{array}{l}\text { Feminino } \\
\text { Masculino }\end{array}$ & $\begin{array}{l}-3,00 \\
-2,42\end{array}$ & $\begin{array}{l}14,70 \\
13,50\end{array}$ & $-0,188$ & 0,851 \\
\hline kob & $\begin{array}{l}\text { Feminino } \\
\text { Masculino }\end{array}$ & $\begin{array}{l}1,29 \\
0,24\end{array}$ & $\begin{array}{l}5,26 \\
3,30\end{array}$ & 1,083 & 0,282 \\
\hline $\mathrm{kp}$ & $\begin{array}{l}\text { Feminino } \\
\text { Masculino }\end{array}$ & $\begin{array}{r}0,03 \\
-0,13\end{array}$ & $\begin{array}{l}4,03 \\
2,70\end{array}$ & 0,221 & 0,826 \\
\hline $\mathrm{FC}$ & $\begin{array}{l}\text { Feminino } \\
\text { Masculino }\end{array}$ & $\begin{array}{l}-1,81 \\
-1,45\end{array}$ & $\begin{array}{l}11,90 \\
11,10\end{array}$ & $-0,140$ & 0,889 \\
\hline $\mathrm{CF}$ & $\begin{array}{l}\text { Feminino } \\
\text { Masculino }\end{array}$ & $\begin{array}{l}-0,77 \\
-0,07\end{array}$ & $\begin{array}{l}11,00 \\
10,10\end{array}$ & $-0,041$ & 0,968 \\
\hline
\end{tabular}

\begin{tabular}{cccccc}
\hline $\begin{array}{c}\text { Variáveis } \\
\text { Rorschach }\end{array}$ & Sexo & $\begin{array}{c}\text { Diferença } \\
\text { Média }\end{array}$ & $\begin{array}{c}\text { Desvio } \\
\text { Padrão }\end{array}$ & $\begin{array}{c}\text { Estatística } \\
(t)\end{array}$ & $p$-value \\
\hline $\mathrm{C}$ & Feminino & $-0,02$ & 4,00 & $-0,863$ & 0,391 \\
& Masculino & 0,71 & 3,67 & & \\
FE & Feminino & $-0,48$ & 10,20 & $-1,083$ & 0,282 \\
& Masculino & 2,05 & 11,40 & & \\
EF & Feminino & 0,88 & 8,81 & $-0,285$ & 0,776 \\
& Masculino & 1,39 & 6,98 & & \\
E & Feminino & - & - & - & - \\
& Masculino & & & & \\
A & Feminino & $-1,52$ & 19,20 & $-0,128$ & 0,898
\end{tabular}




\begin{tabular}{cccccc}
$\mathrm{H}$ & Feminino & $-1,89$ & 12,60 & 0,116 & 0,908 \\
& Masculino & $-2,20$ & 11,50 & & \\
Anat & Feminino & 1,16 & 15,90 & 0,613 & 0,542 \\
& Masculino & $-0,71$ & 10,90 & & \\
Obj & Feminino & $-2,78$ & 8,42 & $-1,833$ & 0,070 \\
& Masculino & 0,44 & 7,53 & & \\
Bot & Feminino & 0,06 & 9,33 & $-0,713$ & 0,478 \\
& Masculino & 1,42 & 7,34 & & \\
Ban & Feminino & 0,24 & 14,70 & 1,784 & 0,078 \\
& Masculino & $-5,02$ & 11,50 & & \\
\hline
\end{tabular}

Estes resultados revelam que não foram encontradas diferenças estatisticamente significativas relacionadas ao sexo em nenhuma das 27 variáveis do Rorschach presentemente examinadas, ao longo dos 15 anos entre as duas avaliações. Pode-se inferir, portanto, que a variável sexo pareceu não influenciar os resultados de indivíduos adultos nos indicadores desse método de avaliação da personalidade.

Com base na mesma estratégia analítica, verificou-se possível efeito do grau de escolaridade sobre a mudança e/ou estabilidade nas variáveis do Rorschach com o passar do tempo. Importante relembrar que os dados dos adultos de baixo e médio nível de escolaridade foram unidos, tendo em vista o pequeno número de participantes com até dois anos de estudo $(n=4)$. Os resultados dessa análise estão apresentados na Tabela 31.

Tabela 31: Resultados descritivos e comparação estatística das diferenças médias entre avaliação e reavaliação nas variáveis do Rorschach em função da escolaridade.

\begin{tabular}{cccccc}
\hline $\begin{array}{c}\text { Variáveis } \\
\text { Rorschach }\end{array}$ & Escolaridade* & $\begin{array}{c}\text { Diferença } \\
\text { Média }\end{array}$ & $\begin{array}{c}\text { Desvio } \\
\text { Padrão }\end{array}$ & $\begin{array}{c}\text { Estatística } \\
(t)\end{array}$ & $p$-value \\
\hline $\mathrm{R}$ & Baixa/Média & $-0,71$ & 4,83 & $-0,486$ & 0,628 \\
& Alta & 0,29 & 9,13 & & \\
& Baixa/Média & 0,80 & 2,08 & 0,746 & 0,457 \\
RA & Alta & 0,35 & 2,50 & & \\
& Baixa/Média & 0,28 & 0,95 & 1,020 & 0,311 \\
& Alta & 0,07 & 0,78 & &
\end{tabular}




\begin{tabular}{|c|c|c|c|c|c|}
\hline Den & $\begin{array}{c}\text { Baixa/Média } \\
\text { Alta }\end{array}$ & $\begin{array}{l}0,19 \\
0,32\end{array}$ & $\begin{array}{l}0,74 \\
0,66\end{array}$ & $-0,808$ & 0,421 \\
\hline $\mathrm{G}$ & $\begin{array}{c}\text { Baixa/Média } \\
\text { Alta }\end{array}$ & $\begin{array}{c}5,14 \\
-6,63\end{array}$ & $\begin{array}{l}22,10 \\
21,30\end{array}$ & 2,190 & $\mathbf{0 , 0 3 1}$ \\
\hline $\mathrm{D}$ & $\begin{array}{c}\text { Baixa/Média } \\
\text { Alta }\end{array}$ & $\begin{array}{l}0,40 \\
3,18\end{array}$ & $\begin{array}{l}22,70 \\
16,70\end{array}$ & $-0,606$ & 0,546 \\
\hline $\mathrm{Dd}$ & $\begin{array}{c}\text { Baixa/Média } \\
\text { Alta }\end{array}$ & $\begin{array}{l}-5,94 \\
1,75\end{array}$ & $\begin{array}{l}13,11 \\
16,34\end{array}$ & $-1,967$ & 0,052 \\
\hline Dbl & $\begin{array}{c}\text { Baixa/Média } \\
\text { Alta }\end{array}$ & $\begin{array}{c}- \\
0,24\end{array}$ & $\begin{array}{c}- \\
3,88\end{array}$ & $-0,288$ & 0,774 \\
\hline $\mathrm{F} \%$ & $\begin{array}{c}\text { Baixa/Média } \\
\text { Alta }\end{array}$ & $\begin{array}{c}-0,52 \\
2,49\end{array}$ & $\begin{array}{l}24,03 \\
20,80\end{array}$ & $-0,558$ & 0,578 \\
\hline $\mathrm{F}+\%$ & $\begin{array}{c}\text { Baixa/Média } \\
\text { Alta }\end{array}$ & $\begin{array}{l}-7,74 \\
-3,36\end{array}$ & $\begin{array}{l}53,70 \\
32,70\end{array}$ & $-0,453$ & 0,652 \\
\hline $\mathrm{F}+\mathrm{ext} \%$ & $\begin{array}{c}\text { Baixa/Média } \\
\text { Alta }\end{array}$ & $\begin{array}{l}-0,04 \\
-4,58\end{array}$ & $\begin{array}{l}21,60 \\
16,00\end{array}$ & 1,036 & 0,303 \\
\hline $\mathrm{K}$ & $\begin{array}{c}\text { Baixa/Média } \\
\text { Alta }\end{array}$ & $\begin{array}{c}2,95 \\
-0,02\end{array}$ & $\begin{array}{l}12,8 \\
9,43\end{array}$ & 1,152 & 0,252 \\
\hline kan & $\begin{array}{c}\text { Baixa/Média } \\
\text { Alta }\end{array}$ & $\begin{array}{l}-4,90 \\
-2,10\end{array}$ & $\begin{array}{l}15,13 \\
13,90\end{array}$ & $-0,783$ & 0,435 \\
\hline $\begin{array}{l}\text { Variáveis } \\
\text { Rorschach }\end{array}$ & Escolaridade* & $\begin{array}{l}\text { Diferença } \\
\text { Média }\end{array}$ & $\begin{array}{l}\text { Desvio } \\
\text { Padrão }\end{array}$ & $\begin{array}{c}\text { Estatística } \\
(t)\end{array}$ & $p$-value \\
\hline kob & $\begin{array}{c}\text { Baixa/Média } \\
\text { Alta }\end{array}$ & $\begin{array}{l}1,29 \\
0,24\end{array}$ & $\begin{array}{l}5,26 \\
3,30\end{array}$ & 1,083 & 0,282 \\
\hline $\mathrm{kp}$ & $\begin{array}{c}\text { Baixa/Média } \\
\text { Alta }\end{array}$ & $\begin{array}{c}0,03 \\
-0,13\end{array}$ & $\begin{array}{l}4,03 \\
2,70\end{array}$ & 0,221 & 0,826 \\
\hline $\mathrm{FC}$ & $\begin{array}{c}\text { Baixa/Média } \\
\text { Alta }\end{array}$ & $\begin{array}{l}-1,94 \\
-1,58\end{array}$ & $\begin{array}{l}15,20 \\
10,30\end{array}$ & $-0,125$ & 0,901 \\
\hline $\mathrm{CF}$ & $\begin{array}{c}\text { Baixa/Média } \\
\text { Alta }\end{array}$ & $\begin{array}{l}-1,01 \\
-0,64\end{array}$ & $\begin{array}{l}12,30 \\
10,10\end{array}$ & $-0,135$ & 0,893 \\
\hline $\mathrm{C}$ & $\begin{array}{c}\text { Baixa/Média } \\
\text { Alta }\end{array}$ & $\begin{array}{l}0,36 \\
0,23\end{array}$ & $\begin{array}{l}3,82 \\
3,98\end{array}$ & 0,130 & 0,897 \\
\hline $\mathrm{FE}$ & $\begin{array}{c}\text { Baixa/Média } \\
\text { Alta }\end{array}$ & $\begin{array}{l}1,41 \\
0,24\end{array}$ & $\begin{array}{l}11,00 \\
10,70\end{array}$ & 0,434 & 0,666 \\
\hline
\end{tabular}




\begin{tabular}{|c|c|c|c|c|c|}
\hline \multirow[t]{2}{*}{$\mathrm{EF}$} & Baixa/Média & 0,59 & 7,63 & \multirow[t]{2}{*}{$-0,319$} & \multirow[t]{2}{*}{0,751} \\
\hline & Alta & 1,24 & 8,28 & & \\
\hline $\mathrm{E}$ & $\begin{array}{c}\text { Baixa/Média } \\
\text { Alta }\end{array}$ & - & - & - & - \\
\hline \multirow[t]{2}{*}{$\mathrm{A}$} & Baixa/Média & $-3,72$ & 20,29 & \multirow[t]{2}{*}{$-0,709$} & \multirow[t]{2}{*}{0,480} \\
\hline & Alta & $-0,57$ & 16,90 & & \\
\hline \multirow{2}{*}{$\mathrm{H}$} & Baixa/Média & 1,89 & 14,90 & \multirow[t]{2}{*}{1,705} & \multirow[t]{2}{*}{0,092} \\
\hline & Alta & $-3,24$ & 11,00 & & \\
\hline \multirow[t]{2}{*}{ Anat } & Baixa/Média & 1,16 & 15,90 & \multirow[t]{2}{*}{0,613} & \multirow[t]{2}{*}{0,542} \\
\hline & Alta & $-0,71$ & 10,90 & & \\
\hline \multirow[t]{2}{*}{ Obj } & Baixa/Média & $-4,39$ & 8,32 & \multirow[t]{2}{*}{$-1,884$} & \multirow{2}{*}{0,063} \\
\hline & Alta & $-0,58$ & 8,00 & & \\
\hline \multirow{2}{*}{ Bot } & Baixa/Média & $-1,81$ & 9,32 & \multirow{2}{*}{$-1,396$} & \multirow{2}{*}{0,166} \\
\hline & Alta & 1,28 & 8,30 & & \\
\hline \multirow[t]{2}{*}{ Ban } & Baixa/Média & 2,78 & 15,40 & \multirow[t]{2}{*}{1,796} & \multirow[t]{2}{*}{0,076} \\
\hline & Alta & $-3,30$ & 12,90 & & \\
\hline
\end{tabular}

*Escolaridade baixa/média: $n=21 ;$ Escolaridade alta: $n=57$.

Verificaram-se duas diferenças estatisticamente significativas, identificadas nas variáveis $\mathrm{G}$ e $\mathrm{Dd}$. O grupo de baixa/média escolaridade apresentou aumento de $\mathrm{G}$ e diminuição de Dd ao longo do tempo, enquanto o grupo de alta escolaridade diminuiu sua proporção de G e elevou uso de Dd na segunda avaliação.

$\mathrm{Na}$ análise da possível interferência da idade, também foram agrupados os indivíduos em três faixas etárias diferentes: 34 a 49 anos $(n=31)$ os indivíduos entre 50 a $59 \operatorname{anos}(\mathrm{n}=28)$ e entre 60 a 69 anos $(\mathrm{n}=29)$. Os dados foram comparados pelo método da Análise de Variância (ANOVA), verificando possíveis diferenças significativas entre grupos pelo teste post hoc de Bonferroni. Os resultados dessa análise estão apresentados na Tabela 32. 
Tabela 32: Resultados descritivos e comparação estatística das diferenças médias entre avaliação e reavaliação nas variáveis do Rorschach em função da idade.

\begin{tabular}{|c|c|c|c|c|c|}
\hline $\begin{array}{l}\text { Variáveis } \\
\text { Rorschach }\end{array}$ & $\begin{array}{l}\text { Faixas } \\
\text { Etárias }\end{array}$ & $\begin{array}{l}\text { Diferença } \\
\text { Média }\end{array}$ & $\begin{array}{l}\text { Desvio } \\
\text { Padrão }\end{array}$ & $\begin{array}{c}\text { Estatística } \\
(F)\end{array}$ & $p$-value \\
\hline $\mathrm{R}$ & $\begin{array}{l}34-49 \\
50-59 \\
60-69\end{array}$ & $\begin{array}{c}1,90 \\
-3,00 \\
1,45\end{array}$ & $\begin{array}{l}7,70 \\
9,20 \\
7,20\end{array}$ & 3,001 & 0,055 \\
\hline RA & $\begin{array}{l}34-49 \\
50-59 \\
60-69\end{array}$ & $\begin{array}{c}-0,16 \\
0,64 \\
0,96\end{array}$ & $\begin{array}{l}2,40 \\
1,40 \\
2,90\end{array}$ & 1,778 & 0,175 \\
\hline Rec & $\begin{array}{l}34-49 \\
50-59 \\
60-69\end{array}$ & $\begin{array}{l}0,12 \\
0,21 \\
0,03\end{array}$ & $\begin{array}{l}0,56 \\
0,78 \\
1,08\end{array}$ & 0,331 & 0,719 \\
\hline Den & $\begin{array}{l}34-49 \\
50-59 \\
60-69\end{array}$ & $\begin{array}{l}0,38 \\
0,25 \\
0,24\end{array}$ & $\begin{array}{l}0,71 \\
0,51 \\
0,78\end{array}$ & 0,429 & 0,653 \\
\hline G & $\begin{array}{l}34-49 \\
50-59 \\
60-69\end{array}$ & $\begin{array}{l}-3,43 \\
-4,04 \\
-4,00\end{array}$ & $\begin{array}{l}19,70 \\
20,90 \\
25,60\end{array}$ & 0,007 & 0,993 \\
\hline D & $\begin{array}{l}34-49 \\
50-59 \\
34-49\end{array}$ & $\begin{array}{c}-0,06 \\
1,67 \\
6,11\end{array}$ & $\begin{array}{l}18,30 \\
17,00 \\
19,30\end{array}$ & 0,901 & 0,410 \\
\hline $\mathrm{Dd}$ & $\begin{array}{l}34-49 \\
50-59 \\
60-69\end{array}$ & $\begin{array}{c}0,86 \\
1,94 \\
-3,06\end{array}$ & $\begin{array}{l}14,90 \\
16,10 \\
-3,06\end{array}$ & 0,789 & 0,458 \\
\hline $\begin{array}{l}\text { Variáveis } \\
\text { Rorschach }\end{array}$ & $\begin{array}{l}\text { Faixas } \\
\text { Etárias }\end{array}$ & $\begin{array}{c}\text { Diferença } \\
\text { Média }\end{array}$ & $\begin{array}{l}\text { Desvio } \\
\text { Padrão }\end{array}$ & $\begin{array}{c}\text { Estatística } \\
(F)\end{array}$ & $p$-value \\
\hline Dbl & $\begin{array}{l}34-49 \\
50-59 \\
60-69\end{array}$ & $\begin{array}{c}0,42 \\
0,19 \\
-0,07\end{array}$ & $\begin{array}{l}4,35 \\
3,54 \\
1,77\end{array}$ & 0,157 & 0,855 \\
\hline $\mathrm{F} \%$ & $\begin{array}{l}34-49 \\
50-59 \\
60-69\end{array}$ & $\begin{array}{r}-1,75 \\
7,74 \\
-0,21\end{array}$ & $\begin{array}{l}24,10 \\
21,00 \\
18,20\end{array}$ & 1,636 & 0,201 \\
\hline $\mathrm{F}+\%$ & $\begin{array}{l}34-49 \\
50-59 \\
60-69\end{array}$ & $\begin{array}{c}-6,95 \\
8,45 \\
-14,10\end{array}$ & $\begin{array}{l}32,10 \\
31,00 \\
47,80\end{array}$ & 2,654 & 0,076 \\
\hline $\mathrm{F}+\mathrm{ext} \%$ & $\begin{array}{l}34-49 \\
50-59 \\
60-69\end{array}$ & $\begin{array}{l}-4,17 \\
-2,55 \\
-3,69\end{array}$ & $\begin{array}{l}15,30 \\
15,00 \\
22,00\end{array}$ & 0,064 & 0,938 \\
\hline K & $\begin{array}{l}34-49 \\
50-59 \\
60-69\end{array}$ & $\begin{array}{r}0,75 \\
2,48 \\
-1,12\end{array}$ & $\begin{array}{c}10,10 \\
10,90 \\
9,93\end{array}$ & 0,864 & 0,425 \\
\hline
\end{tabular}




\begin{tabular}{|c|c|c|c|c|c|}
\hline kan & $\begin{array}{l}34-49 \\
50-59 \\
60-69\end{array}$ & $\begin{array}{c}-3,35 \\
-6,79 \\
1,70\end{array}$ & $\begin{array}{l}12,10 \\
15,80 \\
13,70\end{array}$ & 2,672 & 0,075 \\
\hline kob & $\begin{array}{l}34-49 \\
50-59 \\
60-69\end{array}$ & $\begin{array}{c}0,34 \\
-0,31 \\
1,45\end{array}$ & $\begin{array}{l}3,12 \\
3,58 \\
4,65\end{array}$ & 1,564 & 0,215 \\
\hline $\mathrm{kp}$ & $\begin{array}{l}34-49 \\
50-59 \\
60-69\end{array}$ & $\begin{array}{c}-0,98 \\
0,49 \\
0,30\end{array}$ & $\begin{array}{l}3,01 \\
2,75 \\
3,24\end{array}$ & 2,123 & 0,126 \\
\hline $\mathrm{FC}$ & $\begin{array}{l}34-49 \\
50-59 \\
60-69\end{array}$ & $\begin{array}{l}-0,07 \\
-2,79 \\
-2,28\end{array}$ & $\begin{array}{l}12,60 \\
10,30 \\
11,70\end{array}$ & 0,462 & 0,632 \\
\hline $\mathrm{CF}$ & $\begin{array}{l}34-49 \\
50-59 \\
60-69\end{array}$ & $\begin{array}{r}1,29 \\
-1,05 \\
-2,58\end{array}$ & $\begin{array}{c}9,62 \\
10,20 \\
11,90\end{array}$ & 1,014 & 0,367 \\
\hline $\mathrm{C}$ & $\begin{array}{l}34-49 \\
50-59 \\
60-69\end{array}$ & $\begin{array}{l}0,35 \\
0,12 \\
0,31\end{array}$ & $\begin{array}{l}4,87 \\
3,24 \\
3,49\end{array}$ & 0,026 & 0,974 \\
\hline $\mathrm{FE}$ & $\begin{array}{l}34-49 \\
50-59 \\
60-69\end{array}$ & $\begin{array}{c}2,48 \\
-0,16 \\
-0,90\end{array}$ & $\begin{array}{c}11,80 \\
10,30 \\
9,90\end{array}$ & 0,822 & 0,443 \\
\hline $\mathrm{EF}$ & $\begin{array}{l}34-49 \\
50-59 \\
60-69\end{array}$ & $\begin{array}{c}0,55 \\
-0,86 \\
3,54\end{array}$ & $\begin{array}{l}8,66 \\
7,05 \\
8,04\end{array}$ & 2,284 & 0,108 \\
\hline A & $\begin{array}{l}34-49 \\
50-59 \\
60-69\end{array}$ & $\begin{array}{r}2,10 \\
-3,02 \\
-3,35\end{array}$ & $\begin{array}{l}18,00 \\
17,00 \\
18,10\end{array}$ & 0,894 & 0,413 \\
\hline
\end{tabular}

\begin{tabular}{cccccc}
\hline $\begin{array}{c}\text { Variáveis } \\
\text { Rorschach }\end{array}$ & $\begin{array}{c}\text { Faixas } \\
\text { Etárias }\end{array}$ & $\begin{array}{c}\text { Diferença } \\
\text { Média }\end{array}$ & $\begin{array}{c}\text { Desvio } \\
\text { Padrão }\end{array}$ & $\begin{array}{c}\text { Estatística } \\
(F)\end{array}$ & $p$-value \\
\hline $\mathrm{H}$ & $34-49$ & $-4,13$ & 10,30 & 1,616 & 0,205 \\
& $50-59$ & 1,29 & 14,20 & & \\
& $60-69$ & $-2,95$ & 11,50 & & \\
Anat & $34-49$ & $-1,44$ & 12,70 & 0,220 & 0,803 \\
& $50-59$ & 0,26 & 11,40 & & \\
& $60-69$ & 0,48 & 12,80 & & \\
Obj & $34-49$ & $-0,65$ & 7,72 & 0,659 & 0,520 \\
& $50-59$ & $-0,94$ & 7,76 & & \\
& $60-69$ & $-2,92$ & 9,13 & & \\
Bot & $34-49$ & 1,89 & 9,82 & 2,008 & 0,141 \\
& $50-59$ & $-2,03$ & 7,04 & & \\
& $60-69$ & 1,84 & 8,16 & & \\
Ban & $34-49$ & $-4,75$ & 11,8 & 1,337 & 0,268 \\
& $50-59$ & $-1,59$ & 12,5 & &
\end{tabular}


Apenas na variável $\mathrm{R}$ identificou-se tendência à diferença estatisticamente significativa entre os três grupos etários. O teste post hoc de Bonferroni indicou que a faixa etária de 34-49 anos teve valores aumentados de número de respostas na segunda avaliação, enquanto a faixa etária 50-59 anos diminuiu seu número de interpretações ao Rorschach após 15 anos (na segunda avaliação). Ou seja, em termos gerais, pode-se notar possível influência da idade no sentido de poder se associar a diminuição na quantidade de interpretações dos cartões do Rorschach. Contudo, mais uma vez, uma variável isolada em um teste psicológico deve ser examinada de forma cuidadosa, visto que o relevante nas interpretações é o conjunto dos indicadores técnicos e não apenas um sinal, como foi o caso do número de respostas.

Diante do exposto pode-se argumentar que foi possível identificar indicadores de estabilidade no padrão geral dos resultados ao Rorschach produzidos pelos adultos ao longo de suas vidas. Algumas variáveis desse método projetivo mostraram-se mais sensíveis à passagem do tempo, sugerindo que a personalidade sofre influências diversas no período de 15 anos, como é o caso do presente Estudo 1. No entanto, o relevante foi explorar essa perspectiva longitudinal de avaliação da personalidade de adultos, examinados a partir do Método de Rorschach, o que se configura, em si, contribuição original desse trabalho.

Em relação aos dados avaliados pelo Self-Reporting Questionnaire-20 (SRQ-20), abaixo faz-se uma breve apresentação dos dados obtidos pelos indivíduos avaliados neste primeiro estudo. 


\subsubsection{Perfil geral dos adultos no SRQ-20}

O Self-Reporting Questionnaire-20 (SRQ-20) foi desenvolvido pela Organização Mundial de Saúde com o objetivo de avaliar elementos relativos à saúde mental (OMS, 2001), apresentando adequados índices de validade e de consistência interna também na realidade nacional (Santos, Araújo \& Oliveira, 2009). Na adaptação do Brasil, o SRQ ficou composto por 20 itens, sendo a nota de corte como igual ou superior a sete ou oito pontos. No presente trabalho o SRQ-20 foi aplicado em formato de entrevista, possibilitando a realização do rapport com os participantes do Estudo 1. Foi possível, desse modo, complementar os dados para caracterizar o padrão atual de saúde mental dos adultos avaliados.

Os resultados gerais dos 88 adultos no $S R Q-20$ foram sistematizados em termos de pontos obtidos. A Tabela 33 apresenta a distribuição dos adultos em função da pontuação total obtida nesse instrumento avaliativo, sendo que os indivíduos foram divididos de acordo com sexo e nível socioeconômico (baixo e alto).

$\underline{\text { Tabela } 33}$ - Distribuição dos adultos do Estudo $1(n=88)$ na pontuação do SRQ-20, divididos em função do sexo e do nível socioeconômico.

\begin{tabular}{ccccccccc}
\hline Pontos & \multicolumn{2}{c}{ Baixo nível socioeconômico } & \multicolumn{3}{c}{ Alto nível socioeconômico } & \multicolumn{2}{c}{ Total } \\
no SRQ & M $^{*}$ & $\mathrm{~F}^{*}$ & Subtotal & $\mathrm{M}$ & $\mathrm{F}$ & Subtotal & $\mathrm{f}$ & $\%$ \\
\hline $0-1$ & 3 & 4 & 7 & 15 & 8 & 23 & & \\
$2-3$ & 2 & 8 & 10 & 6 & 10 & 16 & 356 & 64 \\
& & & & & & & & \\
$4-5$ & 2 & 5 & 7 & 4 & 5 & 9 & & \\
6 & - & 3 & 3 & 2 & 1 & 3 & 322 & 25 \\
$7-8$ & - & 5 & 5 & - & 1 & 1 & & \\
$9-10$ & 1 & 1 & 2 & - & 1 & 1 & 310 & \\
$11-12$ & - & - & - & - & - & - & & \\
\hline
\end{tabular}




\begin{tabular}{ccccccccc}
\hline $13-14$ & - & - & - & - & - & - & 11 \\
$\geq 15$ & - & 1 & 1 & - & - & 1 & & \\
Total & 8 & 27 & 35 & 27 & 26 & 53 & 88 & 100,0 \\
\hline
\end{tabular}

${ }^{*} M=$ sexo masculino $; F=$ sexo feminino.

Em relação ao instrumento $S R Q-20$, neste estudo, a maior parte dos indivíduos avaliados alcançou resultados entre zero e três pontos (56 casos, correspondendo a $64 \%$ da amostra). Outra grande parte da amostra obteve entre quatro e seis pontos nesse instrumento (22 indivíduos, totalizando 25\%). Os demais 10 participantes (11\%) dos 88 avaliados obtiveram pontuação igual ou superior a $7 / 8$ pontos, o que seria indicativo de dificuldades de ordem de saúde mental. Desse modo, pode-se considerar os indivíduos avaliados, enquanto grupo, apresentaram indicadores de preservação geral de seu padrão de saúde psíquica, condição que foi inicialmente inferida por entrevista inicial na primeira avaliação em Pasian (1998). 


\subsection{RELATIVOS ao ESTUDO 2}

\subsubsection{Perfil geral dos adultos no Rorschach}

Com base em um dos principais objetivos desse estudo (voltado à elaboração de referenciais normativos atualizados para interpretação do Rorschach), foram caracterizados dados relativos aos índices de produtividade e ao ritmo associativo frente a esse método projetivo de avaliação psicológica, conforme Escola Francesa (Rausch de Traubenberg, 1998). Cabe lembrar que o Estudo 2 englobou a avaliação de 102 novos casos (voluntários adultos) e foram incluídos também 66 indivíduos do Estudo 1, compondo uma amostra de 168 voluntários adultos.

A Tabela 34 apresenta a estatística descritiva da produtividade e ritmo no Rorschach dos adultos avaliados.

Tabela 34 - Estatística descritiva da produtividade e do ritmo no Rorschach da amostra do Estudo 2 (n=168).

\begin{tabular}{cccccc}
\hline Variável* & Média & DP & Mínimo & Mediana & Máximo \\
\hline R & 18,71 & 9,81 & 8 & 16 & 88 \\
RA & 1,35 & 1,76 & 0 & 1 & 11 \\
Rec & 0,30 & 0,64 & 0 & 0 & 3 \\
Den & 0,18 & 0,48 & 0 & 0,18 & 3 \\
TLm & 20,0 & 10,10 & 6,22 & 17,50 & 52,80 \\
TRm & 35,1 & 14,90 & 10,60 & 32,60 & 35,10 \\
\hline
\end{tabular}

${ }^{*} R=$ número total de respostas; $R A=$ número de respostas adicionais; Rec $=$ número de recusas; Den $=$ número de respostas negadas durante o inquérito; TLm = tempo de latência médio (em segundos); TRm= tempo de reação médio (em segundos).

A análise dos dados relativos à produtividade do Rorschach no Estudo 2 demonstra que os adultos avaliados apresentaram adequado número médio de respostas $(\mathrm{R}=18,7)$. Considerando o tempo de latência médio $(T L m=20,0$ segundos $)$ e o tempo 
de resposta médio (TRm $=35,1$ segundos), nota-se boa capacidade associativointerpretativa da realidade. Além disso, há que se comentar que respostas adicionais, recusas e denegações ocorreram com baixa frequência, sugerindo adequado envolvimento dos voluntários com a atividade proposta.

Em complemento às análises dos indicadores de produtividade no Rorschach, apresenta-se o número de respostas, de respostas adicionais, de recusas e de denegações para cada prancha do conjunto total de participantes, buscando retratar as diferenças de reação frente a cada estímulo específico do teste. Estes resultados se encontram na Tabela 35.

Tabela 35- Resultados descritivos (frequência simples e porcentagem), para cada cartão, das variáveis associadas à produtividade no Rorschach.

\begin{tabular}{ccccccccc}
\hline Cartão & \multicolumn{2}{c}{ R } & \multicolumn{2}{c}{ RA } & \multicolumn{2}{c}{ Rec } & \multicolumn{2}{c}{ Den } \\
Rorschach & $f$ & $\%$ & $f$ & $\%$ & $f$ & $\%$ & $f$ & $\%$ \\
\hline I & 347 & 11,03 & $\mathbf{1 3}$ & 5,78 & 1 & 1,92 & 3 & 10,00 \\
II & 329 & 10,46 & 19 & 8,45 & 1 & 1,92 & 4 & 13,30 \\
III & 353 & 11,22 & 32 & 14,22 & 1 & 1,92 & 0 & - \\
IV & 261 & 8,30 & 23 & 10,22 & $\mathbf{8}$ & 15,38 & 4 & 13,30 \\
V & 257 & 8,17 & 17 & 7,56 & 0 & - & 3 & 10,00 \\
VI & $\mathbf{2 5 5}$ & 8,11 & 15 & 6,66 & $\mathbf{9}$ & 17,03 & 0 & - \\
VII & 259 & 8,23 & 26 & 11,55 & 7 & 13,46 & 4 & 13,30 \\
VIII & 327 & 10,40 & 20 & 8,89 & 0 & - & 3 & 10,00 \\
IX & 257 & 8,17 & 27 & 12,00 & $\mathbf{2 0}$ & 38,46 & $\mathbf{5}$ & 16,70 \\
X & $\mathbf{4 9 9}$ & 15,80 & $\mathbf{3 3}$ & 14,67 & 5 & 9,61 & 4 & 13,30 \\
Total & 3.144 & 100,00 & 225 & 100,00 & 52 & 100,00 & 30 & 100,00 \\
\hline
\end{tabular}

$R=$ Respostas; $R A=$ Respostas adicionais; Rec-Recusas aos cartões; Den = Denegações. 
Foram obtidas 3.144 respostas no total dos protocolos dos adultos deste estudo. Obteve-se ainda 255 respostas adicionais, 52 recusas e 30 denegações. O cartão X foi o que obteve um maior número de respostas $(15,8 \%)$, seguido do cartão III $(11,2 \%)$ e do cartão I (11,0\%). Nota-se considerável diferença entre o cartão com maior número de interpretações (X) e aqueles com menos respostas (VI, V e IX), evidenciando importante variação (quase metade) na quantidade de produção diante dos diferentes estímulos (cartões com manchas) que compõem o método de Rorschach.

No que diz respeito às respostas adicionais, recusas e denegações, que sinalizam impacto emocional diante dos estímulos, estas se mostraram pouco evidentes, considerando o total de respostas obtidas nos protocolos analisados. O cartão X foi aquele que apresentou maior número de respostas adicionais (33 respostas, representando 14,7\%), seguido pelos cartões III e IX (14,2\% e 12,0\% respectivamente).

A ocorrência de recusas nas pranchas ocorreu com maior frequência no cartão IX (20 recusas, representando 38,5\% do total de recusas), seguido pelo cartão VI e IV. Já em relação às denegações, estas se mostraram com maior incidência também no cartão IX (cinco denegações, representando $16,7 \%$ do total identificado nesta categoria). O cartão IX parece ter mobilizado impacto emocional nos adultos (cartão com maior número de recusas e de denegações), talvez por provocar contato com elementos menos estruturados e, simbolicamente, representativos de aspectos mais primitivos e inconscientes da personalidade.

Pode-se notar, portanto, que os diferentes cartões do Rorschach possuem especificidades estimulatórias aos indivíduos, favorecendo ou inibindo interpretações, em diferentes áreas de suas manchas. Nesse sentido, ao se examinar as interpretações produzidas diante desse método de avaliação da personalidade, será importante ter em conta essas variáveis de configuração do material apresentado. 
No esforço de mapear o padrão geral de produção dos adultos no Rorschach avaliados nesse trabalho elaborou-se a Tabela 36. Ela traz os dados da distribuição do conjunto de respostas (total de 3.144), produzidas pelos 168 indivíduos, nas diferentes categorias de classificação da produção diante desse teste psicológico.

Tabela 36: Distribuição (em frequência simples e porcentagem) do total de respostas $(R=3.144)$ nas diferentes categorias de classificação do Método de Rorschach.

\begin{tabular}{|c|c|c|c|c|}
\hline $\begin{array}{c}\text { Categorias } \\
\text { classificação }\end{array}$ & $\begin{array}{r}\text { Variáveis } \\
\text { Rorschach } \\
\end{array}$ & f & $\%$ & \\
\hline \multirow{5}{*}{ Localização } & $\mathrm{G}$ & 1.211 & 38,5 & \\
\hline & $\mathrm{D}$ & 1.242 & 39,5 & \\
\hline & $\mathrm{Dd}$ & 645 & 20,5 & \\
\hline & Dbl & 48 & 1,5 & \\
\hline & Do & - & - & \\
\hline \multirow{18}{*}{ Determinantes } & $\mathrm{F}+$ & 654 & 20,8 & \multirow{3}{*}{\} $33,4 \%$} \\
\hline & $\mathrm{F}+-$ & 20 & 0,6 & \\
\hline & F- & 376 & 12,0 & \\
\hline & $\mathrm{K}$ & 305 & 9,7 & \multirow{5}{*}{$29,8 \%$} \\
\hline & kan & 575 & 18,2 & \\
\hline & kob & 37 & 1,2 & \\
\hline & $\mathrm{kp}$ & 23 & 0,7 & \\
\hline & $\Sigma \mathrm{k}$ & 635 & 20,1 & \\
\hline & & & & \\
\hline & $\mathrm{FC}$ & 384 & 12,2 & \multirow{3}{*}{\} $22,1 \%$} \\
\hline & $\mathrm{CF}$ & 296 & 9,4 & \\
\hline & $\mathrm{C}$ & 18 & 0,5 & \\
\hline & FE & 294 & 9,3 & \multirow{3}{*}{\} $14,2 \%$} \\
\hline & $\mathrm{EF}$ & 154 & 4,9 & \\
\hline & $\mathrm{E}$ & 0 & - & \\
\hline & FClob & 8 & 0,25 & \multirow{3}{*}{\} $0,31 \%$} \\
\hline & ClobF & 2 & 0,06 & \\
\hline & Clob & 0 & - & \\
\hline
\end{tabular}




\begin{tabular}{|c|c|c|c|c|}
\hline $\begin{array}{c}\text { Categorias } \\
\text { classificação }\end{array}$ & $\begin{array}{c}\text { Variáveis } \\
\text { Rorschach }\end{array}$ & f & $\%$ & \\
\hline & A & 1.238 & 39,4 & \\
\hline & (A) & 145 & 4,6 & \\
\hline & Ad & 171 & 5,4 & $51,4 \%$ \\
\hline & (Ad) & 64 & 2,0 & \\
\hline & $\mathrm{H}$ & 352 & 11,2 & \\
\hline & $(\mathrm{H})$ & 128 & 4,0 & \\
\hline & $\mathrm{Hd}$ & 139 & 4,4 & $20,5 \%$ \\
\hline & (Hd) & 29 & 0,9 & \\
\hline \multirow[t]{14}{*}{ Conteúdos } & Anat & 200 & 6,4 & \\
\hline & $\mathrm{Sg}$ & 2 & 0,06 & \\
\hline & Sex & 44 & 1,4 & \\
\hline & Obj & 280 & 8,9 & \\
\hline & Art & 19 & 0,6 & \\
\hline & Arq & 27 & 0,9 & \\
\hline & Simb & 35 & 1,1 & \\
\hline & Abs & 11 & 0,3 & \\
\hline & Bot & 127 & 4,0 & \\
\hline & Geo & 62 & 2,0 & \\
\hline & Nat & 9 & 0,3 & \\
\hline & Pais & 21 & 0,7 & \\
\hline & Elem & 4 & 0,1 & \\
\hline & Frag & 33 & 1,0 & \\
\hline Banalidades & Ban & 792 & $25,2 \%$ & \\
\hline
\end{tabular}

A análise da distribuição do conjunto das respostas obtidas entre os modos de apreensão dos estímulos permite notar maior ocorrência de recortes do tipo Grande Detalhe $(D=39,5 \%)$ e, quase em proporção semelhante, as respostas Globais $(G=38,5 \%)$. A seguir aparecem as respostas localizadas em pequenos detalhes dos cartões $(\mathrm{Dd}=20,5 \%)$ e, com baixa frequência, as respostas Detalhe branco $(\mathrm{Dbl}=1,5 \%)$. A localização Do não foi verificada entre as respostas analisadas. Esses achados sugerem tendência, por parte dos adultos avaliados, de apreenderem a realidade a partir de 
elementos práticos e relevantes do contexto, mas também considerando o todo, com menor atenção a minúcias sem, contudo, deixarem de ser relevantes.

Quanto aos determinantes, pode-se observar que pouco mais de um terço das respostas emitidas pelos adultos foi determinada pela forma $(\mathrm{F} \%=33,4 \%)$. Em seguida, aparecem os determinantes associados ao movimento $(29,8 \%)$, cor $(22,1 \%)$ e ao sombreado $(14,2 \%)$, demonstrando que esses adultos utilizaram os elementos formais com moderação, permitindo espaço para a manifestação de elementos imaginativos e afetivos em suas interpretações dos estímulos propostos.

Ao analisar a qualidade formal (F+, F-, F+-) das respostas unicamente determinadas pela forma, observa-se predomínio de $\mathrm{F}+(20,8 \%)$, seguido por F- $(12,0 \%)$ e posteriormente $\mathrm{F}+/-(0,6 \%)$ com inexpressivo número de codificações. A proporção entre respostas de qualidade formal positiva $(\mathrm{F}+)$ e negativa $(\mathrm{F}-)$ indicou adequada precisão perceptiva da realidade por parte dos adultos.

A respeito dos determinantes relacionados ao movimento, houve predominância das pequenas cinestesias em relação às grandes cinestesias $[(\mathrm{kan}+\mathrm{kob}+\mathrm{kp}=20,1 \%)>(\mathrm{K}$ $=9,7 \%)$ ]. Estes dados podem sinalizar que os recursos internos voltados à imaginação e à criação se encontram ainda pouco amadurecidos (predomínio de pequenas cinestesias), uma vez que atingem proporção duas vezes maior que as respostas de grande cinestesia. Indicam ainda que, apesar de haver capacidade para o uso da expressão criativa e simbólica, essa não parece ser completamente aproveitada.

Em relação aos determinantes associados à cor, diante do quadro total de respostas, houve predomínio de $\mathrm{FC}(12,2 \%)$ sobre $\mathrm{CF}(9,4 \%)$ e $\mathrm{C}(0,5 \%)$. E, em relação aos sombreados, também houve predomínio de respostas FE (9,3\%) sobre as respostas EF (4,9\%) e E (0\%). Esses elementos sugerem adequada integração do elemento racional a determinantes associados ao afeto. Por sua vez, a inexpressiva frequência de cor pura 
"C" e ausência de sombreado (puro "E" ou disfórico "Clob"), bem como baixa frequência dos determinantes associados aos sombreados difusos (FClob e ClobF) sinalizam adequada continência lógica de eventuais vivências de angústia.

Quanto à distribuição dos conteúdos presentes nas respostas, houve claro predomínio do conteúdo animal $(51,4 \%)$ e posteriormente conteúdo humano $(20,5 \%)$, totalizando $71,9 \%$ das respostas emitidas no Rorschach pelos adultos avaliados. Apesar dessa concentração de interesses em conteúdos animais e humanos, os adultos avaliados também apresentaram outros conteúdos em suas respostas, sugerindo diversificação de possibilidades interpretativas. Houve respostas de conteúdo objeto $(8,9 \%)$, anatômico $(6,3 \%)$, botânico $(4,0 \%)$ e geográfico $(2,0 \%)$. Os demais conteúdos apresentaram frequência próxima a 1,0\% do total de respostas, sendo, portanto, pouco expressivos.

Analisando as subclasses de resposta animal e humano, houve predomínio de perceptos íntegros $[A+(A)=44,0 \%$ e $H+(H)=15,2]$ sobre os parciais $[\mathrm{Ad}+(\mathrm{Ad})=7,4 \%$ e $\mathrm{Hd}+(\mathrm{Hd})=5,3]$. Compreende-se que a integridade destes perceptos pode representar, simbolicamente, a identidade preservada desses indivíduos. Há que se destacar também que a proporção das respostas de conteúdo animal corresponde a mais que o dobro das respostas de conteúdo humano, o que pode sugerir pouca maturidade no processo do contato com a realidade. Essa análise acompanha a tendência, já apontada, ao predomínio de pequenas cinestesias (kan, kob e kp) em relação às grandes cinestesias $(\mathrm{K})$.

A última variável descritiva da distribuição do conjunto de respostas pelas categorias de classificação do Rorschach é a categoria da banalidade. Houve 25,2\% de respostas banais no total da amostra avaliada, sinalizando adequação ao pensamento coletivo nesses adultos avaliados. 
Esta descrição inicial da distribuição dos resultados permite observar, de maneira ampla, o comportamento dos adultos de 18 a 65 anos diante do Rorschach. Porém, faz-se necessário aprofundar a análise de seus dados, como a seguir explanado.

Após essa breve análise inicial dos resultados (relacionados a localizações, determinantes e conteúdos), focalizar-se-á as variáveis do Método de Rorschach associadas à vivência emocional. A Tabela 37 apresenta esses dados, a partir das duas primeiras fórmulas afetivas da Escola Francesa, a saber: Tipo de Ressonância Íntima (TRI, primeira fórmula) e Tendências Latentes (TL, segunda fórmula).

Tabela 37: Distribuição (em frequência simples e porcentagem) dos adultos ( $n=168$ ) em função do Tipo de Vivência Afetiva(TRI) e da Fórmula das Tendências Latentes (TL).

\begin{tabular}{|c|c|c|c|c|c|c|c|}
\hline \multicolumn{2}{|c|}{ Tipo de vivência afetiva } & \multicolumn{3}{|c|}{ TRI } & \multicolumn{3}{|c|}{ Tendências Latentes (TL) } \\
\hline & & \multicolumn{2}{|c|}{ Frequência simples } & \multirow{2}{*}{$\begin{array}{c}\text { Porcentagem } \\
\} 55,9\end{array}$} & \multicolumn{2}{|c|}{ Frequência simples } & \multirow{2}{*}{$\begin{array}{l}\text { Porcentagem } \\
\}_{16,1}\end{array}$} \\
\hline Extratensivo & $\begin{array}{l}\text { Puro } \\
\text { Dilatado }\end{array}$ & $\begin{array}{l}19 \\
75\end{array}$ & 94 & & $\begin{array}{c}1 \\
26\end{array}$ & 27 & \\
\hline Introversivo & $\begin{array}{l}\text { Puro } \\
\text { Dilatado }\end{array}$ & $\begin{array}{c}6 \\
34\end{array}$ & 40 & \} 23,8 & $\begin{array}{c}9 \\
107\end{array}$ & 116 & \} 69,1 \\
\hline Ambigual & & 7 & 7 & 4,2 & 3 & 3 & 1,8 \\
\hline $\begin{array}{c}\text { Coartativo } \\
\text { Coartado }\end{array}$ & & $\begin{array}{l}14 \\
13\end{array}$ & 27 & 16,0 & $\begin{array}{l}11 \\
11\end{array}$ & 22 & 13,0 \\
\hline
\end{tabular}

Os resultados apontam predomínio dos indivíduos com tipo de Ressonância Íntima (TRI) extratensivo (55,9\%), sinalizando tendência para a manifestação da afetividade de maneira mais direta no ambiente, com recursos de reflexão e vivência interiorizada dos afetos, uma vez que grande parte do subgrupo apresentou fórmula vivencial dilatada. Os tipos introversivos $(23,8 \%)$ e coartativo/coartado $(16,0 \%)$ aparecem em menores proporções e, com ainda menor expressão, o tipo ambigual (4,2\%). 
No tocante à segunda fórmula vivencial, das Tendência Latentes (TL), mais da metade dos adultos foi classificada como introversiva $(69,1 \%)$, seguida pelas proporções de extratensivos $(16,1 \%)$ e coartativos/coartados $(13,0 \%)$, com apenas $1,8 \%$ dos casos classificados como ambiguais. Pode-se notar predominância de uma orientação afetiva voltada para o mundo interior, com capacidades imaginativas e reflexivas latentes, não diretamente associadas à expressão emocional no ambiente.

O exame da reatividade emocional dos indivíduos ainda pode ser realizado a partir da Terceira Fórmula Afetiva (Rausch de Traubenberg, 1998). Os dados dos 168 adultos avaliados nesse trabalho, referentes à reatividade cromática, foram sistematizados de modo a compor a Tabela 38 .

$\underline{\text { Tabela } 38}$-Distribuição dos adultos $(n=168)$ e estatística descritiva (em porcentagem) na Terceira Fórmula Afetiva do Rorschach na atual avaliação.

\begin{tabular}{cccccc}
\hline Terceira Fórmula Afetiva & \multicolumn{2}{c}{ Casos } & \multicolumn{3}{c}{ Dados descritivos (\%) } \\
& $f$ & $\%$ & Média & DP & Mediana \\
\hline Extratensivo & 34 & 20,2 & & & \\
Introversivo & 56 & 33,3 & 33,1 & 8,5 & 33,3 \\
Ambigual & 78 & 46,4 & & & \\
\hline
\end{tabular}

Nota-se que quase metade da amostra apresentou estilo ambigual $(46,4 \%)$ de reatividade às cores, seguido pelos estilos introversivo $(33,3 \%)$ e extratensivo $(20,2 \%)$. Os adultos demonstraram sensibilidade aos elementos cromáticos dos cartões (representantes afetivos), mas sem deixarem de estar atentos a outros determinantes durante a produção das respostas. Além disso, boa parte dos adultos apresentaram estilo introversivo e, em menor frequência, reatividade emocional do tipo extratensiva. Esses 
achados sugerem sensibilidade e flexibilidade dos adultos às demandas ambientais, com possibilidades de reflexão antes de reação imediata aos estímulos, característica do tipo introversivo.

Ainda em relação à descrição das características afetivas dos adultos a partir do Método de Rorschach, focalizou-se análise de algumas variáveis relacionadas ao controle dos impulsos. Esses resultados encontram-se na Tabela 39, que apresenta a distribuição do total de 3.144 respostas dos 168 indivíduos em função de sua somatória e proporção média em algumas categorias avaliativas desse método projetivo de avaliação psicológica (Rausch de Traubenberg, 1998).

Tabela 39: Distribuição das respostas (somatória e dados médios) em variáveis do Rorschach associadas ao controle afetivo.

\begin{tabular}{ccc}
\hline Variáveis do Rorschach & $\begin{array}{c}\text { Frequência total } \\
\text { (somatória) }\end{array}$ & Proporção média \\
\hline $\mathrm{G}: \mathrm{K}$ & $1211: 352$ & $3,5: 1,0$ \\
$\mathrm{~K}: \mathrm{k} \mathrm{F}$ & $352: 635$ & $1,0: 1,8$ \\
$\mathrm{FC}: \mathrm{CF}+\mathrm{C}$ & $384: 314$ & $1,2: 1,0$ \\
$\mathrm{FE}: \mathrm{EF}+\mathrm{E}$ & $294: 154$ & $1,9: 1,0$ \\
\hline
\end{tabular}

A análise da relação entre o total de respostas localizadas na área global do cartão (G) e as grandes cinestesias (determinante K) sugere amplitude na captação dos elementos da realidade, com restrição em interpretações reflexivas e elaboradas. Esses resultados apontam tendência a interpretações superficiais do contexto por parte dos adultos avaliados. A mesma tendência está demonstrada na proporção entre grandes e pequenas cinestesias $\left(\mathrm{K}: \sum \mathrm{k}\right)$, uma vez que os participantes sinalizaram bom potencial de dinamismo interno, porém, utilização parcial dos mesmos recursos (inferência a partir do predomínio de respostas determinadas por pequenas cinestesias). 
Com relação às proporções $(\mathrm{FC}: \mathrm{CF}+\mathrm{C}) \mathrm{e}(\mathrm{FE}: \mathrm{EF}+\mathrm{E})$, os adultos apresentaram sinais sugestivos de aparente controle racional das emoções, tendo em vista a preponderância das respostas determinadas prioritariamente pela forma (FC e FE). Indicaram, desse modo, estabilidade no controle afetivo nesse grupo de adultos, compatível com o esperado por se tratarem de indivíduos não pacientes, selecionados de população não clínica.

Até o momento foram apresentadas as evidências descritivas relativas ao padrão geral de resultados no Rorschach dos adultos avaliados neste estudo. A partir de agora, são apresentadas as análises estatísticas de natureza inferencial, examinando-se a possível influência das variáveis: sexo, escolaridade e idade (subdivididas por faixas etárias) nos dados dessa amostra.

\subsubsection{Análise da influência do sexo no Rorschach}

A influência eventual do sexo na avaliação de personalidade de adultos, embora pouco relatada pela literatura científica da área, foi aqui examinada. As Tabelas 40 e 41 apresentam os dados relativos a comparação estatística em função do sexo (86 mulheres e 82 homens), primeiramente em relação aos índices de produtividade e ritmo e, em seguida, para as demais variáveis. Para este fim, são apresentados os resultados descritivos e comparação estatística dos resultados médios (Teste $t$ de Student para amostras independentes, $p \leq 0,05)$. As variáveis que apresentaram diferenças significativas foram destacadas em negrito.

Tabela 40 - Resultados descritivos e comparação estatística nos índices de produtividade e ritmo do Rorschach dos adultos presentemente avaliados $(n=168)$ em função do sexo.

$\begin{array}{llll}\text { Variáveis } & \text { Sexo } & \text { Dados descritivos } & \text { Comparação Estatística }\end{array}$




\begin{tabular}{|c|c|c|c|c|c|c|}
\hline Rorschach & & Média & $\mathrm{DP}$ & Mediana & $t$ & $p$-value \\
\hline \multirow[t]{2}{*}{$\mathrm{R}$} & Feminino & 19,3 & 11,0 & 16,0 & \multirow[t]{2}{*}{0,745} & \multirow[t]{2}{*}{0,38} \\
\hline & Masculino & 18,1 & 8,3 & 16,0 & & \\
\hline \multirow[t]{2}{*}{ RA } & Feminino & 1,4 & 1,5 & 1,0 & \multirow[t]{2}{*}{0,706} & \multirow[t]{2}{*}{0,402} \\
\hline & Masculino & 1,3 & 1,9 & 1,0 & & \\
\hline \multirow[t]{2}{*}{ Rec } & Feminino & 0,2 & 0,5 & 0 & \multirow[t]{2}{*}{7,760} & \multirow[t]{2}{*}{0,006} \\
\hline & Masculino & 0,4 & 0,7 & 0 & & \\
\hline \multirow{2}{*}{ Den } & Feminino & 0,2 & 0,5 & 0 & \multirow[t]{2}{*}{1,489} & \multirow[t]{2}{*}{0,224} \\
\hline & Masculino & 0,16 & 0,4 & 0 & & \\
\hline \multirow{2}{*}{ TLm } & Feminino & 17,3 & 7,9 & 15,6 & \multirow[t]{2}{*}{8,663} & \multirow[t]{2}{*}{0,004} \\
\hline & Masculino & 22,8 & 11,5 & 20,9 & & \\
\hline \multirow[t]{2}{*}{ TRm } & Feminino & 31,6 & 10,8 & 29,7 & \multirow[t]{2}{*}{7,756} & \multirow[t]{2}{*}{0,006} \\
\hline & Masculino & 38,9 & 17,5 & 35,7 & & \\
\hline
\end{tabular}

$R=$ número total de respostas; $R A=$ número de respostas adicionais; Rec $=$ número de recusas; Den $=$ número de respostas negadas durante o inquérito; TLm = tempo de latência médio (em segundos); TRm = Tempo de reação médio.

Foram identificadas diferenças estatisticamente significativas em função do sexo dos adultos nas variáveis: recusas e as relacionadas aos tempos de latência e de reação médio. O número médio de recusas foi maior para os homens, embora bastante pequeno em ambos os grupos, com significado pouco expressivo no conjunto dos achados. É interessante notar que as mulheres levaram menos tempo para reagirem aos estímulos e para completarem suas interpretações ao Rorschach, enquanto o grupo masculino precisou de tempo ligeiramente maior para se envolver e concluir essa atividade. Essa peculiaridade é sugestiva de maior agilidade associativa no grupo feminino de adultos.

As demais variáveis do Rorschach estão sistematizadas e organizadas na Tabela 41, tendo em vista a comparação em função do sexo dos indivíduos. 
$\underline{\text { Tabela } 41}$ - Resultados descritivos (em porcentagem) e comparação estatística em variáveis do Rorschach relacionadas aos modos de apreensão, determinantes, conteúdos e banalidades dos adultos presentemente avaliados $(n=168)$ em função do sexo.

\begin{tabular}{|c|c|c|c|c|c|c|}
\hline \multirow{2}{*}{$\begin{array}{l}\text { Variáveis } \\
\text { Rorschach }\end{array}$} & \multirow[t]{2}{*}{ Sexo } & \multicolumn{3}{|c|}{ Dados descritivos } & \multicolumn{2}{|c|}{ Comparação Estatística } \\
\hline & & Média & $\mathrm{DP}$ & Mediana & $t$ & $p$-value \\
\hline \multirow[t]{2}{*}{ G } & Feminino & 41,2 & 23,5 & 43,1 & & \\
\hline & Masculino & 47,0 & 24,6 & 44,2 & 0,264 & 0,608 \\
\hline \multirow{2}{*}{$\mathrm{D}$} & Feminino & 40,6 & 16,1 & 40,9 & & \\
\hline & Masculino & 36,1 & 17,8 & 35,3 & 1,938 & 0,166 \\
\hline \multirow{2}{*}{$\mathrm{Dd}$} & Feminino & 17,2 & 15,4 & 15,3 & & \\
\hline & Masculino & 15,2 & 12,4 & 15,1 & 1,887 & 0,171 \\
\hline \multirow[t]{2}{*}{ Dbl } & Feminino & 1,02 & 2,5 & 0 & & \\
\hline & Masculino & 1,68 & 3,1 & 0 & 8,197 & 0,005 \\
\hline Do & $\begin{array}{l}\text { Feminino } \\
\text { Masculino }\end{array}$ & - & - & - & - & - \\
\hline \multirow[t]{2}{*}{$\mathrm{F}+$} & Feminino & 19,0 & 11,9 & 18,2 & 1,351 & 0,247 \\
\hline & Masculino & 23,0 & 14,2 & 23,2 & & \\
\hline \multirow[t]{2}{*}{$\mathrm{F}+-$} & Feminino & 0,2 & 1,2 & 0 & 24,861 & $\leq 0,001$ \\
\hline & Masculino & 1,1 & 2,9 & 0 & & \\
\hline \multirow[t]{2}{*}{ F- } & Feminino & 11,0 & 8,6 & 9,09 & 4,198 & 0,042 \\
\hline & Masculino & 11,4 & 8,7 & 10,42 & & \\
\hline \multirow[t]{2}{*}{$\mathrm{F} \%$} & Feminino & 30,1 & 15,7 & 29,7 & 1,108 & 0,294 \\
\hline & Masculino & 35,4 & 17,7 & 33,3 & & \\
\hline \multirow[t]{2}{*}{$\mathrm{F}+\%$} & Feminino & 60,6 & 25,6 & 61,2 & 0,012 & 0,912 \\
\hline & Masculino & 67,1 & 25,9 & 68,3 & & \\
\hline \multirow{2}{*}{$\mathrm{F}+\mathrm{ext} \%$} & Feminino & 71,1 & 14,2 & 70,5 & 0,304 & 0,582 \\
\hline & Masculino & 73,1 & 12,9 & 73,7 & & \\
\hline \multirow[t]{2}{*}{$\mathrm{K}$} & Feminino & 10,0 & 7,6 & 8,33 & 2,978 & 0,086 \\
\hline & Masculino & 11,1 & 9,6 & 9,09 & & \\
\hline \multirow{2}{*}{ kan } & Feminino & 20,0 & 11,8 & 17,42 & 0,467 & 0,496 \\
\hline & Masculino & 18,0 & 12,2 & 16 & & \\
\hline \multirow{2}{*}{$\begin{array}{l}\text { Variáveis } \\
\text { Rorschach }\end{array}$} & Sexo & \multicolumn{3}{|c|}{ Dados descritivos } & \multicolumn{2}{|c|}{ Comparação Estatística } \\
\hline & & Média & DP & Mediana & $t$ & $p$-value \\
\hline \multirow[t]{2}{*}{ kob } & Feminino & 0,9 & 2,4 & 0 & 9,412 & $\mathbf{0 , 0 0 3}$ \\
\hline & Masculino & 1,5 & 3,0 & 0 & & \\
\hline \multirow[t]{2}{*}{$\mathrm{kp}$} & Feminino & 0,8 & 2,4 & 0 & 5,069 & 0,026 \\
\hline & Masculino & 0,5 & 1,6 & 0 & & \\
\hline
\end{tabular}




\begin{tabular}{|c|c|c|c|c|c|c|}
\hline \multirow[t]{2}{*}{$\sum \mathrm{k}$} & Feminino & 21,6 & 12,4 & 19,3 & & \\
\hline & Masculino & 20,0 & 13,4 & 18 & 0,924 & 0,338 \\
\hline \multirow{2}{*}{$\mathrm{FC}$} & Feminino & 12,5 & 9,3 & 11,1 & \multirow{2}{*}{0,409} & \multirow{2}{*}{0,523} \\
\hline & Masculino & 11,3 & 8,6 & 11,1 & & \\
\hline \multirow{2}{*}{$\mathrm{CF}$} & Feminino & 10,0 & 7,4 & 9 & \multirow{2}{*}{0,419} & \multirow{2}{*}{0,518} \\
\hline & Masculino & 8,3 & 7,6 & 7,27 & & \\
\hline \multirow[t]{2}{*}{$\mathrm{C}$} & Feminino & 1,0 & 2,5 & 0 & \multirow{2}{*}{7,566} & \multirow{2}{*}{$\mathbf{0 , 0 0 7}$} \\
\hline & Masculino & 0,5 & 1,9 & 0 & & \\
\hline \multirow[t]{2}{*}{$\mathrm{FE}$} & Feminino & 9,9 & 7,8 & 8,33 & \multirow[t]{2}{*}{0,740} & \multirow[t]{2}{*}{0,391} \\
\hline & Masculino & 9,8 & 6,8 & 10 & & \\
\hline \multirow{2}{*}{$\mathrm{EF}$} & Feminino & 4,9 & 6,7 & 2,94 & \multirow[t]{2}{*}{2,388} & \multirow{2}{*}{0,124} \\
\hline & Masculino & 4,2 & 4,9 & 2,93 & & \\
\hline \multirow{2}{*}{$\mathrm{E}$} & Feminino & - & - & - & \multirow[t]{2}{*}{ - } & \multirow[t]{2}{*}{ - } \\
\hline & Masculino & - & - & - & & \\
\hline \multirow{2}{*}{ FClob } & Feminino & 0,4 & 1,5 & 0 & \multirow{2}{*}{10,209} & \multirow{2}{*}{0,002} \\
\hline & Masculino & 0,1 & 0,6 & 0 & & \\
\hline \multirow[t]{2}{*}{ ClobF } & Feminino & - & - & 0 & \multirow[t]{2}{*}{8,648} & \multirow[t]{2}{*}{0,004} \\
\hline & Masculino & 0,17 & 1,1 & 0 & & \\
\hline Clob & Feminino & - & - & - & - & - \\
\hline & Masculino & - & - & - & & \\
\hline A & Feminino & 41,8 & 15,7 & 41,6 & 0,425 & 0,515 \\
\hline & Masculino & 38,1 & 16,3 & 37,8 & & \\
\hline (A) & Feminino & 5,3 & 6,6 & 4,88 & 0,131 & 0,718 \\
\hline & Masculino & 4,6 & 5,1 & 3,7 & & \\
\hline Ad & Feminino & 4,4 & 6,1 & 0 & 0,014 & 0,906 \\
\hline & Masculino & 4,7 & 6,2 & 1,31 & & \\
\hline (Ad) & Feminino & 1,2 & 3,1 & 0 & 14,995 & $\leq \mathbf{0 , 0 0 1}$ \\
\hline & Masculino & 3,1 & 4,8 & 0 & & \\
\hline$\sum \mathrm{A} \%$ & Feminino & 52,7 & 15,4 & 53,3 & 0,158 & 0,691 \\
\hline & Masculino & 50,6 & 16,0 & 50 & & \\
\hline $\mathrm{H}$ & Feminino & 11,2 & 7,7 & 8,71 & 5,417 & 0,021 \\
\hline & Masculino & 12,7 & 10,1 & 10 & & \\
\hline$(\mathrm{H})$ & Feminino & 4,1 & 4,7 & 3,37 & 0,783 & 0,377 \\
\hline & Masculino & 4,3 & 5,7 & 1,47 & & \\
\hline Variáveis & Sexo & & s des & itivos & Compar & io Estatística \\
\hline Rorschach & & Média & DP & Mediana & $t$ & $p$-value \\
\hline (Hd) & Feminino & 0,7 & 2,1 & 0 & 2,952 & 0,088 \\
\hline & Masculino & 1,1 & 3,5 & 0 & & \\
\hline$\sum \mathrm{H} \%$ & Feminino & 19,1 & 10,3 & 17,7 & 5,954 & 0,016 \\
\hline & Masculino & 22,8 & 14,9 & 20 & & \\
\hline Anat & Feminino & 6,7 & 8,7 & 3,7 & 0,013 & 0,908 \\
\hline
\end{tabular}




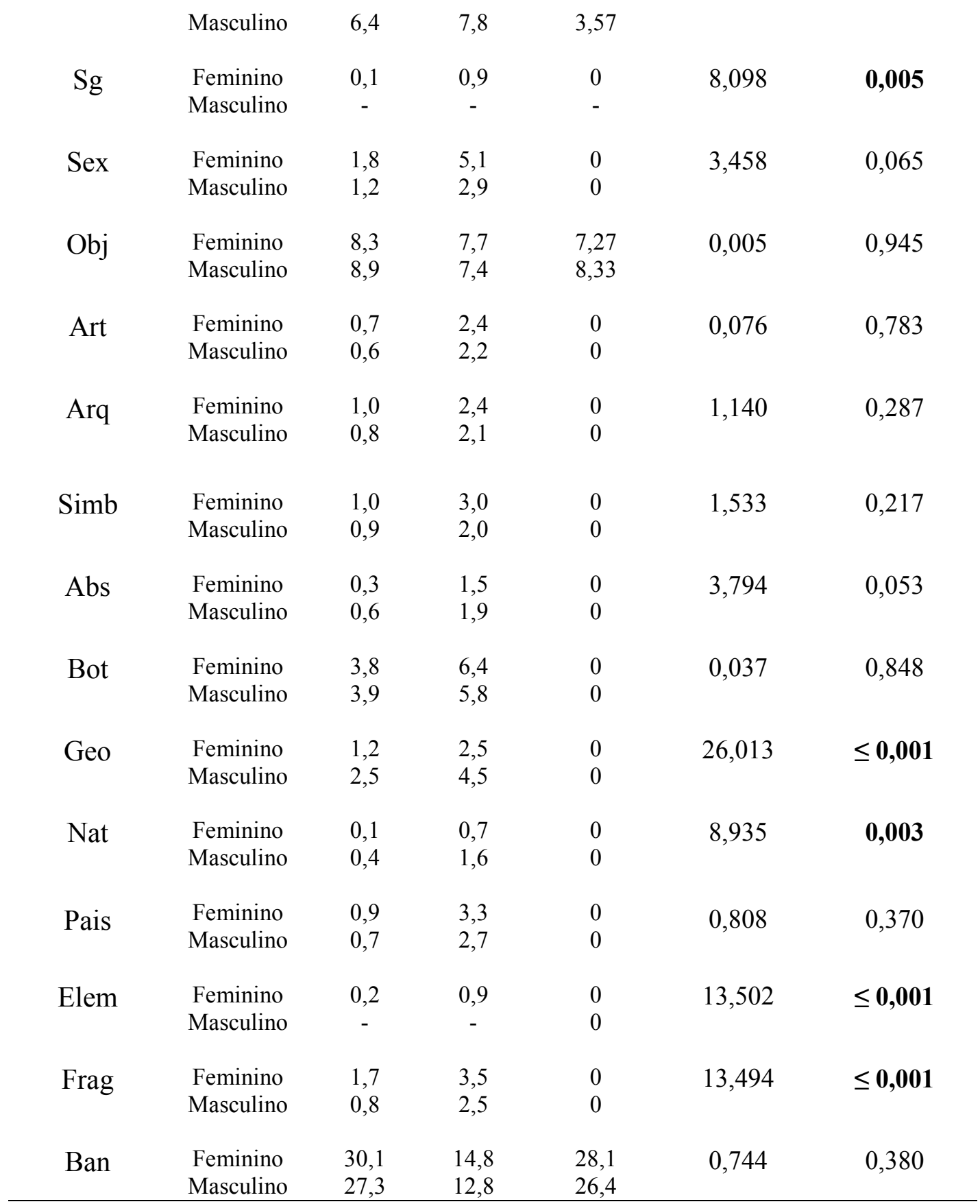

Foram encontradas diferenças estatísticas significantes em 16 das 50 variáveis acima descritas, a saber: na localização Dbl; nos determinantes F+-, F-, kob, kp, C, FClob, ClobF e nos conteúdos (Ad), H, $\sum \mathrm{H} \%$, Sg, Geo, Nat, Elem, Frag. Contudo, antes de prosseguir com possíveis inferências, faz-se necessário ressaltar que 11 das 16 variáveis (Dbl, F+-, kob, kp, C, FClob,ClobF, Sg, Nat, Elem e Frag) apresentaram frequência muito baixa (a média foi inferior a $2 \%$,em ambos os sexos). Isso torna relativo o valor das 
diferenças estatísticas encontradas, havendo pouca relevância do ponto de vista clínico nessas diferenças entre os resultados do grupo feminino e masculino, nessas variáveis de baixa incidência.

É válido considerar e refletir sobre as diferenças encontradas no determinante F-, demonstrando que os homens apresentaram mais falhas na precisão perceptiva do que as mulheres. Em relação aos conteúdos, o grupo masculino apresentou maior frequência média no conteúdo $\mathrm{Ad}$, contudo, na somatória de conteúdos animais ( $\left.\sum \mathrm{A} \%\right)$, essa diferença desapareceu entre os grupos. O conteúdo H foi mais frequente entre os homens, bem como $\sum \mathrm{H} \%$, o que pode sinalizar maior abertura ou interesse para o contato humano no sexo masculino. Os homens também apresentaram maior frequência média de respostas geográficas, podendo sugerir algum tipo de estereotipia em sua produção. Fazse necessário comentar, no entanto, que essas especificidades encontradas em função do sexo dos adultos devem ponderadas frente ao conjunto dos dados, pois muitas das variáveis onde se detectou diferença estatisticamente significativa entre os grupos ocorreram em reduzida proporção nos protocolos do Rorschach, relativizando sua relevância clínica nos achados.

No conjunto da produção das 56 variáveis avaliadas, observa-se que as diferenças significativas encontradas em função do sexo foram pouco expressivas. Estes dados, portanto, não justificam a elaboração de referenciais normativos do Rorschach específicos para adultos em função do sexo, a partir do conjunto de 168 indivíduos presentemente examinados por esse método projetivo de avaliação psicológica.

\subsubsection{Análise da influência da escolaridade no Rorschach}

Para análise do possível efeito dos níveis de escolaridade sobre as variáveis do Rorschach, os adultos foram divididos em três subgrupos: baixo nível de escolaridade (indivíduos com até o antigo primeiro grau - $8^{\mathrm{a}}$ série) $(\mathrm{n}=31)$; média escolaridade 
(indivíduos com até o segundo grau - ensino médio) $(\mathrm{n}=52)$ e alta escolaridade (ensino superior completo e/ou pós-graduação) $(\mathrm{n}=85)$. Recorreu-se a análise de variância (ANOVA), seguida pelo procedimento post hoc de Bonferroni. Foram comparados os resultados em 56 variáveis do Rorschach, obtendo-se os dados apresentados na Tabela 42.

$\underline{\text { Tabela } 42}$ - Resultados descritivos e comparação estatística nos índices de produtividade e ritmo do Rorschach dos adultos presentemente avaliados $(n=168)$ em função dos níveis de escolaridade.

\begin{tabular}{|c|c|c|c|c|c|c|}
\hline \multirow{2}{*}{$\begin{array}{c}\text { Variáveis } \\
\text { Rorschach* }\end{array}$} & \multirow{2}{*}{$\begin{array}{c}\text { Escolaridade* } \\
*\end{array}$} & \multicolumn{3}{|c|}{ Dados descritivos } & \multirow{2}{*}{$\begin{array}{c}\text { Comparação } \\
z\end{array}$} & \multirow{2}{*}{$\begin{array}{r}\text { Estatística } \\
p \text {-value }\end{array}$} \\
\hline & & Média & DP & Mediana & & \\
\hline \multirow{3}{*}{$\mathrm{R}$} & Baixa & 17,1 & 7,3 & 15 & \multirow{3}{*}{0,490} & \multirow{3}{*}{0,614} \\
\hline & Média & 19,3 & 12,3 & 15 & & \\
\hline & Alta & 18,8 & 9 & 17 & & \\
\hline \multirow{3}{*}{ RA } & Baixa & 1,65 & 1,36 & 1 & \multirow{3}{*}{0,263} & \multirow{3}{*}{0,769} \\
\hline & Média & 1,27 & 1,52 & 1 & & \\
\hline & Alta & 1,32 & 2 & 1 & & \\
\hline \multirow{3}{*}{ Rec } & Baixa & 0,52 & 0,9 & 0 & \multirow{3}{*}{2,806} & \multirow{3}{*}{0,063} \\
\hline & Média & 0,17 & 0,43 & 0 & & \\
\hline & Alta & 0,31 & 0,63 & 0 & & \\
\hline \multirow{3}{*}{ Den } & Baixa & 0,23 & 0,61 & 0 & \multirow[b]{3}{*}{0,186} & \multirow[b]{3}{*}{0,830} \\
\hline & Média & 0,17 & 0,43 & 0 & & \\
\hline & Alta & 0,16 & 0,45 & 0 & & \\
\hline \multirow[b]{3}{*}{ TLm } & Baixa & 21,7 & 10,8 & 20 & \multirow{3}{*}{2,330} & \multirow{3}{*}{0,101} \\
\hline & Média & 21,7 & 11,2 & 19 & & \\
\hline & Alta & 18,3 & 9,06 & 16,8 & & \\
\hline \multirow{3}{*}{$\mathrm{TRm}$} & Baixa & 37,7 & 20,8 & 34,2 & \multirow{3}{*}{2,270} & \multirow{3}{*}{0,107} \\
\hline & Média & 37,5 & 13,5 & 35,4 & & \\
\hline & Alta & 32,7 & 12,7 & 29,8 & & \\
\hline
\end{tabular}

A princípio, não foram encontradas diferenças estatisticamente significativas entre os indivíduos de diferentes graus de escolaridade em relação aos índices de produtividade e ritmo. Após a análise post hoc de Bonferroni, apresentada mais abaixo, 
na Tabela 44, observou-se que os indivíduos de baixo nível de escolaridade apresentaram índices mais altos de recusa do que os grupos de mais alta escolaridade, indicando uma possível maior dificuldade na realização da atividade. Contudo, tendo em vista seu baixo índice de frequência, e que o número médio de respostas não obteve diferença estatística significante entre os grupos, deve-se minimizar sua possível compreensão clínico.

Tabela 43 - Resultados descritivos (em porcentagem) e comparação estatística nas variáveis do Rorschach relacionadas aos modos de apreensão, determinantes, conteúdos e banalidades dos adultos presentemente avaliados $(n=168)$ em função dos níveis de escolaridade.

\begin{tabular}{|c|c|c|c|c|c|c|}
\hline \multirow{2}{*}{$\begin{array}{l}\text { Variáveis } \\
\text { Rorschach }\end{array}$} & \multirow[t]{2}{*}{ Escolaridade } & \multicolumn{3}{|c|}{ Dados descritivos } & \multicolumn{2}{|c|}{ Comparação Estatística } \\
\hline & & Média & DP & Mediana & $z$ & $p$-value \\
\hline \multirow{3}{*}{$\mathbf{G}$} & Baixa & 34,5 & 23,2 & 27,2 & \multirow{3}{*}{3,069} & \multirow{3}{*}{0,049} \\
\hline & Média & 45,4 & 25,5 & 48,3 & & \\
\hline & Alta & 46,7 & 23,7 & 44,4 & & \\
\hline \multirow{3}{*}{ D } & Baixa & 45,1 & 15 & 50 & \multirow{3}{*}{3,160} & \multirow{3}{*}{0,045} \\
\hline & Média & 36 & 16,2 & 36 & & \\
\hline & Alta & 37,4 & 17,7 & 37,04 & & \\
\hline \multirow{3}{*}{$\mathrm{Dd}$} & Baixa & 18,2 & 14,7 & 20 & \multirow{3}{*}{1,283} & \multirow{3}{*}{0,280} \\
\hline & Média & 17,8 & 16 & 15,3 & & \\
\hline & Alta & 14,5 & 12,2 & 13,8 & & \\
\hline \multirow{3}{*}{ Dbl } & Baixa & 2 & 3,41 & 0 & \multirow[t]{3}{*}{2,441} & \multirow[t]{3}{*}{0,090} \\
\hline & Média & 0,7 & 1,81 & 0 & & \\
\hline & Alta & 1,47 & 3,04 & 0 & & \\
\hline \multirow{3}{*}{$\begin{array}{l}\text { Variáveis do } \\
\text { Rorschach }\end{array}$} & \multirow[t]{3}{*}{ Escolaridade } & \multicolumn{3}{|c|}{ Dados descritivos } & \multicolumn{2}{|c|}{ Comparação Estatística } \\
\hline & & \multicolumn{2}{|c|}{ Média } & DP & \multirow{2}{*}{\multicolumn{2}{|c|}{$\begin{array}{l}z \\
\text { value }\end{array}$}} \\
\hline & & & Mediar & & & \\
\hline \multirow[t]{3}{*}{$\mathrm{F}+$} & Baixa & 20,2 & 12,1 & 18,2 & \multirow{3}{*}{0,497} & \multirow{3}{*}{0,609} \\
\hline & Média & 19,8 & 12 & 17,1 & & \\
\hline & Alta & 22 & 14,3 & 21,4 & & \\
\hline \multirow[t]{2}{*}{$\mathrm{F}+-$} & Baixa & 0,95 & 3,34 & 0 & \multirow[b]{2}{*}{0,429} & \multirow[b]{2}{*}{0,652} \\
\hline & $\begin{array}{c}\text { Média } \\
\text { Alta }\end{array}$ & 0,61 & 2,09 & 0 & & \\
\hline
\end{tabular}




\begin{tabular}{|c|c|c|c|c|c|c|}
\hline \multirow{4}{*}{ F- } & & 0,52 & 1,8 & & \multirow{4}{*}{0,213} & \multirow{4}{*}{0,808} \\
\hline & Baixa & 12,2 & 10,7 & 9,1 & & \\
\hline & Média & 11 & 7,68 & 9 & & \\
\hline & Alta & 11 & 10,11 & 9,1 & & \\
\hline \multirow{3}{*}{$\mathrm{F} \%$} & Baixa & 33,5 & 16,7 & 31 & \multirow{3}{*}{0,420} & \multirow{3}{*}{0,658} \\
\hline & Média & 31 & 15 & 27,2 & & \\
\hline & Alta & 33,5 & 18 & 32,2 & & \\
\hline \multirow{3}{*}{$\mathrm{F}+\%$} & Baixa & 60,8 & 12 & 62,5 & \multirow{3}{*}{0,349} & \multirow{3}{*}{0,706} \\
\hline & Média & 63,1 & 24,7 & 66,6 & & \\
\hline & Alta & 65,2 & 26,6 & 66,7 & & \\
\hline \multirow{3}{*}{$\mathrm{F}+\mathrm{ext} \%$} & Baixa & 73,2 & 12 & 72,7 & \multirow{3}{*}{0,230} & \multirow{3}{*}{0,795} \\
\hline & Média & 71,2 & 13,5 & 71,2 & & \\
\hline & Alta & 72,3 & 14,3 & 72,7 & & \\
\hline \multirow{3}{*}{$\mathrm{FC}$} & Baixa & 11,5 & 10,3 & 10 & \multirow{3}{*}{1,216} & \multirow{3}{*}{0,299} \\
\hline & Média & 10,5 & 9 & 8,1 & & \\
\hline & Alta & 13 & 8,4 & 12,5 & & \\
\hline \multirow{3}{*}{$\mathrm{CF}$} & Baixa & 7,23 & 6,68 & 7,14 & \multirow{3}{*}{1,595} & \multirow{3}{*}{0,206} \\
\hline & Média & 9 & 7,14 & 8,3 & & \\
\hline & Alta & 10 & 8 & 8,3 & & \\
\hline \multirow[t]{3}{*}{$\mathrm{C}$} & Baixa & 0,54 & 2,1 & 0 & \multirow{3}{*}{1,313} & \multirow{3}{*}{0,272} \\
\hline & Média & 0,43 & 1,78 & 0 & & \\
\hline & Alta & 1,03 & 2,55 & 0 & & \\
\hline \multirow[t]{3}{*}{$\mathrm{FE}$} & Baixa & 10,4 & 7,3 & 10 & \multirow{3}{*}{0,247} & \multirow{3}{*}{0,781} \\
\hline & Média & 9,32 & 6,77 & 8,16 & & \\
\hline & Alta & 10 & 7,73 & 10 & & \\
\hline \multirow{3}{*}{$\mathrm{EF}$} & Baixa & 3,66 & 4,78 & 0 & \multirow{3}{*}{0,425} & \multirow{3}{*}{0,654} \\
\hline & Média & 4,8 & 5,56 & 4,16 & & \\
\hline & Alta & 4,7 & 6,4 & 2,13 & & \\
\hline \multirow{3}{*}{$\mathrm{E}$} & Baixa & 0 & & & & \\
\hline & Média & 0 & - & - & - & - \\
\hline & Alta & 0 & & & & \\
\hline Variáveis do & Escolaridade & & os descr & & Compar & Estatística \\
\hline Rorschach & & Média & DP & & $z$ & $p-$ \\
\hline & & Mediana & & & value & \\
\hline & Baixa & 0,11 & 0,61 & 0 & & \\
\hline FClob & Média & 0,40 & & & 0,728 & 0,485 \\
\hline
\end{tabular}




\begin{tabular}{|c|c|c|c|c|c|c|}
\hline & Alta & 0,2 & $\begin{array}{l}1,45 \\
1,09\end{array}$ & $\begin{array}{l}0 \\
0\end{array}$ & & \\
\hline ClobF & $\begin{array}{c}\text { Baixa } \\
\text { Média } \\
\text { Alta }\end{array}$ & $\begin{array}{l}0 \\
0 \\
0\end{array}$ & - & - & 2,210 & 0,113 \\
\hline Clob & $\begin{array}{c}\text { Baixa } \\
\text { Média } \\
\text { Alta }\end{array}$ & $\begin{array}{l}0 \\
0 \\
0\end{array}$ & - & - & - & - \\
\hline $\mathbf{K}$ & $\begin{array}{c}\text { Baixa } \\
\text { Média } \\
\text { Alta }\end{array}$ & $\begin{array}{l}6,77 \\
12,9 \\
10,5\end{array}$ & $\begin{array}{c}7,16 \\
10,3 \\
7,8\end{array}$ & $\begin{array}{l}5,88 \\
9,84 \\
9,52\end{array}$ & 4,999 & 0,008 \\
\hline kan & $\begin{array}{l}\text { Baixa } \\
\text { Média } \\
\text { Alta }\end{array}$ & $\begin{array}{l}24,2 \\
19,8 \\
16,7\end{array}$ & $\begin{array}{l}14,2 \\
10,9 \\
11,2\end{array}$ & $\begin{array}{l}23,5 \\
18,1 \\
14,8\end{array}$ & 4,770 & 0,010 \\
\hline kob & $\begin{array}{l}\text { Baixa } \\
\text { Média } \\
\text { Alta }\end{array}$ & $\begin{array}{c}1,1 \\
1,05 \\
1,3\end{array}$ & $\begin{array}{c}2,6 \\
2,38 \\
2,96\end{array}$ & $\begin{array}{l}0 \\
0 \\
0\end{array}$ & 0,148 & 0,862 \\
\hline $\mathrm{kp}$ & $\begin{array}{c}\text { Baixa } \\
\text { Média } \\
\text { Alta }\end{array}$ & $\begin{array}{c}0,96 \\
0,9 \\
0,41\end{array}$ & $\begin{array}{l}2,42 \\
2,32 \\
1,62\end{array}$ & $\begin{array}{l}0 \\
0 \\
0\end{array}$ & 1,356 & 0,261 \\
\hline$\sum \mathbf{k}$ & $\begin{array}{l}\text { Baixa } \\
\text { Média } \\
\text { Alta }\end{array}$ & $\begin{array}{l}26,2 \\
21,6 \\
18,4\end{array}$ & $\begin{array}{c}15,5 \\
12 \\
11,7\end{array}$ & $\begin{array}{l}25,9 \\
18,6 \\
16,6\end{array}$ & 4,514 & 0,012 \\
\hline $\mathbf{A}$ & $\begin{array}{c}\text { Baixa } \\
\text { Média } \\
\text { Alta }\end{array}$ & $\begin{array}{c}53 \\
38,8 \\
36\end{array}$ & $\begin{array}{l}16,8 \\
13,6 \\
14,9\end{array}$ & $\begin{array}{l}46,1 \\
41,6 \\
35,2\end{array}$ & 15,050 & $\leq 0,001$ \\
\hline (A) & $\begin{array}{c}\text { Baixa } \\
\text { Média } \\
\text { Alta }\end{array}$ & $\begin{array}{c}3 \\
5,77 \\
5,17\end{array}$ & $\begin{array}{c}3,5 \\
5,91 \\
6,45\end{array}$ & $\begin{array}{c}0 \\
5,88 \\
4,17\end{array}$ & 2,280 & 0,105 \\
\hline Ad & $\begin{array}{c}\text { Baixa } \\
\text { Média } \\
\text { Alta }\end{array}$ & $\begin{array}{c}4,4 \\
5,31 \\
4,11\end{array}$ & $\begin{array}{l}5,82 \\
6,81 \\
5,78\end{array}$ & $\begin{array}{c}0 \\
3,43 \\
0\end{array}$ & 0,617 & 0,541 \\
\hline$(\mathrm{Ad})$ & $\begin{array}{l}\text { Baixa } \\
\text { Média } \\
\text { Alta }\end{array}$ & $\begin{array}{l}1,37 \\
2,24 \\
2,41\end{array}$ & $\begin{array}{l}2,76 \\
5,06 \\
3,84\end{array}$ & $\begin{array}{l}0 \\
0 \\
0\end{array}$ & 0,745 & 0,477 \\
\hline$\sum \mathbf{A}$ & $\begin{array}{l}\text { Baixa } \\
\text { Média } \\
\text { Alta }\end{array}$ & $\begin{array}{l}61,8 \\
52,1 \\
47,7\end{array}$ & $\begin{array}{l}14,8 \\
15,1 \\
14,8\end{array}$ & $\begin{array}{c}58,8 \\
53,3 \\
50\end{array}$ & 10,242 & $\leq \mathbf{0 , 0 0 1}$ \\
\hline
\end{tabular}

\begin{tabular}{ccrrrrr}
\hline $\begin{array}{c}\text { Variáveis do } \\
\text { Rorschach }\end{array}$ & Escolaridade & \multicolumn{4}{c}{ Dados descritivos } & \multicolumn{2}{c}{ Comparação Estatística } \\
& & Média & DP & Mediana & $\boldsymbol{z}$ & $p$-value \\
\hline H & Baixa & 8,8 & 7,26 & 7,7 & & \\
& Média & 13,4 & 9,82 & 10,1 & 10,242 & $\leq \mathbf{0 , 0 0 1}$ \\
\hline
\end{tabular}




\begin{tabular}{|c|c|c|c|c|c|c|}
\hline & Alta & 12,1 & 8,74 & 10 & & \\
\hline \multirow{3}{*}{$(\mathrm{H})$} & Baixa & 2,39 & 4,16 & 0 & \multirow{3}{*}{2,680} & \multirow{3}{*}{0,072} \\
\hline & Média & 5,08 & 6,2 & 3,5 & & \\
\hline & Alta & 4,34 & 4,8 & 4,17 & & \\
\hline \multirow{3}{*}{$\mathrm{Hd}$} & Baixa & 3,8 & 6,21 & 0 & \multirow{3}{*}{0,027} & \multirow{3}{*}{0,973} \\
\hline & Média & 3,72 & 4,75 & 0 & & \\
\hline & Alta & 3,94 & 5,54 & 0 & & \\
\hline \multirow{3}{*}{ (Hd) } & Baixa & 1,14 & 2,55 & 0 & \multirow{3}{*}{0,448} & \multirow{3}{*}{0,640} \\
\hline & Média & 1,11 & 3,47 & 0 & & \\
\hline & Alta & 0,7 & 2,55 & 0 & & \\
\hline \multirow{3}{*}{$\sum \mathrm{H}$} & Baixa & 16,1 & 12,5 & 12,5 & \multirow{3}{*}{3,137} & \multirow{3}{*}{0,046} \\
\hline & Média & 23,3 & 12,3 & 19,5 & & \\
\hline & Alta & 21,1 & 13 & 18,7 & & \\
\hline \multirow{3}{*}{ Anat } & Baixa & 3,15 & 5,55 & 0 & \multirow[t]{3}{*}{5,975} & \multirow[t]{3}{*}{$\mathbf{0 , 0 0 3}$} \\
\hline & Média & 5,39 & 6 & 4,46 & & \\
\hline & Alta & 8,55 & 9,67 & 5,56 & & \\
\hline \multirow{3}{*}{$\mathrm{Sg}$} & Baixa & 0 & 0 & 0 & \multirow[t]{3}{*}{0,301} & \multirow[t]{3}{*}{0,74} \\
\hline & Média & 0,12 & 0,86 & 0 & & \\
\hline & Alta & 0,07 & 2,55 & 0 & & \\
\hline \multirow{3}{*}{ Sex } & Baixa & 3,08 & 6,51 & 0 & \multirow[t]{3}{*}{2,941} & \multirow[t]{3}{*}{0,05} \\
\hline & Média & 0,9 & 3,45 & 0 & & \\
\hline & Alta & 1,3 & 3,32 & 0 & & \\
\hline \multirow{3}{*}{ Obj } & Baixa & 5,45 & 0 & 7,08 & \multirow[t]{3}{*}{4,207} & \multirow[t]{3}{*}{$\mathbf{0 , 0 1}$} \\
\hline & Média & 8,24 & 7,69 & 7,06 & & \\
\hline & Alta & 9,93 & 8,7 & 7,74 & & \\
\hline \multirow{3}{*}{ Art } & Baixa & 0,63 & 2,83 & 0 & \multirow{3}{*}{1,164} & 0,315 \\
\hline & Média & 0,3 & 1,5 & 0 & & \\
\hline & Alta & 0,91 & 2,5 & 0 & & \\
\hline & Baixa & 0,9 & 2,5 & 0 & 0,050 & 0,951 \\
\hline Arq & Média & 0,83 & 2,3 & 0 & & \\
\hline & Alta & 0,96 & 2,2 & 0 & & \\
\hline & Baixa & 0,41 & 1,8 & 0 & 0,907 & 0,406 \\
\hline Simb & Média & 1 & 2,88 & 0 & & \\
\hline & Alta & 1,15 & 2,69 & 0 & & \\
\hline Abst & Baixa & 0,3 & 1,63 & 0 & & \\
\hline & Média & 0,66 & 2,1 & 0 & 0,753 & 0,472 \\
\hline & Alta & 0,32 & 1,44 & 0 & & \\
\hline & Baixa & 3,88 & 6,68 & 0 & 1,490 & 0,228 \\
\hline Bot & Média & 2,7 & 3,56 & 0 & & \\
\hline & Alta & 4,5 & 6,7 & 0 & & \\
\hline
\end{tabular}

\begin{tabular}{|c|c|c|c|c|c|}
\hline \multirow{3}{*}{$\begin{array}{l}\text { Variáveis do } \\
\text { Rorschach }\end{array}$} & \multirow[t]{3}{*}{ Escolaridade } & \multicolumn{3}{|c|}{ Dados descritivos } & \multirow{2}{*}{$\begin{array}{c}\text { Comparação } \\
\text { Estatística }\end{array}$} \\
\hline & & Média & DP & Mediana & \\
\hline & & & & & $p$-value \\
\hline
\end{tabular}




\begin{tabular}{|c|c|c|c|c|c|c|}
\hline \multirow[t]{3}{*}{ Geo } & Baixa & 1,9 & 4,02 & 0 & \multirow{3}{*}{0,175} & \multirow{3}{*}{0,840} \\
\hline & Média & 2 & 4,06 & 0 & & \\
\hline & Alta & 1,64 & 3,26 & 0 & & \\
\hline \multirow{3}{*}{ Nat } & Baixa & 0,35 & 1,11 & 0 & \multirow[t]{3}{*}{1,185} & \multirow{3}{*}{0,308} \\
\hline & Média & 0,42 & 1,8 & 0 & & \\
\hline & Alta & 0,12 & 0,63 & 0 & & \\
\hline \multirow{3}{*}{ Pais } & Baixa & 0,24 & 1,38 & 0 & \multirow{3}{*}{1,670} & \multirow{3}{*}{0,191} \\
\hline & Média & 0,5 & 2,03 & 0 & & \\
\hline & Alta & 1,23 & 3,83 & 0 & & \\
\hline \multirow{3}{*}{ Elem } & Baixa & 0 & 0 & 0 & \multirow[t]{3}{*}{1,003} & \multirow[t]{3}{*}{0,369} \\
\hline & Média & 0,2 & 0,93 & 0 & & \\
\hline & Alta & 0,07 & 0,6 & 0 & & \\
\hline \multirow{3}{*}{ Frag } & Baixa & 1,62 & 4,06 & 0 & \multirow[t]{3}{*}{2,283} & \multirow[t]{3}{*}{0,105} \\
\hline & Média & 1,17 & 3,07 & 0 & & \\
\hline & Alta & 1,2 & 2,74 & 0 & & \\
\hline \multirow{3}{*}{ Ban } & Baixa & 32,8 & 17,24 & 26,3 & \multirow[t]{3}{*}{2,283} & \multirow[t]{3}{*}{0,105} \\
\hline & Média & 29,5 & 16,05 & 26 & & \\
\hline & Alta & 26,8 & 12,6 & 28,5 & & \\
\hline
\end{tabular}

De forma geral, os indivíduos de diferentes níveis de escolaridade apresentaram semelhanças no modo de responder ao Rorschach. Contudo, foram observadas diferenças estatisticamente significativas em 10 das 56 variáveis examinadas: $\mathrm{G}, \mathrm{D}, \mathrm{K}, \mathrm{kan}, \sum \mathrm{k}, \mathrm{A}$, $\sum \mathrm{A} \%, \sum \mathrm{H} \%$, Anat e Obj. Por meio do teste pós hoc de Bonferroni foi possível identificar a direção dessas especificidades de produção, associadas ao nível de escolaridade dos adultos. A Tabela 44 apresenta esses achados.

Tabela 44: Resultados da análise post hoc de Bonferroni das variáveis com diferenças estatisticamente significativas no Rorschach, em função da escolaridade. 


\begin{tabular}{|c|c|c|c|}
\hline Variáveis & Médias & Escolaridade & $p$-value \\
\hline \multirow{3}{*}{$\operatorname{Rec}$} & 0,52 & Baixa X Média & $\mathbf{0 , 0 5 7}$ \\
\hline & 0,17 & Baixa X Alta & 0,355 \\
\hline & 0,31 & Média X Alta & 0,717 \\
\hline \multirow{3}{*}{ G } & 34,5 & Baixa X Média & 0,139 \\
\hline & 45,4 & Baixa X Alta & 0,049 \\
\hline & 46,7 & Média X Alta & 1,000 \\
\hline \multirow{3}{*}{ D } & 45,1 & Baixa X Média & $\mathbf{0 , 0 5 4}$ \\
\hline & 36 & Baixa X Alta & 1,000 \\
\hline & 37,4 & Média X Alta & 0,088 \\
\hline \multirow{3}{*}{$\mathbf{K}$} & 6,77 & Baixa X Média & 0,006 \\
\hline & 12,9 & Baixa X Alta & 0,114 \\
\hline & 10,5 & Média X Alta & 0,346 \\
\hline \multirow{3}{*}{ kan } & 24,2 & Baixa X Média & 0,305 \\
\hline & 19,8 & Baixa X Alta & 0,008 \\
\hline & 16,7 & Média X Alta & 0,407 \\
\hline \multirow{3}{*}{$\sum \mathbf{k}$} & 26,2 & Baixa X Média & 0,319 \\
\hline & 21,6 & Baixa X Alta & 0,011 \\
\hline & 18,4 & Média X Alta & 0,460 \\
\hline \multirow{3}{*}{$\mathbf{A}$} & 53 & Baixa X Média & $\leq 0,0001$ \\
\hline & 38,8 & Baixa X Alta & $\leq 0,0001$ \\
\hline & 36 & Média X Alta & 0,857 \\
\hline \multirow{3}{*}{$\sum \mathbf{A}$} & 61,8 & Baixa X Média & 0,014 \\
\hline & 52,1 & Baixa X Alta & $\leq 0,001$ \\
\hline & 47,7 & Média X Alta & 0,279 \\
\hline
\end{tabular}




\begin{tabular}{cccc}
\hline Variáveis & Médias & Escolaridade & $\boldsymbol{p}$-value \\
\hline \multirow{2}{*}{$\mathbf{H}$} & 16,1 & Baixa X Média & $\mathbf{0 , 0 4 1}$ \\
& 23,3 & Baixa X Alta & 0,188 \\
& 21,1 & Média X Alta & 0,986 \\
\hline \multirow{2}{*}{ Anat } & 3,15 & Baixa X Média & 0,664 \\
& 5,39 & Baixa X Alta & $\mathbf{0 , 0 0 5}$ \\
& 8,55 & Média X Alta & 0,079 \\
\hline \multirow{2}{*}{ Obj } & 5,45 & Baixa X Média & 0,299 \\
& 8,24 & Baixa X Alta & $\mathbf{0 , 0 1 4}$ \\
& 9,93 & Média X Alta & 0,5973 \\
\hline
\end{tabular}

No geral, nas variáveis em que foram encontradas diferenças estatisticamente significativas observa-se que o grupo de baixa escolaridade diferiu dos demais grupos. Os adultos de média e alta escolaridade não sinalizaram diferenças relevantes entre si diante do Rorschah. Nas variáveis G, K, $\sum \mathrm{H} \%$, Anat e Obj o grupo de baixa escolaridade apresentou média menor que os demais, enquanto que para as variáveis $\mathrm{D}, \mathrm{kan}, \sum \mathrm{k}, \mathrm{A}$, $\sum \mathrm{A} \%$ apresentou média maior que os grupos de média e alta escolaridade.

Os grupos de média e alta escolaridade apresentaram maiores índices de respostas globais do que o de baixa escolaridade, indicando maior atenção aos elementos gerais e possibilidades de integração dos elementos apresentados no processo de interpretação da realidade. Os grupos mais escolarizados também revelaram índices superiores em relação aos movimentos humanos $(\mathrm{K})$ e aos conteúdos humanos $\left(\sum \mathrm{H} \%\right)$, sugestivos de maior possibilidade de reflexão, interiorização e interesse maior no contato humano. Por outro lado, o grupo de baixa escolaridade apresentou maiores índices de movimento animal (kan), maior soma de pequenas cinestesias $(\Sigma \mathrm{k})$, de conteúdo animal A e na soma de conteúdos animais ( $\Sigma \mathrm{A} \%)$,indicando sinais de imaturidade emocional e espontaneidade na interpretação dos cartões. Por fim, é preciso comentar que os adultos de média e alta 
escolaridade apresentaram maior número de respostas de conteúdos anatômicos e objetos, o que se configuram como indicadores de vivências de angústia e tentativas de racionalização associadas a maior treino acadêmico.

Cumpre destacar, no entanto, que os atuais achados relativos às influências do nível de escolaridade nos adultos diante do Rorschach precisam ser ponderados no conjunto das variáveis desse método de avaliação da personalidade, visto que apenas o conjunto do protocolo permite adequadas visualização e interpretação dos resultados. Variáveis isoladas, ainda que estatisticamente significativas, podem induzir a vieses interpretativos e de risco para a compreensão da personalidade, tendo em vista sua complexidade, sendo, portanto, necessária cautela nas inferências derivadas dessas análises. Diante do exposto e ao se considerar a análise global dos dados, o número das especificidades de produção diante do Rorschach associadas ao nível de escolaridade pareceu não ser relevante o suficiente para justificar a elaboração de normas avaliativas específicas para o grupo de adultos, embora devam ser consideradas como aspectos clinicamente relevantes nos processos de interpretação desse método projetivo.

\subsubsection{Análise da influência da idade no Rorschach}

Para verificar eventual efeito da idade dos adultos sobre as variáveis do Método de Rorschach foram realizadas comparações estatísticas dos resultados em função das faixas etárias, compondo-se quatro subgrupos: 18-29 anos $(\mathrm{n}=24), 30-39$ anos $(\mathrm{n}=29)$, 40-49 $\operatorname{anos}(n=39)$ e 50 a $65 \operatorname{anos}(n=76)$. Os procedimentos adotados foram os mesmos descritos para a análise da escolaridade (ANOVA e post hoc de Bonferroni), sendo que os resultados encontrados se encontram na Tabela 45 . 


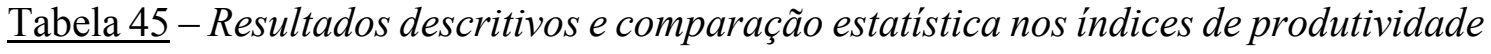
e ritmo do Rorschach dos adultos presentemente avaliados $(n=168)$ em função dos níveis da idade.

\begin{tabular}{|c|c|c|c|c|c|c|}
\hline \multirow{3}{*}{$\begin{array}{c}\text { Variáveis } \\
\text { Rorschach } \\
*\end{array}$} & \multirow[t]{3}{*}{ Faixa etária } & \multirow{2}{*}{\multicolumn{3}{|c|}{ Dados descritivos }} & \multirow{2}{*}{\multicolumn{2}{|c|}{$\begin{array}{c}\text { Comparação } \\
\text { Estatística }\end{array}$}} \\
\hline & & & & & & \\
\hline & & Média & DP & Mediana & $z$ & $p$-value \\
\hline \multirow{4}{*}{$\mathrm{R}$} & 18-29 anos & 19,5 & 8,47 & 17 & \multirow{4}{*}{0,139} & \multirow{4}{*}{0,936} \\
\hline & 30-39 anos & 18 & 8 & 16 & & \\
\hline & 40-49 anos & 18,3 & 7,37 & 16 & & \\
\hline & $50-65$ anos & 19 & 11,8 & 16 & & \\
\hline \multirow{4}{*}{ RA } & 18-29 anos & 1,29 & 1,78 & 0 & \multirow{4}{*}{0,216} & \multirow{4}{*}{0,885} \\
\hline & 30-39 anos & 1,34 & 1,69 & 1 & & \\
\hline & 40-49 anos & 1,53 & 2,12 & 1 & & \\
\hline & $50-65$ anos & 1,26 & 1,6 & 1 & & \\
\hline \multirow{4}{*}{ Rec } & 18-29 anos & 0,38 & 0,71 & 0 & \multirow{4}{*}{0,666} & \multirow{4}{*}{0,574} \\
\hline & 30-39 anos & 0,31 & 0,8 & 0 & & \\
\hline & 40-49 anos & 0,18 & 0,45 & 0 & & \\
\hline & $50-65$ anos & 0,34 & 0,6 & 0 & & \\
\hline \multirow{4}{*}{ Den } & 18-29 anos & 0,08 & 0,28 & 0 & \multirow{4}{*}{1,145} & \multirow{4}{*}{0,333} \\
\hline & 30-39 anos & 0,10 & 0,31 & 0 & & \\
\hline & 40-49 anos & 0,15 & 0,43 & 0 & & \\
\hline & $50-65$ anos & 0,25 & 0,60 & 0 & & \\
\hline \multirow{4}{*}{ TLm } & 18-29 anos & 24,8 & 14 & 23,6 & \multirow{4}{*}{2,179} & \multirow{4}{*}{0,093} \\
\hline & 30-39 anos & 19 & 10 & 17 & & \\
\hline & 40-49 anos & 19,8 & 10,2 & 16 & & \\
\hline & $50-65$ anos & 19 & 8,48 & 17,5 & & \\
\hline \multirow[t]{4}{*}{$\mathrm{TRm}$} & 18-29 anos & 35,2 & 13,4 & 35,3 & \multirow{4}{*}{0,152} & \multirow{4}{*}{0,928} \\
\hline & 30-39 anos & 33,6 & 14,5 & 28,5 & & \\
\hline & 40-49 anos & 35 & 12 & 33 & & \\
\hline & $50-65$ anos & 35,8 & 17 & 32,8 & & \\
\hline
\end{tabular}

${ }^{*} R=$ número total de respostas; $R A=$ número de respostas adicionais; $R e c=$ número de recusas; Den $=$ número de respostas negadas durante o inquérito;TLm = tempo de latência médio (em segundos); TRm = Tempo de reação médio. 
Em relação aos índices de produtividade, não foram encontradas diferenças com significância estatística entre os adultos de diferentes faixas etárias, indicando que o ritmo e modo de associação dos estímulos foi semelhante para estes adultos.

A seguir, a Tabela 46, apresenta os resultados descritivos para as demais variáveis do Rorschach, relativos aos modos de apreensão, determinantes, conteúdos e banalidades.

$\underline{\text { Tabela } 46}$ - Resultados descritivos (em porcentagem) e comparação estatística em variáveis do Rorschach relacionadas aos modos de apreensão, determinantes, conteúdos e banalidades dos adultos presentemente avaliados $(n=168)$ em função da idade.

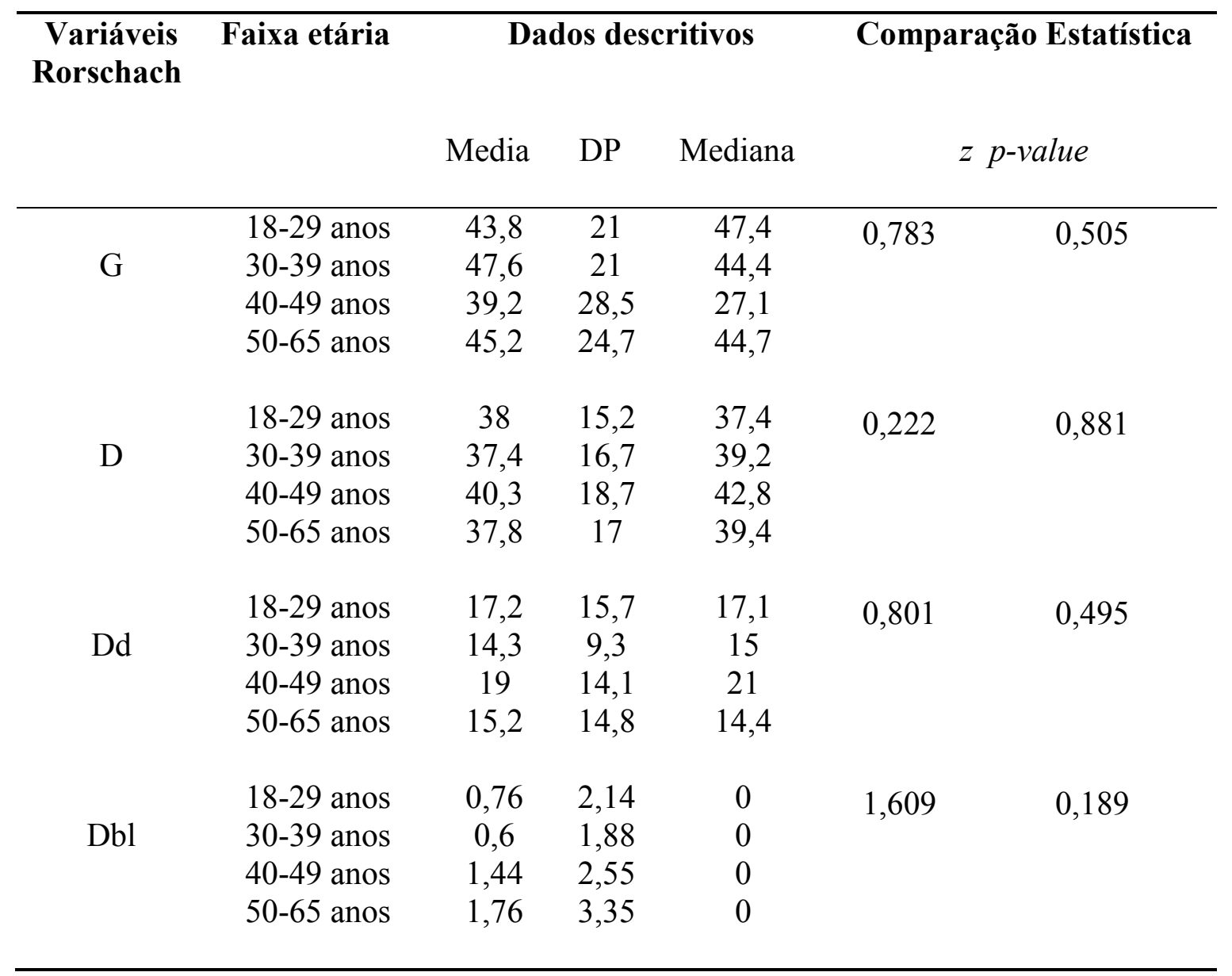

\begin{tabular}{|c|c|c|c|c|c|}
\hline \multirow{2}{*}{$\begin{array}{l}\text { Variáveis } \\
\text { Rorschach }\end{array}$} & \multirow{2}{*}{$\begin{array}{l}\text { Faixa } \\
\text { etária }\end{array}$} & \multicolumn{3}{|c|}{ Dados descritivos } & Comparação Estatística \\
\hline & & Média & $\mathrm{DP}$ & Mediana & $p$-value \\
\hline
\end{tabular}




\begin{tabular}{|c|c|c|c|c|c|c|}
\hline \multirow{4}{*}{$\mathrm{F}+$} & 18-29 anos & 25,5 & 14,1 & 23,1 & \multirow{4}{*}{1,437} & \multirow[t]{4}{*}{0,234} \\
\hline & 30-39 anos & 21,8 & 11,2 & 21,4 & & \\
\hline & 40-49 anos & 21 & 15 & 18,2 & & \\
\hline & $50-65$ anos & 19,2 & 12,5 & 18 & & \\
\hline \multirow{4}{*}{$\mathrm{F}+-$} & 18-29 anos & 0 & 0 & 0 & \multirow[t]{4}{*}{2,444} & \multirow[t]{4}{*}{0,066} \\
\hline & 30-39 anos & 1,55 & 2,87 & 0 & & \\
\hline & 40-49 anos & 0,45 & 1,74 & 0 & & \\
\hline & $50-65$ anos & 0,56 & 2,45 & 0 & & \\
\hline \multirow{4}{*}{ F- } & 18-29 anos & 12 & 8,33 & 12,1 & \multirow[t]{4}{*}{1,719} & \multirow[t]{4}{*}{0,165} \\
\hline & $30-39$ anos & 9,78 & 7,31 & 8,33 & & \\
\hline & 40-49 anos & 9 & 7,08 & 7,7 & & \\
\hline & $50-65$ anos & 12,7 & 11,3 & 9 & & \\
\hline \multirow{4}{*}{$\mathrm{F} \%$} & 18-29 anos & 37,5 & 17,1 & 36,5 & \multirow{4}{*}{1,064} & \multirow[t]{4}{*}{0,366} \\
\hline & 30-39 anos & 33,1 & 13,6 & 33,3 & & \\
\hline & 40-49 anos & 29,7 & 16 & 27,2 & & \\
\hline & $50-65$ anos & 32,5 & 18,1 & 34 & & \\
\hline \multirow{4}{*}{$\mathrm{F}+\%$} & 18-29 anos & 68,7 & 18,8 & 66 & \multirow[t]{4}{*}{0,349} & \multirow[t]{4}{*}{0,706} \\
\hline & 30-39 anos & 66,4 & 23,7 & 66,6 & & \\
\hline & 40-49 anos & 65,8 & 27,3 & 66,7 & & \\
\hline & 50-65 anos & 59,6 & 27,6 & 62,1 & & \\
\hline \multirow{4}{*}{$\mathrm{F}+\operatorname{ext} \%$} & 18-29 anos & 70,6 & 12 & 71,2 & \multirow{4}{*}{0,230} & \multirow{4}{*}{0,795} \\
\hline & 30-39 anos & 73,8 & 13,5 & 73 & & \\
\hline & $40-49$ anos & 74,2 & 9,85 & 75 & & \\
\hline & $50-65$ anos & 71 & 15,8 & 71,4 & & \\
\hline \multirow{4}{*}{$\mathrm{FC}$} & 18-29 anos & 11,2 & 8,9 & 11 & \multirow{4}{*}{0,104} & \multirow{4}{*}{0,958} \\
\hline & 30-39 anos & 12,4 & 7,86 & 11,1 & & \\
\hline & 40-49 anos & 12,3 & 9,76 & 10 & & \\
\hline & $50-65$ anos & 11,8 & 9,11 & 11,1 & & \\
\hline \multirow{4}{*}{$\mathrm{CF}$} & 18-29 anos & 11,7 & 6,41 & 12,2 & \multirow[t]{4}{*}{1,473} & \multirow{4}{*}{0,224} \\
\hline & 30-39 anos & 9,74 & 8,44 & 8,33 & & \\
\hline & 40-49 anos & 9,12 & 6,67 & 7,14 & & \\
\hline & $50-65$ anos & 8,1 & 7,8 & 7,41 & & \\
\hline & 18-29 anos & 0,26 & 1,27 & 0 & \multirow[t]{4}{*}{1,173} & \multirow[t]{4}{*}{0,322} \\
\hline & 30-39 anos & 0,67 & 2,53 & 0 & & \\
\hline $\mathrm{C}$ & $40-49$ anos & 1 & 2,7 & 0 & & \\
\hline & $50-65$ anos & 0,96 & 2,46 & 0 & & \\
\hline & 18-29 anos & 8,22 & 6,4 & 7,7 & 0,822 & 0,484 \\
\hline FE & 30-39 anos & 10,1 & 7,4 & 10,2 & & \\
\hline & 40-49 anos & 9,16 & 7 & 8,33 & & \\
\hline & $50-65$ anos & 10,3 & 7,71 & 10 & & \\
\hline
\end{tabular}

\begin{tabular}{|c|c|c|c|c|c|c|}
\hline \multirow{2}{*}{$\begin{array}{l}\text { Variáveis } \\
\text { Rorschach }\end{array}$} & \multirow{2}{*}{$\begin{array}{l}\text { Faixa } \\
\text { etária }\end{array}$} & \multicolumn{3}{|c|}{ Dados descritivos } & \multicolumn{2}{|c|}{ Comparação Estatística } \\
\hline & & Media & DP & Mediana & $z$ & $p$-value \\
\hline $\mathrm{EF}$ & 18-29 anos & 3,16 & 1,28 & 3,56 & 1,295 & 0,278 \\
\hline
\end{tabular}




\begin{tabular}{|c|c|c|c|c|c|c|}
\hline & 30-39 anos & 4,7 & 5,58 & 4,76 & & \\
\hline & 40-49 anos & 3,88 & 4,46 & 3,33 & \multirow{6}{*}{ - } & \multirow{6}{*}{ - } \\
\hline & $50-65$ anos & 5,46 & 7,28 & 1,06 & & \\
\hline \multirow{4}{*}{ E } & 18-29 anos & 0 & \multirow{4}{*}{-} & \multirow{4}{*}{ - } & & \\
\hline & 30-39 anos & 0 & & & & \\
\hline & 40-49 anos & 0 & & & & \\
\hline & $50-65$ anos & 0 & & & & \\
\hline \multirow{4}{*}{ FClob } & 18-29 anos & 0,20 & 0,97 & 0 & \multirow[t]{4}{*}{0,308} & \multirow[t]{4}{*}{0,819} \\
\hline & 30-39 anos & 0,43 & 1,65 & 0 & & \\
\hline & 40-49 anos & 0,21 & 0,92 & 0 & & \\
\hline & 50-65 anos & 0,20 & 10,9 & 0 & & \\
\hline \multirow{4}{*}{ ClobF } & 18-29 anos & 0 & & & \multirow[t]{4}{*}{0,785} & \multirow[t]{4}{*}{0,504} \\
\hline & 30-39 anos & 0 & & & & \\
\hline & 40-49 anos & 0 & - & - & & \\
\hline & $50-65$ anos & 0 & & & & \\
\hline \multirow{4}{*}{ Clob } & 18-29 anos & & & & \multirow{4}{*}{ - } & \multirow{4}{*}{-} \\
\hline & $30-39$ anos & & & & & \\
\hline & $40-49$ anos & - & - & - & & \\
\hline & $50-65$ ano & & & & & \\
\hline \multirow{4}{*}{$\mathrm{K}$} & 18-29 anos & 10,1 & 8,6 & 9,3 & \multirow{4}{*}{0,578} & \multirow{4}{*}{0,630} \\
\hline & 30-39 anos & 9,97 & 7,31 & 9,5 & & \\
\hline & 40-49 anos & 12,1 & 10,6 & 8,33 & & \\
\hline & 50-65 anos & 10 & 8,3 & 8,33 & & \\
\hline \multirow{4}{*}{ kan } & 18-29 anos & 15,1 & 10,2 & 14,3 & \multirow[t]{4}{*}{1,216} & \multirow[t]{4}{*}{0,306} \\
\hline & 30-39 anos & 18 & 13,2 & 15,3 & & \\
\hline & 40-49 anos & 19,5 & 11,6 & 18,1 & & \\
\hline & $50-65$ anos & 20,3 & 12,1 & 18,1 & & \\
\hline \multirow{4}{*}{ kob } & 18-29 anos & 1,9 & 3,06 & 0 & \multirow[t]{4}{*}{1,726} & \multirow[t]{4}{*}{0,164} \\
\hline & 30-39 anos & 0,7 & 2,14 & 0 & & \\
\hline & 40-49 anos & 1,72 & 3,37 & 0 & & \\
\hline & $50-65$ anos & 0,87 & 2,36 & 0 & & \\
\hline \multirow{4}{*}{$\mathrm{kp}$} & 18-29 anos & 0,7 & 2,42 & 0 & \multirow[t]{4}{*}{0,765} & 0,515 \\
\hline & 30-39 anos & 0,6 & 1,92 & 0 & & \\
\hline & 40-49 anos & 1,07 & 2,55 & 0 & & \\
\hline & $50-65$ anos & 0,47 & 1,58 & 0 & & \\
\hline & 18-29 anos & 17,4 & 10 & 16,6 & 0,955 & 0,415 \\
\hline$\sum \mathrm{k}$ & 30-39 anos & 19,1 & 14 & 16,6 & & \\
\hline & 40-49 anos & 22,3 & 13,4 & 21,4 & & \\
\hline & 50-65 anos & 21,7 & 13,1 & 18,7 & & \\
\hline Variáveis & Faixa & & s des & ritivos & Compar: & statística \\
\hline Rorschach & etária & Medi & DP & Mediana & $z$ & $p$-value \\
\hline & 18-29 anos & 38,4 & 16,7 & 40,8 & 1,455 & 0,229 \\
\hline
\end{tabular}




\begin{tabular}{|c|c|c|c|c|c|c|}
\hline \multirow[t]{3}{*}{$\mathrm{A}$} & 30-39 anos & 38 & 17,7 & 37,5 & & \multirow{7}{*}{$\mathbf{0 , 0 1 1}$} \\
\hline & 40-49 anos & 36,5 & 13,7 & 38,1 & \multirow{6}{*}{3,827} & \\
\hline & $50-65$ anos & 42,7 & 16,8 & 42,7 & & \\
\hline \multirow{4}{*}{ (A) } & $18-29$ anos & 3,02 & 3,03 & 3,66 & & \\
\hline & $30-39$ anos & 8,2 & 9 & 7,7 & & \\
\hline & 40-49 anos & 6,05 & 5,34 & 5,88 & & \\
\hline & $50-65$ anos & 4,05 & 5,53 & 2,95 & & \\
\hline \multirow{4}{*}{ Ad } & 18-29 anos & 6,47 & 8,31 & 2,38 & \multirow[t]{4}{*}{1,035} & \multirow[t]{4}{*}{0,379} \\
\hline & 30-39 anos & 3,2 & 3,7 & 0 & & \\
\hline & 40-49 anos & 4,65 & 6,11 & 2,63 & & \\
\hline & $50-65$ anos & 4,16 & 5,65 & 0 & & \\
\hline \multirow{4}{*}{ (Ad) } & 18-29 anos & 3 & 6,15 & 0 & \multirow{4}{*}{1,114} & \multirow{4}{*}{0,345} \\
\hline & 30-39 anos & 2 & 4,56 & 0 & & \\
\hline & 40-49 anos & 2,7 & 4,62 & 0 & & \\
\hline & $50-65$ anos & 2 & 3,47 & 0 & & \\
\hline \multirow{4}{*}{$\sum \mathrm{A}$} & 18-29 anos & 51 & 16,6 & 51,6 & \multirow{4}{*}{0,335} & \multirow{4}{*}{0,800} \\
\hline & 30-39 anos & 49,5 & 19,3 & 47 & & \\
\hline & 40-49 anos & 50 & 11,7 & 53 & & \\
\hline & $50-65$ anos & 53 & 17 & 50 & & \\
\hline \multirow[t]{4}{*}{$\mathrm{H}$} & 18-29 anos & 12,3 & 9,34 & 9,6 & \multirow{4}{*}{0,103} & \multirow{4}{*}{0,958} \\
\hline & 30-39 anos & 13,5 & 11,2 & 9,5 & & \\
\hline & $40-49$ anos & 12,4 & 9,66 & 9 & & \\
\hline & $50-65$ anos & 11,5 & 8,96 & 10 & & \\
\hline \multirow{4}{*}{$(\mathrm{H})$} & 18-29 anos & 4 & 4,3 & 3,28 & \multirow{4}{*}{0,274} & \multirow{4}{*}{0,844} \\
\hline & 30-39 anos & 4,7 & 5,72 & 4,76 & & \\
\hline & 40-49 anos & 4,4 & 5,85 & 3,45 & & \\
\hline & $50-65$ anos & 3,91 & 4,95 & 0 & & \\
\hline \multirow{4}{*}{$\mathrm{Hd}$} & 18-29 anos & 4,6 & 6,06 & 0 & \multirow{4}{*}{0,402} & \multirow{4}{*}{0,752} \\
\hline & 30-39 anos & 3,23 & 4,96 & 0 & & \\
\hline & 40-49 anos & 4,11 & 5,07 & 0 & & \\
\hline & $50-65$ anos & 3,8 & 5,65 & 0 & & \\
\hline \multirow{4}{*}{$(\mathrm{Hd})$} & 18-29 anos & 1,01 & 3,68 & 0 & \multirow{4}{*}{0,630} & \multirow[t]{4}{*}{0,596} \\
\hline & 30-39 anos & 1,11 & 2,9 & 0 & & \\
\hline & 40-49 anos & 1,4 & 3,92 & 00 & & \\
\hline & $50-65$ anos & 0,63 & 1,78 & & & \\
\hline \multirow{4}{*}{$\sum \mathrm{H}$} & 18-29 anos & 22 & 10 & 19,5 & 0,374 & 0,772 \\
\hline & 30-39 anos & 20 & 14 & 18,1 & & \\
\hline & 40-49 anos & 22,3 & 11,8 & 20 & & \\
\hline & $50-65$ anos & 20 & 14 & 18 & & \\
\hline
\end{tabular}

\begin{tabular}{ccccccc} 
Variáveis & Faixa & \multicolumn{3}{c}{ Dados descritivos } & \multicolumn{2}{c}{ Comparação Estatística } \\
Rorschach & etária & Media & DP & Mediana & $z$ & $p$-value \\
\hline & $18-29$ anos & 5 & 6,2 & 1,61 & 0,502 & 0,682 \\
\hline
\end{tabular}




\begin{tabular}{|c|c|c|c|c|c|c|}
\hline \multirow[t]{3}{*}{ Anat } & 30-39 anos & 7,78 & 8,4 & 5 & \multirow{7}{*}{0,872} & \multirow{7}{*}{0,457} \\
\hline & $40-49$ anos & 6,16 & 7,4 & 3,57 & & \\
\hline & $50-65$ anos & 7,15 & 9,31 & 3,7 & & \\
\hline \multirow{4}{*}{$\mathrm{Sg}$} & 18-29 anos & 0,26 & 1,27 & 0 & & \\
\hline & 30-39 anos & 0 & 0 & 0 & & \\
\hline & $40-49$ anos & 0 & 0 & 0 & & \\
\hline & $50-65$ anos & 0,08 & 0,71 & 0 & & \\
\hline \multirow{4}{*}{ Sex } & $18-29$ anos & 0,29 & 1 & 0 & \multirow[t]{4}{*}{2,140} & \multirow[t]{4}{*}{0,097} \\
\hline & 30-39 anos & 0,34 & 1,27 & 0 & & \\
\hline & $40-49$ anos & 2,14 & 5,1 & 0 & & \\
\hline & $50-65$ anos & 2 & 4,82 & 0 & & \\
\hline \multirow{4}{*}{ Obj } & $18-29$ anos & 9,4 & 8 & 8,33 & \multirow[t]{4}{*}{0,277} & \multirow[t]{4}{*}{0,842} \\
\hline & 30-39 anos & 8,4 & 6,65 & 8,3 & & \\
\hline & $40-49$ anos & 8,7 & 6,82 & 7,41 & & \\
\hline & $50-65$ anos & 8,03 & 8,19 & 6,67 & & \\
\hline \multirow{4}{*}{ Art } & 18-29 anos & 0,16 & 0,81 & 0 & \multirow[t]{4}{*}{1,226} & \multirow[t]{4}{*}{0,302} \\
\hline & 30-39 anos & 1,82 & 4,06 & 0 & & \\
\hline & $40-49$ anos & 0,38 & 1,71 & 0 & & \\
\hline & $50-65$ anos & 0,75 & 2,61 & 0 & & \\
\hline \multirow{4}{*}{ Arq } & 18-29 anos & 1,57 & 3 & 0 & \multirow{4}{*}{1,226} & \multirow{4}{*}{0,302} \\
\hline & 30-39 anos & 0,73 & 2,28 & 0 & & \\
\hline & $40-49$ anos & 1,15 & 2,51 & 0 & & \\
\hline & $50-65$ anos & 0,64 & 1,85 & 0 & & \\
\hline \multirow{4}{*}{ Simb } & $18-29$ anos & 1,33 & 3,14 & 0 & \multirow{4}{*}{1,717} & \multirow[t]{4}{*}{0,166} \\
\hline & 30-39 anos & 1,57 & 3,36 & 0 & & \\
\hline & $40-49$ anos & 1,25 & 2,57 & 0 & & \\
\hline & $50-65$ anos & 0,48 & 2,04 & 0 & & \\
\hline \multirow{4}{*}{ Abs } & 18-29 anos & 0,2 & 0,97 & 0 & \multirow[t]{4}{*}{1,154} & \multirow[t]{4}{*}{0,329} \\
\hline & 30-39 anos & 0,63 & 2,09 & 0 & & \\
\hline & $40-49$ anos & 0,77 & 2,35 & 0 & & \\
\hline & $50-65$ anos & 0,23 & 1,27 & 0 & & \\
\hline \multirow{4}{*}{ Bot } & $18-29$ anos & 4,6 & 5,3 & 3,93 & \multirow[t]{4}{*}{0,959} & \multirow[t]{4}{*}{0,414} \\
\hline & 30-39 anos & 4 & 8 & 0 & & \\
\hline & $40-49$ anos & 2,42 & 3,61 & 0 & & \\
\hline & $50-65$ anos & 4,18 & 6,45 & 0 & & \\
\hline & $18-29$ anos & 1,7 & 3,6 & 0 & 1,303 & 0,275 \\
\hline Geo & 30-39 anos & 1,8 & 3,97 & 0 & & \\
\hline & $40-49$ anos & 2,8 & 3,78 & 0 & & \\
\hline & $50-65$ anos & 1,4 & 3,47 & 0 & & \\
\hline Variáveis & Faixa & & s des & itivos & Compar & statística \\
\hline Rorschach & etária & Med & DP & Mediana & $z$ & $p$-value \\
\hline & $18-29$ anos & 0,33 & 1,16 & 0 & 0,781 & 0,506 \\
\hline
\end{tabular}




\begin{tabular}{ccccccc}
\hline Nat & $30-39$ anos & 0 & 0 & 0 & & \\
& $40-49$ anos & 0,17 & 0,77 & 0 & & \\
& $50-65$ anos & 0,37 & 1,56 & 0 & & \\
& & & & & & \\
Pais & $18-29$ anos & 0,82 & 2,3 & 0 & 0,050 & \\
& $30-39$ anos & 0,7 & 2,68 & 0 & & \\
& $40-49$ anos & 0,74 & 3,03 & 0 & & \\
& $50-65$ anos & 0,91 & 3,4 & 0 & & \\
& & & & & & \\
Elem & $18-29$ anos & 0,25 & 1,2 & 0 & 0,585 & \\
& $30-39$ anos & 0 & 0 & 0 & & \\
& $40-49$ anos & 0,08 & 0,53 & 0 & & \\
& $50-65$ anos & 0,08 & 0,64 & 0 & & \\
& & & & & & \\
Frag & $18-29$ anos & 1,05 & 2,35 & 0 & 0,394 & \\
& $30-39$ anos & 1,08 & 3,43 & 0 & & \\
& $40-49$ anos & 0,97 & 2,28 & 0 & & \\
& $50-65$ anos & 1,55 & 3,55 & 0 & & \\
& & & & & & \\
& $18-29$ anos & 27,3 & 20,6 & 18,7 & 0,445 & \\
\hline \multirow{6}{*}{ Ban } & $30-39$ anos & 26,7 & 11 & 25 & & \\
& $40-49$ anos & 28,2 & 11,8 & 28,5 & & \\
& $50-65$ anos & 30,1 & 13,7 & 28,1 & & \\
\hline
\end{tabular}

Apenas na variável (A) foram encontradas diferenças estatisticamente significativas entre os grupos etários de adultos, sendo o grupo de 30-39 anos com maior porcentagem média em relação aos demais. Contudo, este dado fragiliza-se quando se observa a variável $\sum \mathrm{A}$, em que tal diferença passa a não mais existir entre os grupos. Desse modo, pode-se inferir que em indivíduos que atingiram seu desenvolvimento (adulto), o padrão de respostas ao método projetivo utilizado nesse trabalho não pareceu se modificar ao longo da vida, pelo menos na faixa etária de 18 a 65 anos. Esses achados empíricos apontam não ser necessário elaborar referenciais normativos específicos do Rorschach para adultos em função da idade.

\subsubsection{Análise comparativa do Rorschach em relação às normas para adultos}


Uma outra perspectiva analítica foi pensada para os dados do presente trabalho, tendo em vista o objetivo de verificar eventuais modificações no padrão de respostas ao Rorschach em indivíduos adultos. Realizou-se análise comparativa das médias obtidas nas variáveis analisadas neste estudo $(\mathrm{n}=168)$ com os índices obtidos por Pasian (1998), junto aos adultos $(n=405)$ avaliados por meio do Rorschach. Na Tabela 47 estão apresentados os resultados de 51 variáveis analisadas e suas respectivas comparações entre os dados de ambas amostras com adultos, utilizando-se como parâmetro os resultados médios em porcentagem.

Tabela 47- Resultados médios (em porcentagem) da atual amostra $(n=168)$ e sua comparação estatística com o estudo normativo de Pasian ( $n=405)$.

\begin{tabular}{ccccc}
\hline $\begin{array}{c}\text { Variável } \\
\text { Rorschach }\end{array}$ & \multicolumn{2}{c}{ Dados descritivos (\%) } & \multicolumn{2}{c}{ Comparação Estatística } \\
Dados atuais & Pasian $(1998)$ & $t$ & $p$-value \\
\hline $\mathrm{R}$ & 18,7 & 16,0 & 1,549 & 0,214 \\
$\mathrm{RA}$ & 1,4 & 1,8 & 6,357 & 0,012 \\
$\mathrm{Rec}$ & 0,3 & 0,6 & 32,270 & $\leq \mathbf{0 , 0 0 1}$ \\
Den & 0,2 & 0,4 & 30,549 & $\leq \mathbf{0 , 0 0 1}$ \\
$\mathrm{G}^{3}$ & 44,0 & 48,6 & 1,705 & 0,192 \\
$\mathrm{D}^{4}$ & 38,4 & 33,5 & 1,456 & 0,228 \\
$\mathrm{G}(\mathrm{com} \mathrm{Gtec})^{5}$ & 48,5 & 48,6 & 2,480 & 0,116 \\
$\mathrm{D}(\mathrm{sem} \mathrm{Gtec})^{6}$ & 33,8 & 33,5 & 1,413 & 0,235 \\
Dd & 16,2 & 16,0 & 0,240 & 0,625 \\
Dbl & 1,3 & 0,9 & 6,739 & $\mathbf{0 , 0 1 0}$ \\
Do & - & 1,0 & 84,190 & $\leq \mathbf{0 , 0 0 1}$ \\
F\% & 32,7 & 35,1 & 2,432 & 0,119
\end{tabular}

\footnotetext{
${ }^{3}$ Nos dados normativos atuais, provenientes de nosso estudo, a antiga área Gtec (parte preta do cartão III) passou a ser classificada como D, seguindo a literatura internacional contemporânea. Desta forma, duas diferentes análises foram realizadas para fins de comparação com a amostra de Pasian (1998), uma vez que em seus dados havia a classificação Gtec que era contabilizada como G. Na atual amostra normativa, o G não inclui Gtec, tendo esta área sido classificada e contabilizada como D.

${ }^{4}$ Nesta classificação, a antiga área Gtec é classificada e contabilizada como D, presente na amostra normativa atual.

5 Em uma segunda análise - em que se lê "G (com Gtec)"- a área D correspondente a antiga área Gtec (parte preta do cartão III), foi então classificada como Gtec e contabilizada como G, realizando a mesma classificação de Pasian (1998).

${ }^{6}$ Nesta classificação, a área a parte preta do cartão (nomeada atualmente como área D) não foi classificada como tal.
} 


\begin{tabular}{|c|c|c|c|c|}
\hline $\begin{array}{c}\text { Variável } \\
\text { Rorschach }\end{array}$ & $\begin{array}{l}\text { Dados atuais } \\
\text { (1998) }\end{array}$ & Pasian & $t$ & $p$-value \\
\hline $\mathrm{F}+\%$ & 63,8 & 60,0 & 4,898 & 0,027 \\
\hline $\mathrm{F}+\mathrm{ext} \%$ & 72,1 & 69,0 & 6,869 & 0,009 \\
\hline $\mathrm{FC}$ & 11,9 & 9,2 & 1,087 & 0,298 \\
\hline $\mathrm{CF}$ & 9,2 & 7,5 & 0,111 & 0,739 \\
\hline $\mathrm{C}$ & 0,8 & 0,8 & 0,137 & 0,712 \\
\hline $\mathrm{FE}$ & 9,9 & 9,7 & 4,154 & 0,042 \\
\hline $\mathrm{EF}$ & 4,5 & 5,6 & 13,950 & $\leq \mathbf{0 , 0 0 1}$ \\
\hline $\mathrm{E}$ & - & 0,1 & 13,950 & $\leq \mathbf{0 , 0 0 1}$ \\
\hline FClob & 0,2 & 0,4 & 3,822 & 0,051 \\
\hline ClobF & 0,1 & 0,1 & 2,768 & 0,097 \\
\hline Clob & - & - & - & - \\
\hline $\mathrm{K}$ & 10,5 & 8,6 & 0,988 & 0,321 \\
\hline kan & 19,1 & 20,7 & 2,408 & 0,121 \\
\hline kob & 1,2 & 1,4 & 1,995 & 0,158 \\
\hline $\mathrm{kp}$ & 0,7 & 0,9 & 3,522 & 0,061 \\
\hline$\sum \mathrm{k}$ & 21,0 & 23 & 1,749 & 0,187 \\
\hline A & 40,0 & 40,5 & 1,628 & 0,202 \\
\hline (A) & 4,6 & 4,9 & 5,442 & 0,020 \\
\hline Ad & 5,4 & 7,7 & 13,575 & $\leq \mathbf{0 , 0 0 1}$ \\
\hline (Ad) & 2,1 & 0,7 & 78,389 & $\leq \mathbf{0 , 0 0 1}$ \\
\hline$\sum \mathrm{A}$ & 51,7 & 53,8 & 8,256 & 0,004 \\
\hline $\mathrm{H}$ & 11,9 & 8,1 & 3,517 & 0,061 \\
\hline (H) & 4,2 & 3,1 & 0,015 & 0,903 \\
\hline $\mathrm{Hd}$ & 3,9 & 4,0 & 1,162 & 0,281 \\
\hline$(\mathrm{Hd})$ & 0,9 & 0,9 & 0,007 & 0,932 \\
\hline$\sum \mathrm{H}$ & 20,9 & 16,1 & 0,013 & 0,909 \\
\hline Anat & 6,6 & 7,3 & 3,322 & 0,069 \\
\hline $\mathrm{Sg}$ & 0,1 & 0,2 & 7,011 & 0,008 \\
\hline Sex & 1,5 & 2,1 & 4,982 & 0,026 \\
\hline Obj & 8,6 & 6,1 & 0,432 & 0,511 \\
\hline Art & 0,7 & 1,5 & 22,222 & $\leq 0,001$ \\
\hline Arq & 0,9 & 0,6 & 5,455 & 0,020 \\
\hline Simb & 0,9 & 0,8 & 2,497 & 0,115 \\
\hline Abst & 0,4 & 0,5 & 0,985 & 0,321 \\
\hline Bot & 3,8 & 3,9 & 0,888 & 0,346 \\
\hline Geo & 1,8 & 1,5 & 3,185 & 0,075 \\
\hline Nat & 0,3 & 1,7 & 97,274 & $\leq 0,001$ \\
\hline Pais & 0,8 & 0,1 & 87,503 & $\leq 0,001$ \\
\hline Elem & 0,1 & 0,4 & 14,177 & $\leq 0,001$ \\
\hline Frag & 1,3 & 3,3 & 43,851 & $\leq 0,001$ \\
\hline Ban & 28,7 & 29,8 & 0,361 & 0,548 \\
\hline
\end{tabular}


Dentre as 51 variáveis analisadas, foram observadas diferenças estatisticamente significativas entre a amostra de Pasian (1998) e atuais dados em 22 indicadores do Rorschah. Contudo, 14 destas variáveis apresentaram baixa frequência nos dois momentos de avaliação, a saber: RA, Rec, Den, Dbl, Do, E, Sg, Sx, Art, Arq, Nat, Pais, Elem, Frag, o que fragiliza a diferença detectada entre os dois grupos comparados. As oito variáveis restantes que apresentaram diferenças estatisticamente significativas foram: F+\%, F+ext\%, FE, EF, (A), Ad, (Ad) e $\sum \mathrm{A} . \mathrm{Na}$ amostra atual, houve aumento da média nas variáveis $\mathrm{F}+\%, \mathrm{~F}+\mathrm{ext} \%$, $\mathrm{FE}$ e (Ad) e diminuição da média das variáveis $\mathrm{EF},(\mathrm{A}), \mathrm{Ad}$ e $\sum A$. Pode-se inferir, portanto, que os adultos avaliados no presente trabalho sinalizaram maior índice de precisão em suas análises lógicas dos estímulos, conseguindo coordenar racionalmente vivências de angústia. Além disso, sinalizaram menos respostas associadas a conteúdos comuns, como os animais, dando margem para emergência de outros tipos de respostas ao Rorschach. Essas especificidades de produção podem decorrer de características amostrais, bem como do próprio tempo decorrido entre as duas avaliações (15 anos), frente às mudanças ocorridas no contexto sociocultural. Nesse momento, no entanto, essas observações exigem atenção dos avaliadores de personalidade por meio de métodos projetivos, como o Rorschach, para poderem ter em consideração essas variáveis em suas análises e avaliações, em momento oportuno de seu trabalho clínico.

\subsubsection{Síntese geral do Rorschach (dados normativos atuais)}

Após verificar o possível efeito do sexo, do nível de escolaridade e da idade nas variáveis codificadas no padrão de respostas de adultos ao Rorschach, elaborou-se uma tabela descritiva e analítica para visualizar, no conjunto atual de dados, as diferenças estatisticamente significativas entre as variáveis.Esses achados compõem a Tabela 48. 
É apresentado o perfil global da amostra avaliada, apontando as estatísticas descritivas e os resultados sintéticos das análises estatísticas inferenciais realizadas no conjunto das 56 variáveis da Escola Francesa do Rorschach. Os dados estão apresentados em porcentagem (exceto para as variáveis R, RA, Rec, Den) e podem funcionar como parâmetros normativos para os adultos de 18 a 65 anos de idade em regiões com características sócio demográficas e culturais similares às do presente estudo.

Tabela 48 - Resultados descritivos e inferenciais das variáveis do Rorschach em adultos $(n=168)$.

\begin{tabular}{|c|c|c|c|c|c|c|}
\hline \multirow{2}{*}{$\begin{array}{l}\text { Variáveis } \\
\text { Rorschach }\end{array}$} & \multicolumn{5}{|c|}{ Dados descritivos } & \multirow{2}{*}{$\begin{array}{c}\text { Diferenças } \\
\text { estatísticas* }\end{array}$} \\
\hline & Mediana & Média & DP & Mínimo & Máximo & \\
\hline $\mathrm{R}$ & 16,0 & 18,7 & 9,8 & 8,0 & 88,0 & - \\
\hline RA & 1,0 & 1,3 & 1,8 & 0 & 11,0 & - \\
\hline Rec & 0 & 0,3 & 0,6 & 0 & 3,0 & $\mathrm{M}>\mathrm{F}$ \\
\hline Den & 0 & 0,17 & 0,5 & 0 & 3,0 & - \\
\hline TLm & 17,5 & 20,0 & 10,1 & 6,2 & 52,8 & $\mathrm{M}>\mathrm{F}$ \\
\hline $\mathrm{TRm}$ & 32,6 & 35,1 & 14,9 & 10,7 & 134,1 & $\mathrm{M}>\mathrm{F}$ \\
\hline G & 43,7 & 44,0 & 24,2 & 0 & 100,0 & $\mathrm{E}(\mathrm{B}<\mathrm{A})$ \\
\hline $\mathrm{D}$ & 39,0 & 38,4 & 17,1 & 0 & 78,5 & $\mathrm{E}(\mathrm{B}<\mathrm{M})$ \\
\hline $\mathrm{Dd}$ & 15,3 & 16,2 & 14,0 & 0 & 74,3 & \\
\hline Dbl & 1,3 & 0 & 2,8 & 0 & 11,1 & $M>F$ \\
\hline Do & 0 & 0 & 0 & 0 & 0 & - \\
\hline $\mathrm{F}+$ & 19,0 & 21,0 & 13,2 & 0 & 78,6 & - \\
\hline $\mathrm{F}+-$ & 0 & 0,6 & 2,2 & 0 & 16,6 & $\mathrm{M}>\mathrm{F}$ \\
\hline F- & 9,1 & 11,2 & 9,5 & 0 & 50,0 & - \\
\hline $\mathrm{F} \%$ & 31,1 & 32,7 & 16,8 & 0 & 85,7 & - \\
\hline $\mathrm{F}+\%$ & 66,6 & 63,8 & 25,9 & 0 & 86,7 & - \\
\hline $\mathrm{F}+\mathrm{ext} \%$ & 72,7 & 72,1 & 13,6 & 24,0 & 69,2 & - \\
\hline $\mathrm{K}$ & 8,3 & 10,5 & 9,8 & 0 & 50,0 & $\mathrm{E}(\mathrm{B}<\mathrm{M})$ \\
\hline kan & 16,7 & 19,0 & 12,0 & 0 & 62,5 & $\begin{array}{c}\mathrm{E}(\mathrm{B}>\mathrm{M} \text { e } \mathrm{B}> \\
\mathrm{A})\end{array}$ \\
\hline kob & 0 & 1,2 & 2,7 & 0 & 13,3 & $\mathrm{M}>\mathrm{F}$ \\
\hline $\mathrm{Kp}$ & 0 & 0,7 & 2,0 & 0 & 10,2 & $\mathrm{M}<\mathrm{F}$ \\
\hline$\Sigma \mathrm{k}$ & 18,3 & 20,8 & 12,8 & 0 & 62,5 & $E(B>A)$ \\
\hline $\mathrm{FC}$ & 11,1 & 11,9 & 8,9 & 0 & 40,0 & - \\
\hline $\mathrm{CF}$ & 8,3 & 9,2 & 7,5 & 0 & 31,2 & - \\
\hline Variáveis & & & os de & ritivos & & \\
\hline
\end{tabular}




\begin{tabular}{|c|c|c|c|c|c|c|}
\hline Rorschach & Mediana & Média & $\mathrm{DP}$ & Mínimo & Máximo & $\begin{array}{c}\text { Diferenças } \\
\text { estatísticas* }\end{array}$ \\
\hline $\mathrm{C}$ & 0 & 0,8 & 2,3 & 0 & 10,0 & $\mathrm{M}<\mathrm{F}$ \\
\hline $\mathrm{FE}$ & 9,0 & 9,9 & 7,3 & 0 & 40,0 & - \\
\hline $\mathrm{EF}$ & 2,9 & 4,5 & 5,9 & 0 & 30,7 & - \\
\hline $\mathrm{E}$ & 0 & 0 & 0 & 0 & 0 & - \\
\hline FClob & 0 & 0,2 & 1,2 & 0 & 8,3 & $\mathrm{M}<\mathrm{F}$ \\
\hline ClobF & 0 & 0,1 & 0,8 & 0 & 8,3 & $\mathrm{M}>\mathrm{F}$ \\
\hline Clob & 0 & 0 & 0 & 0 & 0 & - \\
\hline A & 40 & 40,0 & 16,1 & 5,6 & 100,0 & $\begin{array}{c}\mathrm{E}(\mathrm{B}<\mathrm{M} \text { e } \mathrm{B}< \\
\mathrm{A})\end{array}$ \\
\hline (A) & 4,3 & 4,9 & 5,9 & 0 & 33,3 & - \\
\hline $\mathrm{Ad}$ & 0 & 4,5 & 6,1 & 0 & 27,2 & $M>F$ \\
\hline (Ad) & 0 & 2,2 & 4,1 & 0 & 25,0 & - \\
\hline$\Sigma \mathrm{A}$ & 51,1 & 51,7 & 15,7 & 7,4 & 100,0 & $\begin{array}{c}\mathrm{E}(\mathrm{B}<\mathrm{M} \text { e } \mathrm{B}< \\
\mathrm{A})\end{array}$ \\
\hline $\mathrm{H}$ & 9,6 & 12,0 & 8,9 & 0 & 43,7 & $\mathrm{M}>\mathrm{F}$ \\
\hline (H) & 3,3 & 4,2 & 5,2 & 0 & 28,5 & - \\
\hline $\mathrm{Hd}$ & 0 & 3,9 & 5,41 & 0 & 31,2 & - \\
\hline (Hd) & 0 & 0,9 & 2,86 & 0 & 21,4 & - \\
\hline$\Sigma \mathrm{H}$ & 18,3 & 21,0 & 12,8 & 0 & 87,5 & $\mathrm{M}>\mathrm{F}, \mathrm{E}(\mathrm{B}<\mathrm{M})$ \\
\hline Anat & 3,7 & 6,5 & 8,25 & 0 & 50 & $\mathrm{E}(\mathrm{B}<\mathrm{A})$ \\
\hline $\mathrm{Sg}$ & 0 & 0,1 & 0,67 & 0 & 6,25 & $\mathrm{M}<\mathrm{F}$ \\
\hline Sex & 0 & 1,5 & 4,17 & 0 & 30,7 & - \\
\hline Obj & 7,7 & 8,6 & 7,56 & 0 & 30,7 & $\mathrm{E}(\mathrm{B}<\mathrm{A})$ \\
\hline Art & 0 & 0,7 & 2,31 & 0 & 15,3 & - \\
\hline Arq & 0 & 0,9 & 2,28 & 0 & 10 & - \\
\hline Simb & 0 & 1,0 & 2,61 & 0 & 15,3 & - \\
\hline Abs & 0 & 0,4 & 1,7 & 0 & 9,09 & - \\
\hline Bot & 0 & 3,8 & 6,07 & 0 & 38,1 & - \\
\hline Geo & 0 & 1,8 & 3,65 & 0 & 18,1 & $\mathrm{M}>\mathrm{F}$ \\
\hline Nat & 0 & 0,3 & 1,19 & 0 & 9,09 & $\mathrm{M}>\mathrm{F}$ \\
\hline Pais & 0 & 0,8 & 3,03 & 0 & 20 & - \\
\hline Elem & 0 & 0,1 & 0,67 & 0 & 5,88 & $\mathrm{M}<\mathrm{F}$ \\
\hline Frag & 0 & 1,3 & 3,11 & 0 & 16,6 & $\mathrm{M}<\mathrm{F}$ \\
\hline Ban & 27,2 & 28,7 & 13,9 & 0 & 94,1 & - \\
\hline
\end{tabular}

*Os subgrupos comparados se referem a: M (masculino), F (Feminino) e Escolaridade (E): A (Alta), Média (M), Baixa (B).

É possível verificar que, no conjunto das respostas dos adultos de 18 a 65 anos, houve o predomínio de respostas G sobre D e Dd, índice médio de 32,7\% de respostas determinadas exclusivamente pela forma, com razoável índice de precisão formal nas 
análises dos estímulos do ambiente $(\mathrm{F}+\%=63,8 \%)$, mas também com a presença de outros determinantes $(\mathrm{kan}=19 \%, \mathrm{~K}=10,5 \%$ e $\mathrm{FC}=11,9 \%)$. Os conteúdos mais frequentes nas respostas foram: animal e humano e o índice médio de banalidades foi de $28,7 \%$.

Por meio da análise estatística inferencial realizada com as 56 variáveis do Rorschach observou-se que 27 apresentaram especificidades produtivas em função do sexo e ao nível da escolaridade, destacadas na Tabela 48. Estas evidências empíricas atuais são sugestivas de que, na prática clínica, tais variáveis devem ser examinadas atentamente pelo psicólogo, buscando adequada interpretação dos resultados do Rorschach, embasada sempre no conjunto da produção e não apenas em variáveis isoladas.

\subsubsection{Atlas do Rorschach}

Após a conclusão das análises estatísticas sobre os resultados obtidos com os adultos avaliados, os achados foram sistematizados em relação às áreas interpretadas, as respostas identificadas e o respectivo nível de qualidade formal. Compôs-se a atualização do Atlas do Rorschach (Escola de Paris) para adultos de 18 a 65 anos. As respostas obtidas pelos 168 adultos e seus respectivos recortes interpretativos compõem resultado central nesse trabalho, porém, em função de sua extensão, estão apresentados no APÊNDICE G.

O Atlas apresenta a classificação atualizada dos recortes interpretativos, em termos das possibilidades de classificação técnica: G, D, Dd ou Dbl. Os números atribuídos a cada uma das áreas D, Dd ou Dbl seguiram a frequência de interpretações em cada uma delas, em ordem decrescente. Também foram analisados o nível de precisão formal das respostas emitidas, sendo que as assinaladas como (+) são as que apresentam boa qualidade formal, (-) as de má qualidade formal e ( \pm ) as imprecisas. Os critérios 
quantitativos e qualitativos, descritos na seção Método, foram utilizados para a determinação da precisão formal das respostas.

Também foi realizada análise para verificar quais respostas atingiram critério para serem consideradas como banalidade (Ban), a partir do padrão técnico adotado por Pasian (1998). Para ser considerada resposta banal (Ban), ela precisaria incidir, em uma mesma área do cartão, em pelo menos 28 ocorrências (16,7\% do total de indivíduos investigados). A listagem das 14 respostas Ban encontradas está descrita na Tabela 49.

$\underline{\text { Tabela } 49}$ - Lista das respostas banais ao Rorschach, identificadas a partir do conjunto de respostas emitidas $(R=3.144)$ pela amostra total $(n=168)$.

\begin{tabular}{|c|c|c|c|c|c|}
\hline Cartão & Localização & Posição cartão & Conteúdo & $f$ & $\%$ \\
\hline I & G & $\wedge$ & Borboleta (com ou sem Dbl) & 38 & 22,6 \\
\hline I & G & $\wedge$ & Morcego (com ou sem Dbl) & 75 & 44,6 \\
\hline II & G & $\wedge$ & Figura humana (duas) & 35 & 20,8 \\
\hline II & D1 & $\wedge$ & Animal quadrúpede & 54 & 32,1 \\
\hline III & D1 & $\wedge$ & Figura humana (duas) & 42 & 25,0 \\
\hline III & D1 & $\wedge$ & Figura humana (duas) e objeto & 42 & 25,0 \\
\hline V & G & $\wedge$ & Borboleta & 49 & 29,1 \\
\hline V & G & $\wedge$ & Morcego & 88 & 52,3 \\
\hline VI & G & $\wedge_{\mathrm{v}}$ & Pele ou tapete de animal & 32 & 19,0 \\
\hline VII & G & $\wedge$ & Figura humana (duas) & 31 & 18,4 \\
\hline VII & D1 & $\wedge$ & Figura humana (duas) & 28 & 16,7 \\
\hline VIII & G & $\wedge>$ & Animal Quadrúpede (dois em D1) & 42 & 25,0 \\
\hline VIII & D1 & $\wedge>$ & Animal Quadrúpede & 58 & 34,5 \\
\hline $\mathrm{X}$ & D1 & $\wedge_{\mathrm{V}}$ & Aranha ou caranguejo & 32 & 19,0 \\
\hline
\end{tabular}


Nota-se que as respostas Ban aparecem em diferentes proporções de ocorrência. O conteúdo Morcego, localizado na área global, nos cartões I e V, ocorreu com maior frequência dentre todos os conteúdos banais. Já as duas figuras humanas, nas localizações G e D no cartão VII, apresentaram, praticamente, o critério esperado para uma resposta ser considerada banal (principalmente em D1). Desta forma, é possível perceber que até mesmo dentro das respostas consideradas como banalidades, algumas são mais esperadas e frequentes que outras. Essa observação faz-se necessária, uma vez que, do ponto de vista qualitativo, a eventual ausência de determinadas interpretações no conjunto das respostas fornecidas faz-se também relevante.

Em comparação com os dados normativos de Pasian (1998), os achados atuais diferem em relação a quatro cartões. Na presente revisão das normas, no cartão II, na área Global (G), há a inclusão do conteúdo "Figura Humana (duas)". O cartão IV apresentava em 1998 "Monstro animal" como conteúdo banal e, neste presente estudo essa resposta não atingiu o critério para esta mesma classificação. No cartão VII, em 1998, o conteúdo "cabeça de animal"alcançou o critério para ser considerado resposta Ban, porém, no atual trabalho isso não ocorreu. Por fim, no cartão VIII, na pesquisa atual, a resposta "animal quadrúpede (dois)" na área $\mathrm{G}$ foi incluída na lista de respostas Ban. Pode-se notar, portanto, que há especificidades na produção de respostas comuns ao método de Rorschach, ainda que em indivíduos adultos, o que deve ser considerado no momento de análise de um protocolo específico, levando-se em conta seu contexto sociocultural.

\section{DISCUSSÃO}




\subsection{ESTUDO 1}

Ao iniciar a reflexão sobre os atuais achados empíricos, faz-se importante retomar uma das questões principais do presente trabalho: os processos vivenciados pelos indivíduos ao longo do tempo interferem na permanência ou na mudança de aspectos estruturais da personalidade? A reaplicação do Rorschach em indivíduos adultos não pacientes apresentaria indicadores de precisão do método para compreensão de estilos de personalidade?

É possível retomar o delineamento elaborado neste Estudo 1 (reavaliar em 2013, por meio do Método de Rorschach, adultos avaliados em 1998) de modo a se poder afirmar que essa proposta pode ser efetivada, alcançando-se amostra com 88 casos. Passados 15 anos do primeiro momento avaliativo (realizado por Pasian, 1998), a taxa de $22 \%$ de participantes reexaminados no presente trabalho pode ser considerada como muito positiva, representando, por si só, um ganho significativo para as possibilidades de conhecimento a respeito das características de personalidade de indivíduos adultos não pacientes. Poucos trabalhos com o Método de Rorschach conseguiram concretizar estudos baseados em reavaliação de indivíduos após longo intervalo de tempo, como o presentemente realizado.

Para além desse satisfatório processo de reavaliação de 88 adultos após 15 anos da primeira aplicação do Método de Rorschach, foi possível, no presente trabalho, examinar indicadores de precisão desse método projetivo, pautando-se pela Escola de Paris. Os valores médios de Kappa encontrados para as quatro grandes categorias de classificação das respostas ao Rorschach foram excelentes, segundo Fleiss e Cohen (1973) e Cicchetti (1994), tanto no Estudo 1: Localização $(0,88)$, Determinantes $(0,78)$, 
Conteúdos $(0,89)$ e Banalidades $(0,89)$, quanto no Estudo 2: Localização $(0,92)$, Determinantes $(0,83)$, Conteúdos $(0,88)$ e Banalidades $(0,90)$. Esses achados fortalecem indicadores de fidedignidade da Escola Francesa do Rorschach em contexto nacional.

No Brasil, diferentes estudos com o Método de Rorschach examinaram a qualidade dos resultados obtidos, recorrendo ao cálculo do coeficiente Kappa para análise de concordância entre juízes independentes. Os índices encontrados variam de acordo com as categorias analisadas nesse método de avaliação psicológica. Nesse momento buscar-se-á referir e examinar alguns desses trabalhos voltados ao estudo da fidedignidade do Rorschach, seguindo-se sua cronologia, de modo a ser possível refletir sobre os achados do atual estudo dentro desse panorama científico nacional.

Em estudo normativo realizado na cidade de São Paulo, Nascimento (2002) alcançou índices Kappa superiores a 0,80 para diferentes categorias de classificação das respostas, apontando claros indicadores de precisão do Rorschach no Sistema Compreensivo. O trabalho de Santonio, Yazigi e Sato (2004), por sua vez, analisou características de personalidade em pacientes com Lúpus Eritematoso Sistêmico (LES) por meio do Rorschach (Sistema Compreensivo), alcançando os seguintes índices de precisão nas diferentes categorias analisadas: Localização: 0,85; Qualidade Evolutiva: 0,73; Determinantes: 0,84; Qualidade Formal: 0,67; Populares: 0,82; Conteúdos: 0,82; Atividade Organizativa: 0,91 e Códigos Especiais: 0,47. Ou seja, esse trabalho, embora com enfoque clínico, apresentou claros resultados de fidedignidade no processo de classificação das respostas ao Rorschach.

A tese de Silva Neto (2008) focalizou, em específico, o tema da fidedignidade e da estabilidade temporal do Sistema Compreensivo do Rorschach (59 variáveis principais), utilizando amostra de 32 adultos não pacientes da cidade de São Paulo. O delineamento de seu estudo envolveu diversas análises, incluindo aplicação e reaplicação 
do Rorschach após intervalo de três a quatro meses. Segundo o pesquisador, a fidedignidade intercodificadores foi substancial $($ iota $>0,60)$ para a maioria das variáveis estudadas. No tocante à estabilidade temporal, o cálculo das correlações entre dados das duas aplicações do Rorschach (teste-reteste) apontou valor médio de $r=0,61$ para as 59 principais variáveis do Sistema Compreensivo, considerado um nível moderado de estabilidade temporal dos dados obtidos por meio desse método de avaliação psicológica.

Também pautadas em estudo de aplicação do Sistema Compreensivo do Rorschach, Scortegagna e Villemor-Amaral (2009) buscaram indicadores de sua validade em vítimas de abuso sexual, avaliando 76 indivíduos de 10 a 14 anos, de ambos os sexos, do ensino fundamental e médio, com nível socioeconômico baixo/médio, moradores do Estado do Rio Grande do Sul, subdivididos em dois grupos: vítimas de abuso intrafamiliar e grupo controle. Obtiveram resultados de satisfatória precisão na classificação dos protocolos do Rorschach, com valores de Kappa superiores a 0,61, considerados como bons a excelentes. Por sua vez, ao avaliarem 80 pacientes adultos diagnosticados com esquizofrenia por meio do Rorschach (Sistema Compreensivo), Resende e Argimon (2012) alcançaram os seguintes valores para concordância entre juízes independentes (índice Kappa): 0,86 para as categorias de Determinantes e Fenômenos Especiais; 0,89 para Conteúdos; 0,92 para Respostas Populares e 0,94 para Localizações. Esses indicadores reafirmaram, com clareza, excelente precisão, fortalecendo os próprios achados clínicos desses estudos.

Cabe destacar que os referidos trabalhos que focalizaram indicadores de precisão do Rorschach foram construídos com base no Sistema Compreensivo. Nos outros sistemas avaliativos do Rorschach utilizados no Brasil também se encontram dados referentes à fidedignidade das classificações das respostas, como nos estudos 
desenvolvidos na perspectiva da Escola de Paris (Cury-Jacquemin, 2012; Fernandes, 2010; Jardim-Maran, 2011; Pasian, 1998; Raspantini, 2010).

De acordo com Urbina (2007) a fidedignidade teste-reteste é compreendida como um "pré-requisito essencial para as evidências de validade" (p. 172) de um instrumento de avaliação psicológica. No caso do Método de Rorschach, as evidências empíricas da estabilidade temporal dos achados já foram amplamente apontadas em investigações internacionais e também realizadas no Brasil.

Embora com diferentes estratégias técnicas, o conjunto dessas investigações científicas é unânime em apontar que, com o devido treinamento profissional, o índice de acordo entre examinadores independentes no Rorschach alcança valores internacionalmente reconhecidos como indicadores de adequada fidedignidade deste método de avaliação psicológica. Assim como nos trabalhos citados, o presente estudo encontrou índices que reforçam a qualidade psicométrica referente à precisão da Escola de Paris do Rorschach.

Dentro das diretrizes inicialmente delineadas para esse Estudo 1 subexiste a possibilidade de exame das variáveis da Escola de Paris do Rorschach, no sentido de se mostrarem representativas de elementos mais estáveis da personalidade (portanto teoricamente relacionados a sua estruturação) ou mais flexíveis e mutáveis com o tempo (associados a componentes situacionais da personalidade). Nesse momento, então, buscar-se-á fazer um paralelo entre as variáveis do sistema francês do Rorschach e suas possibilidades de interpretação (Rausch de Traubenberg, 1998), de modo a permitir uma análise reflexiva sobre os dados encontrados no presente estudo.

Há que se destacar, no entanto, que o exame isolado de variáveis de um instrumento psicológico é tarefa que requer extremo cuidado. Rausch de Traubenberg (1998) afirmou que somente a interação dos fatores (e variáveis) é que oferece ao teste de 
Rorschach uma "situação privilegiada" para análise de características individuais, visto que é nessa interação que atuam processos perceptivos e psicodinâmicos da personalidade. Ao mesmo tempo, em seu livro “A prática do Rorschach”, a autora procura apresentar os aspectos do Método do Rorschach que poderiam ser representativos da estrutura da personalidade. Ela inicia afirmando:

\footnotetext{
"A maneira de abordar a tarefa, a verbalização, a regularidade ou a variabilidade das respostas, em função do tempo, são dados que dependem, parcialmente, da maneira como o sujeito vive a situação do exame; eles constituem um quadro ainda muito próximo do comportamento individual manifesto, mas possuindo já uma significação de estrutura" (Rausch de Traubenberg, 1998, p. 35).
}

No presente Estudo 1, o número de respostas dos indivíduos manteve-se muito semelhante entre as duas aplicações do Método de Rorschach e foi o que alcançou o maior índice de correlação entre as variáveis aqui analisadas, mesmo após 15 anos. Aqueles que na primeira avaliação forneceram poucas respostas $(\mathrm{R})$ tenderam a fornecer poucas respostas na reavaliação, sendo que o mesmo ocorreu com indivíduos que ofereceram muitas respostas (também produziram muitas interpretações na reavaliação). Esse padrão de produtividade estável diante do Rorschach se manteve proporcional para os índices de respostas adicionais (RA) e recusas (Rec), excetuando-se a variável denegação (Den). No entanto, há que se comentar que, diante do número total bruto de respostas (1604 na primeira avaliação e 1599 na reavaliação), em ambos os casos houve inexpressivo número de denegações (36 na primeira e 10 na segunda avaliação), o que fragiliza essa aparente diferença entre os padrões de responder ao Rorschach.

Outras variáveis que se mantiveram semelhantes na avaliação e na reavaliação foram os modos de apreensão do Rorschach, excetuando-se a localização Detalhe Branco, 
que, contudo, apresenta-se em frequência muito baixa em ambos os momentos de aplicação do teste. Rausch de Traubenberg (1998) afirma que os modos perceptivos associam-se a elementos estáveis de uma estrutura mental, embora cargas afetiva e motivacional possam estar presentes, mobilizando ansiedades e mecanismos de defesa dos indivíduos que poderiam interferir em sua maneira de abordar os estímulos do ambiente (modos de apreender os cartões).

Para os determinantes das respostas ao Rorschach vinculados aos aspectos formais dos estímulos $(\mathrm{F} \%, \mathrm{~F}+\%$ e $\mathrm{F}+\mathrm{ext} \%)$ os índices correlacionais dos dois momentos avaliativos foram baixos. Quando Rausch de Traubenberg (1998) aborda o significado de F\%, compreende-o como um esforço de organização racional e também como sinal do empenho de adaptação ao real. Ela ainda afirma que o $\mathrm{F}+\%$ e $\mathrm{F}+\operatorname{ext} \%$ podem se alterar em função do estado afetivo, podendo existir perturbação na eficiência intelectual em função de vivências emocionais. Compreende-se que o investimento racional seria um componente estrutural da personalidade, mas que também reflete o funcionamento mental dos indivíduos. A partir das evidências empíricas do presente trabalho essas variáveis pareceram representar indicadores menos estáveis da personalidade.

Ao retomar princípios básicos do método do Rorschach (Rorschach, 1921; Rausch de Traubenberg, 1998), tem-se que as respostas que incluem as cores como determinantes podem nos ajudar a compreender os afetos dos indivíduos. Rausch de Traubenberg (1998) abre o terceiro capítulo de seu manual do Rorschach com a seguinte afirmação:

“[...] Os determinantes são, sem dúvida, o elemento criativo mais original do Rorschach. Eles são também os mais difíceis para compreender teoricamente, sobretudo na sua relação com a característica psicológica que representam teoricamente, a saber, como é que se explica que o comportamento ou a conduta, em face da cor, sejam os mesmos que em face do afeto? Edificar essa base teórica, 
esse vínculo, foi objeto de numerosos estudos teóricos, experimentais, clínicos e genéticos, cuja convergência foi desigual, seguindo os determinantes”. (p. 77)

A autora ressalta que as cores tem um papel de significado mais pessoal na análise dos estímulos do Rorschach, podendo variar e oscilar de indivíduo para indivíduo. De qualquer forma, o processo perceptivo que desencadeia as respostas determinadas pela cor refere-se a uma posição passiva diante do estímulo visual, revelando uma "perda momentânea do trabalho ativo de organização" (Rausch de Traubenberg, 1998, p. 116). Neste atual trabalho, as respostas com determinantes FC, CF e C apresentaram baixos índices correlacionais entre teste e reteste. Essa evidência empírica leva à inferência de não se tratar de um componente estrutural da personalidade.

Além disso, os resultados da presente investigação apontaram índices de respostas cinestésicas que acompanharam valores normativos médios nas duas avaliações realizadas, contudo, com baixos valores de correlação entre as variáveis em específico. Segundo Rausch de Traubenberg (1998), as respostas movimento, sobretudo as respostas de grande cinestesia $(K)$, tendem a ser compreendidas como elementos de regulação e controle que refletem o papel do ego, além de suscitarem indicadores da capacidade de interiorização, inteligência e criatividade. A pesquisadora também ressalta que, por ser um determinante que está associado a algo que não existe de fato na prancha, a resposta cinestésica oferece espaço para a imaginação, assemelhando-se aos processos do inconsciente e aos processos oníricos descritos por Freud.

Ao se examinar os conteúdos das respostas ao Método de Rorschach, postula-se que representam indicadores da maneira como o indivíduo vive a situação do teste, sinalizando motivações e processos associativos significativamente acumulados ao longo das experiências de desenvolvimento humano. Assim, de acordo com Rausch de Traubenberg (1998), os conteúdos apresentados diante desse método projetivo de 
avaliação psicológica tendem a representar tanto aspectos estruturais quanto psicodinâmicos da personalidade, compondo parte integrante do quadro perceptivo. A referida pesquisadora argumenta que aspectos estruturais poderiam ser revelados pelos interesses/conteúdos dominantes, demonstrando o processo de adaptação e organização do indivíduo, derivados do inconsciente, mas que ganhariam expressão situacional vinculada à experiência momentânea e ao processo avaliativo em curso. Esses indicadores devem ser considerados como um todo para embasar adequados processos interpretativos dos dados.

No presente trabalho pode-se identificar que os conteúdos mais abordados (A\% e H\%) expressos nas respostas ao Rorschach, nos dois momentos avaliativos, foram similares em termos de frequências médias. Contudo, ao examinar os indicadores de correlação entre as variáveis que os representam no método de Rorschach, observou-se valores sugestivos de baixa e média estabilidade temporal respectivamente (para A\% o valor médio de $r=0,33 \mathrm{e}$, para $\mathrm{H} \%, r=0,48)$. Observou-se um bom índice de correlação entre as duas aplicações do Rorschach para o número de respostas banais $(r=0,61)$, reafirmando que, para esses adultos, a capacidade de adaptação social está preservada e, praticamente, não sofreu alterações ao longo dos 15 anos.

Oliveira e Bandeira (2013) consideram que uma das características da organização da personalidade normal refere-se a presença de uma "identidade integrada", em que há uma experiência subjetiva do sentido do "eu" e do "outro" de maneira efetiva e duradoura. O conteúdo humano é considerado uma variável que também indica o interesse pelo relacionamento interpessoal, para isso, é preciso que o indivíduo se reconheça e reconheça o outro. A partir dos achados do presente trabalho, onde se identificou correlação moderada de H\% entre as avaliações, esta variável do Rorschach pareceu se constituir como representante de característica estável da personalidade. 
Em relação à análise dos resultados gerais do Rorschach presentemente obtidos comparativamente a sua primeira avaliação (transcorrido longo período de tempo entre essas aplicações), os dados médios demonstraram que as diferenças não foram estatisticamente significativas na quase totalidade das variáveis examinadas (relacionadas à produtividade, aos modos de apreensão da realidade, aos conteúdos e às banalidades). Foi possível identificar variados níveis de significativas correlações entre os dois momentos avaliativos dos adultos nas variáveis do Rorschach. Os índices de maior ou moderada estabilidade foram: número de respostas $(r=0,72)$, respostas banais $(r=0,61)$, respostas globais $(r=0,59)$, número de recusas $(r=0,53)$ e conteúdo humano $(r=0,48)$. Esses dados acompanham estudos internacionais que recorreram à estratégia do testereteste do Rorschach, confirmando indicadores de sua precisão (Exner, Armbruster e Viglione, 1978; Grønnerød, 2003; Perry, McDougall \& Viglione, 1995; Scortegagna \& Villemor-Amaral, 2013; Silva Neto, 2008; Sultan, Andronikof, Réveillère \& Lemmel, 2006). Por outro lado, algumas variáveis apresentaram menores índices de correlação entre resultados dos dois momentos avaliativos, especialmente referentes aos determinantes, como por exemplo: F\% $(r=0,30)$, FC $(r=0,04)$ e $\mathrm{K}(r=0,26)$, contrariando a expectativa de estabilidade nessas variáveis ao longo do tempo.

No conjunto dos resultados, observa-se que há índices da Escola de Paris do Rorschach que se mostraram indicadores de alta (R) ou moderada (Ban, G, Rec e H) estabilidade temporal do método, sugerindo se tratarem de características estáveis da personalidade. Não obstante, encontramos também indicadores técnicos do sistema francês do Rorschach que não revelaram tal estabilidade. O cálculo das correlações entre os dados das duas aplicações do Rorschach apontou valor médio de $r=0,37$, variando entre os valores de 0,72 a $-0,005$. 
Ao comparar os achados do presente trabalho com alguns estudos que examinaram a estabilidade temporal do Rorschach a partir do Sistema Compreensivo (Exner, 2003, Grønnerød, 2003; Silva Neto e Custódio, 2008; Sultan et al., 2006) encontramos valores de correlação teste-reteste menores para as variáveis do sistema francês. Porém, algumas considerações importantes devem ser aqui ponderadas tendo em vista especificidades dos diferentes sistemas de classificação das respostas, o que pode interferir nos resultados alcançados.

No Sistema Compreensivo o participante deve fornecer um número mínimo de 14 respostas por protocolo, além disso, na análise das respostas, mais de um determinante pode ser incorporado na classificação. Se o indivíduo explica a sua resposta, por exemplo, em função da cor cromática e do movimento, e se a resposta indica mais de um conteúdo, ambos os determinantes e os conteúdos são considerados na classificação e análise das respostas. No sistema francês, não é exigido um número mínimo de respostas, sendo inclusive, possível recusar a prancha ou, no momento do inquérito, aceitar resposta(s) adicional(ais), além de aceitar a denegação da resposta oferecida previamente no momento da apresentação dos cartões. Os possíveis multideterminantes que apareçam no inquérito são relevantes numa análise posterior do psicograma, porém, apenas um determinante e um conteúdo são classificados como principais e inseridos na análise de frequência e, posteriormente, na análise estatística, enquanto o outro determinante e/ou conteúdo, se houver, será considerado como tendência que será levada em consideração na análise qualitativa. Usualmente, o determinante relacionado ao movimento é indicado como principal, entre os cromáticos/acromáticos e sombreados, por exemplo.

Exner (1988) estudou a estabilidade temporal de 36 pares de protocolos de mesmos indivíduos com diferentes números de respostas, dividindo-os em dois grupos. Em um dos grupos, os protocolos continham menos de 14 respostas e, no outro grupo, os 
protocolos apresentavam 15 ou mais respostas. Os resultados mostraram que os protocolos com menor número de respostas apresentaram menor estabilidade temporal (média de 0,44 ) quando comparados com os de 15 ou mais respostas (média de 0,80 ). Por exemplo, os determinantes F (forma pura), M (movimento humano) e FM (movimento animal), obtiveram correlação média $0,48,0,44$ e 0,28 , respectivamente em protocolos com menos de 14 respostas, enquanto os mesmos determinantes obtiveram correlação média de $0,79,0,87$ e 0,74 em protocolos com pelo menos 15 respostas. Em nosso estudo, na primeira avaliação, em 1998, 43 indivíduos (49\% da amostra) ofereceram 14 ou menos respostas e, na reavaliação, 44 adultos (50\%) ofereceram 14 ou menos respostas. Podemos questionar se a baixa estabilidade temporal (baixos valores de correlação) encontrada nas variáveis relacionadas principalmente aos determinantes tenha ocorrido em função do número de respostas dos indivíduos (muitos protocolos com menos de 14 respostas). Talvez, em uma das avaliações o indivíduo tenha ressaltado um determinante e justifique sua resposta em função deste, sem citar outro, mas isso não implica que o outro elemento do cartão não possa ter sido relevante. Ou até mesmo um possa ter sido justificado como prioritário em um momento, mas não em outro.

Exner (1978) também fez importante observação em relação à consistência temporal do Rorschach ao afirmar que, em suas palavras, uma das falácias relativas ao método é esperar que a estabilidade seja demonstrada para todas as variáveis, como se cada índice do Rorschach pudesse revelar um aspecto do indivíduo que não sofre alteração. O pesquisador defende que muitos dos dados estruturais sejam constantes ao longo do tempo, mas também pondera que algumas das variáveis do Rorschach indicam estarem atreladas a fenômenos situacionais (Exner, 1978).

Roberts e DelVechio (2000) também afirmam que quanto maior o tempo de acompanhamento dos casos em um estudo longitudinal, menor são as estimativas de 
consistência dos traços de personalidade. Consideram importante compreender o efeito do tempo sobre as estimativas descritas nos resultados que são alcançados. Em estudo sobre a consistência dos traços ao longo do tempo, esses autores encontraram que, em pesquisas de avaliação da estabilidade da personalidade com exames de teste e reteste, seria esperado que, após 10 anos, o índice de correlação fosse próximo a 0,49 e, após 20 anos, atingisse valor ao redor de 0,41. O índice médio de correlação das variáveis do Rorschach obtido no presente trabalho estudo $(r=0,37)$ encontra-se bastante próximo a essas expectativas, considerando que a reavaliação dos casos ocorreu após um período de 15 anos. Como já apontado, o cálculo das correlações entre os dados das duas aplicações do Rorschach no atual estudo variou entre os valores de 0,72 a - $-0,005$. Ou seja, superou as estimativas apontadas por Roberts e DelVechio (2000) em alguns casos, constituindose como bons indicadores de precisão da Escola Francesa do Rorschach ou Escola de Paris do Rorschach.

Os referidos pesquisadores ainda afirmaram em seu estudo:

“A segunda hipótese foi que a consistência do traço deveria alcançar um pico em algum momento na vida adulta. Bloom (1964) e McCrae e Costa (1994) argumentaram que os traços de personalidade deveriam alcançar este pico aos 20 ou 30 anos, respectivamente. Estes argumentos não são suportados pelas estimativas metanalíticas. A consistência do traço não alcança um pico até e depois da idade de 50 anos. Alternativamente, nós propomos, com base em uma variedade de teorias e descobertas empíricas, que a consistência do traço atingiria o pico na meia-idade. Os resultados de nossa avaliação apoiam esta hipótese. A hipótese da meia-idade foi baseada no conhecimento de que fatores que se julgam estar associados com as estimativas mais elevadas de consistência do traço, tais como a segurança de identidade, tornam-se mais proeminentes na meia-idade 
(ver, por exemplo, AJ Stewart \& Ostrove, 1998)" (Roberts e DelVechio (2000, p. 18$)^{7}$.

Os pesquisadores consideram que a meia idade estaria localizada na faixa etária dos 40 a 60 anos. No presente estudo, no momento do reteste, $75 \%$ dos participantes encontravam-se dentro desta faixa etária, período em que a consistência dos traços de personalidade assumiriam características mais estáveis.

A análise das duas primeiras fórmulas vivenciais (tipo de ressonância íntima e fórmula das tendências latentes) indicou que os estilos de vivência afetiva de boa parte dos adultos avaliados mostraram-se diferentes com o passar dos anos, assim como o estudo de Pereira (2001). Aqui cabe refletirmos sobre o conjunto dos dados encontrados, no geral, e os estilos de personalidade, análise que contempla o individual, nos dois momentos de avaliação.

Rausch de Traubenberg (1998) ressalta que o Tipo de Ressonância Íntima (TRI) caracteriza os indivíduos em termos de estilo de vivência afetiva, indicando a maneira como poderiam viver e não apenas como são suas reações mais imediatas. Ao explorar adicionais sentidos interpretativos possíveis para o TRI, composto pela relação entre determinantes cinestésicos e cromáticos das respostas ao Rorschach, a autora sinaliza:

\footnotetext{
${ }^{7}$ The second hypothesis was that trait consistency should peak sometime in adulthood. Bloom (1964) and McCrae and Costa (1994) argued that personality traits should peak at age 20 or 30, respectively. These arguments are not supported by the meta- analytic estimates. Trait consistency did not peak until after age 50. Alternatively, we proposed, based on a variety of theories and empirical findings, that trait consistency would peak in middle age. The results of our review support this hypothesis best. The middle age hypothesis was based on the knowledge that factors presumed to be associated with higher estimates of trait consistency, such as identity certainty, become more prominent in middle age (see, e.g., A. J. Stewart \& Ostrove, 1998) (p. 18).
} 
"Não é possível examinar aqui as variações sofridas pelo T.R.I. em função das modificações devido à fadiga, à doença, ao stress fisiológico ou psicológico, etc.[...]. Uma coisa é certa: o T.R.I. é mais variável e mais inconstante do que se pensava a priori e, em particular, as situações de stress dilatam-no ou reduzemno consideravelmente, mostrando então as suas atitudes, a maneira como o indivíduo mobiliza suas defesas, quer acentuando a expressão de si e o recurso imaginário, quer retraindo-se e limitando ao máximo sua participação na situação. Analogamente, uma disposição eufórica, o simples bom humor, dilata o T.R.I. mediante uma utilização mais ampla e desenfreada do registro de ressonância como se a motivação de utilização de seus recursos se reduzisse, declinasse.” (p. 171-172)

No presente trabalho, notou-se mudança no estilo de vivência afetiva para a maioria (53\%) dos adultos avaliados, verificando-se instabilidade no Tipo de Ressonância Íntima entre a avaliação e a reavaliação. Em relação à segunda fórmula afetiva, das Tendências Latentes, a estabilidade nos índices da reavaliação e da avaliação foi maior, mas ainda assim, foi possível verificar mudanças no estilo de vivenciar as emoções dos adultos deste estudo. Os atuais resultados, portanto, sugerem que os estilos de vivência afetiva configuram-se como variáveis representativas do funcionamento psicodinâmico individual, mais do que componente estrutural. Embora essa hipótese interpretativa acompanhe os argumentos acima transcritos de Rausch de Traubenberg (1998), contraria uma noção clássica da Escola de Paris do Rorschach onde os estilos afetivos corresponderiam a elementos estruturais da personalidade.

Exner e Sendín (1999) reafirmam, ao comentar sobre possibilidades interpretativas do Método de Rorschach, que o fator temporal é um elemento crucial que 
impõe dificuldades quando se pretende formular prognósticos de conduta. Esses pesquisadores afirmam que:

“Embora seja certo que os dados da maioria das variáveis do teste permanecem fortemente estáveis ao longo do tempo nos adultos, não existem correlações perfeitas de reteste. É improvável que a estrutura básica da personalidade ou os estilos de resposta de um adulto mudem substancialmente com o passar do tempo, mas certas mudanças funcionais podem aparecer com o tempo como resultado de novas experiências ou novas situações, que podem somar-se ao arsenal de conhecimentos que a pessoa tenha acumulado e induzir, por isso, mudanças de conduta. De modo que, quanto mais amplo seja o período de tempo que o prognóstico trata de abranger, maior será a necessidade de dispor de dados sobre as circunstâncias externas do sujeito.” (p. 31)

Em relação ao significado da análise estatística da correlação entre resultados obtidos em dois momentos avaliativos do Rorschach, esta nos informa o quanto duas variáveis se relacionam, o que depende, em grande parte, da própria ocorrência das variáveis e de sua força de aparecimento no protocolo. Da mesma forma que no Sistema Compreensivo, como apontado por Silva Neto (2008), há variáveis no sistema francês que apresentam distribuição reduzida ocorrência e valores baixos de frequência. $O$ autor comenta que em casos que ocorre "assimetria positiva" de variáveis, haverá predomínio de valores baixos para essas variáveis e isso pode diminuir os índices de correlação no teste e reteste, sem revelar exatamente a magnitude da associação entre as variáveis. Desta maneira, é recomendado analisar a estabilidade temporal de uma variável do Rorschach observando o número de indivíduos que permanecem na mesma faixa interpretativa no momento do teste e do reteste (Silva Neto, 2008). 
Outra forma de relativizar a influência da variabilidade das frequências das variáveis do Rorschach na análise da estabilidade dos dados é a que foi utilizada no presente trabalho, quando se comparou cada avaliação dos casos com o respectivo referencial normativo, respeitando-se o nível de escolaridade. Foram comparadas as posições dos indivíduos com relação às normas na segunda avaliação, realizando-se análise inferencial dos achados pelo Teste de Postos Sinalizados de Spearman para amostras relacionadas. Buscou-se identificar se existiriam diferenças estatisticamente significativas entre avaliação e reavaliação dos indivíduos em 14 principais variáveis do Rorschach, a saber: índices de produtividade (R, RA, Rec e Den), modos de apreensão (G, D, Dd e Dbl), funcionamento lógico (F\%, F+\% e F+ext\%), conteúdo Animal (A\%) e Humano $(\mathrm{H} \%)$ e respostas banais (Ban). Foram encontradas diferenças significativas em três variáveis: Respostas Adicionais (RA), Denegação (Den) e modo de apreensão global (G). As variáveis RA e Den apresentaram baixa frequência no conjunto geral dos dados, desta forma qualquer alteração que seja notada entre os dados dos dois momentos avaliativos oferece um peso maior na detecção de diferenças que, muitas vezes, foram pouco relevantes ao nível individual. Isso enfraquece em muito o sentido interpretativo dessas diferenças detectadas nessas variáveis. Já em relação ao modo de apreensão G, observou-se que os indivíduos no momento da reavaliação apresentaram menor proporção de $\mathrm{G} \%$ do que na avaliação. Isso pode sugerir, a princípio, que no primeiro momento avaliativo mais indivíduos tenderam a captar os elementos da realidade de forma abrangente. No entanto, seria necessário examinar o nível de elaboração implícito nessas respostas globais, de modo a compreender como se deram essas percepções (por exemplo, respostas globais mais simples ou combinadas, mais precisas ou imprecisas, nível de elaboração primário ou secundário) para efetivamente interpretar o significado real dessa mudança. Além disso, há também que se relativizar essa diferença estatística 
visto que os resultados das 11 outras variáveis permaneceram estáveis para todos os participantes. Foi possível observar, portanto, que os adultos mantiveram suas posições nos resultados do Rorschach, em relação ao referencial normativo, ao longo de 15 anos, sinalizando constância dessas variáveis com o passar do tempo. Em outras palavras, esses achados constituem evidências empíricas relevantes sobre a estabilidade temporal de características de personalidade em adultos, a partir do Método de Rorschach (Escola de Paris).

Outra maneira que se encontrou para investigar fatores associados a estabilidade ou não dos dados obtidos, referiu-se a uma comparação ao longo do tempo entre os resultados dos subgrupos:1) feminino versus masculino; 2) baixa/média escolaridade versus alta escolaridade; 3) em função de faixas etárias dos indivíduos. Buscou-se examinar se algum desses fatores: sexo, nível de escolaridade e idade poderiam ter influenciado os nossos resultados. Em relação ao sexo, não foram identificadas diferenças estatisticamente significativas entre avaliação e reavaliação do Rorschach. Em relação à escolaridade, foi encontrada diferença estatisticamente significativa em duas variáveis relacionadas à localização das respostas. O grupo de baixa/média escolaridade apresentou aumento da apreensão global (G) dos estímulos e diminuição dos pequenos detalhes (Dd) ao longo do tempo, enquanto o grupo de alta escolaridade diminuiu sua frequência em $\mathrm{G}$ e aumentou Dd na segunda avaliação (após 15 anos). Contudo, aqui também seria interessante verificar qual é a qualidade formal das respostas que acompanham essas localizações e, em que cartões isso ocorreu, para enriquecer a interpretação analítica desses achados. Por fim, em relação às faixas etárias, uma diferença significativa foi encontrada em relação ao número de respostas, já que, com a passagem do tempo, os indivíduos mais jovens (34-49 anos) parecem ter produzido mais interpretações ao Rorschach e se envolvido mais com a tarefa do que os indivíduos mais velhos (50-59 
anos). A partir dessas análises comparativas intragrupo, pode-se notar, em síntese, poucas variáveis do Rorschach com mudanças estatisticamente significativas entre os dois momentos avaliativos, fortalecendo a hipótese de estabilidade temporal da personalidade em adultos não pacientes.

Sobre a proposição teórica de que as variáveis do Rorschach representariam componentes da estrutura e do funcionamento da personalidade, percebe-se grande dificuldade em estratificar ou associar os indicadores técnicos desse instrumento avaliativo a esse esquema didático a respeito dos indivíduos. É importante considerar que a análise das respostas, prancha a prancha, engloba imensa variedade de possibilidades. As tentativas de examinar a estabilidade temporal nas características dos adultos aqui avaliados constituem-se em estratégias para se identificar componentes recorrentes da personalidade desses indivíduos, fortalecendo hipóteses interpretativas teóricas a partir dessas evidências empíricas, as quais, por fim, configurariam indicadores de validade do Rorschach associados a consistência de seus achados ao longo de 15 anos de vida.

Assim como o criador do método de Rorschach, Anzieu (1986) ressalta que a interpretação temporal ou dinâmica do instrumento deve retomar as respostas na ordem em que foram dadas pelo indivíduo, facilitando a compreensão global da personalidade. Segundo esse autor, as respostas devem ser examinadas no contexto de cada prancha, como variam ou se sucedem em termos de localizações, determinantes, conteúdos, número de respostas, comentários, tempos, manipulação da prancha, comportamento e atitude do respondente. Nesta direção, Rausch de Traubenberg (1998) afirma que a análise das respostas no Rorschach deve se apegar aos fatores formais presentes no psicograma (síntese quantitativa dos achados), bem como no desenvolvimento das respostas e das reações qualitativas durante o teste. Para ela em todo o protocolo haverá 
indícios, mais ou menos frequentes, que poderão fornecer hipóteses sobre o modo do funcionamento psíquico dos indivíduos.

Essas ponderações também foram reafirmadas, há longa data, por Japur e Jacquemim (1985):

“A consideração de como aparecem, num protocolo de Rorschach, essas Fórmulas Vivenciais oferece importantes indicadores sobre a afetividade da pessoa, embora não esgote por completo a sua compreensão. Para tanto, seria necessário vinculá-las aos demais fatores da técnica, bem como à compreensão da dinâmica e do conteúdo simbólico das respostas.” (p. 148)

De forma geral, os resultados do Estudo 1 demonstraram que ocorreram algumas mudanças nos resultados da primeira e da segunda aplicação do Rorschach, mas também foi possível encontrar padrões semelhantes na abordagem do instrumento e na realização da atividade após 15 anos. Desta forma, foram obtidas evidências empíricas de estabilidade temporal em alguns importantes índices técnicos da Escola de Paris do Rorschach, apontando sua boa precisão para avaliar adultos não pacientes.

Ao refletir sobre o conjunto de resultados presentemente identificados, percebese a importância de ir além dos mesmos, para buscar efetiva compreensão dos indivíduos. Urbina (2007) ressalta que os objetivos da avaliação psicológica ultrapassam a descrição do desempenho dos respondentes. Portanto, segundo suas palavras, é importante considerar que:

“(...) a interpretação válida dos escores de teste muitas vezes acarreta a aplicação do sentido inerente aos escores, seja ele baseado em normas, conteúdo do teste, processo de resposta, padrões estabelecidos de convergência e divergência ou 
qualquer combinação dessas fontes de evidências às inferências pragmáticas necessárias para a tomada de decisões a respeito das pessoas. Nesses casos, as evidências de validade precisam contemplar a significância que os escores podem ter em questões que vão além deles mesmos ou em campos que estão fora da esfera direta do teste.” (p. 183)

No caso da reavaliação dos adultos deste estudo, os possíveis “campos que estão fora da esfera direta do teste" incluem as mudanças no comportamento que podem ter ocorrido, não em função do tempo (entre a primeira avaliação e a reavaliação), mas sim vinculadas aos processos intraindividuais e de acontecimentos do ambiente desses adultos ao longo dos últimos anos. Desse modo, o delineamento de um estudo longitudinal, com acompanhamento qualitativo detalhado de ocorrências ao longo dos anos, poderia fornecer maiores informações a respeito da influência desse e outros fatores sobre o funcionamento psíquico dos indivíduos.

Na literatura científica, encontram-se muitos estudos que abordam, de diversas maneiras, as características da personalidade na fase adulta. Hooker e McAdams (2003), por exemplo, ao argumentarem sobre características de etapas desenvolvimentais, apontam que a personalidade na vida adulta poderia ser vista como estável. Eles afirmam que essa estabilidade é, muitas vezes, vista de forma positiva, pois ao contrário dos domínios físico e cognitivo, ela não sofreria perdas ao longo dos anos. Por outro lado, esse entendimento da personalidade como estável tornou difícil sustentar uma abordagem dinâmica de desenvolvimento da personalidade na vida adulta (Hooke \& McAdams, 2003). Apresentam elementos, portanto, que colocam em questão o próprio conceito de personalidade e suas relações com o desenvolvimento humano.

Ao se tomar como enfoque analítico a proposição teórica de Erikson sobre o desenvolvimento humano, tem-se o princípio de que o mesmo ocorre até a velhice, a partir 
do princípio epigenético e da evolução psicossocial, postulando-se que o ambiente social pode exercer impacto sobre o desenvolvimento da personalidade (com Feist, Feist \& Robberts, 2015). Esta concepção teórica pode ajudar na compreensão de certas mudanças nas características de personalidade dos indivíduos avaliados no presente estudo, afinal, o equilíbrio emocional humano varia, em grande parte, em função do jogo psicodinâmico (de perdas e ganhos) de objetos afetivamente investidos. Ao longo da vida, os indivíduos estão vulneráveis a novas experiências e com potencial transformador que podem impulsionar aquisição de novos mecanismos de enfrentamento (Cândido, 2011). Estes, por sua vez, podem regular a resposta emocional e os mecanismos de adaptação dos indivíduos. Desta forma, as mudanças identificadas nos dados do Rorschach podem não se referir a elementos da estrutura da personalidade, mas a expressão do funcionamento psíquico. Nesta direção, Gavião (2002) cita concepções sobre o conceito apresentado por Trinca referente à mobilidade psíquica. Este conceito refletiria a capacidade da vida psíquica de "dar conta" do viver por apresentar qualidades como flexibilidade, elasticidade, plasticidade e flutuação. Esta mobilidade permitiria aos indivíduos apresentarem maior abertura ao contato consigo mesmo e com novas experiências.

Pode-se, nesse momento, questionar: essa visão dinâmica do funcionamento psíquico (a coexistência de mais de um modo de funcionamento mental, como teoriza Bion) poderia ajudar a compreender teoricamente a mudança em alguns dos estilos de personalidade dos adultos aqui reavaliados pelo Método Rorschach após 15 anos? Provavelmente a perspectiva clínica, de base psicodinâmica, acrescentará elementos relevantes para a adequada interpretação dos resultados no Método de Rorschach, porém os atuais achados relativos a elementos permanentes ao longo do tempo também auxiliam a compreender que existem variáveis nesse método projetivo que podem representar tendências estáveis de reatividade individual, favorecendo predições a respeito desses 
indivíduos. Desse modo, os atuais achados podem ser compreendidos também como evidências de precisão da Escola do Rorschach de Paris no contexto do Brasil. Em função da consistência dos achados pode-se até mesmo apontar que constituem também indicadores empiricamente constituídos sobre características da personalidade de adultos, portanto, indícios de validade do Rorschach.

A respeito da possível influência do sexo sobre o padrão de respostas ao Método de Rorschach, observou-se ausência de diferenças estatisticamente significativas em praticamente todas as variáveis nos adultos avaliados neste estudo. O subgrupo masculino apresentou maior média de respostas nas variáveis $\mathrm{F}+\mathrm{e}(\mathrm{Ad})$, contudo, em relação às somatórias de respostas determinadas pela forma e no somatório dos conteúdos animais observou-se ausência de diferenças estatisticamente significativas, sendo importante, relativizar esse achado inicialmente apontado.

No estudo de Pasian (1998), realizado com 405 adultos não pacientes, foram identificadas também diferenças estatisticamente significativas em função do sexo em apenas sete variáveis: RA, G, D, F+-, FClob, A e Geo, sendo que as mulheres apresentaram maior frequência de respostas adicionais, maior uso dos determinantes FClob e maior frequência de respostas de conteúdo A. O subgrupo masculino do referido estudo, por sua vez, apresentou maior frequência nas variáveis G, F+- e Geo. Naquele momento, discutiu-se que o sexo sinalizou influência estatisticamente significativa em poucas variáveis do Método de Rorschach, várias com baixa incidência no total de respostas, podendo se constituir em efeito espúrio, não relevante para a interpretação clínica dos dados. Também no presente Estudo 1 os resultados apontaram que o sexo se mostrou como uma variável sociodemográfica com reduzido impacto nos padrões de respostas ao Rorschach (Escola Francesa), podendo ser deixado de lado enquanto diferenciador na avaliação da personalidade em adultos não pacientes. 
Em relação a possível influência da escolaridade sobre o padrão de respostas ao Método de Rorschach, notou-se que 15 das 56 variáveis analisadas (Rec, TLm, TRm, F$\mathrm{F}+\%, \mathrm{~K}, \mathrm{kan}, \mathrm{FC}, \mathrm{A},(\mathrm{A}), \sum \mathrm{A} \%, \mathrm{H},(\mathrm{H}), \sum \mathrm{H} \%$ e Obj) apresentaram diferenças estatisticamente significativas entre os subgrupos. No presente trabalho, o grupo de menor escolaridade apresentou maior número de recusas (Rec), levou mais tempo em seus processos associativos (maiores TLm e TRm) e fez maior uso dos determinantes Fe kan. Para as demais variáveis, o subgrupo de maior escolaridade apresentou maiores frequências $\left[\mathrm{F}+\%, \mathrm{FC}, \mathrm{K}, \mathrm{A},(\mathrm{A}), \sum \mathrm{A} \%, \mathrm{H},(\mathrm{H}), \sum \mathrm{H} \% \mathrm{e} \mathrm{Obj}\right]$.

Esses achados podem ser contrapostos aos 405 adultos de Pasian (1998), onde foram encontradas diferenças estatisticamente significativas em função da escolaridade dos participantes (baixa, média ou alta) em 24 variáveis do Rorschach dentro do amplo conjunto de indicadores examinados. Em seu estudo, o subgrupo de baixa escolaridade apresentou significativa maior incidência de recusas (Rec), denegações (Den) e número médio de respostas de conteúdo botânico (Bot) e Natureza (Nat). Já o subgrupo de alta escolaridade obteve significativo maior número de respostas nas variáveis: Ban, G, D, K, kp, CF, FC, FE, STA, (A), H, (H), Hd, (Hd), Anat, Obj, Art, Arq, Abs e número proporcional de respostas, totalizando 20 indicadores técnicos de diferenciação associados a mais anos de estudo. Apesar da complexidade derivada desses achados e da própria interpretação de seus significados, visto que no Rorschach a análise deve englobar o conjunto de variáveis e não indicadores isolados, tem-se evidências consistentes, advindas de dois amplos estudos empíricos, que apontaram que o fator escolaridade pode afetar o padrão de respostas dos indivíduos no Método de Rorschach e, derivado daí, no próprio processo de organização da personalidade em adultos.

Ao tomar em análise o possível efeito da idade sobre os achados dos adultos na reaplicação do Rorschach, observou-se que em apenas duas variáveis, F+- e K, os 
indivíduos tenderam a apresentar diferenças estatisticamente significativas. O grupo de indivíduos mais jovens (34-49 anos) apresentaram maior média do índice F+- (de baixa frequência nos casos) quando comparados com os indivíduos mais velhos. Contudo, esta diferença torna-se pouco relevante na medida em que nas variáveis $\mathrm{F} \%$ e $\mathrm{F}+\%$, ela desaparece. Na variável K, os indivíduos mais novos apresentaram média menor do que os mais velhos, o que pode sugerir menor utilização de seus recursos internos de dinamismo quando comparados com os indivíduos de mais idade e, talvez, indicar um traço de menor maturidade. Contudo, mais uma vez, esta diferença deve ser ponderada frente as demais variáveis existentes na análise do Rorschach.

Em relação aos dados encontrados no SRQ-20, tem-se que a maior parte dos adultos avaliados $(\mathrm{n}=78)$ não apresentou sintomas característicos de possíveis transtornos mentais. No entanto, dez adultos (11,3\% da amostra do Estudo 1) alcançaram e/ou superaram a nota de sete/oito pontos no instrumento. Faz sentido contrapor esse achado clínico frente aos indicadores de saúde mental disponíveis na literatura nacional. O estudo de Santos e Siqueira (2010) objetivou examinar a prevalência dos transtornos mentais na população adulta brasileira por meio de uma revisão sistemática da literatura, englobando o período de 1997 a 2009. Os autores encontraram 67 trabalhos com essa temática, podendo examinar minuciosamente um total de 25 artigos. Nos estudos revisados, os instrumentos utilizados para detecção dos sintomas psiquiátricos eram questionários autoaplicáveis, simples e rápidos para a investigação, como SRQ-20, General Health Questionnaire (GHQ-12) e Questionário de Morbidade Psiquiátrica em adultos. Os resultados apontaram altos índices de prevalência geral de transtornos mentais na população adulta, que variaram de $20,0 \%$ a $56,0 \%$, atingindo principalmente mulheres e trabalhadores. Apesar dos altos índices, os pesquisadores argumentam que esses estudos possuem limitações, como, por exemplo, o fato de que a maioria das pesquisas avaliou 
apenas indivíduos do sexo feminino, além de problemas metodológicos na condução das investigações (como falta de padronização e rigor na definição de casos). Desse estudo de revisão da literatura, os autores comentam que índices mais elevados de transtornos mentais ocorreram em indivíduos com vários fatores de risco à saúde, como pobreza, desemprego, reduzida escolaridade, entre outros. De qualquer maneira, os autores concluem que boa parte das amostras avaliadas nessas pesquisas apresentou algum tipo de sofrimento psíquico, o que deve ser considerado ao se estudar características de personalidade em indivíduos adultos. Dentro dessa perspectiva, a taxa de 11,0\% atualmente identificada no presente Estudo 1 pode ser considerada como índice aceitável para compor uma amostra que represente a diversidade de indivíduos na faixa etária adulta no contexto contemporâneo do Brasil, fortalecendo os achados relativos à avaliação da personalidade.

\subsection{ESTUDO 2}

Como inicialmente argumentado nesse trabalho, o Estudo 2 teve por objetivo revisar e atualizar evidências psicométricas do Rorschach em adultos (não pacientes), de acordo com a Escola de Paris, referentes aos dados normativos. Buscou, por meio de análises técnicas com base em novas tecnologias e procedimentos estatísticos de maior refinamento, checar a necessidade de atualização dos referenciais normativos elaborados por Pasian $(1998,2000)$ com indivíduos adultos. Esse Estudo 2 procurou fornecer dados que contemplam as diretrizes nacionais do Conselho Federal de Psicologia para uso deste método projetivo de avaliação psicológica no contexto do Brasil.

Os resultados descritivos do Método do Rorschach do Estudo 2, focado sobre os índices de produtividade e ritmo de trabalho de 168 adultos avaliados, demonstram que 
os adultos apresentaram adequado número médio de respostas $(\mathrm{R}=18,7)$, superior ao número médio de respostas ao Rorschach $(\mathrm{R}=16,0)$ obtido por Pasian (1998) com amostra de 405 adultos. Com relação ao tempo médio de resposta (TRm =20 segundos), verificouse que os adultos da amostra atual foram ágeis e, ao mesmo tempo, envolvidos com a tarefa em seus processos associativos $(\mathrm{TRm}=35,1$ segundos $)$. Em termos gerais, sinalizaram bons recursos lógico-associativos, com adequado ritmo de trabalho diante dos estímulos propostos.

As demais variáveis relacionadas à produtividade no Rorschach (respostas adicionais, recusas e denegações), que podem ser indicativas de impacto emocional frente os estímulos desse método projetivo, ocorreram em proporções reduzidas nos protocolos das pesquisas presentemente comparadas. Os adultos aqui avaliados obtiveram média de 1,3 respostas adicionais, 0,3 recusas e 0,18 denegações, próximos à amostra de 405 casos de Pasian (1998), que alcançou média de 1,8 respostas adicionais, 0,63 recusas e 0,42 denegações. Comparativamente aos dados de Pasian (1998, 2000), foram encontradas diferenças estatisticamente significativas em relação ao número de RA, Rec e Den, contudo, diante do número pouco expressivo dessas variáveis em ambas as avaliações, é importante relativizar essa diferença entre os achados.

Em estudo de natureza normativa com adultos franceses (Tychey et al., 2012) encontrou-se índice médio de respostas igual a 28,2. A diferença entre o número de respostas das amostras brasileira e francesa já havia sido detectada anteriormente por Pasian (1998, 2000) em comparação com os índices apresentados por Anzieu (1986), o que reafirma as especificidades relativas a realidades culturais e épocas diferentes. Não é possível afirmar que os adultos aqui avaliados não se engajaram na atividade avaliativa (em função de seu número de respostas), visto que o padrão de interpretações realizado há 15 anos foi muito semelhante ao atual. 
Há que se comentar que os dados normativos dos adultos turcos apresentaram produtividade média de 19,6 respostas no Rorschach (Ikiz et al., 2013), índice próximo ao alcançado pela presente amostra. Além disso, estudos brasileiros que utilizam a Escola de Paris do Método de Rorschach também demonstraram índices de produção semelhantes aos do presente estudo. Assim, na pesquisa desenvolvida por Lelé (2006) com adultos não pacientes foi identificada média de 20,4 respostas, enquanto CuryJacquemin (2012) encontrou índice médio de 21,3 respostas com adolescentes de 12 a 14 anos. Por sua vez, Jardim-Maran (2011) avaliou adolescentes de 15 a 17 anos e encontrou média de 17,7 respostas no Rorschach. Esses dados reforçam um padrão de produção de respostas semelhante nas amostras do Brasil, embora com resultados inferiores ao número de interpretações identificado no estudo realizado com adultos franceses.

Ainda em relação aos índices de produtividade no Rorschach, a análise por cartão indicou que o cartão $\mathrm{X}$ despertou maior número de respostas $(15,8 \%)$, seguido pelos cartões III $(11,2 \%)$ e I $(11 \%)$. O cartão X também obteve o maior número de respostas adicionais (14,6\%). Esses dados apresentam padrão muito semelhante aos encontrados por Pasian (1998). O cartão X continuou a ser o responsável por evocar a maior quantidade de respostas, possivelmente pelo seu caráter fragmentado, colorido e que, pela dispersão das manchas, pode provocar maior atividade perceptiva (Ikiz et al., 2013). Os dados dos adultos turcos (Ikiz et al., 2013) essa tendência também foi observada, uma vez que o cartão $\mathrm{X}$ foi o que apresentou o maior número de respostas. Nas atuais normas francesas com adultos (Tychey et al., 2012) essa análise foi realizada de maneira diferente, visto que os pesquisadores solicitavam aos participantes que indicassem qual cartão poderia ser considerado como representante simbólico da imago paternal, maternal e da representação de si, além de solicitar cartões preferidos e preteridos. Neste estudo, o cartão X foi escolhido como preferido por $25,8 \%$ dos participantes. 
No presente trabalho, o cartão que obteve o maior número de recusas foi o cartão IX (38,5\%), seguido pelos cartões VI (17,0\%) e IV (15,3\%). De acordo com Anzieu (1986) e Rausch de Traunenberg (1998), os cartões IX e VI são identificados como os cartões mais favorecedores deste tipo de reação, que parecem envolver maior impacto emocional diante dos estímulos. O cartão IX também foi o cartão com mais recusas no estudo de Pasian (1998), seguido pelo cartão VI, reforçando a interpretação teórica de que são estímulos que propõem contato com elementos mais primitivos e inconscientes da personalidade (cartão IX) e com aspectos relacionados à sexualidade e representativo da masculinidade (cartão VI), conforme aponta a literatura da escola parisiense do Rorschach (Anzieu, 1986; Pasian, 2000; Rausch de Traubenberg, 1998). Na Turquia, os dados revelaram que o cartão com maior número de recusas também foi o IX (Ikiz et. al., 2013), enquanto no estudo de Tychey et al. (2012) os cartões preteridos pelos adultos foram o IV $(21,2 \%)$ e o VI (12,7\%). É interessante notar que, independente dos fatores culturais, o que se parece fazer presente na maior parte desses dados referem-se às possíveis reações que tais cartões parecem evocar tendo em vista os significados simbólicos dos mesmos. Reações que ultrapassam fronteiras geográficas e culturais, reforçando o valor dos aspectos inconscientes presentes e suscitados pelo Método de Rorschach.

Os participantes apresentaram baixos índices de denegações, sendo o cartão IX o que obteve maior frequência $(16,7 \%)$, correspondendo a apenas cinco de um total de 30 ocorrências. Diante dos demais cartões a proporção de denegações foi variada, mas de baixa frequência (zero até quatro). O cartão IX, por ser o que apresentou maior número de respostas denegadas, reafirma o impacto emocional que provocou nos adultos aqui investigados. Esse achado difere dos encontrados por Pasian (1998), em que os cartões com maiores números de denegações foram os cartões I e V, porém há que se lembrar 
que se trata de variável com reduzida ocorrência, relativizando seu significado em termos gerais.

Como síntese relativa aos resultados obtidos no presente estudo pode-se comentar que houve adequado número médio de respostas,associados a reduzidos índices de recusa, de respostas adicionais e denegações. Isso permite inferir que os adultos avaliados responderam adequadamente ao Método de Rorschach, sem dificuldades emocionais e resistências, envolvendo-se com a pesquisa, o que reforça seus achados.

Em relação aos modos de apreensão, constatou-se que a porcentagem média de respostas globais (G\%) no atual estudo normativo manteve-se alta, alcançando índice de 44,0\%. A média de respostas detalhe (D\%) atingiu valor médio de 38,4\%, enquanto as de pequeno detalhe $(\mathrm{Dd} \%)$ alcançaram $16,2 \%$, os detalhes brancos $(\mathrm{Dbl} \%)$ corresponderam a 1,34\% das respostas, além da ausência de detalhes oligrofênicos ou inibitórios (Do). Quando contrapostos aos dados de Pasian (1998), observa-se diferença significativamente estatística somente em relação a Dbl e Do, que em Pasian (1998) alcançou 0,93\% e 1,0\%, respectivamente. Mais uma vez, as diferenças devem ser relativizadas, tendo em vista que esses modos de apreensão foram pouco frequentes nos dados dos dois estudos. Houve pequena queda na porcentagem média de $\mathrm{G}$ em relação a1998 (que era 48\%)e leve aumento em relação a $\mathrm{D}$ (que era 33,5\%). Contudo, há que se lembrar que, no atual trabalho, a área Gtec do cartão III (que foi contabilizada como área G em Pasian, 1998) passou a ser classificada como D, seguindo a literatura internacional atual. Essa alteração no procedimento pode explicar a diferença nos valores encontrados nesses modos de apreensão dos dois estudos citados.

Ao comparar os resultados atuais aos dados de adultos franceses (Tychey et al., 2012) é possível identificar diferenças, uma vez que os franceses apresentaram as seguintes porcentagens médias: $\mathrm{G} \%=37,0 ; \mathrm{D} \%=57,2 ; \mathrm{Dd} \%=3,13 ; \mathrm{Dbl}=1,99$. As 
mesmas variáveis encontraram, na amostra normativa turca (Ikiz et. al., 2013), os seguintes valores médios: $\mathrm{G} \%=27,0 ; \mathrm{D} \%=65,9 \% ; \mathrm{Dd} \%=2,8 \% ; \mathrm{Dbl}=2,5$. Os dados obtidos no atual estudo refletem maior frequência de percepções globais quando comparados às normas francesas e turcas, a busca da abrangência e compreensão do todo e, a princípio, com menor atenção a detalhes significativos. É importante considerar que foram identificadas, no presente trabalho, 39 áreas classificadas como grande detalhe (D), com porcentagem média de $38,4 \%$, sugerindo frequência suficiente para concluir que os indivíduos estejam mantendo o vínculo imediato e prático com a realidade.

$\mathrm{Na}$ distribuição dos determinantes das respostas ao Rorschach relacionados à forma e à precisão formal, os achados do presente estudo apontaram os seguintes valores médios: $\mathrm{F} \%=32,7 \% ; \mathrm{F}+\%=63,8 \% ; \mathrm{F}+\mathrm{ext} \%=72,1 \%$. Os determinantes puramente formais corresponderam a pouco mais de um terço do conjunto das respostas, semelhante aos dados de Pasian (1998) que alcançou índice de 35,1\% nessa variável do Rorschach. Já os índices de $\mathrm{F}+\%$ e F+ ext\% identificados nesse trabalho alcançaram médias um pouco superiores quando comparados com os encontrados em $1998(\mathrm{~F}+\%=60,0 \% ; \mathrm{F}+\mathrm{ext} \%=$ 69,0\%), mostrando-se estatisticamente diferentes.

Ao comparar aos atuais achados aos referenciais normativos da França e da Turquia, disponíveis atualmente, é possível notar índices de F\% bastante diferentes. Em adultos franceses (Tychey et al., 2012) F\% atingiu porcentagem média de 57,8\%, enquanto nos dados turcos (Ikiz et.al, 213) a proporção de F\% alcançou 61,0\%. No tocante à variável $\mathrm{F}+\%$ do Rorschach, os resultados do presente trabalho foram semelhantes aos franceses $(61,0 \%)$ e inferiores aos obtidos na Turquia (74,5\%). Pode-se comentar que os adultos do Brasil, avaliados nesse estudo, continuaram a utilizar de forma considerável outros determinantes além dos aspectos formais dos estímulos para produzir suas interpretações ao Rorschach, associados a elementos afetivos e imaginativos, 
relacionados a movimento, cor e sombreado, característica que se preservou com o passar do tempo. Além disso, mostraram preservação de análises acuradas da realidade, favorecendo sua adaptação sócio-intelectual.

$\mathrm{Na}$ amostra atual, os determinantes relacionados a cor também mantiveram frequência média semelhante aos dados de Pasian (1998). A média de FC, CF e C foram: $11,9 \%, 9,2 \%$ e $0,8 \%$. Já os dados relacionados aos determinantes de sombreado, apesar de apresentarem médias parecidas, indicaram diferenças estatisticamente significativas entre os dois estudos agora comparados, ainda que, a princípio, não aparentem expressivas modificações, dada sua reduzida incidência nas duas amostras. Na amostra atual, FE, EF e E atingiram os seguintes valores médios: 9,9\%, 4,5\% e 0\%, respectivamente, enquanto em 1998 a média destes determinantes foram, respectivamente: $9,7 \%, 5,6 \%$ e $0,1 \%$. Os sombreados difusos também não apresentaram diferenças significativas entre os dados das duas amostras, tendo aparecido em frequências muito baixas. De toda a forma, os adultos aqui avaliados apresentaram sinais de capacidade de controle racional sobre as emoções, bem como, controle racional das vivências de ansiedade, visto que as proporções de respostas determinadas prioritariamente pela forma e associadas a cor ou ao sombreado predominaram em relação a CF e EF, com praticamente ausência de respostas unicamente determinadas pela cor ou pelo sombreado puro (C ou E, respectivamente).

Os determinantes relacionados ao movimento (K, kan, kob e kp, cuja soma das porcentagens médias atingiu o valor de 31,4\%) também apresentaram proporção muito semelhante a encontrada no estudo de Pasian (1998), onde o valor médio obtido foi $31,53 \%$. Nos dois momentos, a soma das pequenas cinestesias superou o total das grandes cinestesias, o que teoricamente contradiz o esperado para a faixa etária adulta, pois sugerem que os recursos internos de dinamismo estão pouco amadurecidos. Porém, como 
os dados se repetem ao longo do tempo, isso pode refletir uma forma mais espontânea e menos elaborada de uso dos processos reflexivos internos em adultos do Brasil, avaliados por esses dois estudos.

Em relação aos conteúdos, as proporções médias identificadas no presente trabalho foram semelhantes aos dados de Pasian, com algumas exceções. Da mesma forma que em 1998, houve predomínio majoritário dos conteúdos animal e humano sobre os demais tipos de conteúdo. Na amostra atual, A\% = 51,7\% e, em 1998,foi 53,8\%, valores próximos, porém a análise estatística apontou diferenças significativas. Os dados dos adultos franceses (Tychey et al., 2012) referentes aos conteúdos interpretados no Rorschach também refletem elevada porcentagem de conteúdo animal, ainda que não majoritária, com $\mathrm{A} \%=42,5 \%$, enquanto os resultados dos adultos turcos atingiram valor médio de $\mathrm{A} \%=45,0 \%$ (Ikiz, et al., 2013).

Ao focalizar as proporções identificadas nas respostas dos adultos desses estudos em termos de conteúdos humanos $(\mathrm{H} \%)$, houve algumas diferenciações entre os trabalhos. No presente estudo, o índice H\% atingiu 20,9\%, enquanto em 1998 (Pasian, 1998) este resultado foi igual a $16,1 \%$. Apesar de um leve aumento de $\mathrm{H} \%$ nos dados atuais, não foram encontradas diferenças estatisticamente significativas entre os resultados de 1998. No estudo realizado na França (Tychey et al., 2012) este índice apareceu com frequência de 15,8\% das respostas e, na amostra turca, atingiu 14,7\% (Ikiz, et. al, 2013). De forma geral, o índice médio de $\mathrm{H} \%$ encontrado no presente trabalho foi superior aos demais grupos normativos.

Nesse momento cabe destacar relevante ponderação sobre o presente trabalho. Inicialmente, a amostra delineada para este estudo continha uma proporção variada e equilibrada de participantes entre as faixas etárias, mas com a inclusão de 66 adultos do Estudo 1, a faixa etária predominante passou a ser dos indivíduos entre 50 a 65 anos. Ikiz 
et al. (2013) apontaram que em seu estudo houve grande variação de H\% entre subgrupos divididos pela idade, comentando que indivíduos entre 35 e 49 anos ofereceram menos respostas humanas que adultos de 20 a 34 anos e que os mais velhos, entre 50 a 64 anos. Os autores compreenderam esse achado como representativo da busca por um objeto simbólico reconfortante ser comum entre os indivíduos com maior idade, em uma tentativa de equilibrar a possível instabilidade vivida com o passagem do tempo.

Outros conteúdos que foram destacados pelos adultos de presente trabalho foram Objeto $(\mathrm{Obj} \%=8,6)$, Anatomia $($ Anat $=6,6 \%)$ e Botânico $(\operatorname{Bot} \%=3,6 \%)$, bem semelhantes aos encontrados por Pasian (1998). Esses conteúdos teoricamente indicam possível projeção de elementos representativos de vivência de ansiedade (como Anat e Bot), e também de racionalização (Obj), segundo Rausch de Traubenbergh (1998).

Outra importante informação revelada pelo Método de Rorschach refere-se à avaliação das vivências afetivas. Na avaliação atual, a fórmula vivencial do Tipo de Ressonância Íntima (TRI) indicou predomínio de indivíduos do tipo extratensivo (56,0\%), mesma direção encontrada por Pasian (1998, com 41,5\%), mas hoje em proporção ainda maior. Ambos os dados apontam tendência dos adultos em apresentar abertura psíquica e expressar de forma mais direta no ambiente suas necessidades afetivas. O segundo tipo vivencial mais frequente no presente trabalho foi o tipo introversivo (23,8\%), seguidos pelo tipo coartado/coartativo (16,0\%) e ambigual $(4,2 \%)$. Os dados de Pasian (1998) indicaram, no entanto, que o segundo tipo mais frequente de vivências afetivas era ligado a coartação emocional (tipos coartados/coartativos, com 37,3\%). Essa diferença faz-se relevante e interessante por indicar que a amostra atual parece ter se comportado de forma menos restritiva, com mais manifestações afetivas e menos inibitórias. Já nos estudos normativos internacionais da Escola Francesa do Rorschach, os resultados relativos aos adultos franceses (Tychey et al., 2012) e aos turcos 
(Ikiz, et al., 2013) não apresentaram informações referentes à primeira e segunda fórmula vivenciais do Rorschach, não sendo possível examinar comparativamente esse tipo de achados.

Com relação a segunda fórmula afetiva do Rorschach (também denominada por Jacquemin, 1976, como referente às Tendências Latentes) também indicou predominância do tipo introversivo no presente trabalho $(69,0 \%)$, seguindo a mesma direção descrita por Pasian (1998) onde 66,0\% dos adultos, naquele momento, também apresentaram a introversão como estilo prevalente, sugerindo recursos internos predominantemente de caráter reflexivo e imaginativo, mas sem uso cotidiano nas vivências afetivas (daí serem interpretados como tendências latentes).

Ainda no Brasil, Gavião (2002) encontrou, em seu estudo do Rorschach com idosos, dados semelhantes aos atuais no tocante a primeira fórmula (tipo de ressonância íntima, TRI) e na segunda fórmula afetiva (tendências latentes, TL). Na primeira fórmula afetiva metade $(50,0 \%)$ dos idosos sinalizaram estilo extratensivo e, na segunda fórmula, 74\% dos indivíduos classificaram-se como estilo introversivo. Nota-se, portanto, similaridades entre os estilos afetivos identificados em idosos e em adultos, a partir do presente trabalho.

Rausch de Traubenberg (1998) sugere que uma expressão vigorosa do polo cinestésico, nessa segunda fórmula afetiva, pode resultar em interpretações distintas para indivíduos de diferentes faixas etárias. Assim, na criança, pode indicar uma posterior evolução introversiva e, no adulto, pode sugerir uma atitude descontraída. Em relação à primeira fórmula afetiva do Rorschach (TRI), a pesquisadora faz interessante ressalva sobre o sentido interpretativo das relações entre essa variável e as demais fórmulas afetivas. Afirma o seguinte sobre o significado do TRI, em associação com os outros indicadores de vivências afetivas: 
“(...) é ele próprio mais um potencial de ressonância do que uma realização concreta, pois indica como o sujeito poderia viver e não como ele conduz a sua ação, podendo o registro do vivido ser mais amplo do que o da realização real" (Rausch de Tranbenberg, 1998, p.175).

Portanto, a aparente inconsistência entre as fórmulas afetivas identificadas nos trabalhos anteriormente citados, inclusive nos dados atuais, deve ser ponderada e relativizada. Tratam-se de recursos afetivos dos indivíduos, similares entre adultos contemporâneos e idosos, como apontado pelos achados descritos.

A terceira fórmula afetiva do Rorschach, relativa a reatividade cromática, possibilita inferências a respeito da responsividade dos indivíduos diante de estímulos considerados como essencialmente representativos de elementos emocionais (cartões VIII, IX e X, totalmente cromáticos). No presente estudo, quase metade da amostra apresentou estilo ambigual (46,4\%), seguido pelos introversivos $(33,3 \%)$ e extratensivos (20,2\%). Diante dessas evidências empíricas, pode-se notar que os adultos presentemente avaliados se mostraram sensíveis às cores do Rorschach e, portanto, abertos à expressão da afetividade, mas continuaram atentos a outros determinantes durante a produção das respostas. Esse dado se confirma ao observar a distribuição variável no uso de diferentes determinantes presentes neste estudo. Assim foi possível notar que os indivíduos evidenciaram reatividade cromática predominante com características de plasticidade em relação às demandas ambientais (tipo ambigual), além do estilo introversivo (segundo mais frequente), que sugere possibilidades de ponderação antes de reação direta no ambiente ou de caráter mais impulsivo. $\mathrm{O}$ valor médio encontrado nos dados atuais para a terceira fórmula afetiva foi de $33,1 \%$, próximo às médias francesa e turca $(35,9 \%$ e $37,0 \%$, respectivamente). Não foi possível comparar esses dados com os adultos da 
amostra de Pasian (1998), uma vez que essa informação não foi disponibilizada nesse trabalho anterior.

Os dados referentes à proporção de respostas globais (número de $\mathrm{G}$, indicador da captação geral dos estímulos e da realidade) em relação às grandes cinestesias (número de respostas K, sinalizadoras de elaboração e de reflexão) constituem em indicadores referentes ao controle afetivo dos indivíduos (Rausch de Traubenberg, 1998). No presente trabalho foi identificada maior proporção de $G$ em relação a $K(3,5: 1)$, acompanhando o que ocorreu nos dados de Pasian (1998), sugerindo nível de aspiração maior do que de realização por parte dos adultos avaliados. A proporção entre a somatória de respostas de grandes cinestesias $(\mathrm{K})$ com valor menor do que as respostas determinadas pelas pequenas cinestesias $(\mathrm{k})(1: 1,8)$ reafirma certa dificuldade na coordenação das vivências afetivas por parte dos adultos avaliados, também identificada por Pasian (1998), onde foi encontrada a proporção 1:2,7 para essas variáveis.

Ainda ao focalizar agrupamentos de variáveis do Rorschach vinculados a informações sobre a coordenação lógica dos afetos, a proporção das respostas FC em relação a somatória de $\mathrm{CF}$ e $\mathrm{C}$ constitui-se como indicador relevante, assim como a proporção de FE em relação a soma de EF e E. No presente estudo, a relação [FC: $(\mathrm{CF}+$ C)] atingiu a proporção de 1,2:1, indicando predomínio de respostas determinadas prioritariamente pela forma, mas associadas a cor. Esse dado sugere relativo controle racional sobre as vivências emocionais, ainda que possa ocorrer alguma manifestação afetiva mais espontânea e menos contida racionalmente, o que inclusive seria esperado em adultos, vinculando-se a própria espontaneidade. Essa proporção atingiu valores semelhantes nos dados de Pasian (1998) (1: 1). No tocante a proporção [FE: (EF + E)], o dado encontrado no presente trabalho foi igual a $1,9: 1$, evidenciando eficiência no controle das vivências de ansiedade nos adultos presentemente avaliados. Esse resultado 
foi bastante semelhante à proporção identificada por Pasian (1998) para essas variáveis, atingindo 1,5: 1, reafirmando o sentido interpretativo atribuído às evidências de adequada coordenação lógica da ansiedade.

Com relação as respostas frequentemente produzidas pelos indivíduos diante do Rorschach, denominadas de banais (Ban) na Escola Francesa, foram considerados os atuais resultados em relação aos dados de Pasian (1998), deTychey et al. (2012) e de Ikiz et al. (2013). É importante considerar que, na última pesquisa de dados normativos franceses de adolescentes (Azoulay et al., 2007), os autores formaram duas listas de respostas banais, uma com critério definido quando uma resposta é dada por $16,7 \%$ dos indivíduos e a outra com uma lista de uma resposta dada por 33,3\% dos indivíduos. Tychey et. al. (2012) utilizaram o critério de 33,3\% no estudo normativo com adultos. E o estudo turco (Ikiz et al. 2013) usou o mesmo critério que o presente trabalho (quando uma resposta é dada por $16,7 \%$ ).

As respostas identificadas como banais e convergentes no atual trabalho e nos trabalhos normativos com adultos franceses e turcos foram:

Cartão I: Morcego na área G (para os quatro estudos) e Borboleta na área G (exceção no estudo turco, que não apresentou esta resposta como banal).

Cartão III:Figura humana na parte preta (D).

Cartão V: Borboleta ou Morcego na área G.

Cartão VIII: Animal quadrúpede na área D lateral (parte rosa).

Cartão X: Aranha no D (lateral azul) (exceção do estudo francês).

Metade dos cartões apresentam semelhança na lista de suas respostas banais, independente do contexto cultural em que os estudos foram realizados. Esta observação favorece a percepção e interpretação dos conteúdos que são socialmente compartilhados 
por adultos, e fortalecem o Método de Rorschach como revelador do funcionamento lógico e socialmente construído.

Algumas diferenças encontradas nos achados atuais e os demais estudos referidos, no entanto, devem ser destacadas. Em Pasian (1998) foram levantadas 13 áreas interpretadas como banais e, nesta avaliação, 14 áreas foram identificadas como respostas banais. O estudo francês (Tychey et al., 2012) apresentou nove respostas banais e, o estudo turco, (Ikiz et al., 2013) identificou 12 respostas banais.

Em comparação com os dados normativos de Pasian (1998), os resultados atuais diferem em relação a quatro cartões. No cartão II, na área Global (G), o presente trabalho incluiu a resposta de conteúdo "Figura Humana (duas)"como banal. Nessa nova lista de banalidades, houve exclusão dos conteúdos "Monstro animal" na área G do cartão IV e "cabeça de animal" no cartão VII (na área D superior) já que, no atual trabalho, as proporções encontradas não alcançaram o critério para serem incluídas na lista de respostas banais. E finalmente, no cartão VIII, na pesquisa atual, foi incluída a resposta "animal quadrúpede (dois)" na área G deste cartão. Pode-se comentar, portanto, que há evidências de especificidades amostrais entre os estudos realizados, porém, de forma geral, as evidências encontradas fortalecem indicadores de conteúdos comuns e socialmente compartilhados por adultos diante do Rorschach, independentemente de seu contexto sociocultural.

Diante dessas comparações realizadas entre resultados gerais nas variáveis do Rorschach referentes a estudos normativos produzidos em diferentes países (França e Turquia) e em dois momentos no interior do Estado de São Paulo (Pasian, 1998 e os dados atuais), torna-se importante também examinar a possível influência de variáveis sócio demográficas nesse método de investigação psicológica. Essa abordagem passa, então, a ser focalizada no presente trabalho. 
Em relação às análises específicas sobre a possível influência do sexo, da escolaridade e da idade sobre os dados do Rorschach, o presente trabalho identificou algumas especificidades de produção. Foi possível encontrar, para algumas variáveis do Rorschach, poucas diferenças estatisticamente significativas na comparação dos grupos masculino e feminino, em relação aos níveis de escolaridade e grupos etários. Esse conjunto de achados merece, portanto, a devida explanação nesse momento.

As diferenças estatisticamente significativas entre homens e mulheres estiveram presentes em 19 de 56 variáveis examinadas no presente trabalho. Essas especificidades de produção ocorreram diante das seguintes variáveis do Rorschach: recusa (Rec), tempos de latência médio (TLm) e de reação médio (TRm), localização Dbl; aos determinantes F+-, F, kob, kp, C, FClob, ClobF e aos conteúdos (Ad), H, ¿H\%, Geo, Nat, Elem, Frag. Contudo, como apontado anteriormente nos resultados, 12 variáveis dessas variáveis (Rec, Dbl, F+-, kob, kp, C, FClob, ClobF, Sg, Nat, Elem e Frag) apresentaram frequência muito baixa (média menor que 2,0\%), atribuindo pouca relevância, do ponto de vista clínico, aos achados. Já as variáveis TLm, TRm, F-,(Ad), H, $\sum \mathrm{H} \%$ e Geo revelaram algumas características interessantes da amostra estudada. Em relação aos dados de produtividade, observou-se que, no geral, as mulheres apresentaram índice levemente superior de respostas (R) e respostas adicionais (RA) e menor índice de recusas (Rec), além de maior agilidade no tempo de realização e conclusão da tarefa proposta. Esses resultados sugerem que o engajamento feminino nas atividades foi maior do que o masculino, o que pode inclusive, ter propiciado média ligeiramente maior de imprecisão formal (F-) na análise das respostas dadas pelos homens. O grupo masculino ofereceu mais respostas de conteúdo (Ad), mas por outro lado, apresentaram média maior de conteúdo humano $(\mathrm{H})$ e na somatória de conteúdos humanos $\left(\sum \mathrm{H} \%\right)$, indicando interesse na busca e contato com o outro. Os índices de conteúdo geográfico também foram mais 
abordados pelos homens, revelando talvez, maior vivência de ansiedade, dado o sentido simbólico atribuído a esse conteúdo. Apesar desses comentários interpretativos, as diferenças aqui encontradas não se configuram como suficientes para indicar a elaboração de dados normativos do Rorschach específicos para o grupo masculino e feminino, reafirmando os argumentos de Pasian (1998) também nesse sentido.

Em relação à escolaridade foram detectadas diferenças estatisticamente significativas em 11 das 56 variáveis do Rorschach examinadas no presente trabalho. Foram elas: recusa, modos de apreensão G e D; determinantes $\mathrm{K}$, kan, $\Sigma \mathrm{k}$; conteúdos: A, $\sum \mathrm{A} \%, \sum \mathrm{H} \%$, Anat e Obj. Ao comparar esses resultados com os obtidos por Pasian (1998) observa-se mudanças em relação à influência da escolaridade ao longo do tempo. Em 1998, 24 de 55 variáveis do Rorschach (os tempos de latência e reação médio não foram analisados, mas foi incluída Sucessão do Tipo de Apreensão - STA) apresentaram diferenças estatisticamente significativas entre os três níveis de escolaridade considerados no estudo, enquanto agora foram apenas em 11 variáveis. Os indivíduos de baixa escolaridade de Pasian (1998) apresentaram significativa maior incidência de recusas (Rec), denegações (Den), de respostas de conteúdo botânico (Bot) e Natureza (Nat). Já os adultos de alta escolaridade obtiveram significativo maior número de respostas nas variáveis: R, G, D, K, kp, CF, FC, FE, STA, (A), H, (H), Hd, (Hd), Anat, Obj, Art, Arq, Abs e Ban.

Há que considerar que no estudo desenvolvido em 1998, os níveis de escolaridade foram diferentes dos critérios utilizados no presente momento. No trabalho de Pasian (1998) foram considerados como de baixa escolaridade os indivíduos com até dois anos de estudo $(n=43)$, os de média escolaridade possuíam de três a oito anos de estudo $(n=122)$, enquanto os de alta escolaridade apresentavam nove ou mais anos de estudo $(\mathrm{n}=240)$. No trabalho atual, a princípio, considerando os 102 participantes avaliados em 
São Carlos (SP), apenas quatro indivíduos foram identificados com o que seria considerado baixo grau de escolaridade pelo critério de Pasian (1998), todos da região de baixo nível socioeconômico. Em São Carlos, nessa mesma região, com até oito anos de estudo, foram encontrados 17 adultos e os demais 29 voluntários possuíam nove ou mais anos de estudo. Já na região de alto nível socioeconômico os adultos identificados para a pesquisa possuíam alta escolaridade (nove ou mais anos de estudo) pelos mesmos critérios. Diante do reduzido número de voluntários identificados com níveis de escolaridade semelhante ao existente em 1998 e diante de mudanças relacionadas ao acesso ao ensino, considerou-se sensato que a atual amostra de adultos fosse também subdivida em três níveis de escolaridade, porém a partir dos seguintes critérios: baixa escolaridade $=$ indivíduos que apresentam até o antigo primeiro grau completo (até oito anos de estudo), média escolaridade = indivíduos que tinham até o antigo ensino médio (11 anos de estudo), alta escolaridade = indivíduos com ensino superior ou acima disso (12 ou mais anos de estudo).

Sobre a mudança no perfil escolar dos adultos, faz-se necessário ressaltar que, a partir da Lei de Diretrizes e Bases da Educação (LDB) de 1996, foram lançadas novas diretrizes para a Educação Nacional que apresentaram como princípio básico a "educação como direito de todos e dever da família e do Estado”. Ao alterar a LDB de 1961, a Lei de 1996, também conhecida como "Darcy Ribeiro”, tornou obrigatório e gratuito o ensino fundamental (na época, $8^{a}$ série) e favoreceu a expansão da educação de jovens e de adultos (estendendo os direitos de quem não teve oportunidade na idade própria), da educação profissional, da educação especial, entre outros (Castro, 2007). Esse autor analisa que, após dez anos a aprovação da LDB de 1996, houve crescimento das oportunidades de acesso à educação. Aponta que os dados da Pesquisa Nacional por Amostra de Domicílios (PNAD), do IBGE, ao comparar o contexto educacional da 
população brasileira entre os anos de 1995 e 2005, encontrou relevantes avanços, como cita no seguinte trecho:

“(...) A taxa de analfabetismo das pessoas de quinze anos de idade ou mais caiu de $15,6 \%$ para $10,9 \%$ no periodo. Já a de analfabetismo funcional diminuiu de 34,2\% para 23,2\% (...) Apesar do total da população brasileira matriculada em algum tipo de estabelecimento de ensino ter crescido de 29,2\%, em 1995, para apenas $31,2 \%$, em 2005, houve, no mesmo periodo, aumento da frequência escolar em todas as faixas etárias, com destaque para três grupos: de zero a seis anos (de 27,5\% para 40,8\%), de quinze a dezessete anos (de 66,6\% para 82,0\%) e de 25 anos e mais (de 2,5\% para 5,7\%). (Castro, 2007, pág. 9)

Dados ainda mais recentes divulgados em Fevereiro de 2016 pela organização não governamental "Todos Pela Educação" [por meio de análise feita com base na Pesquisa Nacional por Amostra de Domicílio (PNAD) do IBGE] reafirmam esse cenário ao indicar que, em 2014, entre os mais pobres, $36,8 \%$ concluíram o ensino médio e, entre os mais ricos, $84,9 \%$. Em relação ao ensino fundamental, entre os mais pobres, a taxa de conclusão saltou de 39,8\% em 2005 para $62,7 \%$ em 2014 e, entre os mais ricos, de 90,0\% para 92,2\%. Estas informações revelam que, nos últimos dez anos, o país melhorou em 15,4 pontos percentuais a taxa de conclusão do ensino médio dos jovens de até os 19 anos, uma vez que o percentual de concluintes passou de 41,4\% em 2005 para 56,7\% em 2014. Para o ensino fundamental, o índice de conclusão cresceu nesta mesma proporção: quase 15 pontos percentuais, aumentando de 58,9\% em 2005 para 73,7\% em 2014 (http://www.brasil.gov.br/educacao/2016/02/brasil-diminui-diferenca-entre-ricos-epobres-que-concluem-o-ensino-medio). 
Estas informações demográficas talvez possam explicar o pequeno número de indivíduos localizados, no presente trabalho, com "baixo nível de escolaridade" como encontrados por Pasian em 1998. Vale a pena ressaltar que nenhum adulto da região de baixo nível socioeconômico possuía ensino superior; o nível de escolaridade mais elevado, entre os voluntários identificados nesse subgrupo, foi de ensino médio completo. Esse perfil foi bastante diferente do encontrado na região de alto nível socioeconômico, onde apenas três indivíduos possuíam ensino médio completo; os demais apresentavam nível superior completo ou em curso, e alguns, inclusive, eram pós-graduados. Além disso, os postos de trabalho ocupados no bairro de baixo nível social eram, em sua maioria, relacionados a serviços gerais como pedreiros, carpinteiros, mecânicos, diaristas, alguns aposentados, outros em situação de desemprego, entre outros. Já na classe de alto nível socioeconômico, foram encontrados professores, profissionais autônomos (advogados, engenheiros, fisioterapeutas), entre outros.

Ao retomar à análise dos resultados atuais referentes a possível influência do nível de escolaridade nas variáveis do Rorschach, cabe destacar que os grupos de média e alta escolaridade apresentaram maiores índices de respostas globais $(\mathrm{G})$ em comparação com o grupo de baixa escolaridade. Assim, os grupos mais escolarizados valorizaram os elementos gerais dos estímulos na interpretação da realidade, podendo indicar maior utilização de recursos relacionados à cognição, principalmente porque esses grupos também revelaram índices estaticamente superiores de grande cinestesia (K), associada a elaboração lógica e abstração. De acordo com Rausch de Traubenberg (1998) "onde dominarem as K, a inteligência será diferenciada" (p.86). No trabalho atual, níveis maiores de escolaridade pareceram propiciar essas diferenças no Rorschach, revelando tendência a maior uso da criatividade, reflexão e também maior nível de maturidade. Os subgrupos mais escolarizados também expressaram maior somatório de conteúdo 
humano $\left(\sum \mathrm{H} \%\right)$, indicando maior interesse e disponibilidade para o contato humano e, em conjunto com maior proporção de $\mathrm{K}$, reafirmam uma abordagem mais afetiva da realidade. Os indivíduos dos subgrupos com maior escolaridade apresentaram ainda maior número de respostas de conteúdo anatomia e objeto, sugerindo possível maior nível de ansiedade (respostas Anat) e de racionalização (respostas Obj).

Por outro lado, o grupo de baixa escolaridade apresentou maior índice de recusas, maior uso de respostas Detalhe (D), maiores índices de movimento animal (kan), de somatória das pequenas cinestesias $(\Sigma \mathrm{k})$, de conteúdo animal (A) e somatória de conteúdo animal $(\Sigma \mathrm{A} \%)$. O maior número médio de recusas desse grupo tenderia a revelar maior dificuldade interpretativa ou bloqueio associativo, porém, o número médio de respostas não foi diferente entre os níveis de escolaridade, fragilizando essa interpretação. O modo de apreensão D indica destaque para elementos relevantes da realidade, sugerindo busca por adaptação. Os maiores índices de kan e $\Sigma$ k podem indicar maior imaturidade ou, por outro lado, maior espontaneidade nesses indivíduos menos escolarizados. Contudo, sendo prevalente o conteúdo animal e sua somatória, há que se pensar também numa atitude defensiva e possivelmente estereotipada desses adultos frente aos estímulos da realidade.

Os resultados destacados devem ser ponderados no conjunto das variáveis do Rorschach quando comparados em função da escolaridade. Porém, por serem poucas variáveis com diferenças estatisticamente significativas, não parecem suficientes para justificar a elaboração de normas avaliativas específicas para o grupo de adultos considerando o nível de escolaridade, embora devam ser considerados clinicamente como aspectos relevantes nos processos de interpretação desta técnica projetiva.

Em relação à idade, apesar dos grupos etários apresentarem algumas particularidades em certas variáveis do Rorschach, a análise estatística revelou apenas uma diferença significativa. Ela ocorreu na variável (A), sendo que o grupo de 30 a 39 
anos obteve média maior nessa proporção de respostas de conteúdos animais desvitalizados em relação aos demais grupos etários aqui considerados. Como já apontado, na variável $\Sigma \mathrm{A} \%$, esta diferença não existiu entre os subgrupos etários, o que enfraquece sua importância diante do conjunto das 56 variáveis examinadas. Assim, os dados atuais referentes ao perfil de respostas ao Rorschach de adultos de diferentes faixas etárias não se mostraram suficientes para justificar a elaboração de normas avaliativas específicas em função da idade para o grupo de adultos. Caberá ao profissional que utiliza esse método projetivo ponderar sobre o possível peso da idade e do passar dos anos na vida nos adultos que avaliar, de modo a compor adequada interpretação aos resultados, tendo em vista os atuais achados empíricos.

Frente ao exposto até o momento, é possível apontar que, após 16 anos desde a publicação do atlas e normas do Método de Rorschach da Escola de Paris para a população adulta elaborado por Pasian (2000), de forma geral, a atualização das normas deste método revelou escassas diferenças expressivas ou estatisticamente significativas entre os resultados, com poucas exceções. Tychey et al. (2012) também indicam poucas modificações nos dados gerais do estudo com adultos franceses em relação aos dados apresentados por H. Rorschach em 1921, transcorridos 91 anos. No atual trabalho, as poucas diferenças encontradas em relação aos dados de Pasian (1998), podem ter ocorrido pelo fato dos adultos com maior nível de escolaridade aqui avaliados estarem proporcionalmente em maior número do que no estudo anterior. Naquele momento, $41 \%$ dos adultos eram do grupo de baixa escolaridade (segundo o critério utilizado no presente trabalho, considerando como baixa escolaridade até o primeiro grau completo), contra 19\% na atual amostra. Além disso, 59\% dos adultos de Pasian (1998) tinham média e alta escolaridade, enquanto no atual trabalho, $81 \%$ da amostra pertence a esse nível de escolaridade. 
É inegável a importância que as atualizações das propriedades psicométricas dos instrumentos psicológicos oferecem aos profissionais, aos usuários dos testes e à sociedade em geral, uma vez que procuram garantir a qualidade dos dados para torná-los confiáveis para uso, baseando-se em pesquisas científicas. Ainda assim, é importante refletir sobre se há, e qual seria, o intervalo de tempo ideal para que as revisões psicométricas dos instrumentos ocorram. Em especial, em relação às normas, entende-se que por poderem variar em função do momento histórico em que são produzidas e em função de transformações culturais às quais estão sujeitas à sociedade, tendem a ser relativas e mutáveis. De toda forma é válido questionar: qual seria o melhor período para atualização dessas informações? Para Hutz (2011) o ideal é que existam revisões periódicas dos manuais dos instrumentos de avaliação psicológica. O autor diz:

"Não cabe aqui discutir o 'prazo de validade' dos testes. Porém, não é razoável supor que um manual possa ser usado por duas décadas sem revisão. As teorias mudam, as normas mudam, novas evidências surgem. Enfim, mesmo que não seja necessário refazer as pesquisas de validade do teste psicológico, deveria ser obrigatório publicar uma nova edição do manual a cada cinco anos ou, pelo menos, um adendo ao manual. Nessa nova edição (ou no adendo) seria informado o que foi produzido nos últimos anos: novas pesquisas no Brasil e no mundo, estudos confirmando (ou não) os resultados iniciais, novos estudos de validade, estudos mostrando a possibilidade de utilizar o teste em novos contextos, e assim por diante" (p.50-51).

Esses princípios de contínua atualização técnico-científica dos instrumentos de avaliação psicológica parecem adequados em seus princípios, fortalecendo garantias de qualidade aos serviços prestados à comunidade, pelo menos no tocante aos recursos 
técnicos envolvidos nesses processos. No entanto, há que se pensar que, diante de evidências empíricas de estabilidade temporal de achados relativos a personalidade em adultos, como os atualmente encontrados com o Rorschach, se a proporção custobenefício desses investimentos sustenta as diretrizes atuais referentes aos prazos preconizados pelo Conselho Federal de Psicologia no Brasil. Os resultados do presente trabalho poderão contribuir com reflexões nessa direção, embora ultrapassem os objetivos delineados para a presente investigação.

Estudos com o Método de Rorschach que revisam periodicamente seus índices psicométricos tem se mostrado muito importantes e imprescindíveis, com extensa literatura nacional e internacional demonstrando empiricamente o valor científico deste importante instrumento de avaliação da personalidade. Tal estratégia continuou e continuará exigindo esforços dos pesquisadores da área que, por meio de tais revisões sistemáticas, buscam garantir sua adequada utilização e interpretação em diversos contextos socioculturais. 


\section{CONSIDERACÕES FINAIS}

Com base nos objetivos propostos para o presente trabalho, os resultados encontrados podem ser considerados relevantes e importantes para os processos de investigação da personalidade, além de apresentarem um panorama atualizado a respeito do padrão de respostas de adultos não pacientes, de 18 a 65 anos, no Método de Rorschach (Escola de Paris). Esses achados empíricos poderão auxiliar análises interpretativas e clínicas por profissionais que fazem e venham a fazer uso do Método com adultos desta faixa etária, em regiões com características sócio demográficas e culturais semelhantes às apresentadas no presente trabalho.

Foram colecionadas evidências empíricas de adequados índices de precisão do Método de Rorschach, de acordo com o sistema francês, oferecendo credibilidade aos dados advindos desse método no contexto do Brasil. Foi necessário contar com uma equipe de avaliadores que são ou estiveram envolvidos diretamente em pesquisas com o Método de Rorschach e que receberam formação e treinamento qualificado sobre o instrumento, desde a aplicação até a classificação e interpretação das respostas. Isto reafirma a importância sobre a formação profissional no contexto da avaliação psicológica, e, em especial, com métodos projetivos, que deve ser fruto de estudos e treinamento especializados e contínuos para o devido aprimoramento dos profissionais que façam uso dos diferentes instrumentos psicológicos disponíveis. Foi possível também abordar algumas questões teóricas a respeito do construto personalidade, evidenciando um conjunto de pesquisas com resultados que apoiam e/ou refutam as teorias a respeito da personalidade estável no adulto.

Faz-se também necessário realizar algumas ponderações e apontamentos relativos a limites de atual trabalho. Em relação ao Estudo 1, vale considerar que reavaliar 88 
adultos após um período de 15 anos, com o método de Rorschach, tem extrema relevância no contexto da pesquisa científica que busca evidências psicométricas do método, em especial dados relativos à precisão do instrumento. Contudo, de acordo com Urbina (2007), para reduzir a margem de erro dos dados é importante que o tamanho da amostra seja considerável. Desta forma, quanto maior a amostra,mais confiável serão os achados. Avalia-se que 88 participantes é um número expressivo, mas ainda insuficiente para a generalização dos atuais resultados. Silva Neto (2008) afirma que, para que a estabilidade temporal de um estudo possa ser estimada de modo seguro, seria necessário que a amostra tivesse número "bem maior que 100 participantes" e ressalta que a literatura internacional sugere a constituição de amostras com o mínimo de 300 participantes. No presente trabalho isso exigiria a reavaliação de praticamente todos os indivíduos que participaram do estudo de Pasian, em 1998 ( $\mathrm{n}=405)$, que estivessem dentro dos critérios estabelecidos pelo nosso estudo ( $\mathrm{n}=389)$. Contudo, houve grande dificuldade em encontrar muitos dos participantes ou, mesmo quando foram localizados, alguns mostraram-se reticentes em participar da presente reavaliação. O estudo de Pasian (1998) não foi elaborado para ser um estudo longitudinal, logo alguns cuidados que normalmente são exigidos para este tipo de estudo não foram tomados. E, ainda assim, com as breves informações disponíveis daquela época (nome, sobrenome, endereço residencial ou contato telefônico do participante) foi possível localizar e realizar o trabalho com um número considerável de indivíduos (22\% da amostra de 1998).

Além disso, Silva Neto (2008) descreve, em sua tese de doutorado, alguns fatores que podem interferir em resultados de estabilidade temporal em avaliações psicológicas, tais como, condições ambientais e físicas do local do trabalho e também as características psicológicas dos examinandos e examinadores, de forma que tais fatores não podem ser aqui desconsiderados. Nesse momento vale destacar a questão dos examinadores, uma 
vez que no presente trabalho a aplicação do Rorschach, no teste e reteste, ocorreu com examinadores diferentes. Sultan et al. (2006), em seu trabalho de reaplicação do Rorschach, demonstrou a possível influência de diferentes aplicadores sobre os resultados. Isto indica que, mesmo seguindo uma aplicação padronizada em exame com método projetivo, a avaliação pode estar sujeita a maneira como o avaliando se comporta diante de um ou outro aplicador, e isso pode ter efeitos sobre os resultados encontrados, influência esta que pode ser melhor investigada em pesquisas futuras.

Outra questão a ser pontuada refere-se ao embate das tradições na Psicologia a respeito de duas correntes: a das pesquisas empíricas que buscam leis universais - a aborgadem nomotética versus a busca pelo entendimento da singularidade, da particularidade relativa ao indivíduo - a abordagem idiográfica. Tanto o Estudo 1, quanto o Estudo 02, demonstraram estabilidades nos valores médios das porcentagens das variáveis do Rorschach (Escola de Paris) com poucas diferenças estatisticamente significativas entre algumas delas, ainda que tenha transcorrido considerável intervalo de tempo entre as duas avaliações com os mesmos participantes, ou com a atualização das normas do Rorschach para a população adulta, com nova amostra. Desta forma, ambas as pesquisas ajudam a evidenciar as leis gerais do Rorschach e conferem ao instrumento o status científico tão necessário para a confirmação de suas evidências psicométricas, por meio da abordagem nomotética. Por outro lado, o Estudo 01 que buscou evidências por meio da análise correlacional, revelou possíveis diferenças individuais também detectadas pelo mesmo método, evidenciando seu poder em apontar que há certas características subjetivas e individuais detectadas pelo instrumento, dados que reafirmam e reforçam o valor da análise idiográfica do Rorschach. O que, para alguns, poderia ser compreendido como "ponto fraco" do método, é na verdade, um ponto forte ao reafirmar a sensibilidade do instrumento às variações gerais e individuais. 
Para finalizar, cabe aqui relembrar que é de responsabilidade do profissional que utiliza o instrumento utilizar as informações levantadas pelos estudos psicométricos da forma que melhor contribuir para a compreensão a respeito do funcionamento psíquico de cada indivíduo. As normas, por exemplo, são baseadas em levantamentos estatísticos que revelam aquilo que aparece com maior frequência em uma dada população, mas não podem ser interpretadas como verdades absolutas. Como nos lembra Tavares (2003):

"Por vezes cometemos erros, sendo o pior deles a arrogância de acharmos que sabemos o que a pessoa é, fechando possibilidades ou desconsiderando seu contexto e sua continuidade histórica. Não podemos tomar as pessoas como um dado. Nossas inferências psicológicas sobre cada pessoa devem ser consubstanciadas a cada passo, mediante confirmações independentes, levando sempre em consideração a sua integridade enquanto pessoa em desenvolvimento. Para alcançar uma estratégia diagnóstica que mantenha um compromisso ético e humanitário, precisamos compreender as técnicas que utilizamos, suas funções,vantagens e limitações, respeitando a complexidade de cada técnica, do processo de avaliação psicológica e do sujeito submetido a ele. A compreensão dessas complexidades, como parte da técnica, além do conhecimento dos procedimentos específicos de avaliação e da capacidade de integração destes, exige competência na observação clínica, nos procedimentos de entrevista, no emprego de conhecimentos em psicopatologia, psicodinâmica, teorias de desenvolvimento, etc, dentro de uma visão complexa da interação dessas competências no uso dos procedimentos e na relação com o sujeito" (p. 125).

Desta forma, espera-se que o presente trabalho tenha oferecido contribuições relevantes às evidências e qualidades psicométricas do Rorschach e relembre seu potencial de uso. Há que fazer referência final também a limitação de seu alcance, 
devendo estar a serviço de profissionais adequadamente formados e compromissados com seu uso ético e responsável. 


\section{REFERENCIAS ${ }^{8}$}

${ }^{8}$ De acordo com o padrão APA - American Psychological Association, adaptado pela Universidade de São Paulo (USP). 
Adrados, I. (1985). A Técnica do Rorschach em crianças: perfil psicológico da criança dos sete aos quatorze anos. Petrópolis: Vozes.

Alves, I. C. B. (2009). Reflexões sobre o ensino da Avaliação Psicológica na formação do psicólogo. In: Hutz, C. S. (Org.). Avanços e polêmicas em Avaliação Psicológica. São Paulo: Caso do Psicólogo, p.217-237.

Alves, I. C. B. (2006). Considerações sobre a validade e precisão nas técnicas projetivas. In: Noronha, A. P. P., Santos, A. A. A. \& Sisto, F. F. (Orgs.). Facetas do fazer em avaliação psicológica. São Paulo: Vetor, p. 173-190.

Alonso da Costa, M. F. B. N. \& Ciosak, S. I. (2010). Atenção integral na saúde do idoso no Programa Saúde da Família: visão dos profissionais de saúde. Revista da Escola de Enfermagem da USP. 44,2, 437-444.

Anache, A. A. \& Corrêa, F. (2010). As políticas do Conselho Federal de Psicologia para a avaliação psicológica. Em Conselho Federal de Psicologia (Org.). Avaliação psicológica: diretrizes na regulamentação da profissão (pp.19-30). Brasília, DF: CFP $1^{\text {a }}$ Ed. Brasília (DF): CFP, p.19-30.

Anderson, H. \& Anderson,G. L (1967). Técnicas projetivas do diagnóstico psicológico. Trad. Elza Bennett. $1^{\text {a }}$ ed. São Paulo: Mestre Jou.

Anzieu, D. (1986). Os métodos projetivos. 5a . edição. Rio de Janeiro: Campus.

Azoulay, C. (2014). Nina Rausch de Traubenberg, le long d'une transmission... La question des normes au Rorschach. Psychologie Clinique et Projective. 1, n ${ }^{\circ}$ 20, 139 153. ISBN : 9782749242040 - DOI : 10.3917/pcp.020.0139.

Azoulay, C. \& Emmanuelli, M. (2014). Normative French Rorschach Data in Adolescence: Deepening our reflections about the differences between socioeconomic categories. In Abstract Book of XXI International Congress of Rorschach and Projective Methods. Istanbul University.

Azoulay, C., Emmanuelli, M., Rausch de Traubenberg, N., Corroyer, D., Rozencwajg, P. \& Savina, Y. (2007). Les données normatives françaises du Rorschach à l'adolescence et chez le jeune adulte. Psychologie Clinique et Projective, 13, 371409.

Bandeira, D. R., Trentini, C. M., Winck, G. E. \& Lieberknecht, L. (2006). Considerações sobre as técnicas projetivas no contexto atual. In Noronha, A. P. P., Santos, A. A. A., Sisto, F. F. (Orgs.). Facetas do fazer em avaliação psicológica. São Paulo: Vetor Editora Psicopedagógica, p. 125-139.

Bee, H. (2007). A criança em desenvolvimento. $9^{\text {a }}$ edição. Porto Alegre, Artmed Editora.

Bergeret, J. (2006). A personalidade normal e patológica. $3^{\mathrm{a}}$ edição. Porto Alegre, Artmed Editora. 
Brasil (1996). Senado Federal. Lei de Diretrizes e Bases da Educação Nacional: $n^{\circ}$ 9394/96. Brasília

Camarano, A. A. \& Mello, J. L. (2006). Capítulo 01 - Introdução. In: Camarano, A. A. (Org.). Transição para a vida adulta ou vida adulta em transição?Rio de Janeiro, Ipea, p.13-28.

Camarano, A. A., Mello, J. L. \& Kanso, S. (2006). Capítulo 02 - Do nascimento à morte: principais transições. In: Camarano, A. A. (Org.). Transição para a vida adulta ou vida adulta em transição? Rio de Janeiro, Ipea, p. 31 -60.

Cândido, A. M. (2011). O enlutamento por suicídio: elementos de compreensão na clínica da perda. Dissertação de Mestrado. Universidade de Brasília. Instituto de Psicologia. Departamento de Psicologia Clínica. Brasília, DF. Brasil.

Castro, P. F. (2008). Caracterização da personalidade de pacientes com transtorno de pânico por meio do método do Rorschach: contribuições do Sistema Compreensivo. Tese de Doutorado do Programa de Pós-Graduação em Psicologia. Instituto de Psicologia da USP (SP).

Castro, M. L. O. (2007). A Educação Brasileira nos dez anos da LDB. Texto para Discussão 33. Brasília/DF. Recuperado em Dezembro de 2015, de http://www12.senado.gov.br/senado/institucional/atribuicoes?orgao=49/textos_discu ssao_htm.

Chagnon, J-Y. (2014). L'école de Paris: histoire et développements contemporains. In: Desafios para a prática ética da avaliação psicológica. Ribeirão Preto/SP. VII Congresso da Associação Brasileira de Rorschach e Métodos Projetivos - ASBRo, 2014. CD-ROM (621 p.). ISBN: 978-85-62020-03-2

Cicchetti, D. V. (1994). Guidelines, Criteria and Rules of Thumb for Evaluating Normed and Standardized Assessment Instruments in Psychology. Psychological Assessment. 6, (4), 284-290.

Cohen, J. (1960). A coefficient of Agreement for Nominal Scales. Educational and Psychological Measurement. XX, (1), 37-46.

Conselho Federal de Psicologia. (2003). Resolução CFP 02/2003. Brasília: CFP. Disponível em http:/www.pol.org.br/pol/export/sites/ default/pol/legislacao/legislação Documentos/resolucao2003 02.pdf. Recuperado em Dezembro de 2013.

Conselho Federal de Psicologia (2001). SATEPSI. Brasília, D.F. CFP. Disponível em http://www2.pol.org..br/satepsi. Recuperado em Dezembro de 2013.

Costa, M. F. B. N. A. \& Ciosak, S. I. (2010).Atenção integral na saúde do idoso no Programa Saúde da Família: visão dos profissionais de saúde. Revista da Escola da Enfermagem da USP; 44 (2):437-44 (www.ee.usp.br/reeusp/). 
Critério de Classificação Econômica Brasil/ Associação Brasileira de Empresas (ABEP) (2012). Recuperado em Julho de 2012. http://www.abep.org/

Cury-Jacquemin, R.P. (2012). Padrões normativos do Psicodiagnóstico de Rorschach em adolescentes de 12 a 14 anos. Dissertação de Mestrado. Faculdade de Filosofia Ciências e Letras de Ribeirão Preto, Universidade de São Paulo, Ribeirão Preto. Brasil.

Czeredercka, A. \& Wroclawska, E. (2014) Validation and normalization of the Rorschach Test in the CS-System - a research report from Poland. In Abstract Book of XXI International Congress of Rorschach and Projective Methods. Istanbul University.

Exner, J. E. Jr. (2003). The Rorschach: A Comprehensive System. 4th ed. New York: John Wiley.

Exner, J. E. Jr. \& Sendín, C. (1999). Manual de interpretação do Rorschach para o sistema compreensivo. São Paulo: Casa do Psicólogo.

Exner, J. E. Jr. (1988). Problems with brief Rorschach protocols. Journal of Personality Assessment, 58, (4), 640-547.

Exner, J. E. Jr. (1978). The Rorschach: a Comprehensive System. Volume 2: Interpretation. New York: JohnWilley \& Sons.

Exner, J. E. Jr., Armbruster, G.L. \& Viglione, D. (1978). The temporal stability of some Rorschach features. Journal of Personality Assessement, 42, 474- 482.

Fonseca, R.; Silva, P. \& Silva, R. (2007). Acordo inter-juízes: O caso do coeficiente kappa. Instituto Superior de Psicologia Aplicada, Portugal. Laboratório de Psicologia, 5(1): 81-90.

Fensterseifer, L. \& Werlang, B. S. G. (2008). Apontamentos sobre o status científico das técnicas projetivas. In Villemor-Amaral, A. E. \& Werlang, B. G. (Org.). Atualizações em métodos projetivos para avaliação psicológica. ( $1^{\mathrm{a}}$ ed.). São Paulo: Casa do Psicólogo, pp. 15-33.

Fernandes, S. (2010). Normas do Rorschach em crianças de 6 a 8 anos. Dissertação de Mestrado. Faculdade de Filosofia, Ciências e Letras de Ribeirão Preto, Universidade de São Paulo, Ribeirão Preto. Brasil.

Feist, J., Feist, G. J. \& Roberts, T-A. (2015). Teorias da Personalidade. $8^{\mathrm{a}}$ edição. Porto Alegre: Artmed

Fleiss, J. L. \& Cohen, J. (1973). The equivalence of weighted kappa and the intraclass correlation coeficient as measures of reliability. Educational and Psychological Measurement, 33, 613-619.

Fundação Sistema Estadual de Análise de Dados (SEADE). (2013). Recuperado em Dezembro de 2013. http://www.seade.gov.br/ 
Fernandes, S. Raspantini, R. \& Pasian, S. R. (2013). Rorschach em crianças de diferentes idades na perspectiva da Escola Francesa. In Anais do VI Congresso Brasileiro de Avaliação Psicológica. Maceió (AL). Disponível em: http://www.ibapnet.org.br/congresso2013/lista_trabalhos_mesa_redonda.php. Recuperado em Janeiro de 2016.

Fernandes, S., Pasian, S.R. \& Alves, D. P. B. (2011). Origem escolar e a produtividade no Rorschach de crianças escolares. Resumos painéis do V Congresso de Avaliação Psicológica (IBAP). Bento Gonçalves (RS).

Fernandes, S. (2010). Normas do Rorschach em crianças de seis a oito anos. Dissertação de Mestrado, Faculdade de Filosofia, Ciências e Letras de Ribeirão Preto, Universidade de São Paulo, Ribeirão Preto, SP/Brasil.

Gavião, A. C. D. (2002). A passagem do tempo e suas ressonâncias intimas: psicanálise, Rorschach e envelhecimento. $1^{\text {a }}$ Ed. São Paulo: Vetor.

Gonçalves, D. M.; Stein, A. T. \& Kapczinski, F. (2008). Avaliação de desempenho do Self-Reporting Questionnaire como instrumento de rastreamento psiquiátrico: um estudo comparativo com o Structured Clinical Interview for DSM-IV-TR. Caderno de Saúde Pública. 24, (2), 380-390. Rio de Janeiro, RJ.

Grønnerød, C. (2006). Reanalysis of the Grønnerød (2003) Rorschach Temporal Stability Meta-Analysis Data Set Journal of Personality Assessment, 86(2), 222-225.

Grønnerød, C. (2003). Temporal Stability in the Rorschach Method: A Meta-Analytic Review. Journal of Personality Assessment, 8(3), 272-293.

Hisatugo, C. (2013). R-PAS em crianças de São Paulo: dados preliminares de estudo normativo. In Anais do VI Congresso Brasileiro de Avaliação Psicológica. Maceió (AL). Disponível em:

http://www.ibapnet.org.br/congresso2013/lista trabalhos mesa redonda.php. $\underline{\text { Recuperado em Janeiro de } 2016 .}$

Hooker, K. \& McAdams, D. P. (2003). Personality Reconsidered: A New Agenda for Aging Research. Journal of Gerontology: Psychological Sciences. 58B,(6), 296-304

Hutz, C. S. (2009). Ética na avaliação psicológica. In: Hutz, C. S. (Org.) Avanços e polêmicas em avaliação psicológica. São Paulo: Casa do Psicólogo, p. 297-310.

Hutz, C. S. (2011). Manuais especificando seus contextos de aplicação e âmbitos de ação. In: Ano da Avaliação Psicológica - Textos geradores. Brasília: Conselho Federal de Psicologia, p. 49-52.

International Test Commission (ITC) (2000). International Guidelines for Test Use. Disponível em www.intestcom.org/itc projects.htm. Recuperado em Janeiro de 2016.

Ikiz, T., Düsgör B. P., Atak, I. E., Mete, L. \& Kalem, E. (2014). Turkish Eldery Norms of the Rorschach Test. In Abstract Book of XXI International Congress of Rorschach and Projective Methods. Istanbul University. 
Ikiz, T., Zabci, N., Düsgör B. P., Atak, I. E. \& Sever, A. E. Y. (2014). Normatives Rorschach Data of the Turkish Adolescent Population. In Abstract Book of XXI International Congress of Rorschach and Projective Methods. Istanbul University.

Ikiz, T. Zabci, N., Düsgör B. P., Atak, I. E. \& Kalem, E. (2013). Les normes adultes de la population turque au Rorschach. Psychologie Clinique et Projective, 1, n¹9, 303319, ISBN : 9782749239675. DOI : 10.3917/pcp.019.0303

Ikiz, T. T., Zabci, N., Dusgor, B. P., Atak, I. E., Yavuz, E., Purisa, S. \& Cagatay, P. (2010). Étude normative du Rorschach de la population adolescente turque. Psychologie clinique et projective, 16, 209-232

Instituto Brasileiro de Geografia e Estatística (IBGE). (2013). Recuperado em Fevereiro e Dezembro de 2013, de http:// www.ibge.gov.br/cidadeest/painel

Jacquemin, A. (1976). O Teste de Rorschach em crianças brasileiras. São Paulo, Vetor.

Japur, M. \& Jacquemim, A. (1985): O Psicodiagnóstico de Rorschach: estudo das fórmulas vivenciais e dos índices de conflito em pré-adolescentes. Arquivo Brasileiro de Psicologia. 37(2), 145-155. Rio de Janeiro.

Jardim-Maran, M. L. C., Pasian, S. R. \& Cury-Jacquemim, R. (2013). Método de Rorschach em adolescentes brasileiros, franceses e turcos. In Anais do VI Congresso Brasileiro de Avaliação Psicológica. Maceió (AL). Disponível em: http://www.ibapnet.org.br/congresso2013/lista_trabalhos_mesa_redonda.php. $\underline{\text { Recuperado em Janeiro de } 2016 .}$

Jardim-Maran, M. L. C. (2011) O Psicodiagnóstico de Rorschach em adolescentes: Normas e evidencias de validade. Tese de Doutorado. Faculdade de Filosofia Ciências e Letras de Ribeirão Preto, Universidade de São Paulo, Ribeirão Preto, SP, Brasil.

Klein, M. (1959). Nosso mundo adulto e suas raízes na infância. Inveja e gratidão e outros trabalhos (194601963). Rio de Janeiro, Imago Ed.

Laurent, M., Rivat, M., Alnot, J. L., Claudon, P., Huckel, C. \& Tychey, C. (2014). New's adults French Rorschach Norms and Society Evolution: Some reflections. In Abstract Book of XXI International Congress of Rorschach and Projective Methods. Istanbul University.

Lelé, A. J. (2008b). Estudo preliminar de dados normativos brasileiros no Rorschach no estado de Minas Gerais. In: Encontro da Associação Brasileira de Rorschach e Métodos Projetivos. Ribeirão Preto: ASBRo, CD-ROM.

Lelé, A. J. (2006). Perception of reality and norm: A study of the popular responses to Rorschach's Psychodiagnostis in Brazil. Rorschachiana, 28 (1). 81-99 
Lopes, W. M G. (2009). Teste de inteligência não-verbal (INV) de Pierre Weil: parâmetros psicométricos. Tese (doutorado) - Programa de Pós-Graduação Stricto Sensu em Psicologia da Universidade São Francisco. Itatiba. SP. Brasil.

Nascimento, R. S. G. F. \& Resende, A. C. (2013). Estudo Comparativo de resultados do Rorschach (SC) com adolescentes de São Paulo e de Goiânia. In Anais do VI Congresso Brasileiro de Avaliação Psicológica. Maceió (AL). Disponível em: http://www.ibapnet.org.br/congresso2013/lista trabalhos_mesa_redonda.php. Recuperado em Janeiro de 2016.

Nascimento, R. S. G. F. (2002). Resultados de Estudo Normativo para o Sistema Compreensivo do Rorschach: um estudo para o Estado de São Paulo. Psico - USF, $7(2), 121-135$

Noronha, A. P. P. (2009). Testes psicológicos: conceito, uso e formação do psicólogo. . In: Hutz, C. S. (Org.) Avanços e polêmicas em avaliação psicológica. São Paulo: Casa do Psicólogo, p. 71-91

Noronha, A. P. P. \& Alchieri, J. C. (2005). Reflexões sobre os instrumentos de avaliação psicológica. In: Primi, R. (Org.). Temas em Avaliação Psicológica. São Paulo: Casa do Psicólogo., p. 19-36.

Noronha, A. P. P., Primi, R. \& Alchieri, J. C. (2004). Parâmetros psicométricos: uma análise de testes psicológicos comercializados no Brasil. Psicologia: Ciência e Profissão, 24(4), p. 88-99.

Oliveira, S. E. S \& Bandeira, D. R. (2013). O diagnóstico estrutural da personalidade segundo o modelo de Otto F. Kernbergh (Capítulo 12). In: Perspectivas em Psicologia dos transtornos da personalidade. Carvalho, L. F. \& Primi, R. (orgs). São Paulo: Casa do Psicólogo.

Organização Mundial da Saúde/Organização Pan-Americana da Saúde (2001). Relatório sobre a saúde no mundo. Saúde Mental: nova concepção, nova esperança. Genebra.

Pasian, S. R. (2011). Métodos projetivos de Avaliação Psicológica: contribuições para pesquisa e prática profissional em psicologia. Tese de Livre Docência, Faculdade de Filosofia, Ciências e Letras de Ribeirão Preto,- Universidade de São Paulo, Ribeirão Preto.

Pasian, S. R. (2002). Atualizações sobre o psicodiagnóstico de Rorschach no Brasil: breve panorama histórico. Psico-USF, 7(1), pp. 43-52.

Pasian, S. R. (2000). O Psicodiagnóstico de Rorschach em adultos: atlas, normas e reflexões. São Paulo. Casa do Psicólogo.

Pasian, S. R. (1998). O Psicodiagnóstico de Rorschach: um estudo normativo em adultos da região de Ribeirão Preto. Tese de Doutorado, Faculdade de Medicina de Ribeirão Preto, Universidade de São Paulo, Ribeirão Preto, SP. 
Pereira, A. M. T. B. (2001). A saúde mental de profissionais de saúde mental: uma investigação da personalidade de psicólogos. Maringá: Eduem, 2001.

Perry, W., McDougall, A., \& Viglione, D. (1995). A five-year follow-up on the temporal stability of the Ego Impairment Index. Journal of Personality Assessment, 64, 112118.

Primi, R. (2010). Avaliação Psicológica no Brasil: Fundamentos, Situação Atual e Direções para o Futuro. Psicologia: Teoria e Pesquisa, 26. (nºspecial) p. 25-35.

Primi, R.; Muniz, M., \& Nunes, C. H. S. S. (2009). Definições contemporâneas de validade de testes psicológicos. In Cláudio Simon Hutz. (Org.). Avanços e polêmicas em avaliação psicológica. São Paulo: Casa do Psicólogo, p. 243-265.

Rabello, E.T. \& Passos, J. S. (2007). Erikson e a teoria psicossocial do desenvolvimento. Disponível em http://www.josesilveira.com. Recuperado em Dezembro de 2015.

Rappaport, R. C. (1981). Psicologia do Desenvolvimento. Vol. 1 São Paulo: E.P.U., 1981.

Raspantini, R. L. (2010). O Psicodiagnóstico de Rorschach em crianças de 9 a 11 anos: um estudo normativo. Dissertação de Mestrado, Faculdade de Filosofia, Ciências e Letras de Ribeirão Preto, Universidade de São Paulo, Ribeirão Preto, SP/Brasil.

Rausch de Traubenberg, N. (1998). A prática do Rorschach. 1ª Edição. São Paulo: Vetor.

Rebelo, H. (2007). Psicoterapia na idade adulta avançada. Análise Psicológica, 4, XXV, pp 543-557.

Resende, A.C., Martins, L. D., Martins, W. \& Nogueira, T.C (2013). Dados normativos do Rorschach, Sistema Compreensivo, em crianças. Disponível em: http://www.ibapnet.org.br/congresso2013/lista trabalhos mesa redonda.php. $\underline{\text { Recuperado em Janeiro de } 2016 .}$

Resende, A.C., \& Ribeiro, R. K. S. M. (2013). Diferenças interculturais de dados normativos do Rorschach para crianças Disponível em: http://www.ibapnet.org.br/congresso2013/lista trabalhos mesa redonda.php. Recuperado em Janeiro de 2016.

Resende, A. C. \& de Lima Argimon, I. I. (2012). A técnica de Rorschach e os critérios do CID-10 para o Diagnóstico de Esquizofrenia. Psicologia: Reflexão e Crítica, 25(3), 422-434. Porto Alegre.

Ritzler, B. (2006). Aplicações culturais do Rorschach, teste de apercepção e desenhos de figura. In: Silva Neto, N. A. \& Amparo, D. M. (Orgs.). Métodos projetivos: instrumentos atuais para a investigação psicológica e da cultura. Anais do IV Congresso Nacional da Associação Brasileira de Rorschach e Métodos Projetivos Brasília-DF, p. 46-69.

Roberts, B. W. \& DelVecchio, W. F. (2000). The Rank-Order Consistency of Personality Traits From Childhood to Old Age: A Quantitative Review of Longitudinal Studies. Psychological Bulletin, 126, (1), 3-25. 
Romaro, R. A. \& Loureiro, S. R. (1994). Caracterização das manifestações defensivas primitivas em protocolos de Rorschach de pacientes Borderline. Estudos de psicologia, 1994, 11 (3), 57-63.

Rorschach, H. (1921/1967). Psicodiagnóstico. (M. S. V. Amaral, trad.). São Paulo: Mestre Jou.

Roza, D. L. (2011). Padrões espaço-temporais da incidência da tuberculose em Ribeirão Preto, SP: uso de um modelo bayesiano auto-regressivo condicional. Dissertação de mestrado da Faculdade de Medicina de Ribeirão Preto da Universidade de São Paulo. Área de concentração: Saúde na comunidade. Ribeirão Preto, SP.

Santos, E. G. \& Siqueira, M. M. (2010). Prevalência dos transtornos mentais na população adulta brasileira: uma revisão sistemática de 1997 a 2009. Jornal Brasileiro de Psiquiatria, 59 (3): 238-246.

Santos, K. O. B., Araújo, T. M., Pinho, P. S. \& Silva, A. C. C. (2010) Avaliação de um instrumento de mensuração de morbidade psíquica: estudo de validação do SelfReporting Questionnaire (SRQ-20). Revista Baiana de Saúde Pública. 34, (3), 544560.

Santos, K. O, B., Araújo, T. M. \& Oliveira, N. F. (2009). Estrutura fatorial e consistência interna do Self- Reporting Questionnaire (SRQ-20) em população urbana. Cad. Saúde Pública, 25(1). 214-222.

Santos, B. S. dos \& Antunes, D. D. (2007) Vida adulta, processos motivacionais e diversidade. Educação. Porto Alegre/RS. 1,(61), 149-164.

Santoantonio, J., Yazigi, L., Sato, E. (2004). Adolescentes com Lúpus Eritematoso Sistêmico: um estudo por meio do método de Rorschach. Psicologia: teoria e pesquisa, 20 (2), 145-151

Scortegagna, S. A. e Villemor-Amaral, A. E. (2009) Autopercepção no Rorschach de vítimas de abuso sexual infantil. Psico, 40 (3), 328-336. Porto Alegre, RS.

Scortegagna, S. A. e Villemor-Amaral, A. E. (2013). Rorschach e Pedofilia: a fidedignidade no teste-reteste. Psico, 44 (4), 508-517. Porto Alegre, RS.

Silva, I. B. \& Nakano, T.C. (2011). Modelo dos Cinco Grandes Fatores da Personalidade: análise de pesquisas. Avaliação Psicológica, 10(1), 51-62.

Silva-Neto, A. C. P (2008). Fidedignidade do Sistema Compreensivo do Rorschach: revisão e estudo da estabilidade temporal em adultos da cidade de São Paulo. Tese de doutorado do Programa de Pós Graduação da Universidade de São Paulo. Instituto de Psicologia da Universidade de São Paulo.

Silva-Neto, A. C. P. \& Custódio, E. M. (2008). Estabilidade Temporal do Sistema Compreensivo do Rorschach: um estudo com adultos da cidade de São Paulo. $\underline{I n}$ 
Pasian, S. R. (org). In: Avanços do Rorschach no Brasil. São Paulo: Casa do Psicólogo, p. 54-83.

Souza, A. M. D. R. \& Duarte Junior A. P. (2008). As respostas banais de sujeitos paraenses ao teste de Rorschach: Comparação com normas de populações da região sudeste e análise da estabilidade temporal dos resultados. In: Encontro Nacional da Associação Brasileira de Rorschach e Métodos Projetivos, Ribeirão Preto, ABSRo, CD-ROM.

Shapiro, D. (2012). Theoretical Value of Psychological Testing. Journal of Personality Assessment, 94(6), 558-562.

Sultan, S., Andronikof, A., Réveillère C. \& Lemmel, G. (2006). A Rorschach Stability Study in a Nonpatient Adult Sample. Journal of Personality Assessment, 87(3), 330348

Tavares, M. (2003). Validade Clínica. Psico-USF, 8, (2), 125-136.

Tychey, C., Huckel, C., Rivat, M. \& Claudon, P. (2012). Nouvelles normes adultes du test de rorschach et évolution sociétale: quelques réflexions. Bulletin de psychologie. 521, 453-466. ISSN 0007-4403

Weil, P., \& Nick, E. (1971). O potencial de Inteligência do Brasileiro: Levantamento e resultados no teste INV - Manual. Rio de Janeiro: Centro Editor de Psicologia Aplicada

Wolf, A. C, Carvalho, C. V. \& Costa, P. J. (2015). Anais V CIPSI - Congresso Internacional de Psicologia Psicologia: de onde viemos, para onde vamos? Universidade Estadual de Maringá. ISSN 1679-558X.

Urbina, S. (2007). Fundamentos da Testagem Psicológica. (C. Dornelles, trad.). Porto Alegre: Artmed.

Verona, H. (2011). Texto de Apresentação. In: Conselho Federal de Psicologia (CFP). Ano da Avaliação Psicológica - Textos geradores. Brasília: $1^{\text {a }}$ Ed.

Villemor-Amaral, A. E. (2009). Métodos projetivos em avaliações compulsórias: Indicadores e perfis: In: Hutz, C. S. (Org.) Avanços e polêmicas em avaliação psicológica. São Paulo: Casa do Psicólogo, p. 157-174.

Villemor-Amaral, A. E. (2006). Desafios para a cientificidade das técnicas projetivas. In: Noronha, A.P.P., Santos, A.A.A., Sisto, F.F. (Org). Facetas do Fazer em Avaliação Psicológica. 1, 163-172. São Paulo: Vetor.

Villemor-Amaral e Pasqualini-Casado (2006). A cientificidade das técnicas projetivas em debate. Psico-USF, 11, (2), 185-193.

Zimerman, D. (1999). Fundamentos Psicanaliticos: Teoria, técnica e clínica: uma abordagem didática. Porto Alegre, Artmed. 
8. APÊNDICES 
APÊNDICE A - Carta convite para participação no Estudo 01 

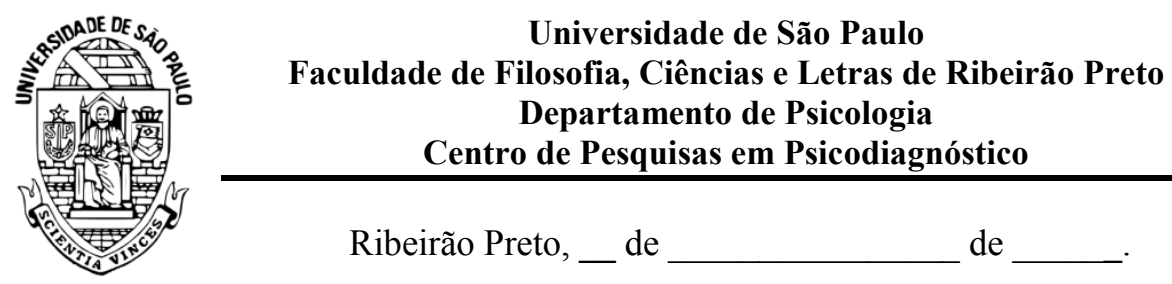

Universidade de São Paulo

Faculdade de Filosofia, Ciências e Letras de Ribeirão Preto

Departamento de Psicologia

Centro de Pesquisas em Psicodiagnóstico

Ribeirão Preto,

de

de

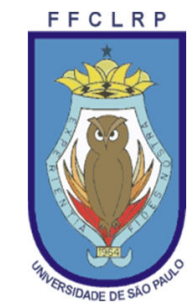

Prezado/a Senhor/a:

Estamos desenvolvendo uma pesquisa sobre características de personalidade ao longo do tempo de pessoas da região de Ribeirão Preto. $\mathrm{O}$ (a) senhor/senhora já colaborou conosco em estudo prévio (desenvolvido há cerca de 15 anos pela psicóloga Sonia Regina Pasian) e, neste momento, estamos convidando-o a mais uma vez participar desta pesquisa, para acompanhar o desenvolvimento da personalidade em adultos, ao longo do tempo. Este novo estudo será realizado pela psicóloga e aluna do doutorado em Psicologia, Fabiana Rego Freitas (CRP 06/78606), sob orientação da $\operatorname{Prof}^{\mathrm{a}} \mathrm{Dr}^{\mathrm{a}}$ Sonia Regina Pasian, ambas do Departamento de Psicologia da Faculdade de Filosofia, Ciências e Letras de Ribeirão Preto - Universidade de São Paulo (FFCLRP-USP).

A pesquisa envolverá cerca de 100 pessoas de diferentes idades e de diversos bairros da cidade. A sua cooperação será muito valiosa e necessária para tornar possível esta pesquisa. Caso aceite colaborar, pedimos que preencha os dados abaixo; esse formulário será recolhido pela pesquisadora.

A pesquisa será realizada da seguinte forma: cada participante passará por avaliação psicológica na própria residência ou local a combinar, de acordo com sua disponibilidade e agendamento prévio, em local reservado, sendo convidado a responder a um questionário sobre sua condição atual de saúde física e emocional e a trabalhar com estímulos disponíveis em cartões de tinta, não implicando em riscos ou prejuízos ao participante. Essas atividades levarão aproximadamente uma hora para serem concluídas e todas as informações serão confidenciais e utilizadas apenas para investigação científica, ou seja, nenhuma forma de identificação pessoal dos participantes será divulgada em qualquer momento. Os resultados serão tratados em conjunto, de forma a garantir o sigilo das informações individuais.

Sua participação é valiosa para que se possa conhecer melhor as condições emocionais de indivíduos adultos da cidade, o que pode auxiliar no planejamento de eventuais ações de saúde mental e no desenvolvimento de métodos de avaliação psicológica no nosso contexto sociocultural.

Esperamos poder contar com sua colaboração e, desde já, agradecemos pela atenção.

Cordialmente,

Fabiana Rego Freitas - CRP (06/78606)

Sonia Regina Pasian - Prof $^{a}$. Dr ${ }^{\mathrm{a}}$. USP

CRP: 06/24.018-0)

OBS.: Quaisquer dúvidas relativas a essa pesquisa podem ser solucionadas por meio dos telefones 882694 26 (Fabiana) e 3602.3785 (Prof ${ }^{a}$. Dra. Sonia Regina Pasian).

1. Você está disposto(a) a colaborar com a pesquisa?

( ) Sim. Qual melhor dia e horário

( )Não. Por favor, diga-nos o motivo:

( )Falta de tempo ( )Desinteresse ou discordância quanto ao trabalho

( )Receio de se expor ( )Outro:

2. Caso você tenha respondido "sim" à questão acima, por favor, preencha a tabela abaixo. Esse formulário será recolhido pelo pesquisador em sua casa no prazo de 02 a 03 dias.

\begin{tabular}{|c|l|c|c|c|c|c|}
\hline Nome Completo & Idade & $\begin{array}{c}\text { Data de } \\
\text { nascimento }\end{array}$ & Sexo & $\begin{array}{c}\text { Estado } \\
\text { civil }\end{array}$ & $\begin{array}{c}\text { Grau de } \\
\text { instrução }\end{array}$ & $\begin{array}{c}\text { Telefone para } \\
\text { contato }\end{array}$ \\
\hline & & & & & & \\
\hline
\end{tabular}


APÊNDICE B - Tabela 50: Frequência idade participantes Estudo 01 
Tabela 50- Frequência relativa e absoluta das idades dos adultos reavaliados no

Estudo 01

\begin{tabular}{|c|c|c|}
\hline Idades & Frequência relativa & Frequência absoluta \\
\hline 34 & 1 & \\
\hline 35 & 2 & \\
\hline 36 & 3 & \\
\hline 37 & 1 & \\
\hline 38 & 3 & \\
\hline Subtotal & 10 & $11,3 \%$ \\
\hline 41 & 2 & \\
\hline 43 & 1 & \\
\hline 44 & 2 & \\
\hline 45 & 3 & \\
\hline 46 & 3 & \\
\hline 47 & 3 & \\
\hline 48 & 5 & \\
\hline 49 & 2 & \\
\hline Subtotal & 21 & $24 \%$ \\
\hline 50 & 3 & \\
\hline 51 & 3 & \\
\hline 52 & 3 & \\
\hline 53 & 2 & \\
\hline 54 & 5 & \\
\hline 55 & 5 & \\
\hline 56 & 1 & \\
\hline 57 & 1 & \\
\hline 58 & 3 & \\
\hline 59 & 2 & \\
\hline Subtotal & 28 & $31 \%$ \\
\hline 60 & 2 & \\
\hline 62 & 6 & \\
\hline 63 & 4 & \\
\hline 64 & 4 & \\
\hline 65 & 1 & \\
\hline 66 & 5 & \\
\hline 67 & 4 & \\
\hline 68 & 1 & \\
\hline 69 & 2 & \\
\hline Subtotal & 29 & $33,7 \%$ \\
\hline Total & 88 & $100 \%$ \\
\hline
\end{tabular}


APÊNDICE C - Self Report Questionaire (SRQ-20) 
Universidade de São Paulo

Faculdade de Filosofia, Ciência e Letras de Ribeirão Preto

Departamento de Psicologia - Centro de Pesquisas em Psicodiagnóstico (CPP)

Nome Completo:

Data Nascimento:

Profissão:

Horas de trabalho semanal:

Escolaridade: Estado Civil:

\section{SRQ - 20}

Sente-se nervoso, tenso ou preocupado?

( ) SIM

( ) NÃO

Assusta-se com facilidade?

( ) SIM

( ) ） NÃO

Sente-se triste ultimamente?

( ) SIM

( ) NÃO

Você chora mais do que de costume?

( ) SIM

( ) NÃO

Tem dores de cabeça frequentemente?

( ) SIM

( ) NÃO

Você dorme mal?

( ) SIM

( ) NÃO

Você sente desconforto estomacal?

( ) SIM

( ) NÃO

Você tem má digestão?

( ) SIM

( ) NÃO

Você tem falta de apetite?

( ) SIM

( ) NÃO

Tem tremores nas mãos?

( ) SIM

( ) NÃO

Você se cansa-se com facilidade?

( ) SIM

( ) NÃO

Tem dificuldade em tomar decisão?

( ) SIM

( ) NÃO

Tem dificuldades de ter satisfação em suas

( ) SIM

( ) NÃO

tarefas?

O seu trabalho traz sofrimento?

( ) SIM

( ) NÃO

Sente-se cansado todo o tempo?

( ) SIM

( ) NÃO

Tem dificuldade de pensar claramente?

( ) SIM

( ) NÃO

Sente-se incapaz de desempenhar papel útil em

( ) SIM

( ) NÃO

sua vida?

Tem perdido o interesse pelas coisas?

( ) SIM

( ) NÃO

Tem pensado em dar fim à sua vida?

( ) SIM

( ) NÃO 
APÊNDICE D - Termo de Consentimento Livre e Esclarecido - Estudo 01 


\section{Universidade de São Paulo \\ Faculdade de Filosofia, Ciência e Letras de Ribeirão Preto \\ Departamento de Psicologia - Centro de Pesquisas em Psicodiagnóstico (CPP)}

\section{TERMO DE CONSENTIMENTO LIVRE E ESCLARECIDO}

Estamos desenvolvendo uma pesquisa em Ribeirão Preto, denominada "Método de Rorschach em adultos: evidências psicométricas da Escola Francesa”, que pretende conhecer características do desenvolvimento emocional de indivíduos adultos. Este trabalho será desenvolvido sob responsabilidade da psicóloga Fabiana Rego Freitas, aluna de Doutorado em Psicologia da Faculdade de Filosofia, Ciências e Letras de Ribeirão Preto (FFCLRP) da Universidade de São Paulo (USP) e da Profa. Dra. Sonia Regina Pasian, docente do Departamento de Psicologia desta mesma Faculdade.

Essa pesquisa estudará cerca de 100 indivíduos de diferentes bairros da cidade de Ribeirão Preto. Cada pessoa passará por avaliação psicológica na própria residência, de acordo com sua disponibilidade e agendamento prévio, em local reservado, sendo convidado a responder a um questionário sobre sua condição atual de saúde física e emocional e a trabalhar com estímulos disponíveis em cartões de tinta, não implicando em riscos ou prejuízos ao participante. Essas atividades levarão aproximadamente uma hora para serem concluídas.

Todas as informações desta pesquisa são confidenciais e somente serão utilizadas para investigação científica. Os resultados deste trabalho deverão ser divulgados sob o formato de comunicações científicas orais e escritas, sem nenhuma identificação das pessoas que as forneceram. Solicitamos também sua autorização para uso dos dados disponíveis em sua primeira avaliação psicológica, realizada há cerca de dez-quinze anos atrás, também sob responsabilidade da professora Sonia Pasian.

A sua cooperação será muito valiosa e necessária para tornar possível esta pesquisa. Não será oferecido aos participantes desta pesquisa nenhum pagamento por sua colaboração neste trabalho, bem como seus resultados individuais (devolutivas), visto que o objetivo do trabalho está na compreensão das características gerais dos adultos de nossa região. Colaborar com essa pesquisa poderá ajudar a conhecer as características afetivas dos indivíduos de Ribeirão Preto e isso poderá auxiliar em planejamentos futuros para serviços clínicos para indivíduos adultos.

Desde já, agradecemos sua colaboração e estaremos disponíveis para outras informações, caso necessário. Atenciosamente,

\section{Fabiana Rego Freitas (CRP: 06/78.606)}

\section{Profa. Dra. Sonia Regina Pasian} (CRP: 06/24.018-0)

$\mathrm{Eu}$, declaro estar disposto a colaborar como voluntário no projeto de pesquisa "Método de Rorschach em adultos: evidencias psicométricas da Escola Francesa”, sob responsabilidade da psicóloga Fabiana Rego Freitas e da Profa. Dra. Sonia Regina Pasian, assim como estou ciente de que os registros relativos a esse trabalho serão utilizados como material de trabalho científico e poderão ser divulgados em congressos e publicados em revistas ou livros especializados, resguardando-se o devido sigilo quanto à nossa identificação. Afirmo que fui informado que tenho o direito de desistir de participar do estudo em qualquer uma de suas etapas e isso não me causará nenhum prejuízo. E ainda, tenho o direito de solicitar à Fabiana Rego Freitas as informações que julgar necessárias sobre o estudo, estando esta comprometida a fornecê-las.

Ribeirão Preto, de de 201

\section{(Assinatura)}

Observação: Se tiver qualquer dúvida, entre em contato com o Departamento de Psicologia da FFCLRPUSP e esclareça-se conosco pelo telefone: (16) 3602.3785, ou fale diretamente com Fabiana Freitas, pelo 
APÊNDICE E - Carta convite participação no Estudo 02 


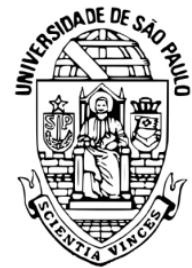

\section{Universidade de São Paulo \\ Faculdade de Filosofia, Ciências e Letras de Ribeirão Preto Departamento de Psicologia - Centro de Pesquisas em Psicodiagnóstico}

Prezado(a) Senhor(a):

Estamos desenvolvendo uma pesquisa sobre as características de personalidade de adultos da cidade. Esta pesquisa está sendo realizada pela Psicóloga e doutoranda em Psicologia Fabiana Rego Freitas (CRP 06/78606), sob orientação da Prof ${ }^{a} \operatorname{Dr}^{a}$ Sonia Regina Pasian, do Departamento de Psicologia da Faculdade de Filosofia, Ciências e Letras de Ribeirão Preto - Universidade de São Paulo (FFCLRP-USP).

A pesquisa envolverá cerca de 100 pessoas com idade entre 18 a 65 anos de diferentes bairros da cidade. Após um sorteio de quarteirões a serem visitados (entre eles, o seu), estamos realizando visitas para convidar pessoas a participarem da pesquisa. A sua cooperação será muito valiosa e necessária para tornar possível esta pesquisa. Caso aceite colaborar, pedimos que preencha os dados abaixo; esse formulário será recolhido pela pesquisadora dentro de dois dias.

A pesquisa será realizada da seguinte forma: cada participante passará por avaliação psicológica na própria residência, de acordo com sua disponibilidade e agendamento prévio, em local reservado, sendo convidado a responder a perguntas de raciocínio, a um questionário sobre sua condição atual de saúde física e emocional e a trabalhar com estímulos disponíveis em cartões de tinta, não implicando em riscos ou prejuízos para o participante. Essas atividades levarão aproximadamente uma hora para serem concluídas e todas as informações serão confidenciais e utilizadas apenas para investigação científica, ou seja, nenhuma forma de identificação pessoal dos participantes será divulgada em qualquer momento. Os resultados serão tratados em conjunto, de forma a garantir o sigilo das informações individuais.

Sua participação permitirá que possamos conhecer melhor as condições psicológicas de indivíduos adultos da cidade, o que pode auxiliar no planejamento de eventuais ações de saúde mental e no desenvolvimento de métodos de avaliação psicológica no Estado de São Paulo.

Esperamos poder contar com sua colaboração e, desde já, agradecemos pela atenção.

Cordialmente,

Fabiana R. Freitas - Psicóloga (CRP 06/78606)

Sonia R. Pasian (Prof ${ }^{\mathrm{a}}$. Dr ${ }^{\mathrm{a}}$ USP/RP)

OBS.: Quaisquer dúvidas relativas a essa pesquisa podem ser solucionadas por meio dos telefones 882694 26 (Fabiana) ou email: fabianafreitas@usp.br e (16) 3602.3785 (Prof ${ }^{a}$. Dra ${ }^{\mathrm{a}}$. Sonia Regina Pasian).

\section{Por favor, preencha os dados abaixo:}

1. Você (ou alguma pessoa que more em sua casa) está disposto(a) a colaborar com a pesquisa?

( ) Sim ( )Não. Por favor, diga-nos o motivo:

( )Falta de tempo

( )Receio de se expor

( )Desinteresse ou discordância quanto ao trabalho

( )Outro:

2. Caso você tenha respondido "sim" à questão acima, por favor, preencha a tabela abaixo. Esse formulário será recolhido pelo pesquisador em sua casa no prazo de dois dias a três dias.

Caracterização das pessoas que residem no domicílio.

\begin{tabular}{|c|c|c|c|c|c|c|}
\hline $\begin{array}{c}\text { Nome da } \\
\text { pessoa }\end{array}$ & Idade & $\begin{array}{c}\text { Data de } \\
\text { nascimento }\end{array}$ & Sexo & $\begin{array}{c}\text { Estado } \\
\text { civil }\end{array}$ & $\begin{array}{c}\text { Grau de } \\
\text { instrução }\end{array}$ & $\begin{array}{c}\text { Telefone para } \\
\text { contato }\end{array}$ \\
\hline & & & & & & \\
\hline & & & & & & \\
\hline & & & & & & \\
\hline
\end{tabular}


APÊNDICE F - Termo de Consentimento Livre e Esclarecido - Estudo 02 
Universidade de São Paulo

Faculdade de Filosofia, Ciência e Letras de Ribeirão Preto

Departamento de Psicologia - Centro de Pesquisas em Psicodiagnóstico (CPP)

\section{TERMO DE CONSENTIMENTO LIVRE E ESCLARECIDO}

Estamos desenvolvendo uma pesquisa em São Carlos, denominada

"Método de Rorschach em adultos: evidências psicométricas da Escola

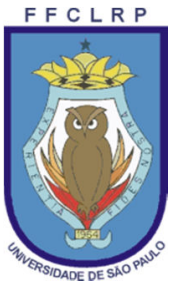

Francesa", que pretender conhecer características do desenvolvimento emocional de adultos entre 18 e 65 anos. Este trabalho será desenvolvido sob responsabilidade da psicóloga Fabiana Rego Freitas, aluna de Doutorado em Psicologia da Faculdade de Filosofia, Ciências e Letras de Ribeirão Preto (FFCLRP) da Universidade de São Paulo (USP) e da Profa. Dra. Sonia Regina Pasian, docente do Departamento de Psicologia desta mesma faculdade.

Essa pesquisa estudará cerca de 100 adultos de diferentes bairros da cidade e será realizada na própria residência de cada participante, de acordo com sua disponibilidade e agendamento prévio. Se você aceitar participar desta pesquisa, você passará por uma breve avaliação psicológica, sendo que este processo implica em que você deverá responder a perguntas de raciocínio, a um questionário sobre sua condição atual de saúde física e emocional e, por último, procurará interpretar figuras com manchas imprecisas, sem que isso apresente riscos ou prejuízos para você. Essas atividades levarão aproximadamente uma hora para serem concluídas.

Todas as informações desta pesquisa são confidenciais e somente serão utilizadas para investigação científica, sem nenhuma identificação de quem as forneceram. A sua cooperação será muito valiosa e necessária para tornar possível esta pesquisa. Não será oferecido aos participantes desta pesquisa nenhum pagamento por sua colaboração neste trabalho, bem como seus resultados individuais (devolutivas), visto que o objetivo do trabalho está na compreensão das características gerais dos adultos de nossa região. Colaborar com essa pesquisa poderá ajudar a conhecer as características afetivas dos adultos da região de Ribeirão Preto e isso poderá auxiliar em planejamentos futuros para serviços de Psicologia nesta região.

Desde já, agradecemos sua colaboração e estaremos disponíveis para outras informações, caso necessário. Atenciosamente,

Fabiana Rego Freitas (CRP: 06/78.606)
Profa. Dra. Sonia Regina Pasian

(CRP: 06/24.018-0)

$\mathrm{Eu}$, declaro

que estou de acordo em participar como voluntário no projeto de pesquisa "Método de Rorschach em adultos: evidências psicométricas da Escola Francesa”, sob responsabilidade da psicóloga Fabiana Rego Freitas e da Profa. Dra. Sonia Regina Pasian, assim como estou ciente de que os registros relativos a esse trabalho serão utilizados como material de trabalho científico e poderão ser divulgados em congressos e publicados em revistas ou livros especializados, resguardando-se o devido sigilo quanto à nossa identificação. Afirmo que fui informado que tenho o direito de desistir de participar do estudo em qualquer uma de suas etapas e isso não me causará nenhum prejuízo. E ainda, tenho o direito de solicitar à Fabiana Rego Freitas as informações que julgar necessárias sobre o estudo, estando esta comprometida a fornecêlas.

São Carlos de de 201

\section{(Assinatura)}

Observação: Se tiver qualquer dúvida, entre em contato com o Departamento de Psicologia da FFCLRPUSP e esclareça-se conosco pelo telefone: (16) 3602.3785, ou fale diretamente com Fabiana Rego Freitas. 
APÊNDICE G - Atlas referente às localizações e à qualidade formal das respostas produzidas pela amostra normativa (Estudo 02) 
9. ANEXOS 
ANEXO 01 - Critério ABEP de Classificação Econômica, 2012. 

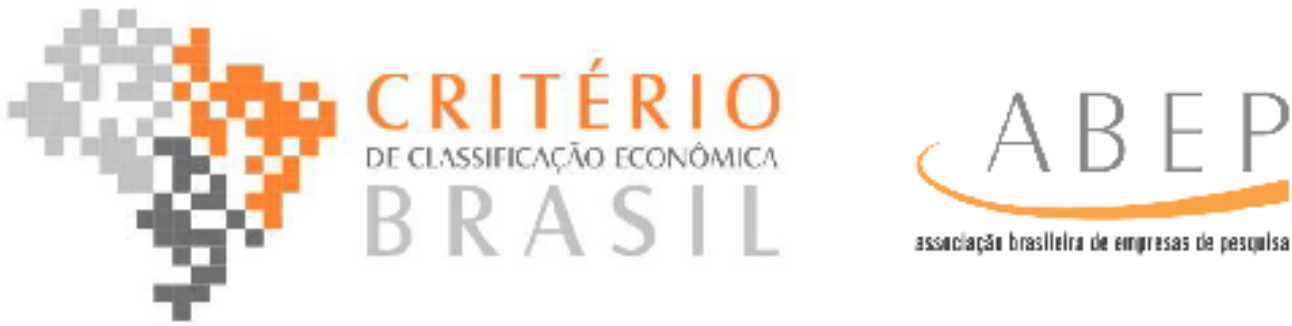

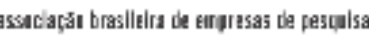

o Critério de Classificação Econômica Brasil, enfatiza sua função de estimar o poder de compra das pessoas e famílias urbanas, abandonando a pretensão de classificar a população em termos de "classes sociais". A divisão de mercado definida abaixo é de classes econômicas.

\section{SISTEMADEPONTOS}

\section{Posse de itens}

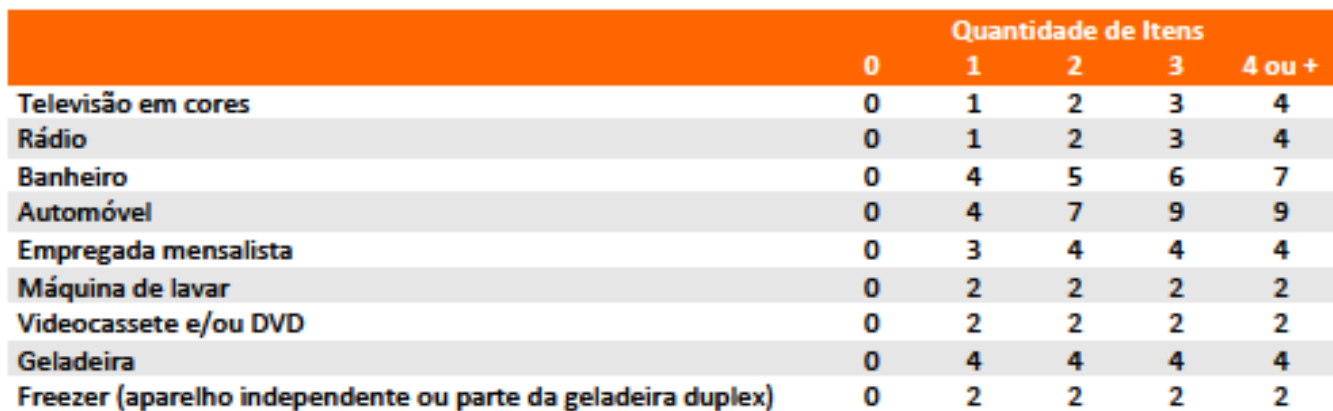

Grau de Instrução do chefe de familia

\begin{tabular}{|lll|}
\hline \multicolumn{1}{|c|}{ Nomenclatura Antiga } & \multicolumn{1}{c|}{ Nomenclatura Atual } \\
\hline Analfabeto/ Primário incompleto & Analfabeto/ Fundamental 1 Incompleto & 0 \\
\hline Primário completo/ Ginasial incompleto & Fundamental 1 Completo / Fundamental 2 incompleto & 1 \\
\hline Ginasial completo/ Colegial incompleto & Fundamental 2 Completo/ Médio Incompleto & 2 \\
\hline Colegial completo/ Superior incompleto & Médio Completo/ Superior Incompleto & 4 \\
\hline Superior completo & Superior Completo & 8 \\
\hline
\end{tabular}

\section{CORTES DO CRITEERIO BRASIL.}

\begin{tabular}{|c|c|}
\hline Classe & Pontos \\
\hline A1 & $42-46$ \\
\hline A2 & $35-41$ \\
\hline B1 & $29-34$ \\
\hline B2 & $23-28$ \\
\hline C1 & $18-22$ \\
\hline C2 & $14-17$ \\
\hline D & $8-13$ \\
\hline E & $0-7$ \\
\hline
\end{tabular}


ANEXO 02 - Aprovação do Comitê de Ética em Pesquisa 
Universidade de Sáo Paulo

Faculdade de Filosofia, Ciências e Letras de Ribeiráo Preto

Comitê de Ética em Pesquisa

Campus de Ribeiräo Preto

Of.CETP/FFCLRP-USP/058/-js!

Ribeirăo Preto, 03 de maio de 2012

Prezada Pesquisadora,

Comunicamos V. Sa. que o trabalho intitulado "MÉtOdo DE RORSCHACH EM ADULTOS: EVDÉnCIAS PSICOMÉtracas DA ESCOLA FRANCESA" foi reanalisado pelo Comitê de Ética em Pesquisa da FFCLRP-USP, em sua $107^{\text {s }}$ Reuniäo, realizada em 26.04.12, e enquadrado na categoria: APROVADO, de acordo com o Processo CEP-FFCLRP n 641/2011 - 2011.1.2832.59.6.

Solicitamos que eventuais modificações ou emendas ao projeto de pesquisa sejam apresentadas ao CEP de forma clara e sucinta, identificando a parte do protocolo a ser modificada e suas justificativas, e que, ao têrmino do estudo, um relatório final seja entregue ao Comitê.

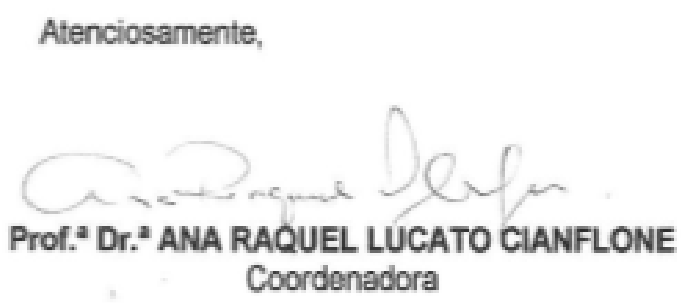

À Senhora

Fabiana Rego Freitas

Doutoranda do Programa de Pós-Graduaçăo em Psicologia da FFCLRP - USP

Com cópia para a orientadora:

Prof." Dr." Sonia Regina Pasian

Departamento de Psicologia da FFCLRP - USP

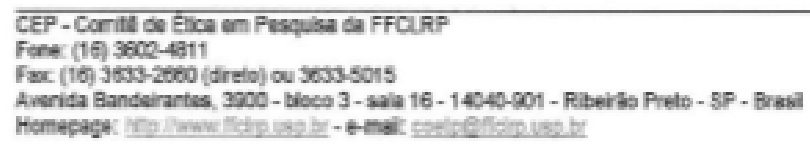

